\title{
Making weather information services usable to support adaptive decision-making in farming in Ghana
}

\author{
Rebecca Sarku
}




\section{Propositions}

1. Making weather information services usable for farming requires interconnected contexts rather than partial contextual considerations.

(this thesis)

2. Improving the usability of forecast information without the availability of decision-making options is worthless.

(this thesis)

3. Public bad situations in society can be addressed when enough individuals take action instead of relying on collective action.

4. Long-term engagement of citizen scientists is impossible without external motivations.

5. Finalising a $\mathrm{PhD}$ thesis is like eating the berry of the Synsepalum dulcificum plant.

6. To conduct transdisciplinary research, one has to be like a man in a polygamous marriage.

Propositions belong to the thesis, entitled

Making weather information services usable to support adaptive decision-making in farming in Ghana

Rebecca Sarku

Wageningen, 13 April 2021 
Making weather information services usable to support adaptive decision-making in farming in Ghana 


\section{Thesis committee}

\section{Promotors}

Prof. Dr A. Dewulf

Personal professor, Public Administration and Policy Group

Wageningen University \& Research

Prof. Dr C.J.A.M. Termeer

Professor of Public Administration and Policy

Wageningen University \& Research

\section{Co-promotor}

Dr EJJ (Erik) van Slobbe

Researcher and Teacher, Water Systems and Global Change Group

Wageningen University \& Research

\section{Other members}

Prof. Dr Cees Leeuwis, Wageningen University \& Research

Dr Hilde Toonen, Wageningen University \& Research

Prof. Dr Uta Wehn, IHE Delft Institute for Water Education

Prof. Dr Joseph Awetori Yaro, University of Ghana, Accra, Ghana

This research was conducted under the auspices of the Wageningen School of Social Sciences. 


\title{
Making weather information services usable to support adaptive decision-making in farming in Ghana
}

\author{
Rebecca Sarku
}

Thesis

submitted in fulfilment of the requirements for the degree of doctor

at Wageningen University

by the authority of the Rector Magnificus,

Prof. Dr A.P.J. Mol,

in the presence of the

Thesis Committee appointed by the Academic Board

to be defended in public

on Tuesday 13 April 2021

at 4 p.m. in the Aula. 
Rebecca Sarku

Making weather information services usable to support adaptive decision-making in farming in Ghana, 265 pages.

$\mathrm{PhD}$ thesis, Wageningen University, Wageningen, the Netherlands (2021)

With references, with summary in English

ISBN: 978-94-6395-717-5

DOI : https://doi.org/10.18174/542025 
Dedicated to my late father, Reginald Sarku, and my mother Vivian Dompreh 
Acknowledgement 
I deem it necessary to extend my utmost gratitude and deepest appreciation to all those who helped me and stood with me throughout the $\mathrm{PhD}$ journey. I first want to express my sincere appreciation to my supervision team. To my first promotor, Professor Art Dewulf, I want to say that I count myself honoured to be mentored and supervised by a seasoned and learned scholar like you. I admire your personality, commitment and approach in steering the $\mathrm{PhD}$ process to the end. My appreciation also goes to my second promotor, Professor Katrien Termeer for her thoughtful and insightful comments in the supervision process. I am thankful to my co-promotor Dr. Erik van Slobbe for his tremendous support throughout my $\mathrm{PhD}$ research. The first time we met in Accra, I knew we were going to work together. Your timely feedback and inputs in the $\mathrm{PhD}$ including the WaterApp project shall always be recounted. Also, to my co-promotor, Prof. Gordana KranjacBerisavljevic, I am immensely grateful for the positive marks, mentoring and provision of all the necessary resources required for the $\mathrm{PhD}$ field research.

Besides my supervision team, I would like to thank other people who contributed in diverse ways to make my $\mathrm{PhD}$ study successful. I recount the support of Professor Fulco Ludwig and Dr. Saskia Werners who are core researchers in the Waterapps project. Your contributions, suggestions and field visits helped shaped my thinking and how to approach research ideas from an interdisciplinary perspective. To Dr. Long Hoang and Dr. Spyros Paparrizos, I say thank you for contributing to my research's success through your relentless support to the Waterapps project.

Prof. Edwin A. Gyasi and Dr. Ebenezer Ashie Goodman Nikoi, I appreciate your kind words, advice, mentorship, and provision of the resources whenever I needed them.

I also feel special to have conducted my $\mathrm{PhD}$ research with the Public Administration and Policy Group. It is needful to say thank you to Prof. Otto Hospes, Dr. Tamara Metze, Dr. Jeroen Candel, Dr. Wieke Pot, Dr. Agatha Siwale, Dr. Robert Biesbroek and Dr. Sylvia Karlsson-Vinkhuyzen. Ideas discussed at the monthly meetings, coffee breaks, Food for thought and PAP's day out, among other activities were all relevant for the $\mathrm{PhD}$ course.

Furthermore, I would like to thank my colleagues and fellow PhDs. Special thanks to Dr. Andy Nyamekye, Dr. Emmanuel Nyadzi and Dr. Talardia Gbangou and Uthpal Kumar Roy who are colleagues from the EVOCA and Waterapps project. Your support and company have inspired me to delve deeper into climate information science research. To the postdocs and colleague PhDs in the Public Administration and Policy Group; Dr. Sumit Vij, Dr. Daniel Polman, Daniel Wiegant, Yannick Buitenhuis, Brenda Namugumya, Efrat Gommeh, Louise Cavalcante de Souza Cabral, Eduardo Padilla, Olga Schagen, Jelle Silvius, Kasper de K. Vaan, Sarah Wright, Lucy Njuguna, Lura Cramer, Jan Starke, Lara Sibbing and Ahmad Dermawan, thank you for your warm chats and being 'nice roomies'. My deepest gratitude also goes to, Maarit Junnikkala, thank you for taking care of me and providing all my needs.

To the 'EVOCA' project $\mathrm{PhD}$ mates, I say that your determination inspired me to steer on to bring this PhD journey to an end. Thank you, Dr. Elias Dantew Assefa, Dr. Christopher Agyekumhene, Dr. Shiferaw Tafesse Gobena, Faith Mutavi, Dr. Nyamwaya Munthali, Dr. Marilyn Murindahabi, Mariette McCampbell, Dr. Domina Asingizwe and Richard Chepkwony. 
My sincerest gratitude goes to farmers in the Ada East District communities, the staff of the Department of Agriculture and Development Unit, Ada East District, and Mr. Muller Tsatsu Siameh for the support during the field study.

My friends who will always send messages each week to check up on me and the progress of the research, I want to say that your messages also motivated me to work hard because I knew some people were looking on to cheer me at the finishing line. To Dr. James Boafo, Dr. Stephen Asante Ampah, Famous Addi, Esther Osei-Bonsu, Ms. Vida Kodzi, Mr. Dominic Alhassan, Mrs. Grace Nyarko and all my friends and colleagues, thanks for your support.

I would also like to express my sincere appreciation to the Ghanaian community in Wageningen (Sikaman). A special thanks go to Mr. \& Mrs. Monica and Steve Hoek and Mr. Sampson Nibi for being my parents in Wageningen. I would also like to thank members of the International Christian Fellowship and the Bornsesterg connect group members for their emotional and spiritual support.

My heartfelt gratitude also goes to the entire Sarku and Dompreh family, especially, Ms. Leticia Sarku, Mrs. Wilhemina Menka, Mr. Daniel Sarku, Ms. Sarlomey Sarku, Mrs. Evelyn Seddodo, Mr. Victor Dompreh, Ms. Faustina Dompreh, Agatha Nutsuga, cousins, nephews and nieces.

My late father, Reginal Sarku may not be alive but it is worth mentioning his name since he supported me with all his resources and being to educate me. Unfortunately, you are not alive to cheer and hug me on this day; however, I am grateful that my mother, Vivian Dompreh is alive to play this role on your behalf. Words in this thesis are not enough to describe my appreciation for the immense support of my mother throughout my life. I am forever indebted and grateful to you. To my senior brother DSP Edem Komla Sarku, "if I can see far, it is because I stood on the shoulders of a giant". You are a typical example of someone who can "put his legs in others' shoes" just to help them make it. Elorm Sarku, Asiwome Sarku and Rita Darkwa thanks for permitting your father and husband to be my supporter in the PhD journey. I cannot forget my lovely sister Cecilia Sarku, and brothers Innocent Yao Sarku and Justice Akpaka I am grateful for being with me and cheering me on. Your prayers and best wishes also contributed to the climax of this journey. 

Abstract 
Interconnecting socio-environmental factors present a challenge for the availability of water for farming in developing country contexts such as Ghana. For instance, climate change and climate variability create uncertain weather conditions, with records of early or late rainfall onset, early cessation, lengthy dry spells in between the farming seasons, and too much or too little rainfall. As a result of this variability in weather conditions, farmers are unable to predict the rainfall as they used to. Furthermore, the unavailability of freshwater and irrigation facilities creates situations where seasonal rainfed farming is indispensable, given the need to intensify food crop production for export and urban markets. Dependence on the variable weather for water to support seasonal food crop production has accentuated the role of weather information in guiding farmers' decisionmaking concerning when to plough, when to sow seeds, the type of crop and variety of seed to select, when to apply agrochemicals, and when to harvest. This situation is not, however, currently reflected in actual practice, as farmers generally do not apply weather information in farming, because of the lack of accurate, location-specific forecasts, untimely delivery of information, and poor communication of information, among several other challenges. Thus, under uncertain weather conditions, farmers rely mostly on their local knowledge and experience to support their decision-making. Several attempts have been made to enhance the usability of weather information for farming; yet, this has not been successful because information providers or scientist play dominant roles in trying to deal with the challenge without involving farmers throughout the entire process. To make weather information usable for farming, there has been a call to shift from the provision of weather and climate information services that are solely science-driven to services that are user-driven through collaboration between scientists, information providers, and users to co-produce information. This thesis is situated within this notion and it seeks to answer the question: What makes weather information services usable for adaptive decision-making in farming within an informational governance context?

To provide answers to the research question, I engaged farmers and information providers in an empirical study in the Ada East District, Ghana. I used a multi-method research approach, comprising interviews, observations, focus group discussions, workshops, and the principle of citizen science participatory environmental monitoring for data collection. Data analysis was carried out through combinations of deductive and inductive coding with Atlas.ti.

I introduced the hybrid informational governance framework based on the integration of ideas from three theories, that is, informational governance, hybrid governance, and hybrid organisation. In the framework, I distinguished forms of hybrid governance: multiplicity, intertwinement, and coalescence. The provision of weather information through multiplicity means that different information providers deliver a variety of weather information systems (WIS) for farming. The provision of weather information through intertwinement means that some organisations have evolved towards joint delivery of WIS by using a combination of technologies including radio, mobile telephony, SMS, call centres, and interactive voice response. Furthermore, information and communication technology (ICT) has played a role in coalescence in WIS provision by creating hybrid organisations that combine key characteristics from the different organisational sectors. In the hybrid informational governance context, I found that farmers apply flexible adaptive decisionmaking strategies such as switching dates for sowing seeds through a wait-and-see or delay strategy, muddling through the farming season with the application of various options, and alternative irrigation strategies. Robust adaptive decision-making strategies are applied to deal 
with uncertain weather conditions include the portfolio strategy of transplanting seedlings in batches, selection of robust (hardy) crops, and intercropping or diversification. The findings indicate that some flexible or robust strategies could have been enhanced with the application of usable weather information.

However, in the study district, various factors affected the usability of WIS for farming. These factors included the origin of the information, information providers' level of interaction with farmers, continuity in the delivery of information, respect for local values, accessible level and mode of payment, among other factors. Most of all, no single type of weather information identified could on its own provide a reliable forecast. Therefore, farmers complemented their local knowledge and observations with forecasts from various sources. On the basis of these findings, I proposed co-production of weather information where farmers' local weather forecasts could be integrated with scientific forecasts. This led to the development of an experiment on the co-production of weather forecasts in the Ada East District, Ghana. The experiment involved a user-driven design and the testing of ICT-based digital (smartphones and apps) and rainfall monitoring tools with 22 farmers who collected data on their local indicators, predictions on whether or not there would be rainfall, and records of the actual rainfall. I derived positive responses based on the level of engagement, increase in usability of the tools and understanding of forecast uncertainty, the dissemination of the information to other farmers, and the improvement in daily farming decision-making. Furthermore, I found that farmers' motivation to engage in the research differed at various periods of the research. Overall, the need to contribute to WIS production, generation of feedback, learning, and ease of data collection were the most important motivational factors.

Using findings from various phases of the thesis study, I identified five interconnecting contexts that answer the main research question. First, I found that the farmer decision-making context, which relates to the conditions existing in farming communities, drives the need to apply WIS for adaptive decision-making. Factors identified in this context include uncertainty in weather conditions and the availability of flexible and/or robust options. Second, the farmer information context relates to farmers' sources of, and access to, information. In this context, I found that information sharing and the everyday use of ICTs in the farming communities contribute to making weather information usable. The findings also show that the WIS provision context identifies the types of WIS and how they meet the information design and delivery criteria. Particular factors associated with this context include local embeddedness, legitimacy, temporal and spatial resolution, predictive skill, and accessibility. The informational governance context provides a broader view concerning how the existing governance arrangement to a large extent determines the kind of actors and the types of WIS provided for farmers and how they are delivered. In this context, I found that the provision of weather information through multiplicity, intertwinement, and coalescence plays a significant role in making weather information usable. The fifth context is overall weather information service design.

In this context, this thesis makes theoretical contributions such as the introduction of hybrid informational governance, adaptive decision-making, and WIS usability criteria for farming. It also provides action-oriented knowledge on the design principles required to co-design and coproduce weather information, and enhance participants' motivations to engage with the citizen science method to support food production and the sustainability of food systems. 




\section{Table of Contents}

$\begin{array}{ll}\text { Chapter 1: Introduction } & 16\end{array}$

Chapter 2: Tracing hybridity in the provision of ICT-enabled agricultural weather 38 information services in Ghana

Chapter 3: Adaptive decision-making under conditions of uncertainty: the case of farming in the Volta Delta, Ghana

Chapter 4: Assessing the usability of weather information services for decision-making 92 in farming: A case study in Southern Ghana

Chapter 5: Coproducing weather forecast information with and for smallholder farmers in Ghana: evaluation and design principles

Chapter 6: Beyond 'experts knowledge': Locals and experts in a joint production of weatherapp and weather information for farming in the Volta Delta, Ghana

Chapter 7: Synthesis

References

Supplementary materials

Summary

About the author

List of publications

Completed training and supervision plan 


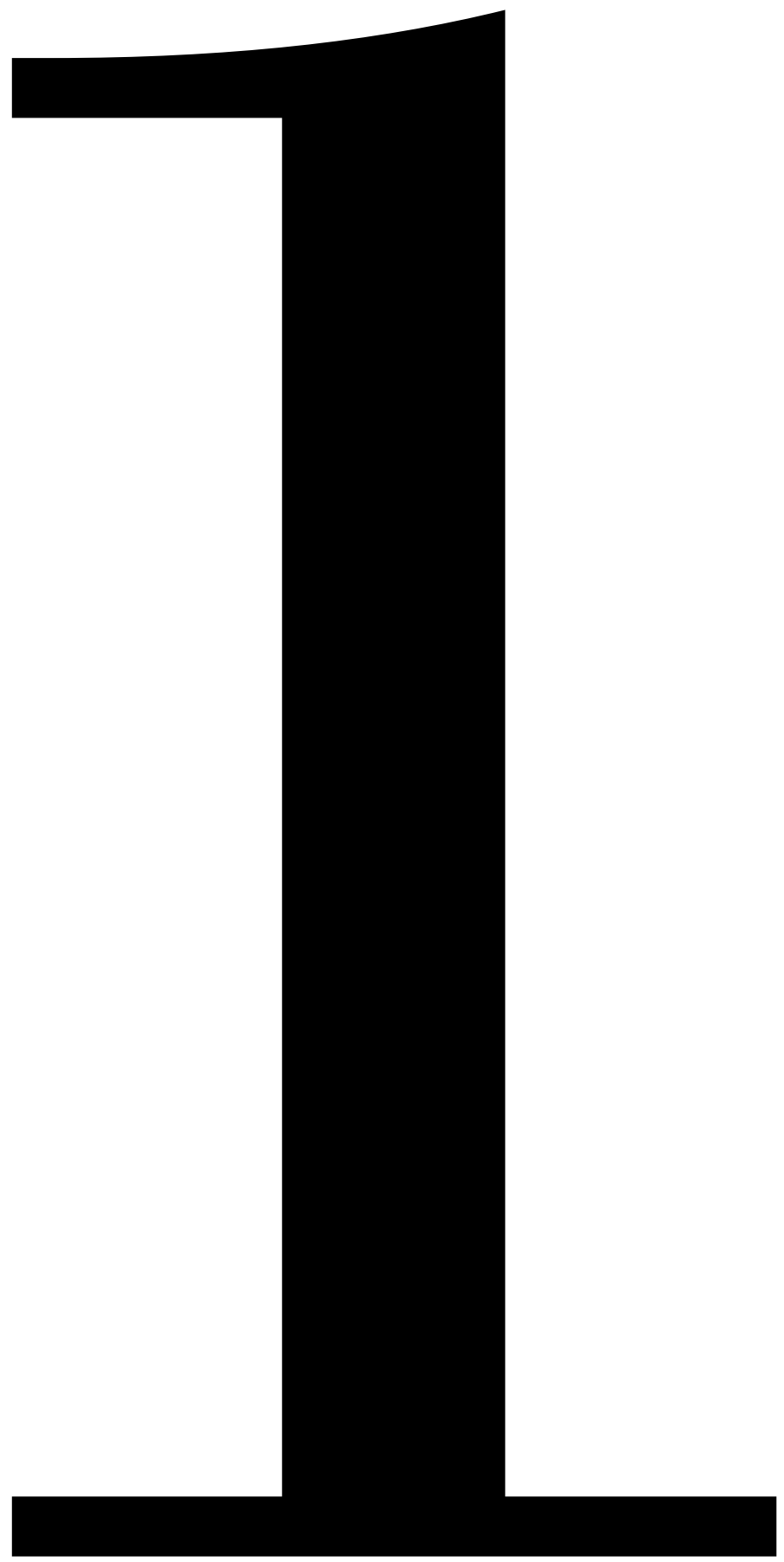


Chapter 1

Introduction 


\section{Chapter I}

\subsection{Background and problem definition}

The availability of water for farming in sub-Saharan African countries is continually affected by interconnecting socio-environmental conditions. In the West African region including Ghana, farming is affected by climate change consequent to global warming (Abdul-Razak \& Kruse, 2017; Sylla et al., 2017). Temperature rise has resulted in a shift in either rainfall patterns, concentration, volume, or intensity across space and time in Ghana (Manzanas et al., 2014; Amekudzi et al., 2015; Baidu et al., 2017; Atiah et al., 2019; Nyadzi et al., 2019; Dapilah \& Nielsen, 2019; Gbangou et al., 2020a). Climate change has intensified the incidence of climate variability more specifically in semi-arid and savanna agroecological regions, where rainfed farming is mostly practiced (Owusu \& Waylen, 2013; Kranjac-Berisavljevic et al., 2014; Teye \& Owusu, 2014; Amisigo et al., 2015; Cazcarro et al., 2018; Adjei et al., 2018; Appeaning-Addo et al., 2018; Nyadzi et al., 2019; Gbangou et al., 2020a).

Besides the effect of climate change and variability on the availability of water for farming in Ghana, the sector is undergoing several transformations whereby subsistence farming is gradually giving way to the intensive application of water for the cultivation of vegetables, fruits, and other crops for export and/or local urban markets (Gonzalez et al., 2016). This development is accompanied by the adoption of modern technologies such as improved seeds, fertilisers, and equipment to enhance food production (Nin-Pratt \& McBride, 2014). Furthermore, areas such as the coastal savanna agroecological region, including the Volta Delta, are experiencing population growth and urbanisation, characterised by changes in land-use patterns, institutional changes, and other livelihood dynamics (Roest, 2018). These changes aggravate the demand for water for coastal savanna and delta farming areas like the Ada East District where rainfall is already variable (Atiah et al., 2019). Moreover, the construction of upstream water infrastructure has affected the Volta River and the flow of water in the delta (Andreini et al., 2000; Mul et al., 2015; Anthony et al., 2016). The provision of irrigation facilities is insufficient, and the low water table does not enable utilisation of groundwater for irrigation in most areas (Sarku et al., 2020a). Consequently, farming in the urbanising coastal savanna and Volta Delta areas in Ghana is mainly rainfed.

The reliance on rainfall under variable climatic conditions for farming creates uncertainties and challenges farmers' decision-making to be adaptive (Berliner et al., 2003; Asante \& AmuakwaMensah, 2015; Derbile et al., 2016; Lawson et al., 2019). For instance, unpredictable weather conditions delay decision-making in the selection of planting dates (Cooper et al., 2008; Nyadzi et al., 2019). Late onset of rainy seasons also affects decision-making concerning the amount of farmland to cultivate, the type of crop to select, the timing for sowing seeds, cropping intensity, and the application of farm inputs (Ndamani \& Watanabe, 2014; Iizumi \& Ramankutty, 2015; Nyamekye et al., 2018). Sometimes, farmers decide to sow, only for a subsequent occurrence of a dry spell to affect the crops and, hence, the need for replanting (Ingram et al., 2002; Logah et al., 2013; Wetterhall et al., 2015; Nyamekye et al., 2018). Although farming communities in Ghana have been coping and autonomously adapting, the uncertain conditions under which they operate require usable information in the form of weather information services (WIS) to support the adaptivity of their decision-making (Dewulf et al., 2020). I use WIS to refer to the provision of information about the condition of the atmosphere at a given place for up to about 14 days (Fleming, 2008; Bazile et al., 2017). The role of WIS in decision-making is not new but has become more relevant (Fosu-Mensah et al., 2012; Córdoba-Pachón \& Paucar-Caceres, 2019) because it involves the generation, provision, and contextualisation of weather- and farming- 
related data to support farmers' decision-making (Armah et al., 2011; Vaughan \& Dessai, 2014; Ouédraogo et al., 2015).

Information and communication technology (ICT) is becoming an enabling driver in the provision of WIS thanks to its ability to support efficient information processing and sharing (Graham et al., 2015; Soma et al., 2016a). Satellite images are available to provide information on emerging storms as well as to validate the time, skill, and certainty of a forecast (Trujillo et al., 2012; Singh et al., 2018). ICTs like social media, short message service (SMS), mobile data collection tools, and digital storage applications (e.g., open data kit) are enabling the provision of different types of agricultural information in Ghana (Munthali et al., 2018). ICTs can also position farmers as information co-producers rather than as consumers (Lie \& Servaes, 2015; Rutten et al., 2017). They also present opportunities for information sharing and alternative forms of connectivity through the exchange of textual, audio, video, and pictorial information between two or more actors in the farming sector in Ghana (Bennett \& Segerberg, 2012; McNamara et al., 2014; Cieslik et al., 2018). Mol (2006b) describes this situation where ICTs and information play a dominant role in connecting people, steering decision-making, and causing institutional changes as informational governance. ICT application for the provision of information such as WIS raises some questions concerning whether or not government organisations are still in charge of the production and delivery of information or whether non-state organisations have taken over their roles. Also, there are concerns about the governance arrangements that could emerge through the involvement of non-state organisations in WIS provision. What could the consequences be for the flow of information with ICTs from the international level to farming communities?

With the emergence of new ICTs, certainly, the production and delivery of weather and climate information services for farming in Ghana have improved (Naab et al., 2019; Partey et al., 2020). However, several recent studies have continued to report on the low uptake of information for decision-making in farming (Nyadzi et al., 2018; Naab et al., 2019; Nyantakyi-Frimpong, 2019). This is attributed to contextual issues (e.g., gender, availability of planting materials) associated with farmers and farming communities. On the other hand, information design and delivery factors such as accessibility of information, poor communication of uncertainty in forecasts, lack of agricultural content information, lack of location-specific forecasts, and so forth also affect the usability of WIS (Nyadzi et al., 2018). The aforementioned barriers are ascribed to the dominance of an information provider-led - rather than a user-driven - approach in WIS production and delivery (Dilling \& Lemos, 2011; Kirchhoff et al., 2013; Lourenço et al., 2016).

Given these challenges, in rainfed farming areas such as the Ada East District in the coastal savanna and Volta Delta region, farmers base decision-making on their local knowledge and experience. However, climate change and variability also affect the reliability of farmers' local indicators and experience in forecasting the weather (Naab et al., 2019). Consequently, the problem with the provision of usable WIS for adaptive decision-making in farming is a complex knot that interconnects farmers' decision-making context, governance arrangements for WIS provision, information design and delivery, and uncertainties in weather conditions. This raises the question of an appropriate approach to provide usable WIS to support farmers' adaptive decisionmaking in the uncertain conditions under which they operate. 


\section{Chapter I}

In recent years, several studies have proposed co-production as an approach that can support the production and delivery of usable weather and climate information services. Co-production involves knowledge exchange and collaboration between scientists, information providers, and farmers to define the problem and co-design new weather and climate information services (Lemos $\&$ Morehouse, 2005; Meadow et al., 2015; Djenontin \& Meadow, 2018; Briley et al., 2015; Bremer $\&$ Meisch, 2017). Against this background, it is anticipated that ICTs can be used to support coproduction processes (Karpouzoglou et al., 2016; Zulkafli et al., 2017; Cieslik et al., 2018; Leeuwis et al., 2018) through the application of citizen science as a method to engage citizens to monitor their environment and collect data to support scientific observations (Gharesifard \& Wehn, 2016; Gharesifard et al., 2017; Wehn \& Almomani, 2019). Farmers can use smartphones to monitor their environment and collect data on local indicators that can be integrated with scientific forecasts to enhance the reliability and certainty of WIS for decision-making (Bohensky \& Maru, 2011; Masinde et al., 2012; Hiwasaki et al., 2014; O’Grady et al., 2016; Jiri \& Mafongoya, 2017). This idea has been continuously promoted theoretically in the weather and climate information service literature on Ghana and other sub-Sahara African countries. Yet, there is a gap in the knowledge on how WIS can become usable through the co-production of scientific forecasts and farmers' local knowledge on weather forecasting for adaptive decision-making in farming in an informational governance context in Ghana. This thesis is placed within this empirical knowledge gap in Ghana, where I carried out a case study in the Ada East District to examine, explain, and provide knowledge on the requirements for making WIS usable for adaptive decision-making in farming in an informational governance context.

Given this gap, I aim to answer the research question: What makes weather information services usable for adaptive decision-making in farming within an informational governance context? In the next section, I present the conceptual framework of the thesis. In section 1.3, the specific research sub-questions are formulated by addressing gaps in the literature. The methodological approach is presented in section 1.4, and the thesis outline is provided in section 1.5.

\subsection{Conceptual framework of the thesis}

To provide answer to the main research question, I develop a conceptual framework based on four theories: informational governance, adaptive decision-making, usable information and coproduction with citizen science method. First of all, we need to define criteria that are suitable for the usability of weather information services. Furthermore, usability of information depends to a large extent on the user context, in this case, the farmer decision-making context. This is because the decision-making context is characterised by uncertainties requiring farmers to adapt to variable weather conditions. Hence, I rely on the concept of adaptive decision-making. Weather information services are provided by actors for variety of reasons and often they try to steer the behaviour of farmers through information. To capture the constellations of public and private actors providing WIS, I rely on the concept of hybrid informational governance. Finally, I also want to contribute to our understanding of how to create more usable WIS, for which I rely on theories of knowledge co-production and citizen science.

\subsubsection{Conceptualising informational governance}

The role of information in supporting the adaptivity of decision-making in farming under uncertain weather conditions is central to this thesis. I refer to information as both data and knowledge with meanings for a target audience (Holm \& Soma, 2016). The ICT age has made information available 
across space and time, in a phenomenon known as informational governance (Mol, 2006b). Informational governance is the process whereby new information technologies, information networks, and information processes fundamentally restructure processes, institutions, and practices in ways that are different from conventional modes of governance where actors rely on authoritative resources, information control, and state power (Toonen, 2013; Soma et al., 2016). In the informational governance era, information is a crucial (re)source with transformative powers for a variety of actors, although nobody is (totally) in control of its production, processing, and delivery (Soma et al., 2016a; Hoefnagel et al., 2013). The emergence of informational governance is attributed to four interconnecting mechanisms.

The first is the role of ICTs in influencing information production, processing, and delivery. Mol (2008) indicated that old ICTs (television and radio) have remained largely under the control of state organisations, whereas new ICTs seem uncontrollable and have transformative powers because numerous actors use them to provide information across space and time.

The second mechanism is globalisation as the process that enables WIS flows from international to local scale and vice versa with ICTs (Some et al 2016a). Globalisation processes emphasise the increasing importance of flows and mobility of information, goods, and so forth (Mol, 2008).

Third, informational governance has emerged from the redefinition of the state's role in the provision of public services such as WIS (and other domains). Currently, non-state actors have come to the fore to provide certain public services (Delmas \& Young, 2009). The involvement of non-state organisations in the provision of public services is attributed to the gaps left in the roles of state agencies consequent to falling economies, overwhelming state budgets, application of new public administration models and neo-liberal policies, complexities of environmental problems, among other issues (Kickert, 2001; Lemos \& Agrawal, 2006; Goodfellow \& Lindemann, 2013; Colona \& Jaffe, 2016; Tosun et al., 2016). As a result, non-state actors are either complementing or outplaying the roles of state organisations, and the use of ICTs means that the flow of information bypasses state agencies (Hoefnagel et al., 2013). The state agencies have not, however, lost their authority completely, and their conventional roles have not come to an end.

The fourth mechanism that contributes to informational governance is the changing position of science in society consequent to science's loss of its automatic monopoly as a trustworthy and credible institution that generates reliable and undisputable information (Spruijt et al., 2014; Burgess, 2014; Vincent et al., 2018). Currently, various actors produce knowledge with participatory approaches to make information credible, salient, and legitimate (Cash et al., 2002, 2003).

These four mechanisms contribute to the interpretation of informational governance in two ways: 1) governing through information and 2) institutional change through information. Governing through information refers to the use of information purposely to guide, steer, control, or manage sectors or facets of society by numerous actors across multiple scales (Hoefnagel et al., 2013; Toonen, 2013). The actors have clearly defined roles, practices, and institutions that set them apart (Lemos \& Agrawal, 2006). There are, however, instances where the roles, practices, and institutions of government, business, and civil society organisation (CSO) actors either co-exist, intertwine, or merge in the provision of information (Boege et al., 2009; Goodfellow \& 


\section{Chapter I}

Lindemann, 2013; Haar \& Heijke, 2013), leading to the formation of hybrid informational governance. In this thesis, I distinguish between different forms of hybrid informational governance arrangements: multiplicity, intertwinement, and coalescence. Governance through information is linked to changes in institutions consequent to information flows.

The second interpretation of informational governance refers to changes in institutions resulting from the role of ICTs (information) (Ge \& Brewster, 2016; Soma et al., 2016d). I interpret institutions broadly as formal and informal rules that enhance or restrain the production, processing, and delivery of information. Institutional changes take the form of changes in certain rules that enable citizens to use ICTs to participate in the information production process (Bailey et al., 2016; Nulman \& Özkula, 2016). Changes in institutions also enable the government and CSOs to apply business models in the provision of information with ICTs (Usher et al., 2018). On this note, governing through information and institutional change through information reinforce each other. Under hybrid information governance, numerous actors that provide information are expected to steer users' decision-making, and the application of the information is expected to enhance adaptive decision-making. Hence, in the next section, I operationalise adaptive decisionmaking in farming.

\subsubsection{Conceptualising adaptive decision-making in farming}

Farming is carried out under changing socio-technical-environmental conditions that create uncertainty, and decision-making is required to deal with this. Uncertainty refers to the state whereby there is no unique and complete knowledge about the condition to be managed because of unpredictability, incomplete knowledge, or ambiguous information (Brugnach et al., 2008; Dewulf \& Biesbroek, 2018). Dewulf and Biesbroek (2018) conceptualised the nature and object of uncertainty to describe types of uncertainties. Based on the distinction of uncertainty by its nature, there exist three types. They include unpredictability (sudden changes resulting from inherently complex system behaviour); limited information (involving the lack of knowledge about a particular system); and multiple knowledge (conflicts between fundamentally different knowledge frames about the issue at hand). Under uncertain conditions such as unpredictability, decision-making has to be adaptive (Philips, 1997).

The limited literature on adaptive decision-making provides a variety of views on the concept (see Payne et al., 1993; Philip, 1997; Hasnoof et al., 2013; Robert al., 2016a; Singh et al., 2016; Kwakkel et al., 2016). I draw ideas from the scant literature to define adaptive decision-making as a pattern of decisions characterised by the application of decision options that are flexible, robust, or both, in response to uncertain socio-technical-environmental conditions. As the unpredictability of socio-technical-environmental conditions and limited information create uncertainty, fully rational decision-making is impossible. Hence, adaptive decision-making builds on bounded rationality (March, 1991) by considering uncertainty through the incorporation of flexible or robust decision-making strategies (Haasnoot et al., 2012, 2013; Dittrich et al., 2016; Kwakkel et al., 2016; Pot et al., 2018).

Flexible adaptive decision-making means that options are selected to the extent that they can be adjusted or reversed over time when additional information becomes available about the existing condition (Colombo \& Byer, 2012; Haasnoot et al., 2013). It is based on the notion that uncertainty is dynamic; hence, the reception of new information enables analysis of the initial option to verify 
whether it requires modification (Walker et al., 2013; Yousefpour \& Hanewinkel, 2016). This does not imply that a flexible adaptive decision-making strategy is a trial-and-error activity; rather, it represents learning while doing an activity (Pahl-Wostl et al., 2008). This form of adaptive decision-making may generate a satisfactory outcome rather than an optimal result. Examples of flexible adaptive decision-making strategies include wait-and-see or delay in decision-making or the application of muddling through options (Colombo \& Byer, 2012; Yousefpour et al., 2017).

Robust adaptive decision-making refers to the selection of decision options that are effective under a wide range of socio-technical-environmental conditions (Lempert et al., 2006). With robust adaptive decision-making, a preferred decision option is selected in anticipation of uncertainties (Kwakkel et al., 2016). Thus, robust adaptive decision-making strategies are often perceived as more adaptive because they can withstand evolving conditions (Lempert \& Groves, 2010; Anderies et al., 2004). Decision options are selected despite incomplete information about their consequences (Lempert et al., 2006; Yousefpour \& Hanewinkel, 2016), and they aim for robustness rather than optimality (Lempert \& Groves, 2010; Bhave et al., 2016). Examples of robust adaptive decision-making include the portfolio strategy (Nalley et al., 2009), the selection of hardy options, and diversification in management measures.

Robustness and flexibility can therefore be seen as two alternative paths to deal with unpredictable conditions and limited information (Dewulf \& Termeer, 2015; Dewulf \& Biesbroek, 2018). From the above definition, adaptive decision-making emphasises the selection of management strategies rather than the outcome of the decision-making process. In this thesis, I focus on how flexible or robust adaptive decision-making is carried out in reaction to uncertain weather conditions and limited information. I conclude by indicating that decision-making on the selection of flexible or robust strategies is enhanced when information is usable, thereby reducing the level of uncertainty characterising a specific condition. However, limited clarity exists on what constitutes useful and usable information, as these ideas are often used interchangeably. Thus, in the next section, I draw a distinction between these ideas and conceptualise usable information for farming.

\subsubsection{Conceptualising usable information}

Information is not always usable for decision-making for specific contexts like farming (Lemos et al., 2012). Often, the terms useful and usable WIS are applied interchangeably in the literature; however, following Dilling and Lemos (2011), I distinguish between the terms by indicating that useful WIS is information designed and delivered with the intention to meet users' decisionmaking goals (Lemos et al., 2012). Examples of useful information include climate models, satellite images, seasonal forecast bulletins, predictions on El Nino Southern Oscillation (ENSO), and so forth, whereas usable WIS is information readily applied by users in formulating adaptive strategies under uncertain climate or weather conditions for farming (Pielke Jr., 2007; McNie, 2007; Dilling \& Lemos, 2011; Lemos, 2015). The distinction between the two terms indicates that useful WIS pertains more to the information providers' perspective, whereas usable WIS is dependent on users' information needs (Ouedraogo et al., 2018).

Information providers usually perceive that they are delivering usable information. In reality however, this information is not always applied by farmers. The premise is that useful information is not necessarily valuable to users. Therefore, the user's definition of what constitutes useful and usable needs to be the starting point in WIS production and delivery (Daly \& Dilling, 2019). Lemos 


\section{Chapter I}

and Rood (2010) alluded to the fact that information providers' and users' differing perceptions and understandings of usable information create a usability gap, which is reflected in the low WIS uptake for decision-making in farming. Many scholars have tackled the usability gap from different and overlapping perspectives (Cash et al., 2003; Stone \& Meinke, 2006; Meinke et al., 2006; Roncoli et al., 2001, 2009; Lourenço et al., 2016; Dilling \& Lemos, 2011; Kirchhoff et al., 2013; Soares \& Dessai, 2015). Dilling and Lemos (2011), however, attributed the usability gap broadly to two perspectives: farmers' context and the information design and delivery process.

Farmers' context refers to the environment where the information is needed and used, including the role of formal or informal institutions like abiding strictly to certain planting dates (Patt \& Gwata, 2002; Lemos, 2008). The dominance of existing knowledge (Meinke et al., 2006) and users' perception of, and attitude towards, risks affect the usability of information (Lemos et al., 2012); environmental changes, cultural issues, belief systems, values, gender roles, and social capital also play critical roles in the usability of WIS (Meinke et al., 2006; Morss et al., 2005; Patt \& Gwata, 2002). Furthermore, users' information-seeking behaviour, human cognition, expertise, and previous positive experience can enhance WIS uptake (Dilling \& Lemos, 2011). These factors affect usable information because, even when the information is made usable, they can obstruct when and how farmers apply it.

The information design and delivery process is the other perspective that affects usable information, and it pertains to the information providers' side. Several factors, including the local embeddedness of the information in farmers' context, affect information design and delivery, with consequences for the usability of information for decision-making in farming (Cash et al., 2003; Vogel \& O'Brien, 2006; Lemos \& Dilling, 2007; Lemos, 2015). Second, issues of scale in information production often affect usable information (Dow et al., 2009). Third, the time at which WIS is delivered can also enhance or obstruct the usability of information (Nyadzi et al., 2018; Cash et al., 2006). Forth, WIS prediction skills affect its usability, because the skill of a forecast can vary depending on the season of the year. Moreover, the very meaning of forecast accuracy differs between providers who are interested in forecasting 'skill' and users who seem to be interested in how well the forecast performs in terms of their needs (Crane et al., 2010; Ogutu et al., 2017). Fifth, the information's legitimacy - which involves the trust that users associate with a forecast and their perception of how legitimate the information is - can enhance or obstruct the usability of information (Cash et al., 2003; Patt \& Gwata, 2002; Sarewitz \& Pielke, 2007; McNie, 2007). Finally, the accessibility of information through the provision of WIS in users' preferred language and the use of suitable ICTs, among other design features, affect WIS usability.

Overcoming the usability gap necessitates an approach that is more collaborative and brings information providers and users together to exchange knowledge on how to deal with context and information design challenges through co-production (Lemos et al., 2018).

\subsubsection{Conceptualising co-production in WIS provision for farming}

I define co-production as the process through which two or more actors collaborate to produce information by integrating different forms of knowledge, including scientific processes with local knowledge and experience to make information usable for farming (Nyadzi, 2020). Interest in the application of the co-production approach for the provision of usable information has increased sharply in the WIS sector (Bremer \& Meisch, 2017; Hewitt et al., 2012; Ziervogel et al., 2016; 
Wamsler, 2017; Daly \& Dilling, 2019; Bremer \& Meisch, 2017). Although the idea of coproduction is now gaining attention in the WIS sector, it has a much longer history in other fields like public administration, service management, marketing, and science and technology studies (Jasanoff \& Wynne,1998; Bovaird et al., 2015; Jasanoff, 2004; Vincent et al., 2018; Alexander \& Dessai, 2019).

The aim of applying a co-production approach is to break the existing unidirectional and linear participation structures. Some criticisms, however, have come to the fore, including the fact that users are included in the process to provide their opinion only when information providers deem it necessary (Patt \& Gwata, 2002; Vogel \& O'Brien, 2003, 2006; Jasanoff, 2004; Osborne \& Strokosch 2013; Tall 2010, 2013). Also, information providers apply mostly provider-driven or science-driven approaches, to the neglect of local knowledge and experience in the co-production process. Therefore, the current provider-driven form of co-production falls short of servicing the needs of users (O'Brien \& Vogel, 2003; Tall, 2010; Vogel et al., 2017; Vincent et al., 2018).

A shift is required from predominantly provider-driven modes to a user-driven co-production approach where regular and sustained interaction and iterative processes exist between information providers and users (McNie, 2007, 2013; Kirchhoff et al., 2013; Dilling \& Lemos, 2011; Nel et al., 2016). This shift in the co-production process for WIS provision may be likened to a situation where users purposely request certain information design and delivery criteria to be evident and they participate in the information production process (Alexander \& Dessai, 2019).

Different types of co-production approaches are applied in the WIS context depending on the extent to which users are engaged in the design, implementation, and/or other tasks that users perform (Meadow et al., 2015; Briley et al., 2015; Bremer \& Meisch, 2017). Despite the existence of various approaches, I focus on citizen science as a method to involve users (farmers) in collecting data in the co-production of WIS (Leeuwis et al., 2018; Cvitanovic et al., 2015b).

The citizen science method has been applied across a range of disciplines in the last decade (Silvertown, 2009; Wehn \& Almomani, 2019), but its application to involve farmers in WIS coproduction is new (Frensley et al., 2017; Beza et al., 2017; Phillip et al., 2018). The definition of citizen science varies depending on the types of participation and the level of engagement (Shirky, 2008; Bonney et al., 2009; Haklay, 2013; Phillips et al., 2018). Citizen science has been defined as the voluntary participation of community members in scientific work, whereby they monitor their environment through the collection and submission, and/or analysis, of relevant data for decision-making (Stevens et al., 2014; Bonney et al., 2016; Cieslik et al., 2018). Participation can vary from the involvement of volunteers in defining research questions, collecting scientific data, analysis and interpretation of these data, or focusing on an aspect. However, most citizen science studies report on how volunteers collect data to support a scientific course. The participation of volunteers in the design of the technical and social components of a citizen science programme provides opportunities for them to express their preferences concerning relevant design choices. This fosters ownership of the programme and capacity building, and enhances the acceptability of results or feedback (Asingizwe et al., 2019). With the help of mobile phones, participatory monitoring can be performed in real-time and at a very low cost by large groups of volunteers (Sullivan et al., 2009; Cieslik et al., 2018). 


\section{Chapter I}

Conceptually and practically, the application of ICTs for citizen science has articulated the potential for integrating knowledge for the co-production of WIS (Haklay, 2013; Buytaert et al., 2014; Roudier et al., 2014; O'Grady et al., 2016). This is because farmers have local knowledge and experience in weather forecasting by using indicators like flowering plants, birds' migratory patterns, wind direction and speed, cloud formations, the position of the moon or the sun, and so on (Orlove et al., 2010; Alexander et al., 2011; Elia et al., 2014; Mafongoya \& Ajayi, 2017).

In the citizen science research literature, major concerns include how to engage and sustain volunteers' motivation in long-term data collection (Raddick et al., 2009; Beza et al., 2017; Frensley et al., 2017; Tinati et al., 2017; Phillips et al., 2018). In many studies, self-determination theory has been used to explain the motivation of volunteers (Ryan \& Deci, 2000a, 2000b). Broadly, self-determination theory explains that people are either intrinsically or extrinsically motivated to participate in voluntary activity. Intrinsic motivation applies to situations where individuals find fulfilment in performing the activity; for example, the need to enjoy (Phillips et al., 2018; Frensley et al., 2017). Extrinsic motivations are about the attainment of a goal, an external outcome, and, to some extent, compliance to norms (Rutten et al., 2017); for example, the need to contribute to eradicating a communal problem (Alexander \& Dessai, 2019). Intrinsic and extrinsic motivations are closely linked (Ryan \& Decci, 2000a), and Rutten et al. (2017), following Ryan and Deci (2000b), identified that motivation can exist as a continuum, ranging from intrinsic motivation, integrated regulation, identified regulation, introjected regulation, extrinsic motivation, to amotivation (barriers). Raddick et al. (2010) concluded that citizens do not have only one motivation for participating in co-production approaches, given that intrinsic motivation may serve as an initial driver towards participation, but it may develop into other types of motivations (Crowston \& Fagnot, 2018).

\subsection{Gaps in the literature and research sub-questions}

In this thesis, I aim to investigate what makes WIS usable for adaptive decision-making in farming in an informational governance context. To work towards this aim, this section introduces the research sub-questions concerning gaps in the literature.

\section{RQ1: Through which hybrid informational governance arrangements are weather information services provided, and with what effects?}

In the context of development, different arguments have been associated with the emergence of hybrid governance arrangements, especially in informal economies like farming (Meagher, 2012). On the one hand, the emergence of non-state actors in public service provision in the developing country context has been regarded as illegitimate: a sign of a fragile state and/or a deliberate strategy of the state to transfer its responsibilities in the provision of certain public service to nonstate actors (Tosun et al., 2016; Colona \& Jaffe, 2016). On the other hand, the emergence of hybrid governance arrangements is indicated to have strengths and resilience because it enables the convergence of disparate knowledge to innovate and provide public services in new ways (Boege et al., 2009; Toonen, 2013). To this end, although several studies have been conducted on ICTs and their contributions to farming in developing countries, including Ghana, most often these studies have focused on the role of specific ICTs for agricultural development. 
Hence, limited knowledge exists on how ICT have resulted in a process whereby information processes, technologies, institutions, and resources linked to it result in different forms of governance arrangements. Against this background, I aim to unravel the hybrid informational governance arrangements associated with ICT application for WIS provision and the effects thereof.

\subsubsection{RQ2: What flexible or robust decision-making strategies are applied to deal with uncertain weather conditions in farming?}

By applying the concept of adaptive decision-making in farming, RQ2 focuses on assessing flexible or robust decision-making strategies are applied to deal with uncertain weather conditions. Decision-making in the context of climate change and variability is fraught with uncertainties (Risbey et al., 1999; Brugnach et al., 2008). Hence, the need to understand farmers' decision-making under uncertain conditions has attracted considerable scholarly attention.

Farmers' decision-making has been studied through disciplinary lenses such as economics, where individuals act to maximise utility. In the agronomic sector, decision-making on the adoption of farm management practice has been studied (Robert et al., 2016a, b, 2017). Other disciplines such as psychology (Armitage \& Connor, 2001; Ajzen et al., 2002; Gifford, 2011) and, more recently, transdisciplinary approaches such as climate change adaptation research have also examined decision-making in farming (Maddison, 2007; Frank et al., 2011; Williams et al., 2013; Jain et al., 2015). Farmers' decision-making has also been studied through various theoretical lenses such as the theory of planned behaviour (Armitage \& Connor, 2001; Ajzen et al., 2002), bounded rationality (Gigerenzer \& Selten, 2002; Güth \& Kliemt, 2004), the logic of consequentiality (Schulz, 2014; March \& Olsen, 2004; Goldmann, 2005), innovation and adoption (Marfo et al., 2008), farming systems (Dorward et al., 1997; Singh et al., 2016; Singh et al., 2018), irrigation and drought conditions (Keshavarz \& Karami, 2014; Tripathi \& Mishra, 2017), among other themes.

Recently, some studies have attempted to investigate adaptive decision-making as a type of bounded rational decision-making (Leister \& Chiappin, 2010; Hihn et al., 2018). Although the concept is now gaining attention in the infrastructural sector and in studies on climate change scenarios under deep uncertainties, little knowledge exists on its application in the farming sector under uncertain conditions. Answers to the research question posed above will provide an empirical understanding of the decision-making strategies are applied in farming and their adaptivity under uncertain weather conditions. Also, answers from this research question will inform whether or not farmers are able to practice adaptive decision-making in the hybrid informational governance context where numerous WIS provisions exist.

RQ3: To what extent are existing weather information services usable for farming and what is required to enhance their usability?

There have been rapid advances in capacities to provide a range of WIS, from historical data, seasonal forecasts, and daily weather forecasts for farming. However, as indicated in section 1.2.3, WIS has not always been usable for decision-making in farming. Although the WIS sector in Ghana is still in its infancy, several studies have been carried out from different perspectives to tackle the challenges associated with usable information. Also, studies have indicated that 


\section{Chapter I}

numerous actors including business and CSOs are involved in the provision of different WIS for farming (McNamara et al., 2014; Munthali et al., 2018; Nyadzi et al., 2018; Nyamekye et al., 2019; Naab et al., 2019; Nyantakyi-Frimpong, 2019).

Although I recognise the strength of this rich literature in elucidating different aspects and contributions made to improve usable WIS for farming, little knowledge exists on the extent to which WIS is used by farmers and the information design and delivery factors that affect the usability of such information in farming.

RQ4: How can WIS be co-produced through the integration of scientific and local knowledge and what motivates farmers to participate in co-producing WIS?

Although not necessarily a prerequisite for the production of usable WIS, co-production is increasingly promoted as a deliberate approach to foster partnerships between scientists, information providers, and farmers to provide usable WIS (Vaughan \& Dessai, 2014; Meadow et al., 2015; Djenontin \& Meadow, 2018; Vincent et al., 2018). Already, farmers draw information from both scientific and local forecasts to support their decision-making. However, this does not resolve the challenges associated with the usability of information, especially the issue of reliability and accuracy (Naab et al., 2019). Studies have suggested that a deliberate integration of scientific weather models and farmers' local knowledge about weather forecasts can increase the reliability and accuracy of WIS to support adaptive decision-making (Orlove et al., 2010; Roudier et al., 2014; Naab et al., 2019; Nyantakyi-Frimpong, 2019; Nyadzi, 2020). Further, studies suggest that citizen science has the potential to enable data collection on local weather indicators for coproduction purposes (Buytaert et al., 2014, Cieslik et al., 2018, Leeuwis et al., 2018). This idea is theorised and discussed but less studied empirically in farming and WIS literature.

Also, irrespective of the location in which citizen science research is conducted, participants' behaviour varies greatly across projects. Numerous initiatives have had to be halted prematurely or cancelled entirely because they could not reach a critical participating mass (Raddick et al., 2013). As citizen science is an emerging methodology for farming and the WIS sector in developing countries, little knowledge exists on the use of citizen science methods for coproduction and participants' motivation to engage in it. Answers to this research question will contribute to the design and development of citizen science methodologies for farming and the WIS sector to enable the engagement of a large number of participants in future research.

\subsection{Study area}

The thesis focuses on the Ada East District, which is one of 16 districts located in the Greater Accra Region, about a 110km drive from Accra, the capital of Ghana (see Figure 1.1). The district is a lowland area about $5 \mathrm{~m}$ above sea level in the Volta Delta with unique ecological resources such as the Volta Estuary, Songhoor Lagoon, and Keta Lagoon (Nicholls et al., 2017; Adjei et al., 2018). The district lies within latitudes $5^{\circ} 45$ and $6^{\circ} 00 \mathrm{~N}$ and longitudes $0^{\circ} 20$ to $0^{\circ} 35 \mathrm{E}$. The population of the district is about 88,321 based on the natural birth and migration rate, with several small communities. The Ada East District is occupied mainly by the Dangbe ethnic group (Ghana Statistical Services, 2020). 
The Ada East District is regionally and economically important because of its location in the Volta River Delta and Estuary. The rich ecosystem fosters the development of economic activities like salt extraction, fishing, non-timber forest harvesting, and agro-processing and trading (Addo et al., 2018). Also, livestock rearing and shrimp and tilapia farming are strengthening the economy of the area. Moreover, new economic activities such as tourism and the hospitality industry are booming in the major towns (Big Ada, Ada Foah, Ada Kasseh). However, farming is a prominent economic activity, and the sector supplies foodstuffs such as maize, cassava, rice, watermelon, and vegetables to neighbouring urban markets (Appeaning-Addo et al., 2018; Gbangou et al., 2020b). Two periodic community markets are held at Ada Foah and Ada Kasseh, where people from various places in Ghana trade in foodstuffs and other products. Men dominate in the production of crops, whereas females are mostly engaged in agro-processing and trading (Sarku et al., 2020a).

The district lies within the dry equatorial climatic zone with bimodal rainfall seasons controlled by the movement of the Inter-Tropical Convergence Zone and the South West monsoon winds (Gampson et al., 2015; Banoeng-Yakubo et al., 2006). Annual average rainfall varies significantly between $146 \mathrm{~mm}$ and $750 \mathrm{~mm}$ interannually (Lazar et al., 2015), and the annual average temperature is about $30^{\circ} \mathrm{C}$ in March and $26^{\circ} \mathrm{C}$ in August (Nicholls et al., 2017). The annual average total rainfall is less than that experienced in other agroecological and climatic regions in Ghana. The main rainfall season spans April and July, and the minor rainfall season is between September and November. Usually, November to February is the long dry season when the North East trade winds (Harmattan winds) dominate in the region (Yidana \& Chegbeleh, 2013). 


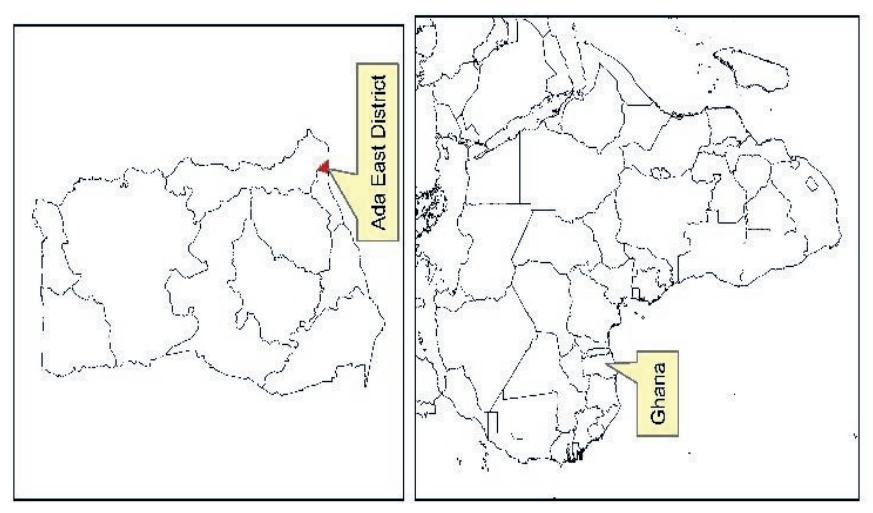

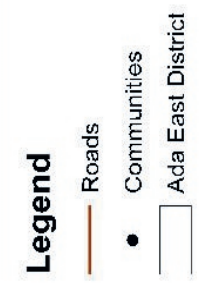
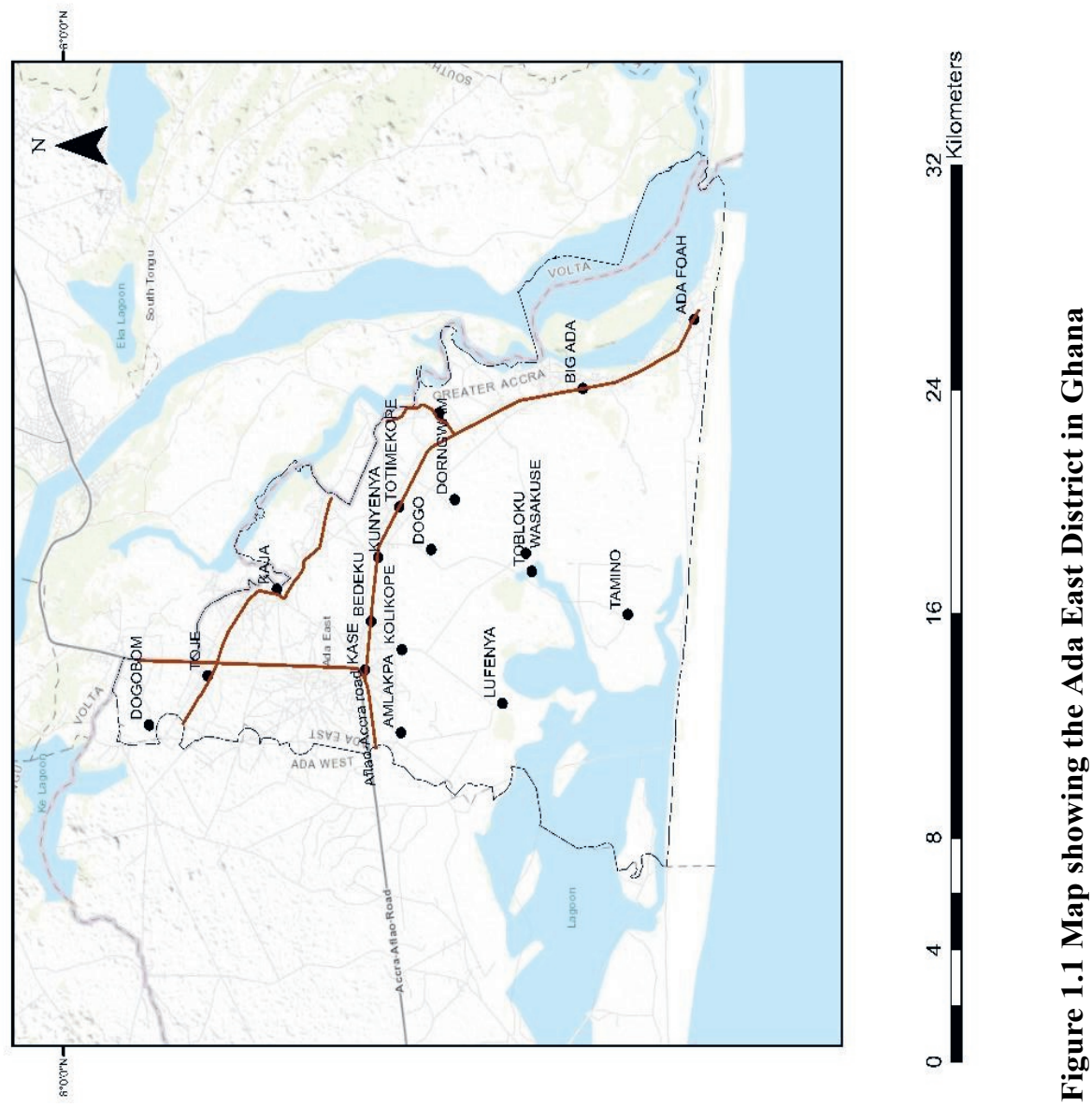
Despite its delta location, farming in the Ada East District is constrained by water availability caused by climate change and climate variability (Addo, 2015; Roest, 2018). Since the 1970s, the West African region has undergone a period of declining rainfall, punctuated by a series of severe droughts and a shift in rainfall regime in the Volta Delta (Owusu \& Waylen, 2008; Gbangou et al., 2020a). The construction of dams and other infrastructures also interrupts the availability of freshwater from the distributaries of the Volta River in the area (Amisigo et al., 2015; Mul et al., 2015; Anthony et al., 2016). An assessment of hazards and vulnerabilities within the Volta Delta shows that the district is at a high risk of climate variability (Deltas, Vulnerability \& Climate Change: Migration \& Adaptation (DECCMA), 2017). Given these challenges and the opportunities associated with farming in the Ada East District in the Volta Delta, the area provides a rich context to examine, explain, and provide knowledge on what makes WIS usable for adaptive decision-making in farming within an informational governance context. Additionally, I selected the Ada East District because the thesis forms part of the WaterApps project, which aims to develop tailor-made water information services with and for farmers in urbanising deltas in Accra, Ghana, and Khulna, Bangladesh, to enhance food production. The project addresses the overall question: How can the potential of water availability forecasts and knowledge sharing platforms and virtual communities be leveraged to create water information services that support adaptive decision-making about water and food production in the peri-urban delta areas? In line with the broad objective of the WaterApps project, the thesis focuses on farming in an urbanising delta region where water availability affects the production and supply of food to urban communities and how farmers can be engaged to co-produce a usable WIS to support their decision-making.

\subsection{Methodological approach}

The overall methodological approach applied in the thesis is transdisciplinary research due to the involvement of scientists from different disciplines and of non-academic actors in a scientific process to unravel the problem together and also to improve the usability of WIS in farming. Transdisciplinary research follows two pathways: it originates from a societal real-life problem that triggers relevant social, technical, and institutional research questions; and then it relies on mutual and joint learning processes between science and society (Siebenhüner, 2004; Stokols, 2006, 2011). These pathways are rarely adopted in WIS research as it is mostly discipline focused as either social or technical science to address a specific constraint. However, the application of social or technical science-based methods and solutions separately may not necessarily be adequate to solve the problem, as a sole discipline or interdisciplinary approach omits relevant problem definitions and solution options (Visser, 2004; Lang et al., 2012; Leeuwis, 2004).

In this thesis, I took account of, and learned from, what actors already know and can do. I reconciled the academic production of knowledge and integrated interdisciplinary knowledge and contextual knowledge from meteorologists, agricultural extension agents, and farmers to define the problem and to develop solution options that are transferable to the scientific community and to societal practice in a real-life situation (Hounkonnou et al., 2012). The transdisciplinary research was conducted in an iterative sequence of three phases: collaboratively identifying and validating the real-life constraints in WIS for farming; co-producing solution-oriented and transferable knowledge through joint participatory experimentation; and applying the knowledge in both science and societal practice (Scholz et al., 2006; Wiek, 2007; Leeuwis, 2004). Transdisciplinary research is also advantageous as it promises to increase the legitimacy, ownership, and reliability of the solution options (Scholz et al., 2006; Lang et al., 2012). I applied the transdisciplinary 


\section{Chapter I}

approach under the Waterapps project. While conducting the research, I was attached to the District Agricultural and Development Unit (DADU) in the Ada East District where I worked directly with agricultural extension agents.

Following the methodological approach of the thesis, I describe its ontological orientation. The thesis is grounded in a critical realist ontological perspective, which takes abductive reasoning into account (Bertilsson, 2004). Critical realists assume that our knowledge of reality is limited because human beings are capable of capturing only an aspect of the world. Also, reality is stratified in the sense that unobservable causal processes lie at the root of reality and cause observable events to occur. These events occur independently of our observation, and therefore some events are experienced, observed, and understood through human (subjective) interpretation, whereas others are not. In an attempt to understand the real world, social scientists apply theories that enable explanations to be formulated (Bhaskar, 1998; Fletcher, 2017; Danermark et al., 2002). In this instance, theories and conceptual frameworks play a role in helping to make sense of reality (Danermark et al., 2002). Because the subjective interpretation of reality depends on the lens of analysis, different theories can be used in an attempt to explain the same phenomenon and generate many explanatory values (Wynn \& Williams, 2012). Causal underlying processes cannot be observed, and therefore inferences are best made about what can be observed and interpreted in multiple ways. Critical realism also highlights the interplay between structure and agency. It assumes that structures are enduring features that shape agency and can be reproduced over time and that agency, although shaped by structures, also co-shapes these structures (Carter \& New, 2004; Fletcher, 2017).

I position this thesis within a critical realist ontology as well as interpretive ideas because our knowledge of reality, including the domain of human action, is a social construction by human actors (Walsham, 2006). Interpretive ideas indicate that people have their perceptions and interpretations of reality and acknowledge the role of explanations. Like realists, interpretivism points to the fact that natural and social scientists can employ a similar methodology, and acknowledge separation between reality and the senses (Geertz, 2008). I combine an interpretive epistemological lens with critical realism in this thesis. This is exhibited in the formulation of my research questions and the application of theories to interpret reality.

\subsubsection{Qualitative case study research}

A combination of critical realist and interpretive ontology calls for the application of a qualitative approach. Qualitative research designs are used to generate in-depth and rich data in a case study. Data generated using a qualitative approach is thought to be more valuable to better understand a new and emerging field or problem (Flyvbjerg, 2006). Also, qualitative research is suitable for situations where there seem to be no clear boundaries between the studied phenomenon and the context (Bryman, 2004; Mason, 2002; Yin, 2009). For instance, in this thesis, information is both the object and the means to study it. Because qualitative research is context dependent, it is difficult to make generalised conclusions. Therefore, findings derived from the qualitative approach are generalised in theoretical or analytical terms (Yin, 2009).

Given the kind of research questions posed in this thesis, I applied a case study design (Yin, 2009). It is an in-depth empirical inquiry and a comprehensive research strategy that relies on multiple sources of evidence to examine a complex problem within its specific context (Yin, 2003; Hyett 
et al., 2014). The selection of case studies such as farming, WIS, and the Ada East District provides a powerful means to examine, explain, and provide knowledge on what makes WIS usable for adaptive decision-making in farming in an informational governance context. Furthermore, a case study design allows for the use of mixed approaches and multiple data sources for triangulation and generation of strong evidence (Yin, 2009).

\subsubsection{Data collection methods}

I adopted multi-interpretive methods, consisting of interviews, observation, focus group discussions (FGDs), and participatory action research because of the overall research question, the objective, and the ontological and epistemological orientation of the thesis.

\section{- Interviews}

To provide answers to the four research sub-questions, I conducted interviews to interact and dialogue with respondents (Mason, 2002). Hence, I carried out the interviews as conversations guided by a list of topics. This gave the interviewees time and freedom to share and elaborate on their discourses and narratives.

\section{- Observation}

Observation constituted another research method that I used for data collection for RQ1 and RQ4. Observation refers to the researcher's participation overtly or covertly in people's daily lives for an extended time and collecting data on whatever is available to generate more insight for the specific research question (Hammersly \& Atkinson, 2007). By working with agricultural extension agents at the DADU, I had the opportunity to attend several workshops organised for farmers and to make home and field visits. Whenever I participated in these activities, I regularly took notes and highlighted the issues that I perceived as important for the study of specific research questions. Being immersed in the farming context through observation also allowed me to interpret the empirical data to derive meaning (Walsham, 2006).

\section{- Focus group discussions}

For RQ2 and RQ4, I conducted FGDs to derive an in-depth knowledge on various aspects of the research questions. The FGDs enabled me to understand the interwoven contextual issues concerning WIS in farming, and participants were able to express multiple opinions that corroborated findings from interviews and observations (Parker \& Tritter, 2006).

\section{- Document analysis}

I carried out document analysis to generate data for RQ1 by surveying grey literature and reviewing bulletins, blogs, pamphlets, policy documents, and websites, as well as published reports, to identify issues relating to WIS production or delivery. This survey generated a list of organisations providing WIS for farmers in Ghana and other issues related to the research question.

\section{- Workshops}

Several workshop sessions were conducted to learn from farmers about their forecast indicators and to co-design the interface of a digital tool (i.e., WeatherApp) following the user-driven design approach (Zulkafli et al., 2017). The use of workshops in the study was also meant to foster learning among farmers and between farmers and agricultural extension agents. Additionally, it supported joint definition of issues and solution options. Farmers were also trained to use digital 


\section{Chapter I}

tools including smartphones, applications (apps), internet handling, and how to install and operate rainfall monitoring tools (Chapter 5). The data collection and analysis methods are described in more detail in the empirical chapters of the thesis.

\subsubsection{Data analysis}

With the interviewees' consent, each interview and FGD was recorded and transcribed. In line with the ontology and methodological approach of the study, an abductive logic of data analysis was followed. This involved a continual iteration between empirical data and existing theories, and between developed ideas and new insights. These iterations allow the researcher to generate more plausible explanations that can be tested in further research (Beach \& Pedersen, 2016; Wolf $\&$ Baehler, 2018). In Chapter 2, the selection and operationalisation of the concepts - multiplicity, intertwinement, and coalescence - required prior theoretical knowledge and empirical insights and resulted in an iterative process (Schneider \& Wagemann, 2010; Gerrits \& Verweij, 2013). A similar approach was adopted for the data analysis in Chapters 3, 4, 5, and 6. Depending on the focus of the chapter, the data coding varied slightly, and, following the inductive codes-to-theory model, recurring topics, key constructs, stories, and discourses were iteratively given codes and through consecutive rounds of coding were later combined into themes (Saldaña, 2013). The iterative processes of coding and data analysis were supported by qualitative data analysis software Atlas.ti (version 8) and Microsoft Excel. I present an overview of the research methodology in Table 1.1.

\section{Table 1.1 Overview of research methods}

\begin{tabular}{|c|c|c|c|c|}
\hline $\begin{array}{l}\text { Research } \\
\text { question }\end{array}$ & Chapter & Objective of the approach & Data collection & Data analysis \\
\hline 1 & 2 & $\begin{array}{l}\text { Assess hybrid informational arrangements } \\
\text { used for the provision of weather } \\
\text { information services provided, and their } \\
\text { effects }\end{array}$ & $\begin{array}{l}\text {-Interviews } \\
\text {-Observations } \\
\text {-Focus group } \\
\text { discussion }\end{array}$ & $\begin{array}{l}\text { Deductive and inductive } \\
\text { coding; Software: Atlas.ti, } \\
\text { Excel }\end{array}$ \\
\hline 2 & 3 & $\begin{array}{l}\text { Examine flexible or robust decision- } \\
\text { making strategies under uncertain weather } \\
\text { conditions in farming }\end{array}$ & $\begin{array}{l}\text {-Interviews } \\
\text {-Observations } \\
\text {-Primary } \\
\text { documents }\end{array}$ & $\begin{array}{l}\text { Inductive and deductive } \\
\text { coding; document analysis; } \\
\text { Software: Atlas.ti, }\end{array}$ \\
\hline 3 & $4 \& 5$ & $\begin{array}{l}\text { Identify the extent to which existing } \\
\text { weather information services are usable for } \\
\text { farming and the factors that can enhance } \\
\text { their usability }\end{array}$ & $\begin{array}{l}\text {-Interviews } \\
\text {-Focus group } \\
\text { discussion }\end{array}$ & $\begin{array}{l}\text { Inductive and deductive } \\
\text { coding; Software: Atlas.ti }\end{array}$ \\
\hline 4 & $5 \& 6$ & $\begin{array}{l}\text { Assess farmers' motivation for engaging in } \\
\text { the co-production of weather information } \\
\text { services that integrate scientific forecasts } \\
\text { and local knowledge }\end{array}$ & $\begin{array}{l}\text {-Interviews } \\
\text {-Observations } \\
\text {-Workshops }\end{array}$ & $\begin{array}{l}\text { Deductive and inductive } \\
\text { coding; Thematic analysis, } \\
\text { Content analysis; } \\
\text { Software: Atlas.ti }\end{array}$ \\
\hline
\end{tabular}

\subsection{Structure of the thesis}

This thesis consists of seven chapters, of which this introductory chapter provides the background and problem definition, the conceptualisation of main theories, research gaps, and questions, the study area, and the research methodology. As indicated in Figure 1.2, Chapter 2 examines the role 
of ICTs in the emergence of hybrid informational governance arrangements for WIS provision and their effects. Chapter 3 examines farmers' decision-making under uncertain weather conditions. This chapter provides information not only on decision-making strategies but also on the pattern of decision-making. Findings from this chapter provided relevant information for subsequent chapters, especially Chapters 5 and 6. Chapter 4 analyses the existing WIS provided in the Ada East District and the extent to which they are usable for farming. In Chapters 5 and 6, I examine the co-design and co-production process of a new WIS that focuses on the integration of scientific forecasts and local knowledge and the level of farmers' engagement and motivation to participate in the process. 
Chapter I

Figure 1.2 The overall structure of the thesis

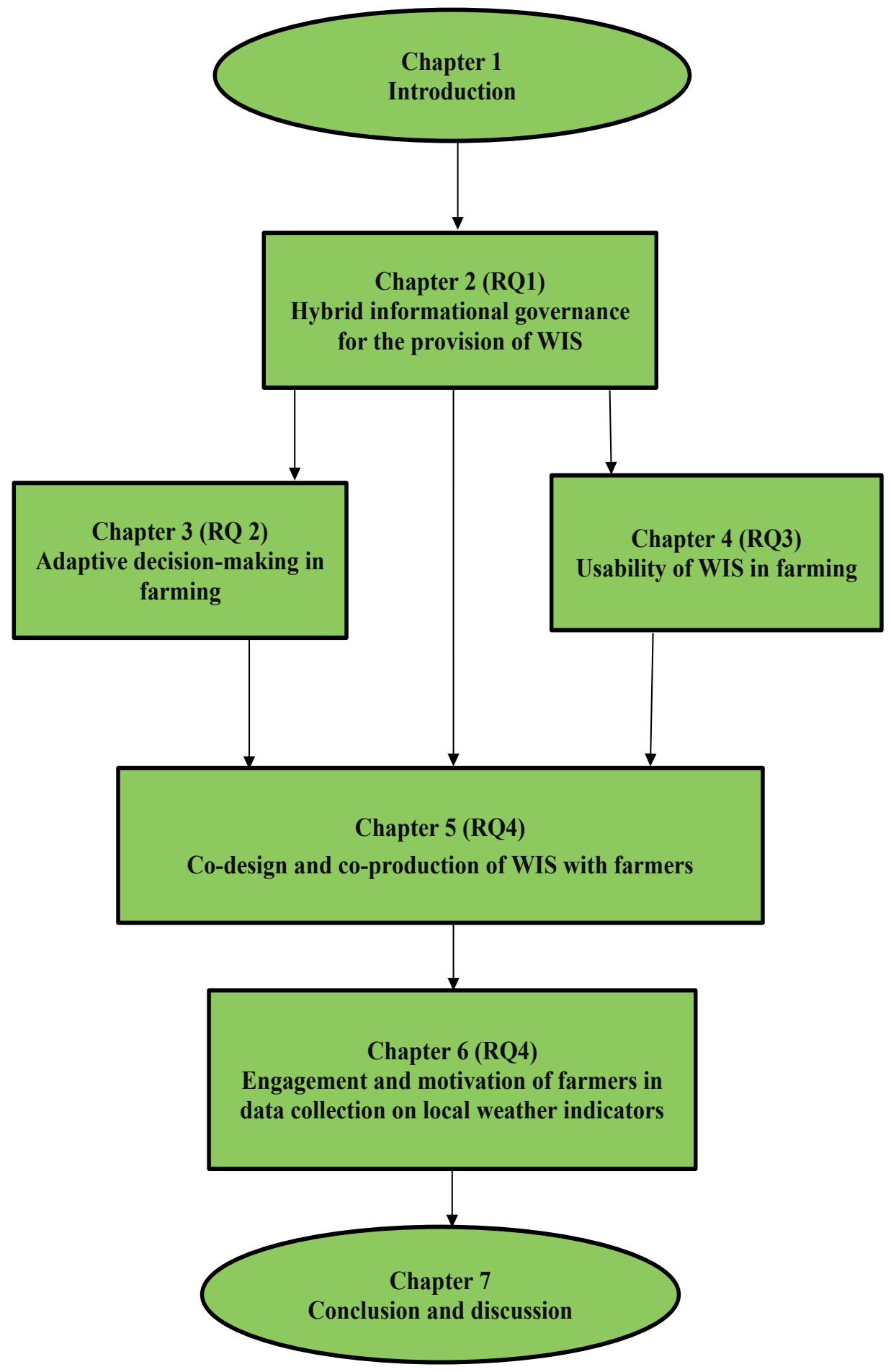


Introduction

ت 


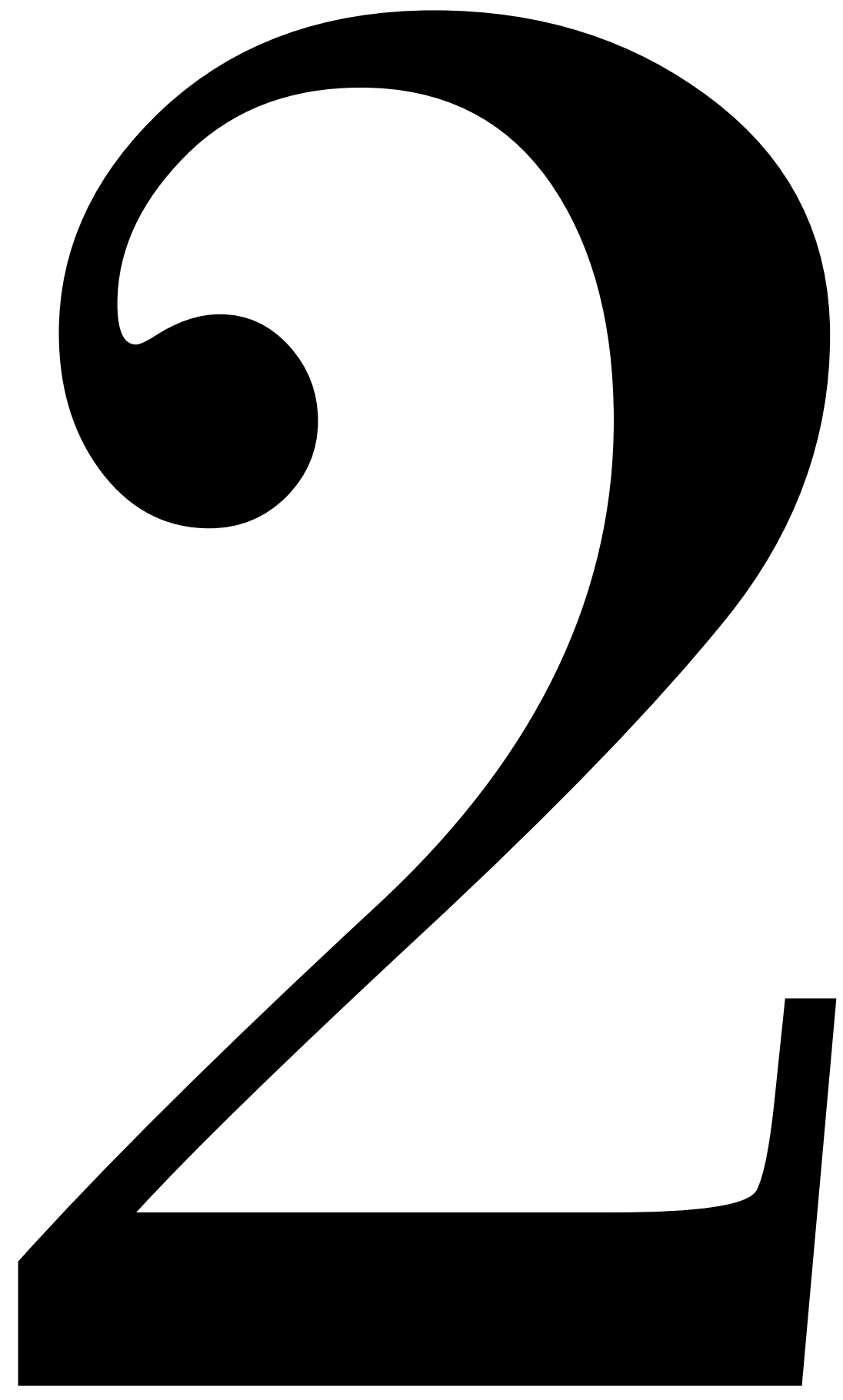




\section{Chapter 2}

\section{Tracing hybridity in the provision of ICT-enabled agricultural weather information services in Ghana}




\title{
Chapter 2
}

\begin{abstract}
This study investigates the hybrid informational governance arrangements involved in the provision of ICT-enabled Weather Information Services (WIS) for farming in Ghana. Semistructured interviews were conducted with farmers and organizations providing WIS. Findings show that multiple technologies are used by combinations of government, business and civil society organisations to provide various WIS for farming. ICT has facilitated the creation of different hybrid informational governance arrangements, categorized as: multiplicity, intertwinement and coalescence. This permits flows of WIS across scales, ranging from international non-state organisations to farming communities, often by-passing national and district-level government organisations. Overall, government organisations remain key players in the provision of WIS.
\end{abstract}

Manuscript accepted: Sarku, R., van Slobbe, E., Siwale, A., Chudaska, R., Teermer, K. \& Dewulf, A. Tracing hybridity in the provision of ICT-enabled agricultural weather information services in Ghana. Accepted for publication in the Journal of Agricultural and Food Information. https://doi.org/10.1080/10496505.2021.1874388 


\subsection{Introduction}

Until recently, Information and Communication Technologies (ICTs) and agriculture in Africa were apart. However, as mobile network coverage has expanded and mobile devices have become progressively cheaper, the level of connectivity across Africa has grown. 3G technology was expected to reach an estimated $45 \%$ of Africans by the end of 2019 , with smartphone connections projected to soar to 700 million in 2025, up from 301 million in 2018 (Global System for Mobile Association [GSMA], 2019, p. 2). ICTs have also spread rapidly among farming communities in Africa, sparking innovations in farming (Duncombe, 2014, 2016; Heeks, 2009).

In Ghana, agricultural information used to be delivered mainly by agricultural extension agents, sometimes complemented by 'old fashioned' ICTs such as radio and television (Asenso-Okyere \& Mekonnen, 2012; Drafor, 2016). Farmers can now access information through web portals and platforms, mobile phone applications such as WhatsApp, short message services (SMS), mobile push and pull services and other ICT-based innovations (Munthali et al., 2018). The low unit cost of using ICTs to establish and maintain contact with smallholder farmers has spurred many innovative initiatives involving government, business and civil society organisations (see, Agyekumhene et al., 2018; Munthali et al., 2018; Partey et al., 2020). Alongside this general rise of ICT capability, the Government of Ghana has enacted policies to promote digitalisation and use of ICTs to increase agricultural production, accelerate development and facilitate national telecommunications and the media (Adaba \& Ayoung, 2017).

This enabling policy environment, combined with the increased availability of information and ICTs in Ghana, has allowed many non-state organisations to provide information services directly to farmers, resulting in new governance arrangements. In these, the role of the state is being redefined, though not necessarily lessened, with non-state organisations coming to the fore to complement or even outplay the roles of the state (Mol, 2008, 2009). In these new arrangements, government organisations either provide information services directly to end-users or are involved indirectly through business and civil society organisations (Asenso-Okyere \& Mekonnen, 2012; Drafor \& Atta-Agyepong, 2005). The provision of similar types of information by state and nonstate organisations to the same users at the same time (Slavova \& Karanasios, 2018) can lead to the emergence of hybrid organisations that operate based on both altruistic and financial models (Haigh et al., 2015). Further, the government has privatised or granted autonomy to some of its agencies, allowing them to exist more autonomously and transact businesses in their own right (Nubuor, 2017). These developments have transformed the nature of public information service delivery.

Some authors perceive the provision of public information services through these new arrangements as a sign of a weak state and as undermining the formal economy and democracy (Boege et al., 2009). Recent research, however, suggests it can be a deliberate strategy for a government to respond to resource constraints (Glin, 2015; Meagher, 2012) while leveraging the potential of ICTs to enhance public information service delivery (Adaba \& Ayoung, 2017). These diverging views have renewed academic interest in the role of informational and hybrid governance and their implications for development.

Among the multiple kinds of agricultural information services provided in Ghana, weather information service (WIS) is a key resource to support decision-making in farming, particularly in 
the face of today's increasingly variable weather and climate change (Fosu-Mensah et al., 2012). Due to its relevance, there is a growing literature on the application of ICTs for the provision of WIS for farming in Ghana. For example, ICTs have been used for participatory monitoring of the weather in farming communities (see, e.g., Clarkson et al., 2019) and its application for integrating farmers' local forecasting knowledge with scientific weather forecast has been explored (Nyadzi et al., 2019). Furthermore, studies on the provision of weather and climate information services have focused on the role of specific ICTs such as, mobile phones among other tools (Chapman et al. 2013; Akudugu et al. 2012; Caine et al., 2015; Etwire et al. 2017; Tarchiani et al., 2017; Nyadzi et al. 2018; Alhassan et al., 2019; Nyamekye et al., 2019; Partey et al., 2020).

While research findings indicate that the application of ICTs are contributing to the provision of agricultural information including the WIS for the development of smallholder farming in Ghana, we argue that the role of ICTs exceeds the mere delivery of information to support decision-making in farming. This is because the application of ICTs for the delivery of information transforms the processes, practices, institutions and resources that are linked to it (Hoefnagel et al., 2013). Hence, despite the fact that many studies have been conducted on the roles of ICTs in the provision of weather and climate information services for farming and the diversity of organisations involved (McNamara et al., 2014), little is known about the governance arrangements that are associated with it. Also, as new governance arrangements are likely to emerge with the provision of WIS with ICTs, it is not known whether or how this affects changes in actors' roles, practices and institutions. We argue that the provision of WIS with ICT for farming by numerous organisations requires an understanding of emerging governance arrangements and its effects. This is a gap in knowledge that exists in the weather and climate information services literature, particularly in the context of developing countries.

Zooming in on the concepts of informational governance, hybrid governance and hybrid organisations, the current study examines the roles played by ICTs in WIS for farming. In focusing on the case of southern Ghana's Ada East District, the research also contributes to the wider discourse on the consequences of ICTs for development (see Zheng et al., 2018). In short, this research examines the hybrid informational governance arrangements that have emerged with the expanding use of ICTs in agricultural WIS in the Ada East District of Ghana.

This research is one of the first studies to examine informational governance in the context of a developing country and the roles played by ICTs in the emergence of modes of governance. It aims to unravel how multiple WIS are provided with the combination of technologies including radio, mobile telephony, SMS, call centres and interactive voice response. It will also illustrate how ICT permits flows of WIS across scales from international non-state organisations to local farming communities and how non-state organisations complement the roles of government organisations.

The paper is organised into six parts. Following this introduction, section 2 reviews three key notions that we combine to create the hybrid informational governance conceptual framework. Section 3 presents the rationale for selection of Ghana's Ada East District for our case study, and for the research methods chosen. Sections 5 and 6, respectively, discuss the key findings and conclusions of the study. 


\subsection{Conceptual framework}

\subsubsection{Three foundational notions}

The hybrid informational governance framework applied in this research links three key notions: informational governance, hybrid governance and hybrid organisation.

Informational governance refers to a situation in which the generation, processing, transmission and use of information leads to societal change and the restructuring of institutions and organisational roles (Mol, 2006a). Four phenomena contribute to the emergence of informational governance. The first is the advent of ICTs to facilitate integration of different organisations, information and their roles at varied temporal and spatial scales (Hoefnagel et al., 2013). The second phenomenon is the redefinition of the role of the state, particularly loss of state dominance in the governance of environmental issues. The third phenomenon is globalisation, which gives rise to a multiplicity of interconnected flows of information and material resources across societies, environments and economies (Lemos \& Agrawal, 2006). The fourth phenomenon is changes in the automatic domination of science as a trusted societal institution (Spruijt et al., 2014). In short, informational governance can be understood in two ways: (1) as governing through information and (2) as institutional change, or changes in steering practices, due to information flows (Soma et al., 2016a, 2016b, 2016c). Informational governance can result in changes in regulatory modes or styles of operation of government organisations. It can also lead to an absence of a central governing authority, and lead to non-state organisations bypassing the state in information provision (Kobrin, 2001). Thus the state loses its monopoly on information provision, since information flows continually via ICTs from less traceable and verifiable sources.

Although informational governance clearly envisages a redefinition of the state's roles and the entrance of new organisations, the concept tells us little about how this may transform the organisations involved. Is a multiplicity or intertwinement of organisations to be expected? Will the organisations involved eventually coalesce? Interestingly, answers to these questions can be sought in the growing literature on hybrid governance and hybrid organisation.

Hybrid governance is defined as an arrangement by which government, business and civil society organisations interact and become entangled with each other in service delivery (Christensen \& Laegreid, 2011). Hybrid governance is a broad concept that encompasses a variety of governance arrangements including hybrid organisations (Boege et al., 2009; Brandsen \& Karré, 2011; Kickert, 2001).

Hybrid organisations cover the broad spectrum between purely government at one end and business or civil society organisations at the other end. According to Billis (2010), hybrid organisations possess "significant characteristics of more than one sector". Thus, hybrid organisations may combine profit and not-for-profit motivations, public and private orientations, and formality and informality (Brandsen \& Karré, 2011). Hybrid organisations represent a fusion of essentially 'conflicting' elements from different organisations belonging to different sectors (Brandsen \& Karré, 2011). They may be newly created or the result of the transformation of traditional organisations into hybrid ones (Battilana \& Dorado, 2010). Hybrid organisations are usually established in deliberate fashion (Vining \& Weimer, 2016). Examples of hybrid organisations are state organisations that operate as businesses; civil society organisations that perform functions of the state; and business organisations that engage in public service provision. 
Other organisations that can be classified as hybrid are non-profits with income-generating activities, socially responsible businesses, corporations practising social responsibility and environmentally friendly firms (Doherty et al., 2014; Haigh et al., 2015).

In the past, hybrid governance was a key concept for analysing state-building and the role of informal institutions in failed or fragile states (Boege et al., 2009; Meagher et al., 2014). However, various authors now de-emphasise the state fragility and failure perspective and focus instead on hybridity as a generative, innovative and adaptive characteristic (see Colona \& Jaffe, 2014; Glin et al., 2017; Meagher, 2012, 2014). Indeed, some studies approach the hybrid governance arrangement as a deliberate strategy that states can use to adapt to constraints such as limited human, economic and knowledge resources (Boege et al., 2009; Tosun et al., 2016). From both perspectives, the role of hybrid governance has been studied in relation to security, clash of institutions and the informal sector in developing countries.

Despite the extensive literature on informational and hybrid governance, little research exists on whether these arrangements are disruptive or contribute beneficially to information services provision. The current research fills this critical gap, while also providing new ways of examining the different dimensions of hybrid governance as a theoretical construct. We linked the three notions discussed above to develop a new conceptual framework to study hybrid informational governance in a case study context. Specifically, we examined the evolving roles of government, business and civil society organisations in provision of WIS in the Ada East District of Ghana.

\subsubsection{A conceptual framework for hybrid informational governance}

The new conceptual framework which we develop defines hybrid informational governance as a situation in which government, business and civil society organisations interact to produce and deliver public information. Here, the state sector consists of government-funded organisations providing public information services to citizens through paid public servants (Billis, 2010). The civil society sector is made up of organisations operating with altruistic motives. These organisations draw their human resources from volunteerism, and derive their financial resources from dues, subscriptions, donations and legacies (Onyx et al., 2018). Examples of the civil society organisations identified in this study are non-governmental organisations (NGOs), knowledge institutions, farmer-based organisations, farmer/farming communities and volunteer groups. The business sector represents organisations owned through shareholding, transactions and fees. Their operational priority is to maximise financial returns through market forces, and they have paid employees (Billis, 2010). These three sectors differ in terms of ownership, financing, products, management approaches and practices.

Both state and non-state organisations can provide public information services within hybrid informational governance arrangements. This study distinguishes three forms of hybrid informational governance: multiplicity, intertwinement and coalescence. These can be compared to fully government-provided public information services, which is our reference category.

\section{Information as a fully government-provided public service}

As the reference situation, we took a situation in which information services are provided only by government organisations. These government organisations are hierarchical, with resource ownership by the state. Paid public servants supply the human resources for information service 
delivery. This form of informational governance represents a view of WIS as a public good, to be produced freely for the general public and financed through tax income (Lemos \& Agrawal, 2006).

\section{Multiplicity}

In the multiplicity form of hybrid informational governance, state and non-state organisations both provide public information services. There is thus a multiplicity of implementing organisations due to the complexity and multiscale character of environmental problems such as climate change, as well as the diverse opportunities offered by ICTs. If in such a situation government organisations lack the capacity to fulfil their conventional roles (Lemos \& Agrawal, 2006), non-state organisations can emerge to also provide public services (Mol, 2006b). With multiplicity, there is no synthesis of state and non-state organisations, institutions and practices (van der Haar \& Heijke, 2013). In most cases, intertwinement is used as a term to refer to the provision of similar services by state and non-state organisations. However, if there is no synthesis of institutions or practices and no incorporation of the structures of one provider into those of the other, multiplicity is a more accurate descriptor (Hesselbein et al., 2006).

\section{Intertwinement}

Intertwinement is a form of hybrid informational governance in which services are provided jointly by government, business and civil society organisations. Intertwinement is an intermediate realm in which organisations from at least two of the three sectors collaborate to deliver a public information service together (Goodfellow \& Lindemann, 2013; Haigh et al., 2015). Depending on the types of organisations involved, four types of intertwinement can emerge:

- joint service provision between government and civil society organisations;

- joint service provision between government and the business sector;

- joint service provision between civil society and business organisations;

- joint service provision between government, business and civil society organisations.

\section{Coalescence}

Coalescence is a form of hybrid informational governance in which two or more existing organisations come together to form a joint department. This new 'tangible' entity is then labelled a hybrid organisation, given its formation from two or more organisations with 'contradictory' characteristics. Coalesced organisations may be organic, entrenched, shallow or enacted, depending on the level of hybridity and the degree of willingness in adoption of the hybrid form (Bassi, 2014; Billis, 2010). A 'shallow hybrid' is an organisation in which the process of hybridisation is very low or modest. An 'entrenched hybrid' is an organisation in which the process of hybridisation is profound in regard to both governance and operations. An 'organic hybrid' is an organisation that was established as a pure, single sector type (government, business or civil society) and then gradually transformed towards a hybrid organisational form as it steadily accumulates practice or resources from other sectors (e.g., rural banks). An 'enacted hybrid' organisation is one established as a hybrid from the start (e.g., a social enterprise).

To summarise, this section is about three forms of hybrid informational governance and a reference case in which government organisations are the sole providers of WIS. Our development and application of hybrid informational governance as the new conceptual framework for this study is distinct from the quasi-hybrid governance arrangements analysed in much of the literature (Haigh et al., 2015; Kickert, 2001). Drawing on these four forms, we posed a number of questions to guide 
our study of hybrid governance arrangements in provision of ICT-enabled WIS for farming in the Ada East District of Ghana:

- What WIS are being provided to farmers in the Ada East District?

- What roles have ICTs played in the rise of multiplicity in WIS provision?

- What roles have ICTs played in the rise of intertwinement between organisations in WIS provision?

- What roles have ICTs played in promoting coalescence of organisations in WIS provision?

\subsection{Research setting and methods}

\subsubsection{Research setting}

The Ada East District lies in Ghana's southern peri-urban coastal savannah agroecological zone. The district occupies an area of $289.783 \mathrm{~km}^{2}$. It has a dry coastal equatorial climate. Average temperatures here range from $23^{\circ} \mathrm{C}$ to $28^{\circ} \mathrm{C}$, and average annual rainfall is about $800 \mathrm{~mm}$ (Ghana Statistical Service, 2014). The district's high annual temperatures coupled with low relative humidity promote high evapotranspiration, limiting water resource availability for farming. Despite the area's bimodal rainfall pattern, with peaks in June/July and October, the main farming season (April-July) and minor farming season (September-November) in the study area are highly variable, particularly with regard to rainfall onset and cessation dates and intra- and inter-season lengths (Teye \& Owusu, 2015). Dry spells are also frequent, with erratic rainfall and the occasional absence of the minor rainy season (Gbangou et al., 2019). Nonetheless, a large proportion of smallholder farmers depend on rainfall to produce food for household consumption and sale in urban markets.

The availability of ICTs has enabled a variety of WIS to support farmers' decision-making in the study area. For example, WIS provides recommendations on when to sow seeds, when to plough and when to harvest. Given the weather variability experienced in the district and the WIS being provided for farming, the Ada East District provides an interesting case to examine how hybrid informational governance might evolve.

\subsubsection{Data collection}

We used an interpretive case study (Walsham, 2006) and qualitative methods, particularly semistructured interviews and document analysis. Case study research design is usually applied to answer a "how" or "why" research question about a contemporary set of phenomena with the aim to provide an intensive, holistic description and analysis on a specific context issue (Pickard, 2013). The application of case study method in most ICT research is aimed at providing explanations from multiple perspectives about the technical and social aspects and their interactions (Walsham, 2006; Flyvbjerg, 2006; Ponelis, 2015).

Case study research is associated with interpretive ideas based on the argument that observations are theory laden (Leitch et al., 2010). This drives the need to understand the world from the perspective of the participant (Ponelis, 2015). In this study, we applied interpretive case study method due to the contemporary nature of the use of ICTs for the provision WIS and the limited knowledge on the governance arrangements that enables the process. In this instance, application of theories are emphasized especially where existing theories are inadequate (Danermark et al. 
2002; Yin, 2009; Fletcher 2017). Usually no hypothesis is formulated and so we applied broad ideas or expectations to serve as a guide for the empirical study.

Qualitative research methods provide holistic understanding of contextual, and generally unstructured, non-numeric data (Mason, 2002; Creswell, 2014). Qualitative research methods allow for a continual iteration between empirical data and existing theories, and between developed ideas and new insights. These iterations allow the researcher to get closer to one or more plausible explanations that can be tested in further research (Beach \& Pedersen, 2016; Wolf \& Baehler, 2018). In contrast, in quantitative approaches, ideas about the research topic are tested against predefined standards, resulting in more robust and precise data while data from qualitative research is thought to be more valuable for a better understanding of a new and emerging field (Ponelis, 2015). From our perspective, the innovative application of hybrid informational governance in a developing country context and the limited knowledge on the governance arrangements that are arising due to the provision of WIS with ICTs calls for application of interpretive case study and qualitative research methods.

Data was collected from the Ada East District and Accra for a 12-month period starting in May 2017. For the document analysis, we initially surveyed grey literature, reviewing bulletins, blogs, pamphlets and websites, as well as published reports, to identify issues relating to WIS production or delivery. This survey generated a list of organisations providing WIS for farmers in Ghana. However, upon closer examination most of these organisations were found to provide services only in the northern part of the country, as this is where the majority of international donor organisations operate. We therefore identified and selected only those organisations whose services reached farmers in the Ada East District (see Table $2 b$ in supplementary materials).

Subsequently, we conducted semi-structured interviews with farmers and agricultural extension agents in the Ada East District in June and July 2017. We interviewed ten farmers from six communities and five agricultural extension agents. The interviews focused on where the farmers got weather information, how farmers accessed the information and who information providers were and where they were located. With the insights gained from these interviews and from the survey of grey literature, we drafted an interview guide for organisations providing WIS. At this point we also generated a new list of organisations providing WIS to farmers in the district including those identified during the interviews. This list provided the starting point to contact organisations to conduct interviews.

We conducted face-to-face interviews with informants from organisations in both Accra and the Ada East District. The interviews consisted of questions about sources of information, how organisations interacted, the original roles of the organisations and changes in roles that had occurred, alongside the reasons for any such changes. Additional questions were also phased from the information derived from the interview we conducted with farmers at the Ada East District to support our initial findings. Some of the organisations suggested further potential interviewees. This led us to conduct semi-structured interviews with representatives of 19 organisations.

Transcribing the interviews and reviewing the fieldnotes and literature on hybrid informational governance, we identified four initial themes: 'organisations and their roles', 'interactions between organisations', 'hybrid organisation' and 'changing roles of organisations'. Subsequently, we 


\section{Chapter 2}

uploaded all interview transcripts, fieldnotes and grey literature into Atlas.ti for coding. Coding was done in a detailed sentence-by-sentence manner, resulting in the generation of new codes and themes. In a second step, the new codes were compiled to create a structured code tree, expanding existing code groups and creating new code groups. During the coding process, the data was further analysed to identify overarching patterns and theories related to the research questions.

\subsection{Findings}

This section presents findings from the analyses in relation to the four questions posed regarding the types of WIS provided to farmers and the roles of ICTs in multiplicity, intertwinement and coalescence of organisations involved in WIS provision.

\subsubsection{Types of WIS provided to farmers}

Farmers in the Ada East District accessed a variety of WIS, provided by government, business and civil society organisations. In some cases organisations from different sectors collaborated to provide WIS. Table 2.1 presents the WIS identified, alongside the organisations providing the base information and categorising the WIS in regard to five broad types:

- General forecasts is provided for a wide range of uses, either as a nationwide or it is focused on a specific geographic area;

- Farming-specific forecasts, provides information on weather parameters of special interest to farmers with 'value added' content on how the information can be applied in agricultural decision-making; for example, "rainfall is likely tomorrow, so harvest rice today";

- Temporal forecasts is either daily, weekly, monthly or seasonal predictions tailored to specific farming locales;

- Subscription WIS requires either payment or registration to access;

- Scheduled WIS is delivered according to a set schedule, for example, at 8:00 AM each morning.

Regarding the application oof ICTs to provide WIS to farmers in the Ada East District, we found a prevalence of ICT use, particularly radio, mobile telephony, websites and SMS. 


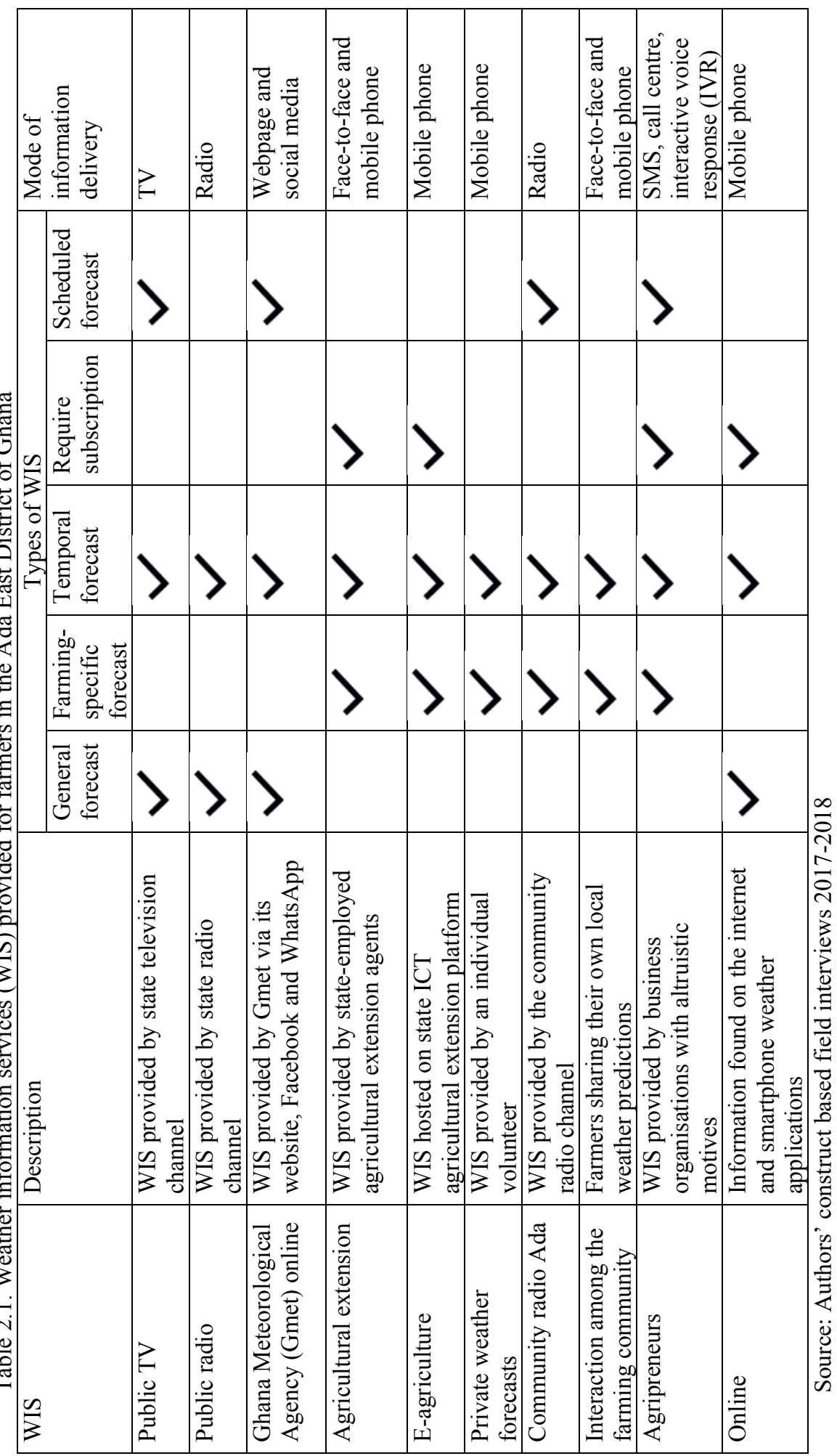




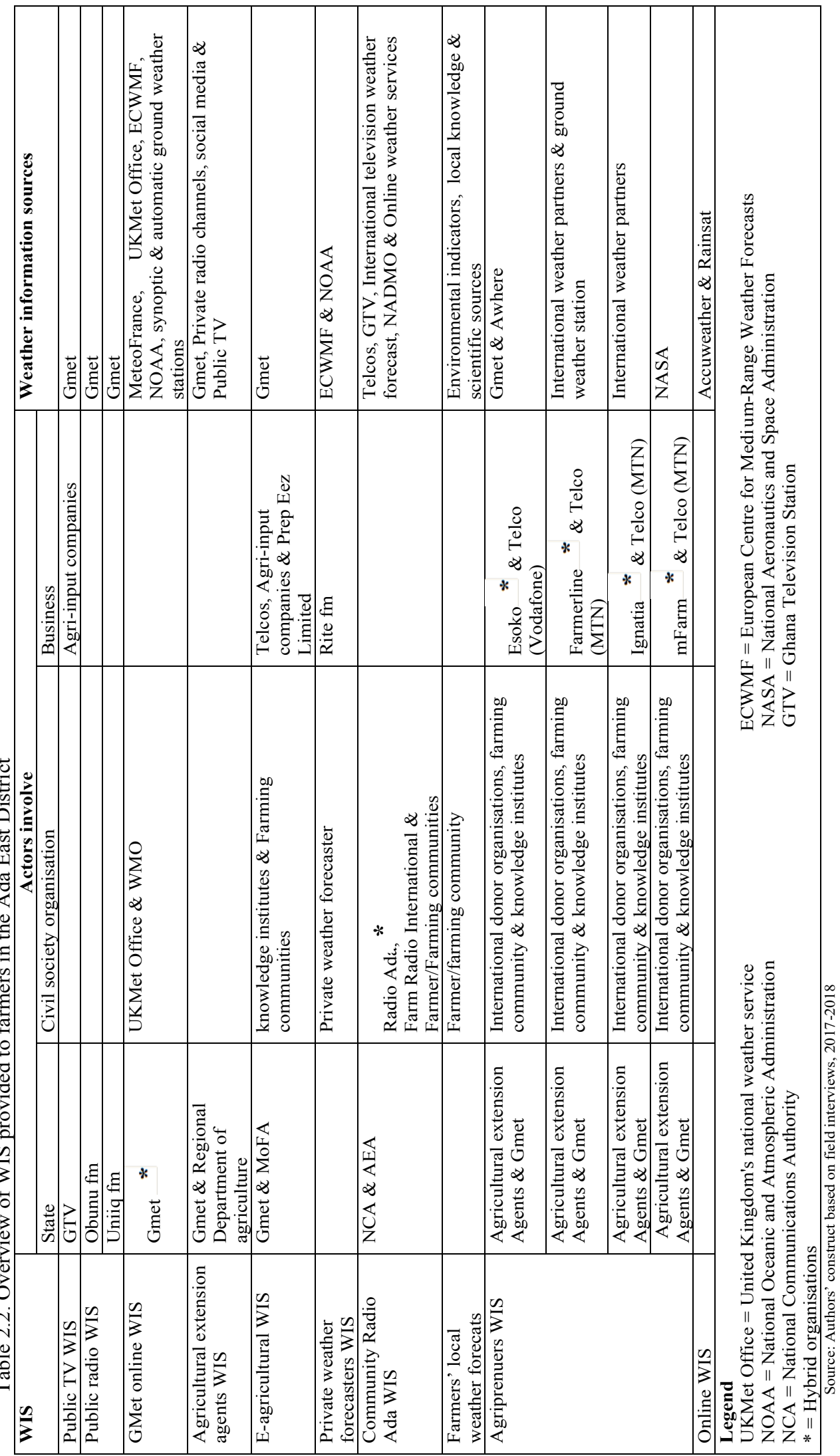


2.4.2 The roles of ICTs in multiplicity, intertwinement and coalescence of organisations involved in WIS provision

\subsubsection{Roles of ICTs in the rise of multiplicity in WIS provision}

The previous section identified the different types of WIS found in the study area. This section presents findings on the roles of ICTs in the emergence of multiplicity of organisations in WIS provision.

The provision of agricultural and weather information for farming was the sole responsibility of government organisations, particularly, the Ghana Meteorological Agency (GMet), the Ghana Television (GTV) of the Ghana Broadcasting Corporation, the Department of Agriculture and Development Unit of the Ministry of Food and Agriculture (MoFA), the Ghana Information Services Department and the National Disaster Management Organisation. These conventional government organisations provided WIS via face-to-face interactions and 'old fashioned' ICTs, such as radio, television, telephone and public address system.

The reference situation in our study area - that is, fully governmental provision of WIS - is represented by the provision of general and temporal forecasts via public radio to farmers in the Ada East District. At the time of our survey, GBC's Uniiq FM and Obonu FM radio stations covered the Greater Accra region, which includes the Ada East District. However, as we can see from Table 2.1, their WIS were irregularly delivered.

Agricultural Extension Agents who operate under the Department of Agriculture and Development Unit in the district provide agricultural advice to farmers regarding production, processing and marketing. The role of these public servants included provision of WIS to farmers in the form of general weather forecasts and temporal (daily) farming-specific forecasts.

GMet is the government organisation responsible for collecting, processing and delivering weather information to the general public. It also advises the government in regard to weather and climate for planning purposes and provides WIS tailored to various themes and industries, including for the general public. GMet delivers scheduled forecasts and a variety of temporal forecasts, some of which require a subscription. GTV broadcasts $24-48$ hour weather forecasts, which it receives from GMet during its evening news programme. GTV used to be the sole state television station operated under the auspices of GBC until 1997 when two non-state television channels began to operate in Accra. The advent of ICTs and enactment of various acts of parliament, such as Act 682 (which established GMet in its current form) and liberalisation of Ghana's media policy, have redefined the roles of GMet and GTV. These government organisations no longer have a monopoly on WIS provision through ICTs. New organisations from the business and civil society sectors have emerged and were providing WIS concurrently with GMet and the other aforementioned government organisations, thereby creating a multiplicity of WIS information providers.

In the civil society organisation sector, Radio Ada was established as a community radio station for the Ada East District. The WIS provided by Radio Ada included general and temporal (daily) forecasts, which were easily accessible and broadcast on a set schedule. Farm Radio International was another civil society organisation involved in providing WIS via Radio Ada in the study district. This source offered farmer-specific information with value added content for farmers. Within the civil society sector in the case study district, a private weather forecaster was also 


\section{Chapter 2}

providing WIS directly to farmers. His forecasts were farming- and location-specific, offered on a regular basis (see Table 2.1).

Regarding the business sector, agripreneurs (agricultural enterprises) had emerged as new WIS providers for farmers. These were business organisations that used ICTs in innovative ways to deliver a variety of agriculture-relevant information to serve farming-related markets. Among the agripreneurs whose WIS reached farmers in the Ada East District were Esoko, mFarm, Farmerline and Ignatia. These organisations provided farming-specific and temporal forecasts. However, they typically required a subscription, though sometimes merely in the form of registration. Delivery of information via SMS and interactive voice response (IVR) were scheduled at specific times of the day (Table 2.1).

In the reference situation, GBC was the sole organisation broadcasting WIS to the general public. After liberalisation of the airwaves and the launching of the internet in Ghana in 1994, GBC's dominance waned. At the time of this research there were more than 100 commercial radio and television stations serving Ghana's major urban areas (National Communications Authority, 2017). Yet, only two commercial television and radio stations provided WIS that reached farming communities in the Ada East District, and these were available only on an irregular basis.

The growing amount of information freely available via the internet gave farmers easy access to WIS online. For example, the Accuweather, Rainsat and Ghana weatherapps were widely consulted using smartphones. Farmers also mentioned international broadcasters, such as the BBC, CNN and Aljazeera, as sources of weather and climate information. Some agri-input companies and dealers provided WIS as part of their service packages for farmers.

Findings on the new organisations providing WIS to farmers in the Ada East District indicate multiplicity and informational governance. New organisations had emerged that provided WIS in accordance with the institutions and practices characteristic of their sector. Furthermore, the WIS they provided were influential in steering farming decision-making and practices. In addition, flows of information had changed from the reference situation; these organisations were delivering WIS directly to farmers without passing through the scrutiny of government organisations. Indeed, much information bypassed government organisations, such as GMet, GTV and the MoFA, remaining outside their control. The new organisations were using ICTs in innovative ways to fill gaps left by government organisations in WIS provision (see Table 2.1).

\subsubsection{Roles of ICTs in the rise of intertwinement in WIS provision}

This section presents findings on the roles of ICTs in intertwinement of organisations, or joint WIS provision, involving organisations from different sectors.

Joint service provision between government and civil society organisations

GMet interacted with organisations at multiple scales to provide WIS. First, it derived weather data from international data sources such as the European Centre for Medium-Range Weather Forecasts (ECMWF), the National Oceanic and Atmospheric Administration (NOAA), Meteo France, the UK Met Office and others. To enhance the delivery of WIS within Ghana, it collaborated with the World Meteorological Organisation (WMO) and other international meteorological organisations, 
regional bodies and knowledge institutions. These interactions resulted in exchanges of weather data, knowledge and other resources.

Until the early 2000s, GMet produced WIS based on its own ground weather stations across the country, manually analysing the data on an hourly basis. Through its collaborations, coupled with the rising availability of ICTs, it became able to use a wider range of data, such as weather models, satellite images, automated and synoptic weather station data. Based on these it introduced more extensive hydromet services, different types of weather forecasts and country-wide daily forecasts, which it made available on its internet site (http://www.meteo.gov.gh/) and social media. GMet additionally collaborated with several organisations to implement development programmes such as the Enhancing National Climate Services (ENACT) initiative, the Participatory Integrated Climate Services for Agriculture (PISCA) project and many other collaborations though little documentation could be found detailing specific MoU (WMO, 2016).

GMet's interactions with these other organisations was shaped by the regulations, resolutions and declarations under which the various organisations operated. For example, World Meteorological Organisation (WMO) involvement meant that the WIS provided had to be made available to all WMO members and to the general public. The growing involvement of non-state organisations in GMet's WIS provision thus resulted in a form of joint steering, influenced by the governance modes of the involved partners (WMO, 2016).

Working under the MoFA, agricultural extension agents interacted with several international and national NGOs to implement projects such as the Planting for Food and Jobs initiative. In these projects, international organisations provided financial and other support aimed at delivering outputs, of which WIS provision was one. Agricultural extension agents also collaborated with knowledge institutes and Radio Ada to deliver WIS to farmers (see Table 2.2). Agricultural extension agents derived their weather information from GMet, through the Regional Department of Agriculture, GTV, commercial radio and television stations and social media. Most agricultural extension agents have resided for extended periods in the communities where they worked. They therefore have some knowledge about the rainfall patterns in the district. And so, usually, they combined this knowledge with WIS from other sources, to advise farmers. Occasionally, farmers and agricultural extension agents shared ideas about weather conditions and forecasts. Agricultural extension agents drew on this knowledge too, to supplement their formal extension knowledge and provide tailored recommendations on what crops to sow, planting times and so on. Interactions with different sources and organisations thus changed the agricultural extension agent's practices in WIS delivery.

Farmers and farming communities used their own local knowledge about, for example, bird movements, cloud formation, sunlight intensity, the shape of the moon, wind patterns and other environmental indicators for weather forecasting. Some farmers had created a chart of previous rainfall to help them determine when rain was likely. Farmers and farming communities usually interacted with Radio Ada and Farm Radio International, alongside other agricultural programmes. The way their interactions with these organisations were carried out resulted in an intertwinement of local knowledge with formal scientific knowledge. This illustrates how WIS can flow in a bottom-up fashion, in this case supporting the role of agricultural extension agents and other organisations in the farming communities. 


\section{Joint service provision between government and business organisations}

The agricultural extension agents served as a contact point for business organisations such as agripreneurs and agri-input companies seeking to provide WIS and other services to farmers in the district. The interactions between the agricultural extension agents and these business organisations were loose collaborations. The Ministry of Information, represented by the National Communications Authority, granted permits and short code to agripreneurs and telecommunications companies (telcos) to provide WIS using IVR, SMS and other voice messaging services. Provision of WIS was initially conceived as a public good to be provided as a free service. Eventually, however, WIS evolved into a quasi-public good, for example, with agriinput companies sponsoring airtime to enable GTV to broadcast weather information. Similarly, GMet contracted and sold weather data to generate funds for its own budget.

\section{Joint service provision between business and civil society organisations}

Government organisations lost their monopoly as providers of WIS for farming. Radio Ada collaborated with farming communities, Farm Radio International and sometimes agribusinesses to provide WIS and other agricultural programming to farming communities in the Ada East District and its environs. It also collaborated with district residents to deliver WIS in the Dangbe language spoken locally, thus making information accessible to all farmers. Through this collaboration, they produced local agricultural content WIS. Farmers described the programmes offered by Farm Radio International in collaboration with Radio Ada as consistent, convenient and entertaining. These programmes were aided by ICT services which sent prompts to listeners before the start of a programme. Listeners were encouraged to phone-in the programmes using ICTs, and other ICT systems were used to generate responses from listeners during and after a programme.

Provision of farming-specific WIS, with value added content for farmers such as the addition of information on agronomic practices, available markets and prices of foodstuffs in urban markets was in the reference situation the responsibility of agrometeorologists in GMet and the agricultural extension agents. This role, however, was being usurped by agripreneurs, which also interacted with international donor organisations, knowledge institutions, NGOs and farming communities to access funding, knowledge and community resources for WIS provision. Agripreneurs were even moving into the terrain of the agricultural extension agents, by adding 'bundled' agricultural information services to their WIS. Such bundles include updates on market prices, crop insurance, bids and offers, and agronomic advisories.

Some agripreneurs, such as Esoko, delivered WIS using a multilingual call centre. To counter problems of low literacy, various organisations switched to WIS delivery via voice alert, and text message. These services were sometimes linked to a call centre or IVR. Upon subscribing to the SMS shortcode, a farmer's location was recorded using GPS technology; the location could then be automatically generated when the code was dialled. Agripreneurs like Farmerline and Ignitia had separate SMS numbers for daily, monthly and seasonal forecasts, while Esoko collaborated with Vodafone to provide special SIM cards for provision of farming information. Agripreneurs provided training for farmers as well, educating them on how to use ICTs to access and apply information in farming. All these extra services in addition to WIS provision created a situation in which agripreneurs outplayed government actors in the district, such as agricultural extension agents, Gmet and GTV. In addition, agri-input companies involved in the sale of seeds, agrochemicals and other agricultural products supplied WIS as part of packages of farming inputs. This increased these organisations' influence on farmer decision-making. 
The rise of a private weather forecaster was another indicator of government organisations' loss of monopoly in WIS provision. At the time of this research, the private forecaster was a primary source of WIS in the district. He carried out this work for altruistic reasons; the service was provided free of charge, though the forecaster did accept donations. He used data modelling and computational and meteorological forecasting skills to produce daily, weekly and seasonal forecasts based on data from the ECMWF and NOOA internet sites. The forecasts were disseminated to farmers in the Dangbe language via mobile phone interactions. Since this forecaster is an indigene of Ada East District, he possessed an abundance of experience about the weather conditions of the communities. This enabled him to produce location-specific forecasts with probabilities. The forecaster received about 20 phone calls each day from farmers, and took 5-10 minutes for each farmer to provide the information requested. This service was similar to GMet and AEA activities, as the information provided included farming-specific recommendations based on the weather information provided. In addition to providing WIS voluntarily to farmers, this forecaster also provided services free of charge to Obonu FM and Radio Ada. At the time of this research he was partnering with a private radio station (Rite FM) to deliver WIS every morning, with that radio station paying a token amount to cover the cost of internet service. This is an example in which ICTs were being used to generate a new information flow, from the global level to an individual and then to the community.

\section{Joint service provision between government, business and civil society organisations}

Under the management of its agricultural extension directorate, the MoFA established an Eagriculture ICT platform to enable agricultural extension agents to provide agricultural information to farmers using mobile phones. The World Bank's West Africa Agricultural Project (WAAP) provided financial assistance for the initiative. The ICT components included an audio library and IVR with a toll-free telephone number and different local language options; e-field extension with smartphones to enable the agricultural extension agents to connect to a diversity of agricultural information; a call centre with a toll-free telephone number and call centre agents; and a web portal. The E-agriculture platform connected different MoFA departments with other government organisations, such as GMet, for the purpose of WIS provision for farming. Yet, the platform was inclusive beyond government, as agri-input companies, telcos, farming communities and knowledge institutes were also involved. The software was developed by a private firm, Prep Eez Limited (Table 2.2).

In all of these cases, institutional change was identified resulting from information flows, specifically new WIS flows and interactions between organisations and emerging uses of ICTs. For example, the private weather forecaster could provide farmers with WIS by deriving weather data from open sources on the internet. His information bypassed other organisations, such as the agricultural extension agents, reaching farmers directly. ICTs also enabled GMet's online WIS and agripreneurs' information to reach farmers directly without passing through agricultural extension agents or GMet staff. These intertwining roles, institutions and practices resulted in a blurring of boundaries between government, business and civil society organisations.

\section{Roles of ICTs in promoting coalescence in WIS provision}

This section presents findings on coalescence, or formation of hybrid organisations, as a result of ICT use in WIS provision for farming. 


\section{Ghana Meteorological Agency}

We have characterised Ghana Meteorological Agency (GMet) as a government organisation, but some of its operational procedures were more representative of a hybrid organisational form. Gmet was created as a semi-autonomous organisation through a process of transformation from a purely governmental department. Originally created in 1937 as the national Meteorological Department, the agency was renamed in 1957 as the Ghana Meteorological Services Department. In 2004, this was reformed into the Ghana Meteorological Agency (GMet) by Act of Parliament 682. That legislation redefined the roles of the predecessor department to create GMet as the semiautonomous organisation it is today. Even so, GMet has remained under the operational control of the Ministry of Communication. That Ministry steers the agency's affairs by appointing its governing boards and executive officers and specifying their tasks and responsibilities. GMet staff, moreover, are paid civil servants, and the organisation's director is appointed by the Head of State. Under the terms of Act 682, GMet is 'free' to manage its own affairs. However, at the time of this research it did not have the authority to register, monitor or check the quality of information provided by other organisations. Act 682 does allow GMet to generate its own funds, to negotiate and enter into contracts and to conduct business transactions on its own.

The Act also allows for establishment of the National Meteorological Fund and for collection of fees for various services, including the sale of weekly and monthly weather forecasts and climate and historical data. GMet has thus come to possess many characteristics more typical of the business sector than a governmental organisation. GMet is therefore an example of an organic hybrid organisation, as it began as a purely government department, but gradually transformed as it accumulated institutions and practices more akin to those of the business sector.

\section{Agripreneurs}

The agripreneurs identified in this research were a typical example of 'enacted' hybrid organisations as they were established as hybrids from the start. They leveraged the availability of ICTs to provide services using a business model and with sponsorship generated from international and national donor organisations or businesses with outgrower or contract farming schemes. The agripreneurs active in our case study district were committed to improving the livelihoods of farmers through provision of subsidised services using ICTs. Based on this, they can be considered social enterprises. To provide WIS, they mostly partnered with international weather organisations in revenue-sharing arrangements (as they had no meteorological data of their own), though some, like Ignitia, used proprietary weather prediction algorithms. Others produced their own weather information or generated it from internet sources. Their collaborations with donors resulted in the provision of 'free' weather information for farmers. It must be noted that while farmers who participate in donor-sponsored agricultural projects received weather information purportedly free of charge, payment for such services was made by donors.

Provision of 'free' WIS was a business strategy used by some agripreneurs to ensure that farmers continued to patronise client businesses' services after the end of the project. However, this was not found in the study area. Government organisations did interact with agripreneurs, for example, contracting them to provide public services with ICTs. Esoko, for example, used its ICT platform to register farmers for the E-agriculture ICT platform associated with the government's Planting for Food and Jobs project in the study district. Agripreneurs also worked closely with agricultural extension agents to raise awareness of WIS within farming communities. No agripreneurs provided 
free WIS to farmers in the Ada East District. To pay for WIS, an amount was deducted from the farmer's call credit each time they accessed information via SMS or used the call centre facility.

\section{Radio Ada}

Radio Ada was established to serve the Ada East District and its environs. The radio station was a typical example of a hybrid organisation, as it received tax relief from the government to support its operations. Establishment of the community radio station was also facilitated by government policies to liberalise the airwaves and to promote community participation in local governance. Radio Ada collaborated with various civil society organisations, particularly Farm Radio International, to provide tailored content in the local Dangme language. Business organisations also developed programmes with the radio station and make donations to support the station's operations. To generate funds, advertisements were sometimes sold. Hence, Radio Ada can be considered an 'organic' hybrid organisational type since it was originally established as a civil society organisation but is undergoing a gradual transformation towards a hybrid organisational form as it accumulated practice and resources from other sectors. A consequence of this transformation might be that the organisations it collaborates with may induce alterations into its practices, for example, by demanding payment for services that used to be provided free of charge. In this regard, the private weather forecaster and GMet provide interesting examples, as they demanded payment for the WIS they provide to the community station since they were of the view that the station has sufficient capacity to raise funds via advertisements. As a result of the radio stations inability to pay for a weather forecasting service provided by GMet and the private weather forecaster, cooperation no longer exists between the Radio Ada and the two entities as at the time this study was conducted.

\subsection{Discussion}

This discussion section highlights key insights gained from the findings of this research.

\section{Multiplicity as a form of hybrid informational governance}

The advent and increased availability of ICTs contributed to the rise of multiplicity as a form of hybrid governance in the provision of WIS for farming in the Ada East District of Ghana. In the past, WIS for farming were limited to daily weather forecasts supplied by government organisations, such as GMet, GTV and the AEA), primarily via radio, television and face-to-face interactions. The contemporary WIS identified in our study were provided through multiplicity arrangements that combined new and old ICTs. For instance, mobile phone was used for delivering the private weather forecaster and AEA's WIS; the television was used for public WIS; SMS was used for agripreneurs and Telcos WIS; while the call center facility was used for agripreneurs and E-agricultural WIS. This parallel provision of information by independently operating government, business and civil society organisations reveals a shift in the number and nature of WIS related to the rise of ICTs. In addition, this research found several characteristics distinguishing the types of WIS provided by the different organisations: coverage (nationwide vs. farmer and location-specific), temporal span and scheduling (routine daily forecasts vs. weekly or season-specific forecasts) and information content (value added for farmers). Multiplicity arrangements for ICT-enabled WIS delivery helped fill capacity gaps left by government organisations. These offered opportunities for farmers in the Ada East District to switch from the use of one WIS to another. 
This is consistent with the findings of other studies on multiplicity in hybrid governance literature (see Boege et al., 2009; DiJohn, 2008; van der Haar \& Heijke, 2013) which indicate that formal and informal public service providers arise in spontaneous fashion without any set plan or policy. These different services tend to coexist in a non-contentious manner; hence, the arrangement helped to reduce the burden on government organisations, and enabled mobilisation of expertise from other sectors to provide WIS using innovative strategies beyond formal arrangements. Multiplicity also eliminated bureaucracy and instigated more linear pathways for the flow of WIS across spatial and temporal scales. This finding reveals that ICTs are not just artefacts but have more subtle roles, including playing a part in diversifying public service provision, such as WIS. Findings on multiplicity in relation to use of ICTs in WIS provision also emphasise the importance of the informal institutional logics associated with ICTs, since their emergence is not promoted by formal arrangements. Multiplicity in provision of WIS using ICTs presumes that organisations coexist. Yet, in practice, organisations interact in a number of ways, sometimes to the extent that they can be considered intertwined.

\section{Intertwinement as a form of hybrid informational governance}

Beyond multiplicity, we found that ICTs played a role in the rise of intertwinement as a form of hybrid governance of WIS provision. By intertwinement, we mean interaction between institutions and practices of organisations from different sectors. Intertwinement can occur between organisations from two distinct sectors (e.g., government and civil society, government and business, or business and civil society) or between all three sectors. In regard to WIS provision, intertwinement can take the form of ICT use by business and civil society organisations to jointly deliver information services to farmers. An example of this is Radio Ada's use of its communitybased approach to develop WIS tailored to the community it served. Farmers were encouraged to call in and interact with radio programmers using telecommunication networks provided by telcos, creating a cross-reliance among organisations. Agripreneurs' strategy of providing WIS and 'bundled' agricultural information to meet farmers' needs is also illustrative of intertwinement. Bundled WIS included weather forecasts, market and input prices, nutrition and agronomic tips, and insurance and credit information. The information was derived from various government, business and civil society organisations operating all along the agricultural value chain. WIS provision by agricultural extension agents also represent intertwinement, this time between all three sectors, as resources were derived from GMet, telcos and the farmer/farming communities themselves. WIS provision by agripreneurs also involved all three sectors: telcos enabled the message delivery, permits for the SMS shortcodes were granted by the National Communications Authority and the cost was covered by international donor organisations.

These examples demonstrate that institutions and practices characteristic of each of the three types of organisations permeated the others. Our findings also suggest that the rise of ICTs in WIS provision can promote intertwinement among organisations from the different sectors and, moreover, that ICTs can be instrumental in unravelling the specific roles attributed to each organisational type. This finding underlines the generative potential of ICTs and their capacity for diverse beneficial outcomes. Another implication is that ICTs' role in promoting intertwinement of organisations could strengthen organisations' ability to continue WIS provision. Additionally, ICTs can drive innovations and cost sharing in WIS production and delivery to farmers. 


\section{Coalescence as a form of hybrid informational governance}

Coalescence was identified as our third form of hybrid governance in WIS provision. Coalescence, or hybrid organisation formation, implies a fusion of characteristics from the three sectors. Agripreneurs' ICT platforms and GMet's online WIS are illustrative of the roles ICTs can play in coalescence. In these examples, institutions and practices from the different sectors became integrated as a consequence of the requirements of the different organisations involved in WIS provision. GMet itself can be understood as a hybrid organisation. Though it was part of a ministerial organisation (the Ministry of Communications), it was largely autonomous due to the authority granted to it by Act 682, it could carry out business and enter into contracts on its own, though its management remained steered by government appointees. While GMet's operations were not strongly linked to the ministerial organisation, the literature describes that other state hybrid organisations do retain strong linkages to their core ministries (see Kickert, 2001).

Our study's findings on hybrid organisations are unique in that they reveal the particular roles that ICTs can play in the formation of organic, entrenched, shallow and enacted hybrid organisations (Billis, 2010). In the case of GMet, the process of hybridisation was organic (Billis, 2010; Onyx et al., 2018) in line with the profound changes in the use of social media and web portals and the partnerships GMet entered into with other organisations to deliver WIS. Agripreneurs, for example, were regarded as social enterprises because they assumed roles of both government organisations (agricultural extension agents and GMet) and business organisations (in providing WIS to farmers in exchange for payment). However, they also assumed a civil society organisation role in providing WIS free of charge to groups of farmers involved in donor-sponsored projects. As such, agriprenuers can be regarded as enacted hybrid organisations, since they combined altruistic and for-profit operational models. Radio Ada can be classified as a shallow hybrid organisation, as its hybridisation was as yet at a very low or modest level. For example, it sold advertisements only when experiencing critical financial need. In these three examples (GMet, agripreneurs and Radio Ada), when the hybrid organisations stepped beyond their status quo and adopted either business strategies or altruistic motives, their organisational values were altered. Thus, there exists a possibility that the hybrid organisations identified in this study might experience 'mission drift' (Brandsen \& Karré, 2011) associated with the relative ease with which they were able to shift between the different sectors. Yet, other factors could also be involved in the shifting of organisational values, such as the political appointment of directors, intra- and inter-departmental relationships and competition with other service providers.

\section{Steering and restructuring relations through ICTs}

Beyond the discussions on multiplicity, intertwinement and coalescence, ICTs were found to play a role in restructuring relations between organisations and actors, due to information's power as a steering instrument. ICTs such as mobile telephones enabled business and civil society organisations to provide a multiplicity of WIS that bypassed government to reach farmers in the Ada East District. Interestingly, government organisations also bypassed each other in the delivery of WIS with ICTs. An example is GMet, which no longer relied solely on GTV, but instead also provided WIS via its website and social media. The private weather forecaster's operation demonstrates that with mobile telephony even an individual can become a key WIS provider. Though operating without the backing of a large organisation and with no institutionalised information flow, the WIS provided by the forecaster was highly requested by farmers, with whom he had strong bonds. 
In the case study district, new organisations were emerging to complement the role of government organisations in WIS provision. This raises the question of whether government organisations were still leading in provision of WIS to farmers. Our findings suggest that government organisations were indeed still in the lead in their continued direct provision of WIS and sometimes through their regulatory functions. For instance, the roles of GMet, GTV and agricultural extension agents in provision of WIS for agriculture had not changed, despite the various public policy reforms. This is consistent with Naab et al. (2019), who found that GMet and the MoFA remained the government organisations in charge of WIS production and delivery. To this we would add that in some instances government organisations claimed publicness and played their roles accordingly, while in other instances, they embraced intertwinement with non-state organisations. This resulted in a blurring of roles, in some cases to the extent that government organisations may appear to be absent.

\section{Other merging factors}

Finally, we found that other factors besides ICTs contributed to hybrid informational governance in WIS provision. These included policy reforms and enactment of legislation. The literature, too, reports decentralisation, market reforms and public policymaking as drivers of hybrid informational governance arrangements (Lemos \& Agrawal, 2006; Tosun et al., 2016). In addition, we identified inadequate economic and knowledge resources as other drivers of hybrid informational governance. In Ghana, government organisations such as GMet and GTV had to sell weather data and airtime to provide operational funds, as the government had cut its own financial support. Rather than being a sign of an absent or weak government, as theorised in much development literature, this can be interpreted as a deliberate government strategy to reduce expenditures by allowing non-state organisations to step forward and play a role (Boege et al., 2009). Hence, hybrid informational governance can be considered an arrangement by which government organisations make room for non-state organisations to perform roles that they are capable of fulfilling (Meagher, 2012; Tosun et al., 2016). When government capacity is low and the cost of delivering information is high, government organisations are likely to resort to hybrid informational governance arrangements, adopting practices such as the sale of information, which can be considered an approach characteristic of business. Alternatively, business and civil society organisations may be allowed to fill capacity gaps left by the government.

Here we must note that when the government stands to generate increased revenues from the provision of WIS, it will protect the sector by limiting the activities of non-state organisations (for an example see the cocoa sector in Ghana, Glin et al., 2015). Our findings on how the government permits non-state organisations to provide WIS with ICTs corroborate Hoefnagel et al.'s (2013), study which concluded that the ICT age has enabled state and non-state organisations to provide information with different governance approaches. However, questions remain concerning the usefulness and usability of the WIS provided to farmers under hybrid informational governance arrangements.

In practical terms, findings from the study can be of use for organisations involved in planning and regulation of the provision of agricultural information including the weather and climate information to design an appropriate governance arrangement with actors from different sectors to 
define the roles, practices and institutions. This may include specification of rules concerning the cost of WIS, division of roles among other issues to govern the delivery of WIS for farming.

\subsection{Conclusion}

This research examined the hybrid informational governance arrangements that resulted from the use of ICT in WIS provision for farming in the Ada East District of southern Ghana. The research used qualitative methods, specifically, semi-structured interviews with farmers, agricultural extension agents and organisations providing WIS to farmers in the study district. Findings from our study confirm that ICTs have enabled provision of multiple WIS in Ghana, varying in coverage, timing and information content. Instead of generating competition and maintaining separation in WIS provision, we found that ICTs engendered intertwinement among government, business and civil society organisations. In some cases, these organisations evolved towards joint delivery of WIS using a combination of technologies including radio, mobile telephony, SMS, call centres and interactive voice response. ICTs furthermore played roles in coalescence, that is, in the formation of hybrid organisations combining key characteristics from the different organisational sectors. ICT-enabled flows of WIS across scales, for example, from internationally operating nonstate organisations to local farming communities, led to situations in which information bypassed national and district-level government organisations, remaining outside their control. In some cases, non-state organisations complemented or outplayed the roles of government organisations in WIS provision.

Nonetheless, the position of government organisations was not weakened; they remained key players in WIS provision in Ghana. At the time of this research, government organisations such as GMet, GTV and the Department of Agriculture and Development Unit still led WIS provision for farming in the study district. Additionally we found that, besides ICTs, other factors contributed to the emergence of hybrid informational governance in our case study, namely, inadequate state funding, international donor funding and the specific business models applied. 


$$
3
$$




\section{Chapter 3}

Adaptive decision-making under conditions of uncertainty: the case of farming in the Volta delta, Ghana 


\title{
Chapter 3
}

\begin{abstract}
Farming in Ghana's Volta delta is increasingly affected by variability in rainfall conditions and changes in land-use patterns. Under such socio- ecological conditions, little is known about farmers' decision-making in response to uncertainties in uncertain rainfall conditions. To fill this gap and add to the literature on adaptive decision-making, we addressed the central question: what are the existing patterns of farming decision-making under uncertain rainfall conditions, and which decision-making strategies are adaptive? We developed an adaptive decision-making framework to investigate the behavior of farmers under variable rainfall conditions in Ghana's Volta delta in the Ada East District. We conducted 5 interviews with agricultural extension agents, 44 in-depth interviews and 4 focus group discussion with farmers. Subsequently, we interviewed a subselection of 32 farmers. Findings of the study shows that farmers carry out different decisionmaking patterns in response to the variable rainfall conditions. We distinguished six strategies: three based on flexibility and three based on robustness. Flexible adaptive decision-making strategies are switching dates for sowing seeds through wait-and-see or delay strategy, muddling through the farming season with the application of various options and alternative irrigation strategies. Robust adaptive decision- making strategies are portfolio strategy of transplanting seedlings in batches, selection of robust (hardy) crops, and intercropping or diversification. Based on how farmers select strategies in response to uncertainty in rainfall conditions, we argue that some decision-making strategies are more adaptive than others. Findings of this study are relevant for the design and implementation of climate related agricultural projects.
\end{abstract}

Published as: Sarku, R., Dewulf, A., van Slobbe, E., Termeer, K. \& Kranjac-Berisavljevic, G. (2020). Adaptive decision-making under conditions of uncertainty: the case of farming in the Volta delta, Ghana. Journal of Integrative Environmental Sciences, 17(1), 1-33. 


\subsection{Introduction}

Deltas are dynamic regions which play relevant roles towards sustainable livelihoods and development. Most delta regions in Asia and Africa host growing populations as they are the interface between the land and the sea (Woodroffe et al. 2006). As a result, several livelihoods including, fishing, salt production, tourism, trade, farming and other economic activities thrive in deltas (Robert 2017). Despite the socio-ecological and economic benefits derived from deltas, they are gradually vulnerable to several environmental stressors such as coastal erosion, sediment deposition, seawater intrusion and changing climatic conditions (Addo 2015). These phenomena threatens food security, increases poverty and the sustainability of livelihoods such as farming.

In the Volta delta in southern Ghana, several socio-economic activities such as fishing, aquaculture, sand mining, fisheries, salt mining and tourism are carried out due to the dynamics of water (Addo et al. 2017). However, farming is one of the main economic activities with huge potential for livelihood and sustainable development in the area (GSS 2014). Yet, the sustainability of farming is being undermined as the Volta delta is under- going socio-economic and physical transformation due to urbanization, expansion of townships and intensive cultivation of food crops (Roest 2018). Intensification of farming is driven by the need to supply agricultural produce to markets in the adjoining cities and towns (Boubacar et al. 2005; Awadzi et al. 2008). Despite intensification, farming in the delta is carried out under uncertain water availability conditions (Amisigo et al. 2015). Water conditions in the delta are characterized by:

- Increasing incidences of drought, high temperatures, flooding and variable rainfall conditions (Ofori-Sarpong and Annor 2001; Owusu et al. 2008; Teye and Owusu 2015).

- Coastal erosion and salt intrusion from sea level rise (Mul et al. 2015; Roest 2018).

- Increasing degradation of natural resources especially freshwater resources, due to an expanding population (Roest 2018).

- Environmental changes due to the construction of hydroelectricity and irrigation facilities upstream (Andreini et al. 2000; Mul et al. 2015; Anthony et al. 2016) and

- Low groundwater table inland and the presence of few water infrastructures such as dams, canals, wells and piped water supplies.

However, the incidence of variability in rainfall is the main water challenge which affects smallholder farming. Rainfall conditions in the delta are marked by increased variability, declining rainfall total, and a shift in rainfall regime towards long dry spells, late onset of seasonal rainfall and early cessation of rainfall (Gbangou et al. 2019). Southern Ghana including the delta area has a bimodal rainy season, locally referred to as the main season (April-July) and the minor season (September-November). Early cessation of rainfall in the main rainy season has resulted in prolonged dry seasons with increased evaporation, while reduction in rainfall amount occurs in the minor season (Owusu et al. 2008). Additionally, the annual evaporation rate (1785 mm) exceeds the annual rainfall in the Volta delta region (Addo et al. 2017).

The incidence of spatial and temporal variability in rainfall in the Volta delta (van de Giesen et al. 2010), affects farmers' reliance on rainfall to cultivate crops. The application of irrigation for farming is limited to the embankment of the distributaries of the Volta river because hydrological construction on the upstream and mid-stream section of the river has affected the flow and course of the river channel (Anthony et al. 2016). Access to groundwater for irrigation farming is also limited to the coastal sandstrip (Gyampoh et al. 2011; Yidana and Chegbeleh 2013). Therefore, farmers who are engaged in irrigation and/ or rainfed farming are all affected by variability in 


\section{Chapter 3}

rainfall conditions. Farmers are constantly left in a dilemma and their decision-making is often marked with several questions - "when is it likely to rain; when do I plough; when do I sow my seeds; will the seeds succeed under the current rainfall condition; should I pump water into the farm, apply fertilizer and the agrochemicals or not, What about if I irrigate now or spray the farm with agrochemicals and then it rains afterwards?" The uncertainty in rainfall conditions, intensive farming situations and the context of dynamic environmental interactions in the Volta delta requires that decision-making for farming is adaptive to ensure sustainable food production throughout the farming seasons. Adaptive decision-making in farming is carried out on short-term and long-term basis in response to both weather and socio- economic and environmental context (Robert et al. 2016).

There is a growing body of literature on decision-making trying to understand how farmers respond to uncertain conditions in the farming context. Previous studies have analysed decision-making under rainfed and drought conditions (Risbey et al. 1999; Keshavarz and Karami 2014; Singh et al. 2016), adaptive capacity to climate change (Wiid and Ziervogel 2012; Hoang et al. 2014), adaptation strategies (Fosu-Mensah et al. 2012; Yaro 2013; Ndamani and Watanabe 2015) and adaptation in farmer decision-making process (Merot et al. 2008; Guillaume et al. 2016; Robert et al. 2016, 2018). Roesch-McNally et al. (2017) examined adaptive strategies in the context of decision-making and farmers' intention to increase their use of three production practices: no-till farming, cover crops and tile drainage across the US Corn Belt. Studies focussing on farm-level decision-making under uncertainty (see Fafchamps 1993; Yengoh et al. 2009) indicate that most farmers use bet-hedging strategies to minimize risks of production failure. Findings of a study carried out in Ghana and Cameroun also suggest that factors such as scale of production, long-term productions, success of technologies in the past and the adoption of technology by opinion leaders among other factors affect the decision-making strategies of farmers (Yengoh et al. 2009). In a similar study, Fafchamps (1993) used a stochastic control model to give account of farmers' behaviour under rainfed farming in the African semi- arid tropics, Burkina Faso. The study found that there is high demand for labour in the event of an early rainfall and this brings about the occurrence of manpower shortages. As a result, farmers incorporate the idea of flexibility in their farm productions as there is a strong relationship between labour and land productivity in various agro-climatic zones of West Africa. Despite the focus of the above-mentioned studies on decisionmaking in farming, there is a marked gap in the number of empirical studies which explicitly analyse farmers' adaptive decision-making under uncertain conditions.

Additionally, little conceptual coherence exists on how adaptive decision-making ought to be analysed. To fill the empirical and conceptual gap, we analyse how water- related decision-making in farming under uncertain rainfall conditions is adaptive or not, by focusing on the processes and strategies. The main question is: What are the existing patterns of farming decision-making under variable rainfall conditions and how adaptive are the decision-making strategies? To enable us answer the question, we developed a conceptual framework for adaptive decision-making by building on the existing literature on decision-making and we empirically studied farming in the Volta delta, in the Ada East District, Ghana. The Volta delta is the land below $5 \mathrm{~m}$ contour in the downstream section of the Volta River basin (Addo et al. 2017). It is made up of nine administrative districts; yet, we selected the Ada East District for the study because it lies at the interface between several waterbodies (Volta estuary, the Songor lagoon, wetlands) and the use of the land mainly for farming (GSS 2014). Despite the existence of waterbodies, access to water for farming in the Ada East District (the western section) of the Volta delta and river, is a challenge as compared to 
the Anloga-Keta sandpit (eastern section) of the delta which has shallow groundwater due to the geological formation in that area (Awadzi et al. 2008; Yidana and Chegbeleh 2013). In the subsequent sections of this paper, we reviewed relevant literature to conceptualize adaptive decision-making under uncertainty in socio- technical-environmental conditions. It is followed by sections on methodology, findings, discussions and conclusions, respectively.

\subsection{Conceptualizing adaptive decision-making}

In a general sense, decision-making is a process of selecting options to deal with a specific condition. Uncertainty lies at the centre of decision-making in complex conditions because it is difficult to assess the consequences of any given decision option when these are influenced by a range of uncertain socio-technical-environmental conditions. In real-life situations, uncertainty constitutes a major obstacle to effective decision-making (Lipshitz and Strauss 1997). Therefore, decision-making is not only about generating options but it also involves dealing with uncertainty.

In this study, we define uncertainty as the state whereby there is no unique and complete knowledge about the condition to be managed (Brugnach et al. 2008) due to unpredictability, incomplete knowledge or ambiguity (Dewulf and Biesbroek 2018). The role of information becomes relevant in uncertain condition as too little or too much information results in uncertainty (Brugnach et al. 2008). This implies that uncertainty is dynamic depending on the information that is available about the condition that needs to be dealt with.

When socio-technical-environmental conditions become increasingly complex and characterized by uncertainty, rational and linear approaches to decision-making have not been able to deal with uncertainty inherent in it (Philips 1997). Moreover, the application of "most-likely future" or "static optimal options" in decision-making under uncertainty have not produced effective outcomes (Hallegatte et al. 2012). A promising way of dealing with uncertainty in decision-making in complex socio-technical- environmental conditions is through adaptive decision-making. Adaptive decision- making builds on bounded rationality (March 1991) by considering uncertainty through incorporation of flexibility and robustness (Haasnoot et al. 2012, 2013; Dittrich et al. 2016; Kwakkel et al. 2016).

We define adaptive decision-making (ADM) as a pattern of decisions characterized by the application of decision options that are flexible, robust or both, in response to uncertain sociotechnical-environmental conditions. The concepts flexible and robust are mostly used as a characteristic of deep uncertainty and long-term adaptation planning in infrastructure (see Lempert and Schlesinger 2000; Groves and Lempert 2007; Colombo and Byer 2012; Hallegatte et al. 2012). Additionally, the concepts are also often mentioned as components in adaptation to climate change planning in general and they are a subtype of adaptation planning theory. In the conceptualization of flexible and robust in our definition of ADM, we positioned the concepts on a general level as they have been applied in other fields regardless of the time horizon. For instance, the concepts have been applied in spatial planning (see Smit and Wandel 2006); adaptive management theory (see Williams and Brown 2014) and farm-level decision-making in the long and short term (Robert et al. 2016). In the subsequent paragraphs of this section, we explain the key concepts (flexible and robust) in the definition of ADM.

The first concept which is key in the definition of ADM is the application of flexible options. Under flexible ADM, options are selected in a way that they can be adjusted or reversed over time when 


\section{Chapter 3}

additional information becomes available (Colombo and Byer 2012; Haasnoot et al. 2013). It is based on the notion that uncertainty is dynamic. Thus, additional information is analysed continually to aid in the selection of further options. This enables the strategy to be modified when there is a change in socio-technical- environmental conditions over time. This means that the initial decision does not result in a situation where new arrangements cannot be made (Colombo and Byer 2012). Flexible ADM also deals with uncertainty by providing room for learning about changes in socio- environmental-technical conditions over time (Pahl-Wostl et al. 2007). Thus, when the initial option no longer meets the condition, additional options are generated in order to achieve a desired goal. Strategies used in applying flexible options include wait-and-see or delay in decisionmaking and introducing new or additional options when circumstances change (Colombo and Byer 2012; Yousefpour et al. 2017).

The second concept in the definition of ADM is the choice of robust options. It indicates the use of options that are effective in a wide range of socio-technical-environmental conditions (Lempert et al. 2006). Robust ADM helps to anticipate or mitigate the impacts of uncertainties in order to minimize regret (Kwakkel et al. 2016). The options are selected despite incomplete information about their consequences (Lempert et al. 2006; Yousefpour and Hanewinkel 2016) and aim for robustness rather than optimality (Lempert and Groves 2010). The selection of options under robust ADM can be achieved with different strategies. For instance, the use of a portfolio strategy enables multiple selections from a discrete set of options (Nalley et al. 2009), such that some options still work when others fail.

We propose that due to the uncertainties which characterize socio-technical- environmental conditions and the limited knowledge about options that are available to deal with, the application of flexible or robust decision options can be carried out on temporal basis, which could either be proactive (in anticipation of uncertain future changes) or reactive (in response to unexpected observed changes) $A D M$ (Robert et al. 2016).

It is important to note that the application of flexible or robust options does not always lead to "successful" decision outcomes because many factors can influence the consequences of options in complex socio-technical-environmental conditions (Payne et al. 1993).

\subsection{Methodology}

\subsubsection{Study area}

The study was conducted throughout the farming seasons in the year 2017 in the Ada East District. The Ada East District lies in the southeast portion of the Greater Accra Region of Ghana. It is about $110 \mathrm{~km}$ drive from Accra (the national capital of Ghana) and Tema (the industrial city of Ghana) (Addo et al. 2017). It covers about $289 \mathrm{~km}^{2}$ with a population of 71,671 based on the 2010 Population and Housing Census. The District shares common boundaries with the Central Tongu, South Tongu and the Ada West Districts and bounded to the south by the Gulf of Guinea (GSS 2014). The Ada East District is the main district which lies in the interface of natural, biophysical and socio-institutional, cultural and economic development (Figure 3.1). That is, the Ada East District has the Volta river estuary at Ada Foah. It also has commercial salt mining, agriculture, livestock rearing, agro-processing, fishery, shrimp and tilapia farming, mining of oysters, craftsmanship, trading, collection of non-timber forest products, the service sector and tourism as economic activities that are practiced in the area. The area experiences variability in rainfall condition in terms of too much, too little, too late or early rainfall and it is affecting farming 
(Gbangou et al. 2019). Since the district lies in the coastal savanna agroecological zone, it forms part of the areas which receives the least amount of rainfall in Ghana (Teye and Owusu 2015). It also has wetlands such as swamps and mangroves with $80 \%$ of cultivable land area (Figure 3.2). As such, the main economic activity practiced in the district is farming by $80 \%$ of households (GSS 2014). Farming is rainfed in the greater part of the district (Kasseh and Big Ada zones) except that pockets of irrigations are carried out on the bank of the Volta River and the coastal sandstrip. The district exhibits a combination of rural and urban characteristics because it has linkages with several urban communities such as Accra, Tema, Prampram, Dawhyenya, Sogakope, Aflao, Denu, Keta, Kpone, etc. (GSS 2014). Two periodic community markets held at Ada Foah and Ada Kasseh draw people from various places to trade in agricultural and other products. We selected the Ada District in the Volta delta for the study because farmers produce crops under different water conditions to meet demands from the urban areas. The conditions under which farmers produce crops provide us with a rich context to study decision-making in farming under uncertainty. In addition, the existing knowledge about farming communities and agricultural extension services by the lead author enabled us to carry out interviews and hold group discussions.

Figure 3.1. Map showing the Volta delta.

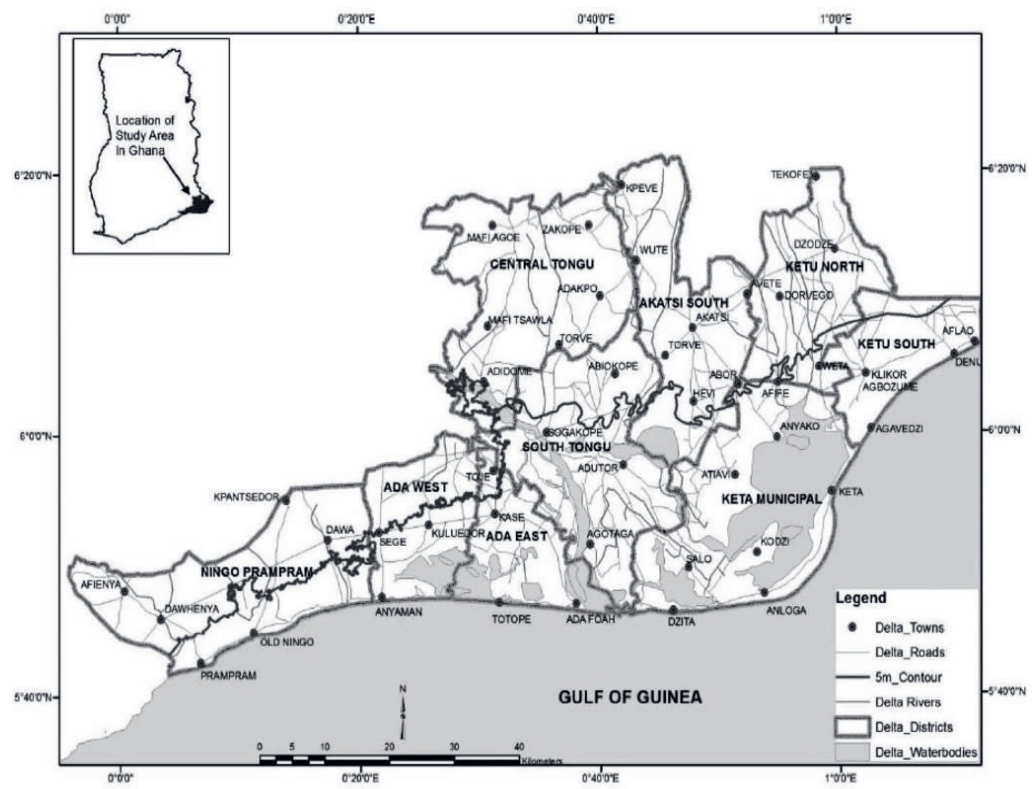

Source: Addo et al. 2017 


\section{Chapter 3}

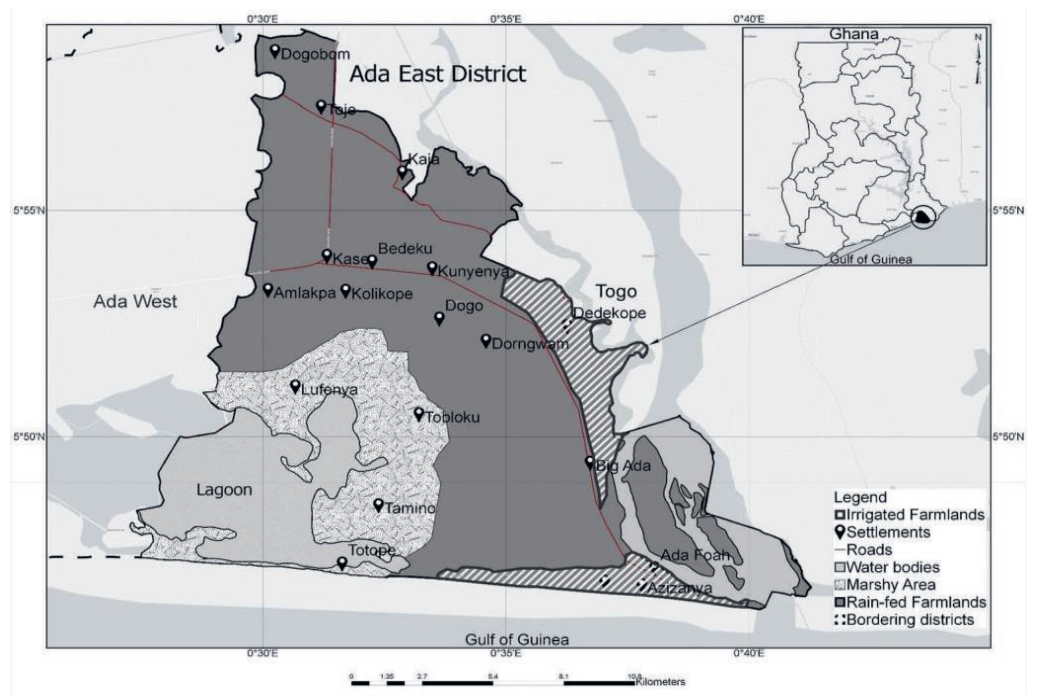

Figure 3.2. Map of Ghana showing the Ada East District.

Source: Authors' construct, 2017

\subsubsection{Research design}

We used an exploratory in-depth case study research design to analyse how water-related decisionmaking in farming under uncertain rainfall conditions is adaptive or not, by focusing on the processes and strategies of farming in the Volta delta, specifically, the Ada East District. Based on the theoretical framework (Section 2) and empirical considerations (Section 3), we applied a novel research design to meet several analytical needs:

(a) Preseason farming (refers to the period, January to March when crops are cultivated immediately before the start of the main rainfall season); (b) Main season farming (refers to the farming period which coincides with the main rainy season; that is, from April or May until July); (c) Minor season farming (usually spans the September to November during which minor rainfall events are recorded); and (d) Strategies of adaptive decision- making across the three farming seasons to analyse whether or not farmers decision- making is adaptive or not.

We used qualitative research methods, including, key informant interviews, in-depth interviews and focus group discussions to generate data for the study. We used the qualitative research approach because we sought for detailed information about rainfall condition, decision-making strategies and the application of the strategies under different rainfall conditions. At the onset of data collection, little information existed on how farmers carried out adaptive decision-making in response to variable rainfall conditions and how we can derive the information from farmers. Therefore, the application of the qualitative research approach enabled us to carry out data collection iteratively and also conducted the interviews, code and analyse the data in a flexible manner. We were able to revise the initial direction and framework of the research when the quality of information generated at the first and second stages of the study did not provide the required results. We included field observations and focus group discussions; thereafter, we were able to derive indicators of decision-making strategies and the number of raining days (see Table 3.1). 
Subsequently, we conducted a second round of interview with some farmers who were initially interviewed. During the data collection process, we were not limited to particular questions and we flexibly directed the structure of the research process until we were satisfied that the data generated has information which could answer the research question.

The lead author has experience in qualitative research as she had conducted extensive qualitative research on various agricultural topics and also participated in various qualitative research courses at different academic levels. She is also familiar with the geographic and socio-economic contexts of farming in the study area. Because data gathered through qualitative research approach is based on experiences, the rich background and experiences of the lead author enabled follow-ups on interesting answers with additional questions. This enhanced the overall database of information that was generated from the study area. The research design is presented in Figure 3.3 and operationalized in seven steps: Key informant interviews; Interview with farmers; Analysis of data generated from the first two stages; Construction of decision-making table step 1 and 2; Interviews with farmers using the decision-making table; Cluster decision-making table into patterns for three seasons and Identifying adaptive decision- making strategies. We provide details on the activities that were carried out in various steps of the research process below:

\section{Step 1: key informant interviews}

We started the study by eliciting information from agricultural extension agents who were key informants and were in charge of three agricultural zones in the Ada East District: Kasseh, Big Ada and Ada Foah. These zones were subdivided into 5 areas under the jurisdiction of 5 agricultural extension agents. We interviewed the agricultural extension agents to derive first-hand information about the decision-making strategy of farmers and various categories of farmers because they have knowledge on farming practices in diverse communities in the district. Agricultural extension agents were interviewed through face-to-face interactions, where they were asked to describe farming activities, farmers' decision-making patterns, cropping cycles, weather events and other relevant issues which affects farming in the district.

\section{Step 2: interview with farmers}

The methodological orientation underpinning the study is ethnography; as such, ethno- graphic interviews, in-depth-interviews, observation and focus group discussions (FGDs) were all used to generate information on daily, weekly, seasonal decision-making practices of farmers in response to rainfall conditions. Each agricultural extension agent had an average of 10 communities under their jurisdiction. They each selected 7-12 farmers from communities in their respective operational areas for the interview. The number of farmers interviewed in each community varied depending on the availability of farmers as well as the homogeneity of the information that was provided. None of the farmers who were approached to participate in the study refused to grant interviews when the objective of the study was explained to them. There was no relationship established between the lead researcher and farmers before the fieldwork was conducted. Therefore, the connection to the communities was mainly set up by agricultural extension agents who identified various categories of farmers, based on the description of the objective of the research by the lead author. The criteria used for the selection of interviewees were guided by gender, age, years of experience, the source of water for farming, level of education and their role in the community (e.g. peasant farmers, lead farmers, opinion leaders or members of a farmerbased organization) (see Table A1). The total number of farmers selected for the study comprised 44 farmers (33 men and 11 women). Few women participated in the study due to the fact that they 


\section{Chapter 3}

were mostly engaged in the processing and trading of farm produce. The face-to-face interviews were conducted through home visits in order to interact with farmers at their convenient time.

The lead researcher was sometimes assisted by agricultural extension agents or opinion leaders in the communities who introduced her to farmers and also arranged the appropriate time suitable for interviews to be conducted. Since the lead researcher is a female, the presence of agricultural extension agents who were males also allowed access to male-dominated farming "spaces" and that facilitated conversations during the interviews.

The interview guide was designed based on an extensive literature review guided by the objective and theory of the study. The interview guide was first piloted with 5 farmers and an agricultural extension agent in a community. Afterwards, alterations were made before the actual interviews were conducted. In the face-to-face interviews, farmers were asked to describe uncertainties in weather conditions, cropping practices and decision- making strategies at the initial, middle and end stages of the cropping seasons. The strategies and the reasons why they were selected were also discussed by farmers. Some farmers emphasized that if a prior response was not successful under a rainfall condition, they considered an appropriate alternative strategy.

In order to derive data on the rainfall conditions in the study area, we took rainfall records from farmers who have created rainfall charts (rainfall days) in different communities. We took farmers' rainfall records because they experience variability in rainfall in-between communities, whereas the official weather data from the meteorological station at Ada Foah are generalized for all the communities in the district. Therefore, farmers' records were slightly different from the data generated from the meteorological station. Since we sought to understudy farmers' decisionmaking in response to the availability of rainfall, we took farmers rainfall records. Even so, we compared farmers' rainfall records with the official meteorological records and there were few difference in terms of rainy days in some communities. Therefore, we took the decision to use farmers rainfall records since their decision-making coincided with their records (rainfall). Armah et al. (2015) indicated that when meteorological records are incomplete or unavailable, information on local perceptions of climatic changes can be used to complement scientific weather evidences because local or place-based evidence of weather changes gained through experiential learning can also be effective than simply studying analytical weather data. Hence, although temperature, evaporation, windy and humidity conditions were experienced by farmers, they kept records on only rainfall days. There were slight difference of 2 or 3 rainfall days among some communities for the months, June-July as some farmers did not consider drizzles or showers as rainfall, while others did. For the months January- May and September-November, the rainfall days were equal with the exception that the dates of the actual occurrence differed. Farmers' records about the amount of rainfall were classified as "normal rainfall", "above normal rainfall", "below normal rainfall" and "abnormal rainfall" conditions because they do not have rain gauges. Farmers regarded below or above normal rainfall conditions as "bad" weather whereas an "abnormal rainfall" condition refers to the occurrence of a rainfall condition in a perceived dry month. We used the number of rainy days as a guide in discussing "good", "bad" and "abnormal" weather conditions during the cropping season and the decision-making associated with it.

The interview process was repeated with farmers in different communities until no new decisionmaking strategy and information were identified again during the interviews. Audio recordings were carried out during the face-to-face interviews and it lasted over varied durations depending 
on the willingness and the settings in which the study was conducted. Overall, the average period for the interviews lasted for about 40 minutes while three interviews exceeded an hour. we sought to generate in-depth information on ADM, we also conducted four FGDs, of which the participants were purposely selected, comprising 8-10 male and female farmers at four different community centres (see Figure 3.2). During the FGDs, the lead author was sometimes assisted by agricultural extension agents, opinion leaders, or lead farmers in the communities to convene participants to the meeting. During the discussions, the lead author took note of pertinent issues that were mentioned by participants and this was also considered as data for the study. Participants of the FGDs were farmers with different socio-economic and demographic characteristics such as sex, type of farming, purpose of farming, age and specific community. Participants of the FGD had no knowledge about the objective of the study until the discussion began and then the objective of the study was explained to them. Audio recordings were also carried out during the FGDs and the discussions lasted for varied durations. 


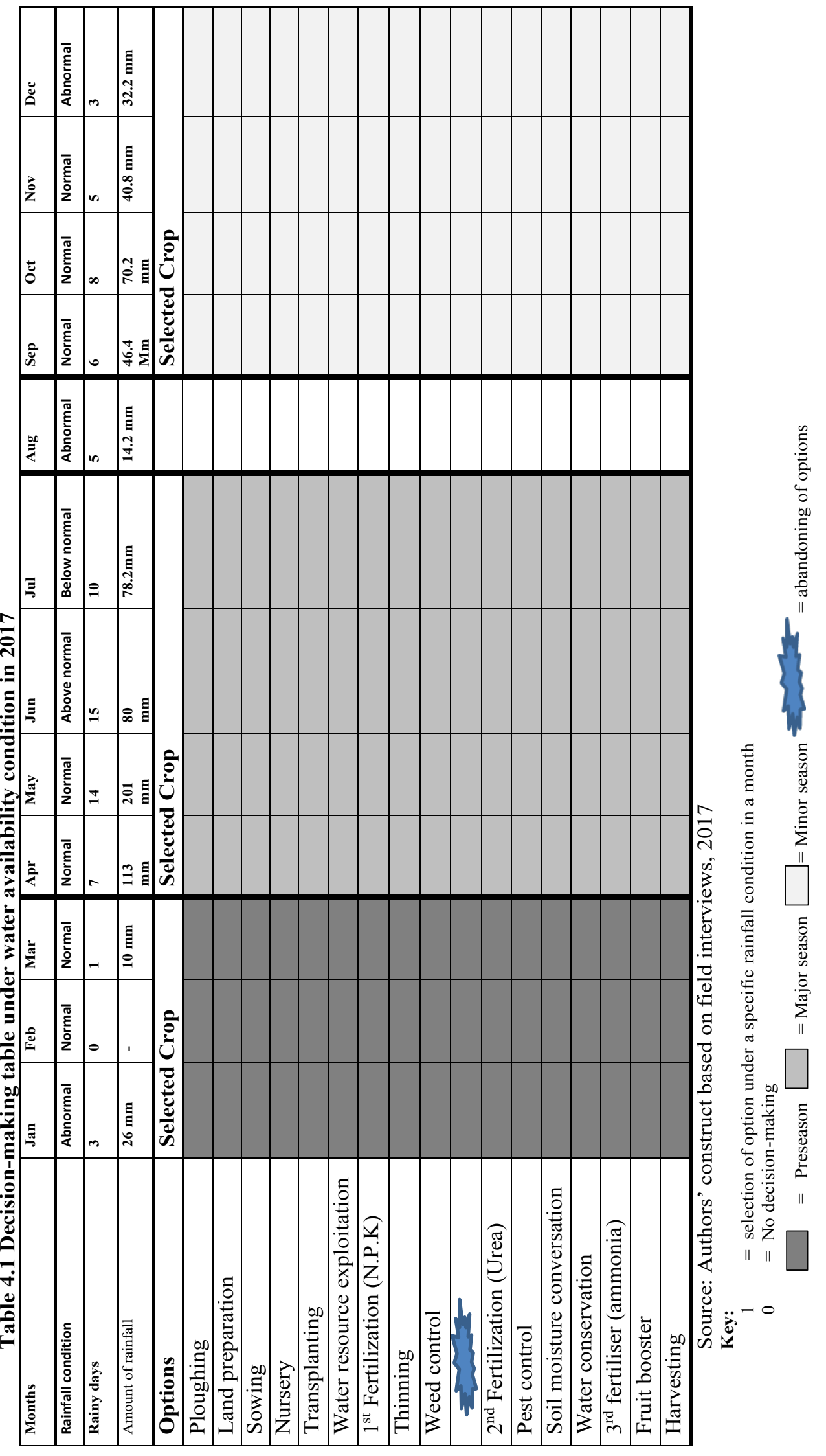




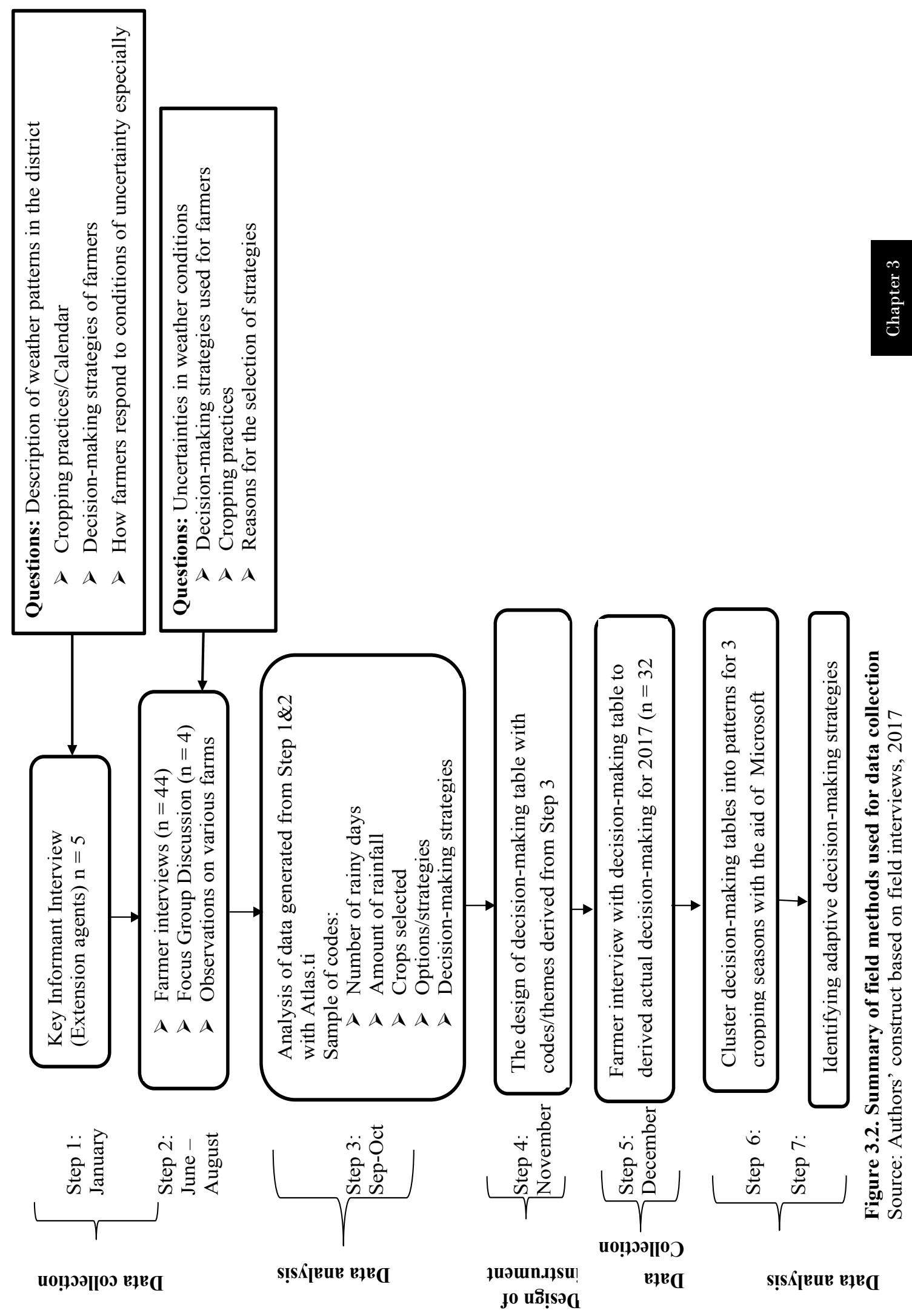




\section{Chapter 3}

\section{Step 3: analysis of data generated from step 1 and 2}

Fieldnotes were synthesized to deduce relevant responses guided by the research question. This was followed by transcriptions of recordings generated from interviews and FGDs into texts. Transcriptions were read several times to extract keywords, phrases and themes, followed by coding of texts with Atlas.ti which was coded by one person. Coding was carried out by sorting the transcripts under various themes and codes were developed for each line of the text to generate a coding tree (see Figure 3.3 \& Table A2). Some of the themes or codes were identified prior to the coding of the data, while some codes were generated during the process.

\section{Step 4: construction of decision-making table}

The codes and themes derived from the data analysis in step 3 were used to construct a decisionmaking table exhibited as Table 3.1, in which the decisions made by each individual farmer could be captured. The upper section of the table shows the rainfall record for each month for the year, 2017. Beneath these rows, there is a section which indicates crops selected for each season. Other decision options such as agronomic practices, irrigation, crop protection and other activities are displayed on the rows of Table 3.1. Hence, if a farmer chooses a crop for a particular season under a specific rainfall condition, there may be the selection of other decision options to support the cultivation of that crop. The use of the figure, 1 or 0 indicates a selection or non-selection of an option in the respective month.

\section{Step 5: interviews with farmers using the decision-making table}

In December 2017, 32 farmers (24 men and 8 women) were revisited to generate in-depth knowledge about their decision-making in response to the rainfall conditions with the decisionmaking table (see Table 3.1). Farmers were asked to describe how they reacted to the rainfall conditions throughout the cropping seasons for the year 2017. We sought not to treat decisionmaking of farmers as homogenous. As a result, we interrogated farmers to provide reasons for the decision-making under the variable rainfall conditions. We also interrogated farmers to differentiate between options that were usually selected in each cropping season and the new responses that were selected due to uncertain rainfall conditions in the year 2017. This aspect of the study was carried out using a recall approach. Thus, the limitation of the study was that we relied on farmers' recall of activities throughout the year. Yet, we catered for this limitation by drawing the 32 respondents from farmers who participated in the in-depth interview in step 2 (see Figure 3.3). In addition, the lead researcher stayed in the communities and took notice of the various decision-making patterns through farm visits.

\section{Step 6: cluster decision-making table into patterns for three seasons}

Interviews conducted with the decision-making table for 32 farmers were entered into a spreadsheet. We used the data tab feature in Microsoft Excel from the data generated from step 5 to identify numbers and percentages of farmers who took specific decision- making options under various conditions or the adjustments made during the seasons. We clustered farmers based on similarities in their decision-making, separately for each of the three seasons to distil patterns of decision-making. We manually interrogated the pattern generated to corroborate our findings.

\section{Step 7: identifying adaptive decision-making strategies}

The patterns of decision-making and the strategies mentioned by farmers were derived from the transcripts guided by the conceptualization of adaptive decision-making. We carried this out by paying attention to combinations of decision options and cessation of options under different 
rainfall conditions. We also supported farmers' decision-making strategies with qualitative evidence from the transcripts. Results of the analysis are presented as findings of the study.

\subsection{Results}

We start the section with findings on farming decision-making patterns for the year 2017 for each farming season. This is followed by results on the strategies that were adopted by farmers under uncertain weather (rainfall) conditions, through flexibility or robustness.

\section{Preseason farming}

The farming calendar for a particular year is divided into periods of different lengths. The conventional cropping seasons are April-July (main season) and September-November (minor season) and they correspond with the main and minor rainfall seasons. Due to experiences about uncertainties in rainfall conditions, pre-season farming is carried out to make use of early rains. The cultivation of crops during January-March is what we refer to as preseason farming. It has become necessary to start farming during that period due to experiences of erratic rainfall in the previous years, with many rains in the preseason and lack of them in the main or minor seasons. Therefore, decision-making for farming starts before or in January, with limited knowledge about how much rainfall will be available throughout the year. We illustrate this finding with a quotation derived from FGD conducted in the Toje community where a maize farmer mentioned that:

Formerly, when we received the first rainfall, we did not use it to plant any crop. We have sown seeds after the fourth or fifth rainfall or after we have celebrated Easter. This has changed and presently, as soon as the rains set in, we start farming, because we do not know what will transpire for the rest of the year. [R9_FGDs, Toje].

For $2017,87 \%$ of farmers cultivated crops in the preseason while $13 \%$ did not cultivate any crop. Decision-making for the preseason comprised planting a number of crops: watermelon $(50 \%)$, green pepper $(7 \%)$, okra $(11 \%)$, onion $(11 \%)$, carrot $(14 \%)$ and tomato $(7 \%)$. Each of these crops have some peculiar characteristics suitable for the preseason and they were associated with different decision-making patterns. We analysed the patterns of decision-making for watermelon in the preseason because it was cultivated by most farmers as a relatively quick and droughtresistant crop.

The preseason farming in 2017 was characterized by a false start, with 3 rainy days in January. There was no rainfall in February and a single rainfall event was recorded in March. We observed 5 decision-making patterns by farmers who cultivated watermelon. The decision-making patterns differed in terms of how farmers took into account uncertainty about the weather and selected options as demonstrated in Table 3.2. With pattern 2.1, farmers took into account uncertainty in the rainfall conditions by cultivating watermelon with other crops (okra, pepper or cassava) on different portions of the same farm or they intercropped it. Several options were introduced on the farm as the rainfall conditions became variable. In pattern 2.2 , farmers cultivated only watermelon and suspended farming when there was no rainfall in the month of February and March but they continued after the onset of rainfall for the main season. In pattern 2.3, farmers cultivated only watermelon. However, they responded to the erratic rainfall conditions with manual or mechanic irrigation and selection of other crop protection practices. In pattern 2.4, farmers cultivated watermelon, but they abandoned the crops on the farm during the prolonged dry spell and reploughed the land to start cultivation of a new crop in the main season. Pattern 2.5 consisted of 


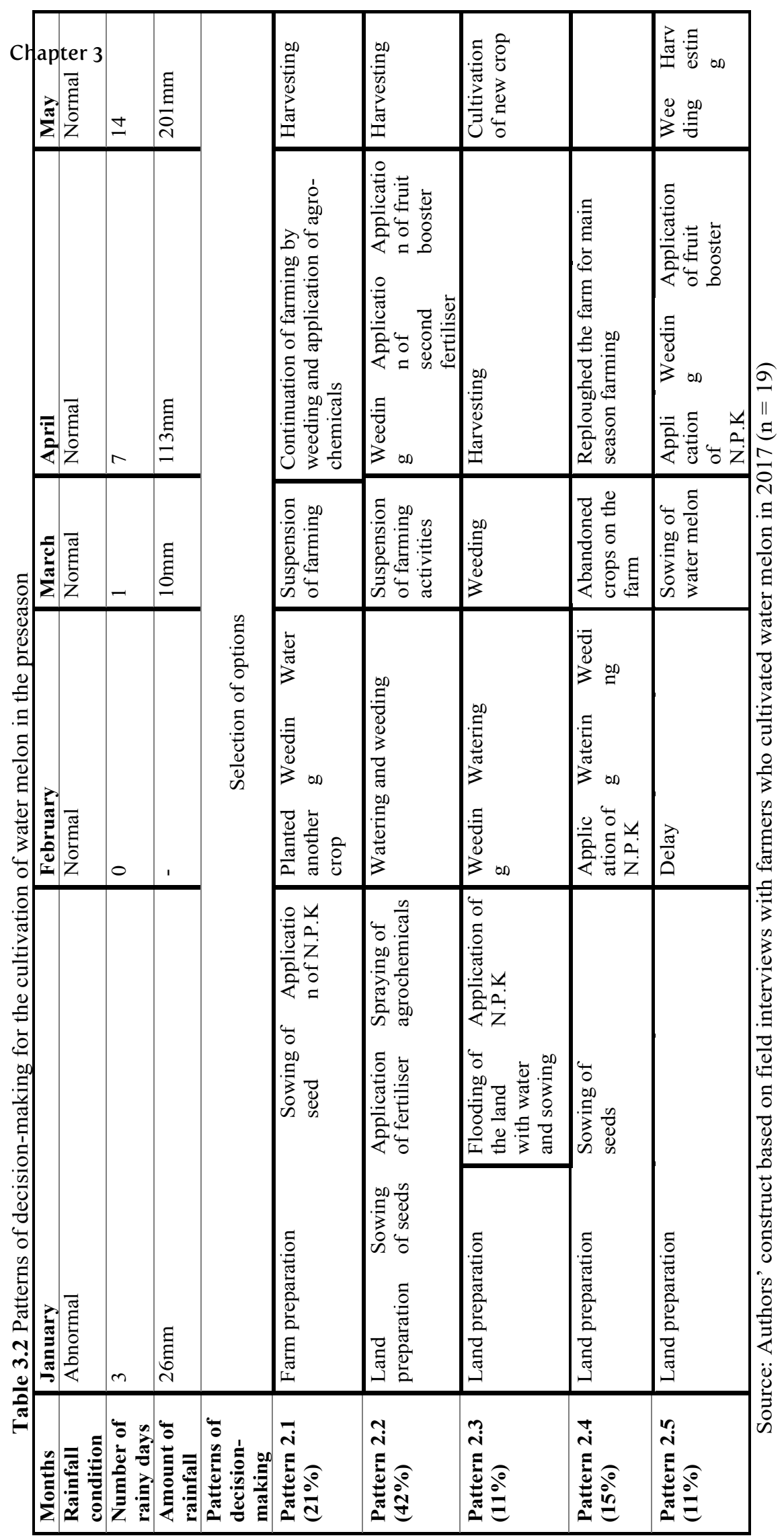


farmers who prepared the land in January; yet, they delayed sowing seeds and they ended up not cultivating watermelon in the preseason but in the main season. In three of the decision-making patterns $(2.1,2.2,2.4)$ identified in the preseason, we recognized that the cultivation of watermelon extended into the month of May. Hence, the preseason extended for longer than the usual ten weeks growth period.

\section{Main season farming}

Although it is stated in the literature (see, for instance, Teye and Owusu 2015) that the main season in the southern part of Ghana is considered to span from April to July, we observed that in the year 2017, it extended to September due to the weather conditions (see Table 3.3). After preseason farming, crops were selected for the main season and the options available for the main season varied. Tomato and pepper are the main crops that are cultivated in the main season due to erratic rainfall conditions, accessibility to markets and other socio-cultural factors. In the year 2017, the main season was also characterized by uncertainty in rainfall conditions. In this case, farmers experienced rainfall above the requirement of the crops. We analysed decision-making pattern associated with the cultivation of the two main crops: pepper and tomatoes.

The cultivation of tomatoes and pepper was associated with 4 decision-making pat- terns as illustrated in Table 3.3. In pattern 3.1, farmers cultivated the local variety in May- July, followed by the cultivation of hybrid varieties. Or, both local and hybrid varieties were cultivated at the same time. Pattern 3.2 is associated with farmers who were involved in intercropping or diversification of tomatoes or pepper on different portions on the farm with other crops. With pattern 3.3, farmers started the cultivation of tomatoes in July while all other patterns described above started in April. Pattern 3.4 was characterized by farmers who transplanted seedlings from the nursery to the farm in batches from the later part of the main season until the onset of the minor season.

\section{Minor season}

The minor season usually starts from mid-September to the last week in November. Farmers differentiate between the main and minor season with a usual break in rainfall (records of dry spell conditions) in August. Afterwards, the occurrence of rainfall from September to November is regarded as the minor season. However, findings from inter- views and FGDs show that the pattern of rainfall has changed as "below normal" rainfall conditions started before August in 2017. In addition, the amount of rainfall and number of rainy days varied during the minor season. In the year 2017, the rainfall ceased in the early part of July. These phenomena informed farmers decision-making for the minor season as we identified 4 patterns of decision-making represented in Table 3.4. In pattern 4.1, farmers decision-making involved no cultivation of any new crops. This decision was based on the expectation that there will be no "good" rainfall condition for the rest of the year. In pattern 4.2, farmers tend the crops on the farm to transcend the main season. Pattern 4.2 also connects with pattern 3.4 in the main season and it is mostly cassava and pepper that was left on the farms. In pattern 4.3, farmers tendered tree crop (mango) and harvested it from November to December. Pattern 4.4 comprised farmers who cultivated new crops purposely for the minor season. The crops cultivated for the minor season were okra, watermelon, maize, cassava and pepper. These crops were purposely selected because they could survive in dry conditions. Some farmers intercropped maize, okra and watermelon with beans or groundnut. Farmers who had access to water planted tomatoes, sweet pepper, onions, carrots and cucumber. 


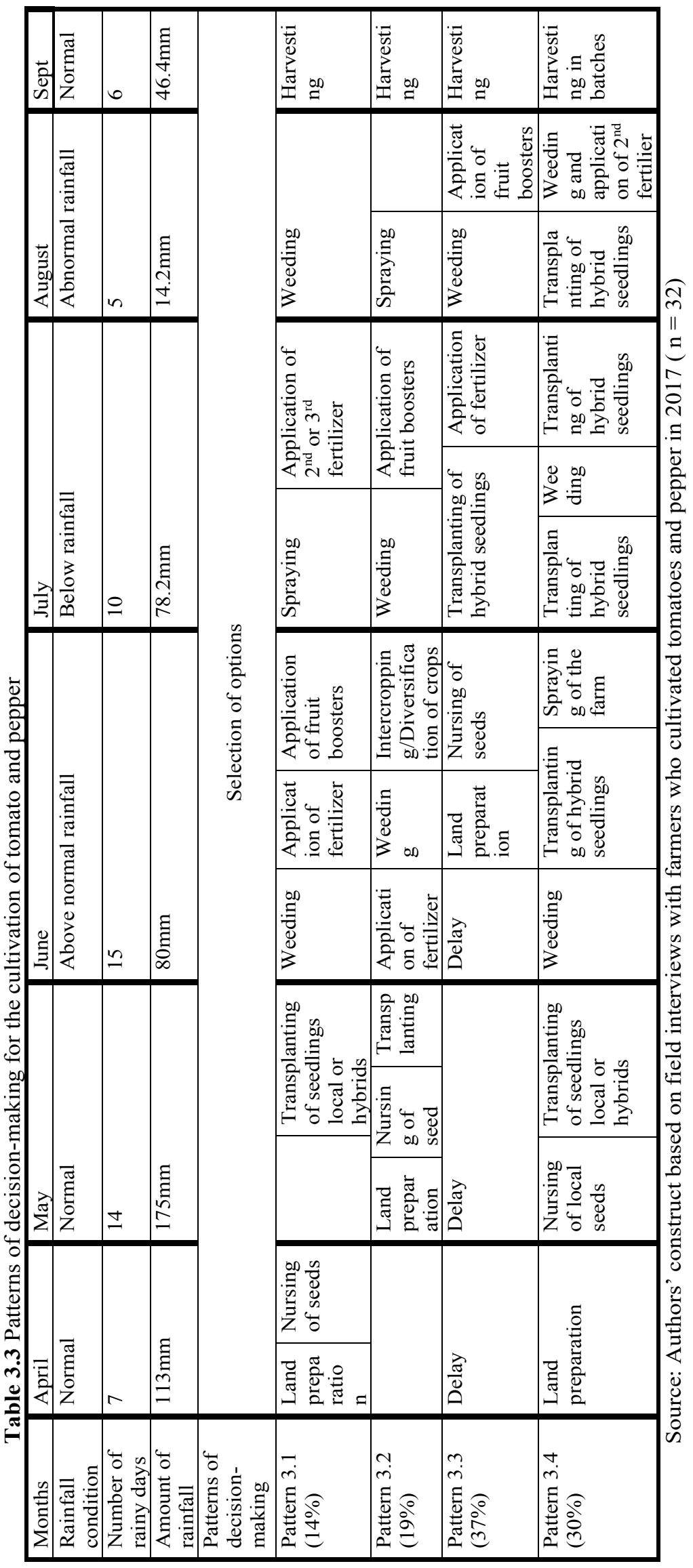




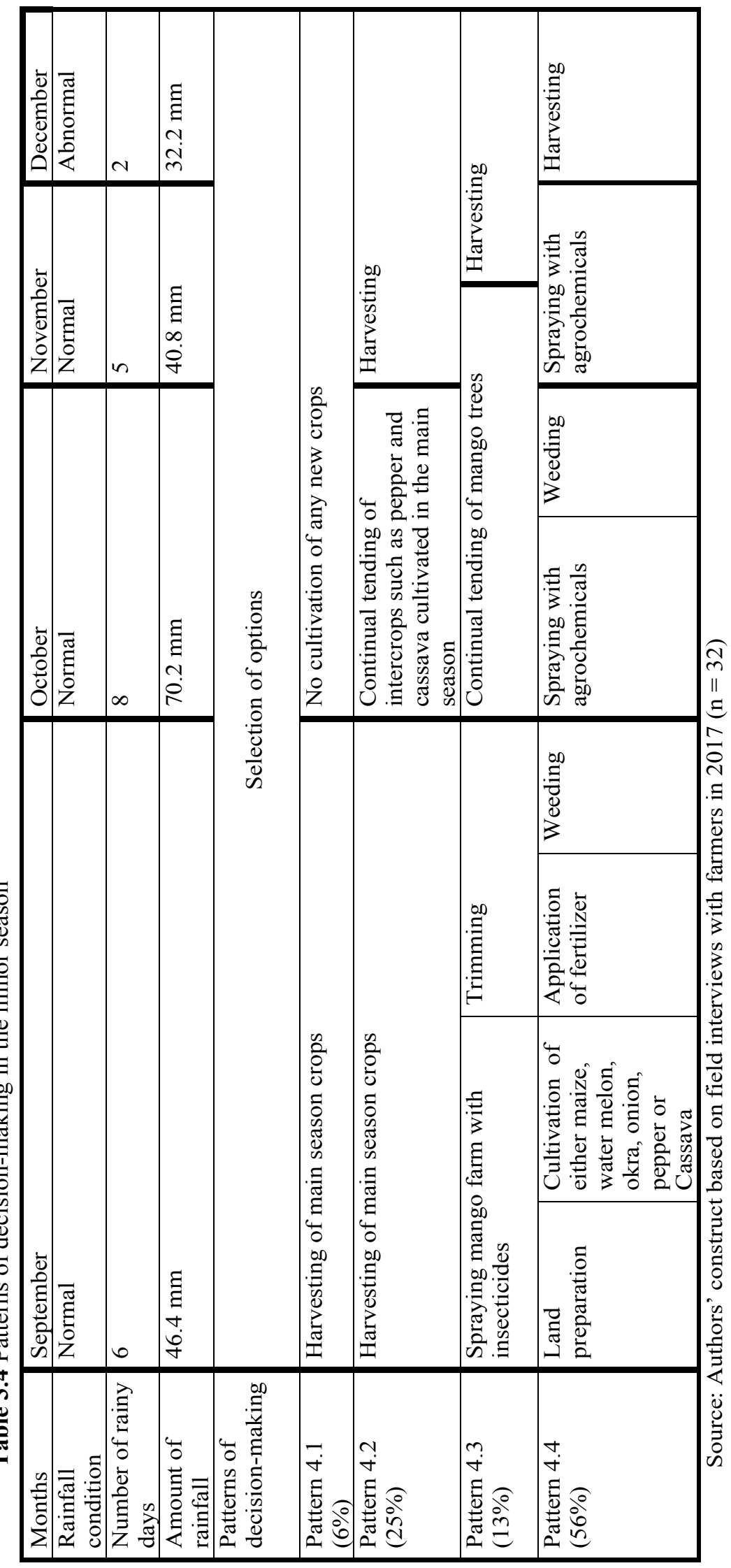




\section{Chapter 3}

Strategies of adaptive decision-making across the three farming seasons

Having described the patterns of decision-making for the three cropping seasons, we now turn to identifying ADM strategies. These strategies are formulated through combining different options from the left side of decision-making table (see page 8) into flexible or robust strategies. We have identified 6 ADM strategies employed by farmers throughout the 2017 cropping seasons: 3 based on flexibility (F1-F3) and 3 based on robustness (R1-R3).

\section{ADM strategies based on flexibility}

F1: Switching dates for sowing seeds through wait-and-see or delay strategy

The usual decision is to prepare the farmland and sow seeds at the onset of each season. The experiences about unpredictable rainfall conditions caused farmers to switch planting dates or start sowing seeds immediately after a rainfall. For instance, in the year 2017 preseason, the cultivation of watermelon started after Christmas. Some farmers ploughed the farm with the last rainfall from the previous year or the farm was ploughed dry before the occurrence of the first rainfall and then seeds were sown immediately after the first rainfall was recorded. Nevertheless, some farmers adopted a strategy by switching dates for sowing seeds through wait-and-see or delay strategy until the rainfall condition was perceived to be "good" enough to plough or sow seeds. Switching dates for sowing seeds by wait-and-see and delay strategy is based on the assumption that natural variation will provide enough information to understand the consequences of selecting option(s) (Colombo and Byer 2012; Yousefpour et al. 2017). Farmers apply wait- and-see and delay strategy by switching between dates on which they plough the land, sow seeds, or transplant seedlings from the nursery to the farm.

This strategy is selected in accordance with the onset, cessation and occurrence of rainfall in the farming seasons. During the study, the strategy was carried out in the preseason and main season ( $2.5 \& 3.3$ in Tables $3.2 \& 3.3$ respectively). Farmers prepared the land; however, they delayed or switch dates for sowing seeds until they have observed and gained enough knowledge that "good" rainfall condition was certain (pattern 4.5 in Table 3.4). Switching dates for sowing seeds through wait-and-see or delay strategy is flexible ADM because farmers can plough the land and refrain from sowing seeds or transplanting seedlings when they observe a "bad" rainfall condition. In some instances, farmers plough the land ahead of the season in response to an impending "dry" condition and then sow seeds at the onset of the rains. Most farmers used their experiential and local knowledge to apply this strategy in response to an impending rainfall condition that has been observed to reduce the cost of production. Therefore, when farmers have not yet sown their seeds or ploughed the land, switching dates for sowing seeds through wait-and-see or delay is one of the strategies that is used especially when their local indicators about the weather and previous decision-making have been less adaptive. These actions reflect flexibility as farmers can reverse or change decision-making easily by not sowing or ploughing when an unfavourable weather condition is observed.

F2: The strategy of muddling through the farming season with the application of various options In response to unpredictable rainfall conditions during various cropping seasons, some farmers integrated various strategies until they harvested some crops. We refer to this strategy as muddling through flexible ADM strategy because farmers "mix" several strategies or practices and then reverse or change some aspects in response to rainfall conditions. With this strategy, farmers attempt to try out any practice or innovations. This could be the application of different agrochemicals or they mixed various practices in a way that when the weather is favourable 
they gain something. Alternatively, they withdraw some practices or strategies when rainfall conditions deteriorate or even increase above their expectation. During the preseason, farmers who conducted some manual or mechanized irrigation continued to integrate various agronomic strategies (see pattern 2.3, Table 3.2). These categories of farmers adopted a "muddling through" strategy in their decision-making because, though they were faced with increasingly "bad" rainfall conditions, they continued in their course of action rather than to abandon it. We found this strategy to be flexible ADM as it consisted of continual implementation or redraw of various crop protection strategies such as weedicides, insecticides, herbicides, pesticides and fungicides and different types of fertilizers (N.P.K, urea and ammonia) and irrigation strategies. However, we indicated that the strategy of muddling through adverse rainfall conditions faced some challenges. For example, when there was a dry spell in the minor season, farmers responded to the condition by spraying the farm with some agrochemicals and some of the above-listed strategies. Yet the crops did not yield as expected because high temperatures and other weather conditions affected flowering and fruit formation. In this way, the flexible strategy of continuing to tend the crop can result in escalation of commitment (Drummond 2014), where a more drastic change of course would have been more adaptive.

\section{F3: Alternative irrigation strategies}

Farmers depend on the rainfall for farming; however, when rainfall is below the normal condition, alternative options of irrigation strategies were implemented. These include a cup of water applied to the base of each plant at suitable times in the day. Some farmers tied water in perforated plastic bags and deposited it at the base of the plant to mimic a drip irrigation technique. Other farmers manually irrigated their farms with water from a dam, wetland, gutters, pond or drains, with a bucket, or PVC pipeline and a pumping machine. These strategies were carried out either once or twice a day, based on knowledge about evapotranspiration rates, humidity or temperature conditions. This flexible strategy faced challenges as well because it could not deal with the very high evapo-transpiration rates and temperatures. Farmers who transported water to the farm in plastic bags and water tanks could not continue this strategy after some time due to excessive evapotranspiration and temperatures (see pattern $2.2 \& 2.4$ in Table 3.2).

\section{ADM strategies based on robustness}

\section{R1: Portfolio strategy of transplanting of seedlings in batches}

A strategy which was peculiar to the main season was the transplanting of tomato/ pepper seedlings systematically when farmers were not certain about the rainfall pattern for the rest of the year. This portfolio strategy encompassed transplanting of improved variety of tomatoes/pepper seedlings from the nursey in batches with at least two-week intervals from June until August as exhibited in pattern 3.4 in Table 3.3. In some cases, this strategy was carried out as relay intercropping because seedlings were transplanted after flowering or before the standing crop is harvested. This strategy creates robustness in decision-making because in the event of poor rainfall condition, farmers benefited as transplanting was implemented at different periods and sometimes, with different varieties of the same crop. The assumption is that seedlings transplanted without success at one point in time can be compensated by successful seedlings at another point in time. We consider this strategy as an ADM strategy because farmers who encountered unfavourable weather conditions from July to September did not record a total loss as some crops had surpassed the stage they were supposed to be affected by the unfavourable weather conditions. 


\section{Chapter 3}

\section{R2: Selection of robust (hardy) crops or varieties}

The selection of crops or varieties of the same crop was carried out carefully in order to generate some harvest or "good enough" harvest. For instance, the "light-green" hybrid variety of watermelon was selected for the preseason due to the notion that it can thrive in poor rainfall condition. In the early part of the main season, farmers selected the local variety of pepper and tomato because they held the perception that they could withstand the heavy rainfall and still bear some amount of fruits (see pattern 3.1). In this instance, farmers avoided a total loss because the selected crops or varieties withstood varied weather conditions; however, they could not generate the maximum harvest. We argue that the selection of robust crops for the various seasons is an ADM strategy because they provide a satisfactory harvest in adjustment to variable rainfall conditions.

\section{R3: Intercropping/diversifying crops}

Diversification or intercropping was used by farmers to respond to variable rainfall conditions. During the preseason in 2017, some farmers incorporated cassava, okra, maize, or pepper in the watermelon farm (pattern 2.2 in Table 3.2). The crops are either long duration or drought-resistant varieties. Some farmers also indicated that these crops have "hard" leaves to withstand the intense insolation. In the main and minor seasons, garden eggs, okra, maize, cassava, sorghum, millet, cowpea, beans, groundnut and sweet potatoes were used as intercrops $(2.1,3.2 \& 4.4$ in Tables 3.2, $3.3 \& 3.4$ respectively). Diversification or intercropping is a portfolio strategy, as farmers used a combination of crops to respond to varied rainfall conditions. We regard intercropping or diversification as a robust strategy because the growth of one crop will be partly offset by the loss of other crops. Hence, diversification or intercropping is an ADM strategy as there is a large potential for crops to respond to different conditions. We tabulate a summary of findings on strategies used by farmers during the three cropping seasons in Table 3.5 with farmers' quotations presented to illustrate the findings and the themes identified in the study. 
Adaptive decision-making under conditions of uncertainty

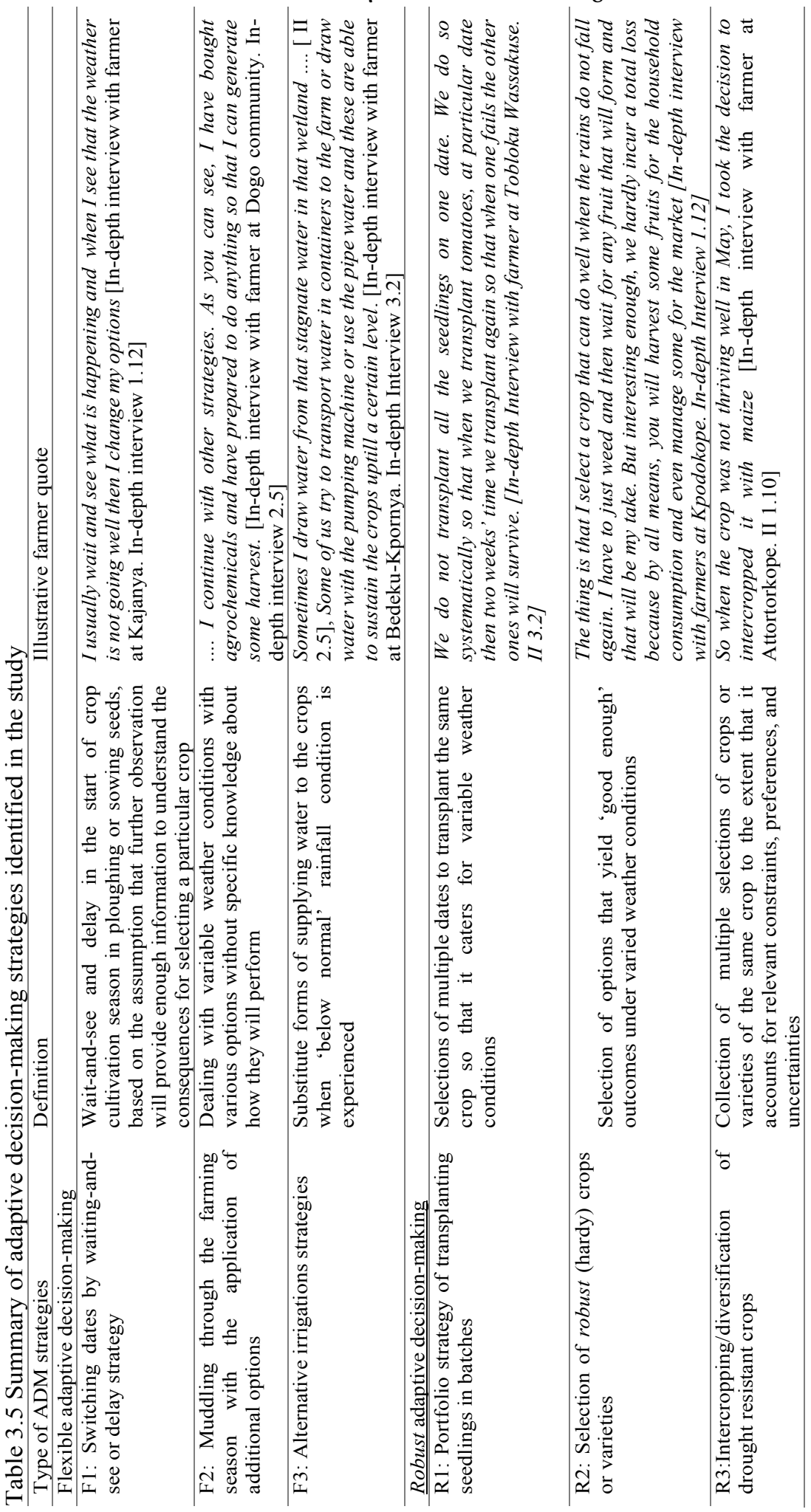




\section{Chapter 3}

\subsection{Discussion}

In this section, we explore four areas identified as important in the findings above: levels of decision-making and changes in decision-making due to uncertainties in rainfall conditions; a reflection on how weather information could have supported ADM in farming; ADM affected by the combination of weather conditions and other factors, and types of ADM strategies identified as flexible or robust.

Our analysis of decision-making in farming in 2017 shows several levels of decision- making. We identified different patterns of decision-making for each cropping season through the use of the innovative decision-making table (see Table 3.1). However, it is difficult to compare these results with the literature because previous studies have not focused on the use of pattern of decisionmaking in farming under uncertain rainfall conditions. With regards to decision-making on seasonal basis, we found that farmers cultivated crops in all three seasons or in two of the three seasons. The identification of three farming seasons indicates that decision-making in farming has evolved from the two traditional cropping seasons to include a new cropping season, which we called preseason farming (January-April). Most farmers use the first rainfall in the year to cultivate the watermelon which is a quick and drought-resistant crop. Pre-season farming is innovative because farmers are likely to generate two to three consecutive harvests from different seasons or at least, they are able to generate one harvest for the year when they experience unfavourable rainfall conditions. This finding is consistent with Meinke et al. (2006) who indicated that farmers in 9 Brazilian Nordeste states make use of the first rainfall in the year to start cultivating crops irrespective of knowledge about its continuity. Cafer and Rikoon (2018) also mentioned how farmers planted quickly at the beginning of the year in response to variability in rainfall condition in Ethiopia. Due to the uncertainties associated with the rainfall pattern, decision-making for farming is mostly carried out for the preseason and main season. Farmers indicated that the minor season farming rarely occurs as there is usually little or no rainfall to enable farming. Owusu (2000) and Yaro (2013) had earlier also observed considerable changes in the cropping seasons in the transitional and coastal agro-ecological belt of Ghana due to changes in weather conditions. In addition, the traditional decision-making for the main and minor season is to cultivate crops from April to July followed by the minor season farming (September- November) which is in accordance with the two rainfall pattern in southern Ghana. In our study, we found that decisionmaking for all the seasons was not carried out distinctly according to the traditional cropping calendar as there was hardly any differences between decision-making for the seasons due to uncertainties in rainfall conditions for the period under study (see Tables 3.2, $3.3 \&$ 3.4). Therefore, though formal weather records may indicate that there are no changes in the patterns of weather conditions, it is important to take note of farmers' daily, weekly and seasonal decision-making in accordance with weather conditions for a specific season or year.

The novelty in the study is the application of flexible and robust concepts to examine whether farmers' decision-making is adaptive or not based on their account on how they monitored the occurrence of rainfall and the decision-making strategies that they applied. This idea is new as none of the literature on decision-making in response to variability in weather condition, rainfall or climate change have analysed farmers' decision-making in this light. Though some studies also attempted to identify the adaptation strategies of farmers under variable or changing climatic conditions, they have not accessed the flexibility or robustness in the strategies applied (see, for instance, Fosu-Mensah et al. 2012; Wiid and Ziervogel 2012; Yaro 2013; Hoang et al. 2014; Ndamani and Watanabe 2015). We also recognized that studies have indicated farming practices 
such as inter- cropping, increasing use of small-scale irrigation methods, diversification of crops and/or varieties on same land, cultivation of new improved varieties, increasing use of agrochemicals, introduction of new crops, changes in crop varieties and in planting times as adaptive strategies that are used to deal with uncertain weather conditions (Armah and Odoi 2011; FosuMensah et al. 2012; Yaro 2013; Ndamani and Watanabe 2015; Tarchiani et al. 2017). These lists of strategies have also been numerously stated in the literature as climate change adaptation strategies adopted by farmers. Yet, there is no clarity on whether these strategies implemented by farmers are flexible or robust ADM. Hence, the application of the concepts, flexible and robust to examine the strategies of farmers under uncertain rainfall conditions is novel.

The application of flexible and robust concepts to the case of decision-making in farming in response to uncertain rainfall conditions helped to indicate that strategies such as switching dates for sowing seeds through wait-and-see, delay strategy, muddling through the farming season with the application of portfolio of agrochemical and alter- native irrigation strategies are flexible ADM. Whereas transplanting seedlings in batches, selection of robust (hardy) crops and intercropping/diversification of drought-resistant crops are robust ADM strategies. Farmers applied the ADM strategies either singly or simultaneously to respond to uncertain rainfall conditions. In addition to the list of adaptive strategies which are already mentioned in the literature, we found the selection of robust (hardy) crops as satisficing strategy which can be considered in the list of ADM strategy. Satisficing strategy involves the selection of "good enough" crops to generate a minimum yield under uncertain rainfall conditions (Brownlee 2007). With this strategy, farmers selected some hardy varieties or crops (okra, pepper and cassava), although they may generate low yield under either "above normal" or "below normal" rainfall conditions. Hence, though harvests may not necessarily meet farmers' expectation, they were satisfied with whatever yield they generated under various weather conditions. In this instance, the strategy may not be economically optimal; however, as long as farmers generate some harvest for household consumption or for the market, it was preferred than doing nothing during a particular season. Another innovative strategy identified in the study is "muddling through with the application of various options". We considered this strategy as a flexible ADM as it enabled farmers to select several options to deal with various rainfall conditions. Even so, the continual tending of crops under "bad" rainfall conditions by "muddling through with the application of various options" without any drastic change in decision-making could result in a situation whereby farmers only escalated their commitment (Drummond 2014) in farming. Therefore, in our study, we seek to point out to the scientific community that it is not enough to merely indicate that farmers are taking certain decisions or adaptation strategies in response to changing rainfall conditions. Analysis should extend such discussions towards evaluating its robust- ness or flexibility.

Third, although farmers used varied flexible or robust strategies to deal with uncertainty in rainfall conditions, some strategies were less adaptive because most decision-making was based solely on farmers' experiences and local knowledge about the weather. The sole use of experiences and local knowledge about the weather conditions do not provide adequate information to serve as a guide in the selection of crops for the seasons. In the preseason, options were selected under uncertainty because there was incomplete information regarding how rainfall conditions will occur for the period. The result is that the maturation period for watermelon was longer than the usual two months and two weeks growth period. While watermelon without irrigation failed to grow due to the absence of rainfall and other unfavourable weather conditions, the outcome was that some farmers had to plough the land again after almost two months of no rainfall and sow again at the 


\section{Chapter 3}

onset of the rains in April (see pattern 2.4 in Table 3.2). When there is no rainfall, sowing two or three times in a season without harvesting any crop can increase the cost of production or farmers can exhaust their seed reserves. In the main season as well, some farmers perceived that a "normal" rainfall condition will occur; hence, their decision-making was to cultivate a hybrid tomatoes variety from April to June. However, their decision-making was affected by an "above normal" rainfall condition which also affected timely flowering and fruiting (pattern 3.1 in Table 3.3). From the findings, it can be realized that most farmers could have carried out more ADM if there was some certainty in their experiences and local knowledge about the rainfall and other weather conditions. The availability of tailored weather information for farmers throughout the year could have been useful in enabling the decision-making of farmers (see pattern $4.1 \& 4.2$ in Table 3.4) to cultivate new crops or robust (hardy) varieties of crops in the minor season since there was an appreciable amount of rainfall and rainy days from September to November. This finding suggests that usable weather information (seasonal, weekly, daily forecast and outlook in the year) tailored specifically for farmers will be important to support ADM in farming. The suggestion is also indicated in various studies conducted by Roudier et al. (2014), Ndamani and Watanabe (2015), Shikuku et al. (2017) and Tarchiani et al. (2017) which also specifies weather information as relevant for the application of adaptive strategies.

Additionally, we found that ADM strategies are a reflection of farmers' considerations of a combination of rainfall conditions and other factors. These factors include socio- cultural issues, cost of input, selling prices, availability of market, access to assets, social networks, self-perception of farmers, household demography, perceived risks, external institutions, bio-geographical context and socio-demographic factors. These factors enabled or constrained flexible or robust ADM under uncertain weather conditions. We found that crops such as sorghum, cowpea, beans, or spices could have thrived under "below rainfall" weather conditions. Yet, specific factors such as social networks, avail- ability of land, market, selling prices among others constrained their cultivation even when farmers had the resources to cultivate them under "below rainfall" condition. Hence, in the preseason and main season, farmers' crop selection was mainly the watermelon and tomato/pepper, respectively, due to some of the above-mentioned factors. Brown et al. (2015), Singh et al. (2016) and Tarchiani et al.'s (2017) also indicated in their studies that household attributes, demographic composition, socio-economic status and external factors (natural resource dependence, market fluctuations, and access to information) can influence ADM in farming.

The outcome of some ADM strategies is immeasurable in terms of yield because the ultimate aim is to generate robust or flexible options rather than to attain optimal results. Therefore, in the discussion of farmers' ADM, attention should be focused more on the selection of flexible or robust strategies and how it can deal with future conditions to avert a total loss. Also, the measurement of the outcome of ADM of farmers can be complex depending on whether it is carried out on individual or collective basis. The outcome of ADM carried out by an individual can be easily identified; yet, the aggregation of the same ADM by numerous farmers or its continual application by an individual for a long term may lead to potentially negative outcome on a large spatial and temporal scale. For instance, a farmer's response to rainfall conditions at the farm level with continual use of irrigation and agrochemicals can yield a good outcome for the specific season under which crops are cultivated. However, there could be long-term negative environmental outcomes as the land may not be to support food production in a sustainable way. This finding is also identified in Roesch-McNally et al.'s (2017) study on farmers' adaption intentions under the corn belt climate change scenario. From these findings, we indicate that it is important that 
sustainability ideas are incorporated into adaptive strategies that are used to deal with uncertain weather conditions (Bhatasara and Nyamwanza 2018). Therefore, farmers and other actors in the agricultural sector ought to prioritize sustain- able strategies in response to variability in weather conditions in a sustainable manner.

With regards to the contribution of our study to theory, we derived ADM strategies from the patterns of decision-making. The application of the concept yielded positive results because it enabled the identification of useful strategies. We added value to the concept by examining decision-making at the individual level, whereas ideas on ADM are mostly discussed at the organizational level under deeply uncertain future climate change scenarios. This implies that the concept of ADM is not limited to organizational decision- making at district, municipal, national or regional levels. For future research, the concept can be developed further by building on the temporal dimensions (proactive and reactive ADM) with the two types of ADM developed for this study. In addition, the flexible nature of the concept can enable it to be combined with other concepts such as naturalistic decision-making (Zsambok and Klein 2014), intuitive decisionmaking (Klein 2003; Lunenburg 2010), logic of appropriateness (March 1991; March and Olsen 2011) and logic of consequentiality in decision-making (March 1994). Therefore, we suggest that future research on adaptive decision-making should consider repeated analysis with the decisionmaking table (see Table 3.1) for multiple years in order to improve insight on farmers' ADM and learning outcomes. This can help to determine whether ADM of farmers is passively or innovatively carried out. Further research is also required on how ADM is affected by a combination of factors such as age, level of education, membership to farmers' groups, household size, sex, type of farming, availability of weather information and sources of water for farming under uncertain weather conditions.

\subsection{Conclusion and implications}

This study examined patterns of farming decision-making under uncertain water avail- ability conditions and identified adaptive decision-making strategies. We conceptualized ADM as a pattern of decisions that is characterized by the application of decision options that are flexible, robust or both in response to uncertain socio-technical-environmental conditions. From our analysis of farming decisions in the Ada East District (Ghana), we identified six different decisionmaking strategies in response to the variable rainfall conditions. The three flexible adaptive decision-making strategies are: switching dates for sowing seeds through wait-and-see or delay strategy, muddling through the farming season with the application of various options and alternative irrigation strategies. The three robust adaptive decision-making strategies are portfolio strategy of transplanting seedlings in batches, selection of robust (hardy) crops and intercropping or diversification of crops. Based on how farmers select strategies in response to uncertainty in rainfall conditions, we argue that some decision-making strategies are more adaptive than others.

In conclusion, results on $\mathrm{ADM}$ strategies in farming have implications on the promotion of $\mathrm{ADM}$ in farming, the provision of information and other resources for farming. First, considering global demand for food and challenges farmers face in producing food under increasingly uncertain climatic conditions, it is important to develop and enhance capacities for ADM. This can be achieved by formulating sound strategies on ADM in farming policies and field extension guidelines, such that flexibility and robust- ness can be built into farming decisions. Second, there is an urgent need for location- specific, timely and relevant weather information for agricultural regions that are noted for variable weather conditions. The timely provision of weather information 


\section{Chapter 3}

with outlooks throughout the season can enable farmers to adapt their farming strategies under various weather conditions. Additionally, extension workers, radio channels, lead farmers, input dealers and the farming community can also work together to provide collaborative assistance for farmers on expected rainfall and ADM strategies. This would help to provide answers to farmers' questions on: how much rain to expect for the season; the possibilities of dry spell during the season; whether or not to start farming; selection of crops and varieties; and opting for other livelihood strategies in response to a weather forecast. The provision of information on the weather and ADM strategies should also take into account farmers' culture, traditions, economies and availability of resources. Third, the communication of information on ADM strategies should not only concentrate on implications for harvest, which borders on economic gains but also implications for the sustainability of other livelihood capitals such as natural and physical resources (e.g. soil quality, soil moisture retention, etc.). Furthermore, programmes on the distribution of seeds and other agricultural inputs should be timely implemented before the onset of the season for ADM. Similarly, the distribution of seeds and other agri-inputs can be targeted at areas where farmers' decision-making failed under "bad" weather conditions during previous seasons. 
Adaptive decision-making under conditions of uncertainty 


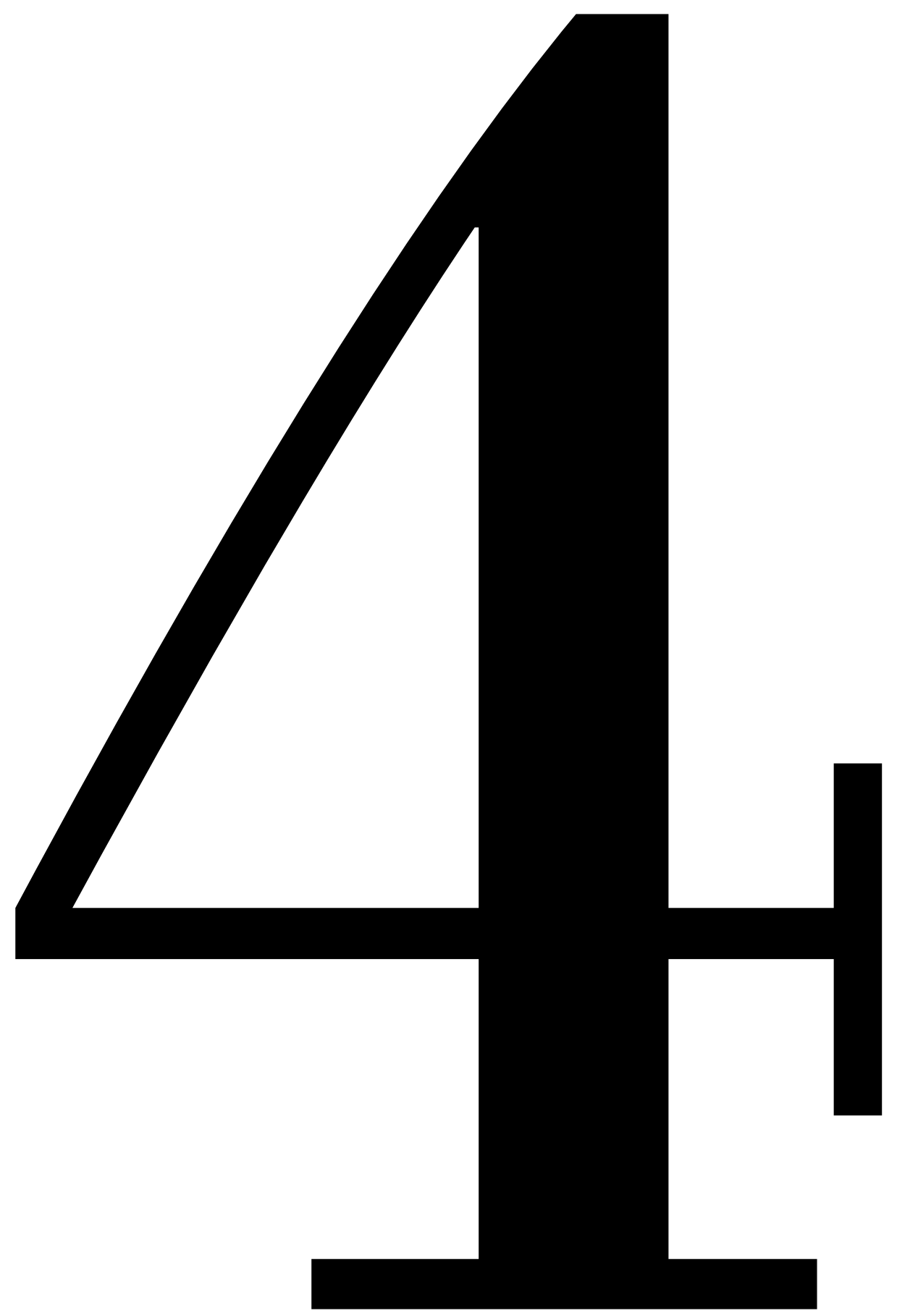




\section{Chapter 4}

Assessing the usability of weather information services for decisionmaking in farming: A case study in Southern Ghana 


\title{
Chapter 4
}

\begin{abstract}
The provision of weather information services (WIS) has become increasingly relevant for smallholder farmers in developing countries to manage the risks and opportunities arising from climate change and variability. However, gaps exist between what information providers understand as useful information and what users recognise as usable WIS, leading to underutilisation of WIS in the farming sector and other domains. Drawing mainly on qualitative research methods, our study examined farmers' perceptions about the usability of existing WIS for farming, with a focus on the Ada East District in the Greater Accra Region in Ghana. We developed five information design and delivery criteria: local embeddedness, legitimacy, spatial and temporal resolution, predictive skill, and accessibility. The findings show that smallholder farmers access 10 different WIS in the study district. However, the extent to which each WIS was used varied, given that the farmer-to-farmer and the private weather forecaster's information were more used than the other available services. The usability of the existing WIS provided for farming was either enhanced or obstructed by various factors, including the origin of the information, information providers' level of interaction with farmers, continuity in the delivery of information, respect for local values, accessible level, and mode of payment, among others. Some of the information design and delivery criteria and factors that affect WIS usability had trade-offs or complementarities, and this is inevitable. In conclusion, we propose that information providers should find a balance between these factors to meet farmers' information needs in a particular context.
\end{abstract}

Manuscript under review: Sarku, R., van Slobbe, E., Termeer, K., Kranjac-Berisavljevic, G. \& Dewulf, A. (2020). Assessing the usability of weather information services for decision-making in farming: A case study in Southern Ghana. Submitted to Journal of Climate Services. 


\subsection{Introduction}

The impact of climate change and climate variability on agricultural livelihoods in resourcedependent societies has led to numerous national and international initiatives that aim to improve decision-making through the application of weather/climate information services (Vaughan \& Dessai, 2014). This reflects the urgency of adapting to global climate change as highlighted by the Intergovernmental Panel on Climate Change (IPCC) report: Global warming at 1.5 degrees (IPCC, 2018) and the need for concerted and aggressive measures to make weather information services (WIS) work at all levels of society (Vaughan \& Dessai, 2014; Hansen et al., 2019).

WIS involves the generation, provision, and contextualisation of information and knowledge about the condition of the atmosphere at a given place for up to about 14 days for decision-making at all levels of society, thus making it a subtype of climate information services (Vaughan \& Dessai, 2014; Bazile et al., 2017). It is increasingly seen as a means through which vulnerability to climate change and climate variability might be reduced and also to improve the resilience of livelihoods (Meinke et al., 2006; Hansen et al., 2019). Although most studies indicate that the use of, and interest in, weather/climate information services have increased over the last decade, every empirical study continues to show that information is not used to its full potential (Etwire et al., 2017; Nyadzi et al., 2018; Vogel et al., 2019; Hansen et al., 2019; Nyamekye et al., 2019; Nyantakyi-Frimpong, 2019). Overall, the empirical literature on weather and climate information services has revealed usability gaps that are influenced by many factors.

Consequently, to narrow the information usability gap, which is a function of both how weather/climate information services are produced (the push-side) and how they are needed and applied by users (the pull-side) in different decision-making contexts (Dilling \& Lemos, 2011), the World Meteorological Organization launched the Global Framework for Climate Services in 2012 to provide and facilitate access to weather and climate information services that meet users' varied requirements through observations and monitoring, research, modelling, prediction, capacity building, and the creation of user interface platforms. These, indeed, have resulted in an explosion in research on the use of WIS across regions in different sectors, including farming (Dinku et al., 2014a, b; Amegnaglo et al., 2017; Roudier et al., 2014).

In Ghana, where this study was undertaken, climate change through global warming causes consequent variability in weather conditions in the form of increasing dry spell length and frequency, early or late rainfall onsets, and reduction in rainfall amount that take a negative toll on agricultural production, the mainstay of the majority of the population (Owusu \& Waylen, 2009; Kranjac-Berisavljevic et al., 2014; Dapilah et al., 2019). Dissemination and farmers' access to WIS have drastically improved, and a substantial body of knowledge on climate information science is developing in Ghana and elsewhere in sub-Sahara Africa (McNamara, 2014; Naab et al., 2019; Nyadzi et al., 2018; Nyamekye et al., 2019; Sarku et al., 2021), but there is little evidence that WIS is incorporated in decision-making processes, including smallholder farmers' adaptive strategies (Sarku et al., 2020a). Meanwhile, variability in climatic conditions continues to affect farmers' decision-making strategies, leading to low crop yields and increasing financial burdens for farmers in Ghana (Manzanas et al., 2014; Baidu et al., 2017; Atiah et al., 2019; Dapilah \& Nielsen, 2019).

We argue that the use of WIS for informed decision-making in farming requires an understanding of the usefulness and usability of WIS in terms of farmers' definitions and perceptions (Dilling \& Lemos, 2011). This is a knowledge gap that is not well understood in the literature in Ghana and 


\section{Chapter 4}

elsewhere in developing countries. Thus, providing WIS that is readily usable for decision-making in farming requires the navigation and the bridging of any differences that might exist between what scientists/information providers perceive as useful and what is usable in practice.

The chapter is organised in six sections. In the next section, the conceptual framework of the study is presented, followed by a section on research methods. Subsequently, the findings of the study are presented section 4, followed by the discussion and the conclusion in sections 5 and 6 , respectively.

\subsection{Conceptual framework}

4.2.1 Usable weather information for farming

Usable information has been studied and defined in different knowledge domains with varying objectives. In the weather/climate information service literature, the concept has been defined in various ways to understand the relationship between information providers and users (see Lemos \& Dilling, 2007; Dilling \& Lemos, 2011; Lemos et al., 2012). We build on earlier definitions by attuning them to the farming context, where usable information refers to farmers' ability to subsume relevant (useful) information into informed decision-making on when to plant or plough, and so on.

Although the terms useful and usable are often used interchangeably in the literature, they do not mean the same thing (Lemos \& Dilling, 2007). Useful information is information that is potentially relevant for decision-making, yet, because users may not know or may have unrealistic expectations about how it fits their decision-making, they may choose to ignore it. Usable information, on the other hand, is knowledge that is readily applicable by users in the formulation of strategies under uncertain conditions like climate change and variability (Lemos et al., 2012). Hence, although all forms of user-inspired knowledge are in principle useful, they are not always usable, unless users and producers take specific steps to ensure that useful information is applied (Buizer et al., 2010; Dilling \& Lemos, 2011). On this note, it can be said that useful information relates to information providers' outlook, whereas usable information pertains to users' viewpoint about how applicable the information is for decision-making in their context, considering factors such as availability of resources (e.g., seeds), enabling institutions, culture, behavioural issues, and so on (Meinke \& Stone, 2005; Spear et al., 2019). It is precisely these different perceptions and understandings of useful and usable information between information providers and users that create the usability gap reflected in the low uptake of WIS for farming and other domains (Lemos et al., 2012).

Numerous studies have applied different frameworks to identify the usability gap in the provision of weather and climate information services (see Patt \& Gwata 2002; Cash et al., 2003; Patt et al., 2005; Meinke \& Stone, 2005; Lemos \& Dilling, 2007; Lemos et al., 2012; Vaughan \& Dessai, 2014; Dewulf et al., 2019). However, Dilling and Lemos' (2011) framework made a distinction by attributing the usability gap to two broad areas: context and information production. For farming, context relates more to the farmer and issues arising from the farming community; for example, conservatism towards new information, competition between new and existing information, religious beliefs, socio-economic characteristics, among other issues. Although this aspect of the usability gap is relevant, our study focuses on the information design and delivery aspect, which pertains to how information providers produce and deliver information to enable its usability. We build on Dilling and Lemos' (2011) framework to develop analytical criteria for our study by 
attuning some of their factors with ours. We expand on their framework, which focuses mainly on the formal scientific production of climate information services on a global scale. We do so by building five information design and delivery analytical criteria by adapting aspects of their framework in addition to other new criteria derived from the literature to assess information design and delivery for farming.

\subsubsection{Usability criteria for information design and delivery}

Information provision is characterised by information design and delivery criteria that should meet users' requirements. The five analytical criteria for information design and delivery are elaborated as follows.

- Local embeddedness

Local embeddedness refers to the extent to which information design and delivery connect with local farming conditions and context in a specific community. This criterion can relate to a situation where WIS is provided including the knowledge of farmers, so that their unique characteristics, rules, farmers' exposure to different sources of information, and information seeking and sharing behaviour are captured in the information design (Meinke et al., 2006; Feleke, 2015; Nidumolu et al., 2018). Additionally, an information design with local embeddedness may include other relevant information design features such as agrometeorological indicators, agronomic tips, and so forth (Meinke et al., 2006). In this instance, information design and delivery need to be linked to the personal relationships and social networks in the farming communities (Lemos \& Morehouse, 2005; Brown et al., 2015). Local embeddedness may result in knowledge exchange and provide the opportunity to alter the content of information to suit changing conditions (Patt \& Gwatab, 2002).

- Legitimacy

Legitimacy denotes that information design and delivery conform to farmers' interests, values, concerns, and perspectives, resulting in acceptability. Farmers may judge the legitimacy of the WIS based on who participated or not in its design and delivery (Cash et al., 2003). Here, the information design and delivery is carried out by considering several options, such as respect for farmers' value and how the WIS connects to the contextual needs of farmers (Cash \& Buizer, 2005; Roncoli et al., 2009b). Thus, legitimacy is grounded in the development and maintenance of mutual trust and respect (McNie, 2007). Legitimacy in the information design also implies the alignment of the information to farmers' local knowledge and values (Roudier et al., 2014). Furthermore, the legitimacy of information can be affected if a forecast fails, is irregularly delivered, or is associated with long delivery chains and political biases (Hansen et al., 2019). For example, Patt and Gwatta (2002) found that, in Zimbabwe, farmers were suspicious of forecasts if they did not understand the scientific methods used to develop them and they were not familiar with the source of the information.

- Temporal and spatial resolution

The temporal aspect of information design and delivery indicates when to expect specific weather conditions for farming, whereas the spatial resolution denotes the surface area for which the forecast is made. The temporal criterion of information design and delivery may consider the time when the information delivery will be relevant to determine when to plough, sow seeds, or select crop varieties. This may be 1 day, weekly, 1-14 days, and 1 month (Gbangou et al., 2019). The 


\section{Chapter 4}

information design and delivery may also include temporal indicators such as onset date, dry spells, and rainy season duration (Ingram et al., 2002; Nyadzi et al., 2019). Also, the presentation of timing as early onset, normal onset, and late onset in a seasonal forecast may be a relevant information design characteristic (Ochola \& Kerkides, 2003; Sultan \& Janicot, 2003). Furthermore, the information design may avoid too early or too late delivery (Meinke et al., 2006; Gwenzi et al., 2016).

With the improvement in technologies such as satellite images, the internet, telecommunication networks, among others, information can be designed for different scales (Rosas et al., 2016). The problem is that forecasts on a regional scale take averages and may miss local weather events. In local communities, farmers draw information from certain environmental indicators to predict weather conditions. Thus, they expect the forecast to corroborate their observations (Roncoli et al., 2009a, b). The disadvantage of local forecasts (high resolution) is that models lose accuracy with increasing resolution (downscale to local scales) (Archie et al., 2014). To resolve this challenge, information can be tailored to meet the specific needs of farming communities (Nyadzi et al., 2019) by analysing the implications of a forecast with farmers (Patt \& Gwata, 2002). When the information design includes the delivery of high spatial resolution, some trade-off needs to be made between skill and scale criteria (Tall et al., 2018; Hansen et al., 2019).

- Predictive skill

Predictive skill refers to the measure of the probability that a predicted weather event will correspond to the observed event. Farmers require WIS that is precise and informs them about what will transpire in a particular period. The predictive skills of WIS are usually tested to ascertain the suitability of weather model systems to provide positive or significant probabilities (Barron, 2004; Crane et al., 2010; Manzanas et al., 2014a; Gbangou et al., 2019, 2020a). Indicating the predictive skill inherent in some agrometeorological indices and the level of accuracy of the forecast information can enable farmers to store water and adopt irrigation and soil moisture conservation strategies (Gbangou et al., 2020a). To aid the reliability of information, farmers' local predictions can be incorporated into the information design (Ingram et al., 2002; Roncoli et al., 2002; Nyadzi et al., 2019). Most of all, information design can be carried out in such a way that it conveys the uncertainty inherent in the forecast, and farmers need to be trained to understand and accept uncertainties as a feature of the weather forecast in order not to raise their expectations (Murphy, 1993; Meinke et al., 2006; Lemos \& Rood, 2010).

- Accessibility

Accessibility is the absence of barriers and the ease of information flow to reach numerous farmers, through user-friendly interfaces and suitable communication strategies. The information design may prioritise its delivery through multiple channels, thereby also catering for two-way information delivery to enhance feedback (Naab et al., 2019; Slavova \& Karanasios, 2018). Second, the delivery may consider the use of interfaces in innovative ways such that they capture information in audio, video, graphics, and images mode. Other multiple delivery options may include informal networks, face-to-face outreach, interactive radio programming, and farmer groups communicating. The information delivery channel should also be appropriate in terms of farmers' age, literacy level, gender, and so on (Mittal, 2016; Nyantakyi-Frimpong, 2019b). Thirdly, the delivery mode should enable the content to be simple, relevant, understandable, and able to overcome biases (Orlove et al., 2004; Stone \& Meinke, 2006). Further, farmers' language and how 
their local institutions and cultures interpret some weather conditions may be considered (Balaji \& Craufurd, 2011; Nyadzi et al., 2018).

We present a summary of the five information design and delivery criteria in Table 4.1. The analytical criteria presented will aid in identifying the empirical factors that affect the usability of WIS from farmers' perspectives on how information providers are closing the usability gap. Against this conceptual background, our study seeks to answer the following specific research questions:

i. What WIS are available in the Ada East District and to what extent are they used by farmers?

ii. What factors contribute to the usability criteria of local embeddedness, legitimacy, spatial and temporal scale, predictive skill, and accessibility of WIS in the Ada East District?

iii. How usable are the different types of WIS in the Ada East District compared to the factors and criteria?

Table 4.1 Usability criteria for information design and delivery in WIS

\begin{tabular}{|l|l|}
\hline Usability criteria & Definition of criterion \\
\hline $\begin{array}{l}\text { Local } \\
\text { embeddedness }\end{array}$ & $\begin{array}{l}\text { The extent to which information design and delivery connect with local } \\
\text { farming conditions and context. }\end{array}$ \\
\hline Legitimacy & $\begin{array}{l}\text { The conformity of information design and delivery to farmers' interests, } \\
\text { values, concerns, and perspectives. }\end{array}$ \\
\hline $\begin{array}{l}\text { Temporal and } \\
\text { spatial resolution }\end{array}$ & $\begin{array}{l}\text { Temporal resolution refers to when to expect specific weather conditions } \\
\text { for farming; spatial resolution denotes the surface area for which the } \\
\text { forecast is made. }\end{array}$ \\
\hline Predictive skill & $\begin{array}{l}\text { The probability that a predicted weather event will correspond to the } \\
\text { observed event. }\end{array}$ \\
\hline Accessibility & $\begin{array}{l}\text { The absence of barriers and the ease of information flow to reach } \\
\text { numerous farmers, through user-friendly interfaces and suitable } \\
\text { communication strategies. }\end{array}$ \\
\hline
\end{tabular}

Source: Authors' construct based on literature

\subsection{Research methodology}

\subsubsection{Study context}

The study was conducted in the Ada East District (Figure 4.1) in the coastal savanna agroecological zone where agriculture is the main economic activity. Agricultural activity in the district consists mainly of the cultivation of vegetables, cassava, maize, watermelon, and other crops (Sarku et al., 2020a). Despite the relevance of farming for livelihood development and the supply of food to urban markets, the area experiences long dry spells, frequent dry spells, and low mean rainfall during the rainy seasons (Gbangou et al., 2020a). It is interesting to note that the coastal savanna agroecological zone also experiences interannual variability in terms of seasonal rainfall (Baidu et al., 2017; Atiah et al., 2019). In the area, the complex series of coastal/oceanic and atmospheric interactions contribute to uncertainty in weather conditions (Owusu \& Waylen, 2009; Manzanas et al., 2014a). These incidences have several implications such as loss of planting materials, crop failure, and low yield for farming in the Ada East District. Therefore, WIS provision has become 


\section{Chapter 4}

relevant for farming in the area and it is expedient to find the extent to which such services are usable.
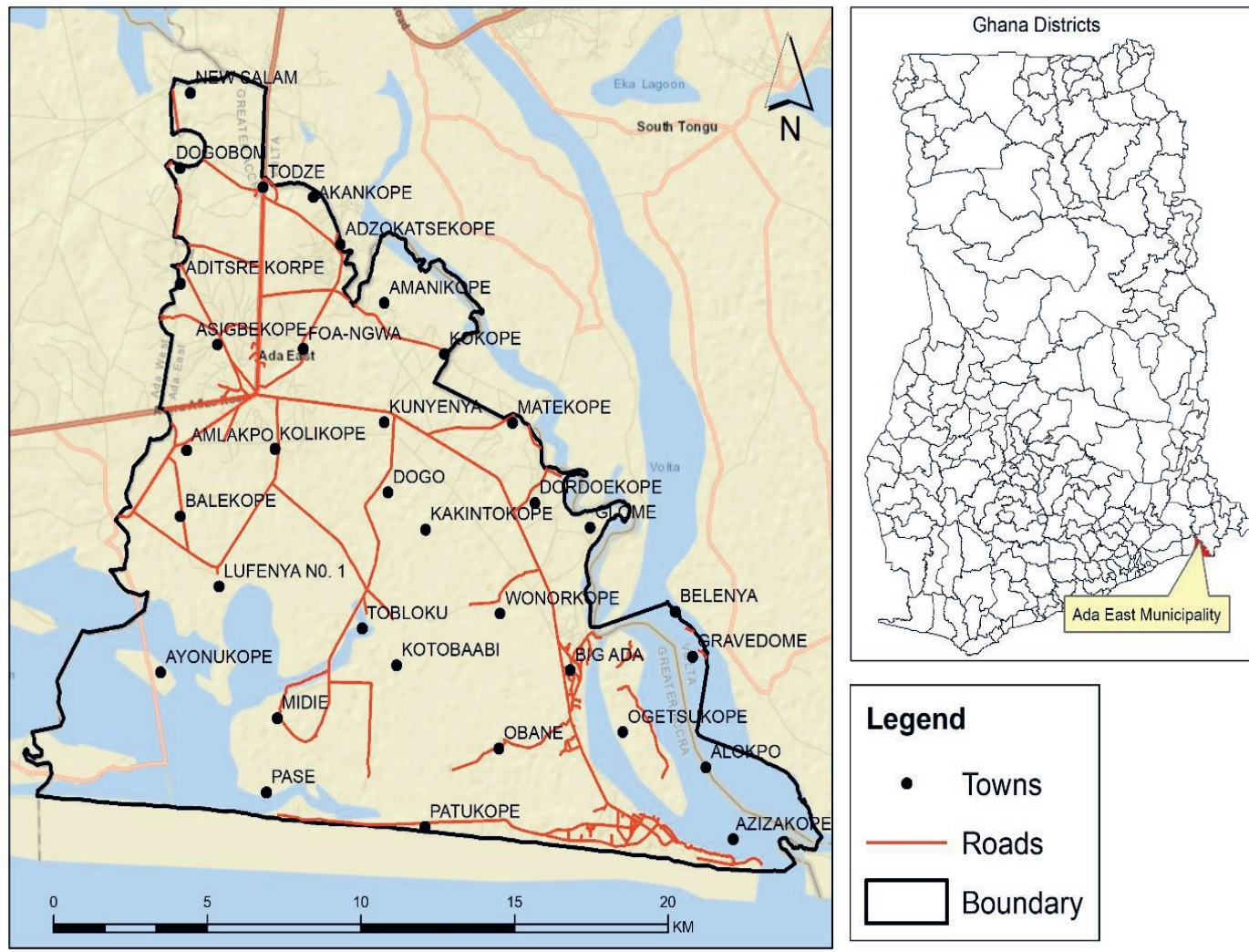

\section{Figure 4.1 Map of the study area in Ghana}

Source: Authors' construct, 2020

\subsubsection{Study design: qualitative case study approach}

Qualitative research provides a holistic understanding of rich, contextual, and generally unstructured non-numeric data (Mason, 2002). It involves the engagement of participants in conversations in a natural setting of a particular case (Creswell, 2014). In the process, theory building is undertaken from the data (Bryman, 2004). The application of a qualitative case study approach in this study is advantageous thanks to the ability to establish rapport with research participants and to obtain rich knowledge from the data that can be transferred to similar situations (Ponelis, 2015). Also, the choice of a case study is based on the need to use the research findings as the basis on which to recommend actions and inform policy towards the provision of climate and weather information for farming and other domains. Furthermore, a qualitative case study provides an opportunity to use a variety of research methods (Kumar, 2019). Hence, in this study, we combined semi-structured interviews and focus group discussion (FGDs) methods to crossvalidate research findings. 


\subsubsection{Data collection}

At most, three farmers were engaged through semi-structured interviews from various communities in the district. With the assistance of agricultural extension agents (AEAs) and some community leaders, farmers were selected based on their availability, gender, use of WIS for farming, age, experience in farming, social status, and farming practices. In the interviews, questions were posed on the types of WIS used, the extent of use, the ranking of the extent of use, and explanations as to why certain WIS were more used, among other emerging questions.

Subsequently, we conducted three FGDs with 8-10 male and female farmers in three communities: Toje, Korlekope, and Wassakuse. The FGDs were designed to elicit the interwoven factors that enhanced or obstructed WIS usability in the communities. These issues were expressed in multiple opinions, as farmers contributed to other participants' opinions and corrected or realigned some views together. For example, when a participant indicated that an information provider delivered regular information, the group discussed and agreed that regular could mean the daily or weekly provision of WIS. Researchers gave a fair chance to each participant by calling on individuals who were quiet to also share their opinion. This helped to moderate the discussion and ensured that overactive participants did not dominate the entire discussions.

\subsubsection{Data analyses}

Data analysis was carried out in three stages. The first stage involved transcription of audio recordings of the semi-structured interviews and FGDs. We edited the transcripts by identifying the responses generated to certain questions, realigned sentence structures, and clarified the construction of some sentences. During this time, in addition to the fieldnotes, notes were taken on emerging issues. The next aspect of this stage involved grouping the transcript contents into specific identifiable themes. Second, we conducted inductive coding to identify the factors that affect WIS usability based on recurring words running through the transcripts. The initial coding started with commonly running words such as: "they", "our information", "sometimes", "we get it from", "the time", "normally listen to ...", and so on. These recurring words were ascribed secondary themes (factors) and other sub-codes were linked to them. Third, we linked the secondary themes (factors) to the information design and delivery criteria in line with their definitions.

\subsection{Findings}

Findings from the empirical data are presented as follows. In section 4.4.1, we present findings on the types of WIS identified in the Ada East District and, in section 4.4.2, the extent of their use for farming. In section 4.4.3, we compare the factors that affect WIS usability with the analytical criteria.

\subsubsection{Types of WIS provided to farmers in the Ada East District}

We identified 10 different WIS used by farmers in the Ada East District. These were public TV, public radio, GMet online, E-agriculture platform, a private weather forecaster, Radio Ada, farmerto-farmer, agripreneurs, and online WIS (see Table 4.2). Of the different WIS identified, innovative ICT-based approaches like on-line, mobile phones, internet platforms, and community radio stations were valuable tools that were used for the delivery of information. The provision of the identified WIS involved actors from government agencies, businesses, and civil society organisations (CSOs), and sometimes they collaborated to produce ICT tools or agricultural content to target specific farmers (Sarku et al., 2021). 
Table 4.2 Types of weather information services in the Ada East District

\begin{tabular}{|c|c|}
\hline Types of WIS & Description of weather information services \\
\hline Public TV WIS & $\begin{array}{l}\text { This is a } 24-48 \text { hours weather forecast broadcast by the Ghana Television } \\
\text { Station (GTV) for the general public. }\end{array}$ \\
\hline Public radio WIS & $\begin{array}{l}\text { The public radio WIS is delivered through public radio channels such as } \\
\text { Obonu FM and Volta Star Radio. }\end{array}$ \\
\hline $\begin{array}{l}\text { Ghana } \\
\text { Meteorological } \\
\text { Agency (GMet) } \\
\text { online WIS }\end{array}$ & $\begin{array}{l}\text { This 24-hour weather forecast is displayed on GMet's website } \\
\text { (https://www.meteo.gov.gh/) and connected to it social media platforms. }\end{array}$ \\
\hline $\begin{array}{l}\text { Agricultural } \\
\text { extension agents' } \\
\text { (AEAs') WIS }\end{array}$ & $\begin{array}{l}\text { This information is provided through combinations from various sources } \\
\text { including farmers' local knowledge. }\end{array}$ \\
\hline $\begin{array}{l}\text { E-agriculture } \\
\text { platform WIS }\end{array}$ & $\begin{array}{l}\text { This is a daily weather forecast displayed on the E-agricultural website } \\
\text { (http://www.e-agriculture.gov.gh/) established by the Ministry of Food and } \\
\text { Agriculture. }\end{array}$ \\
\hline $\begin{array}{l}\text { Private weather } \\
\text { forecaster's WIS }\end{array}$ & $\begin{array}{l}\text { This WIS is produced and delivered by a retired weather forecaster to } \\
\text { farmers in the district. }\end{array}$ \\
\hline Radio Ada WIS & $\begin{array}{l}\text { This type of WIS is delivered by community radio and broadcast in the } \\
\text { Dangbe language for the Ada East District and its environs. }\end{array}$ \\
\hline $\begin{array}{l}\text { Farmer-to-farmer } \\
\text { WIS }\end{array}$ & $\begin{array}{l}\text { This comprises farmers' personal experience and observations of local } \\
\text { environmental indicators about the weather. }\end{array}$ \\
\hline Agripreneurs WIS & $\begin{array}{l}\text { This is a daily weather forecast delivered by business organisations such as } \\
\text { Esoko, Ignitia, farmerline, mfarms on various ICT platforms. }\end{array}$ \\
\hline Online WIS & $\begin{array}{l}\text { This is a daily weather forecast provided on smartphones as weather apps by } \\
\text { organisations like AccuWeather. }\end{array}$ \\
\hline
\end{tabular}

Source: Authors' construction based on field interviews

4.4.2 The extent of use of the different WIS by farmers in the Ada East District

Having identified the types of WIS used by farmers, we probed further to identify the extent to which they were used. The general response indicated that farmers combined various WIS. On average, farmers used two types of WIS, and some responses even indicated that sometimes they used three to five types of WIS. We show the extent of use in Table 4.3.

The farmer-to-farmer WIS was the most used (100\%) information because of the local creation of the information by farmers based on their experience, observations, and creation of rainfall charts. They used this type of WIS before they decided on any other type of WIS. The private weather forecaster's WIS came second ( $78 \%)$.

Other types of WIS were also popular in the farming community but were 'moderately used' by farmers for various reasons. These were Radio Ada WIS (69\%), public TV WIS (56\%), and AEAs' WIS (41\%).

WIS that were rarely used included: public radio WIS (25\%), agripreneurs' WIS $(16 \%)$, online WIS (16\%), GMet online (9\%), and E-agricultural WIS (3\%). Farmers who used any of these WIS 
specified that the frequency of use was either once a month or only at the onset of the farming season.

Table 4.3 The extent of farmers' use of the different types of weather information services

\begin{tabular}{|c|c|c|}
\hline Type of WIS & $\begin{array}{l}\text { Extent of WIS } \\
\text { use by farmers }\end{array}$ & Description \\
\hline $\begin{array}{l}\text { Farmer-to-farmer } \\
\text { WIS }\end{array}$ & $100 \%(n=32)$ & Used by all farmers but has some barriers \\
\hline $\begin{array}{l}\text { Private weather } \\
\text { forecaster's WIS }\end{array}$ & $78 \%(n=25)$ & $\begin{array}{l}\text { Mostly used by farmers but lacks direct delivery to all } \\
\text { farmers }\end{array}$ \\
\hline Radio Ada WIS & $69 \%(n=22)$ & $\begin{array}{l}\text { Information source is well known among all farmers in } \\
\text { the district, but it is provided irregularly }\end{array}$ \\
\hline Public TV & $56 \%(n=18)$ & Known to many famers but has many constraints \\
\hline $\begin{array}{l}\text { Agricultural } \\
\text { extension agents' } \\
\text { WIS }\end{array}$ & $41 \%(n=13)$ & $\begin{array}{l}\text { Information source known to all farmers but rarely } \\
\text { reaches a larger farmer audience directly }\end{array}$ \\
\hline Public radio WIS & $25 \%(n=8)$ & Rarely used due to irregular delivery \\
\hline Agripreneurs' WIS & $16 \%(n=5)$ & Some use, with a number of barriers \\
\hline Online WIS & $16 \%(\mathrm{n}=5)$ & $\begin{array}{l}\text { Used mainly by young farmers who have access to } \\
\text { smartphones }\end{array}$ \\
\hline GMet online WIS & $9 \%(n=3)$ & Limited use because it is delivered through a website \\
\hline E-agricultural WIS & $3 \%(n=1)$ & $\begin{array}{l}\text { Little knowledge in the farming communities about its } \\
\text { existence }\end{array}$ \\
\hline
\end{tabular}

Source: Authors' construction based on field interviews

4.4.3. Assessment of the WIS in light of the factors affecting usability and information design and delivery criteria

We found different factors that affect WIS usability as indicated in section 4.1. These factors are aligned to the five usability criteria: local embeddedness, legitimacy, spatial and temporal resolution, predictive skill, and accessibility based on farmers' perceptions of how information providers are closing the usability gap (Table 4.4). Table 4.5 presents the comparison between WIS, information design and delivery criteria, and the factors affecting information.

Table 4.4 Farmers' views concerning factors affecting WIS usability for farming in the Ada East District

\begin{tabular}{llll}
\hline $\begin{array}{l}\text { Usability } \\
\text { criteria }\end{array}$ & Factors contributing to WIS usability & Description \\
\hline $\begin{array}{l}\text { Local } \\
\text { embeddedness }\end{array}$ & $\bullet \quad$ Origin of information & $\begin{array}{l}\text { Local presence/traceability of WIS source in the } \\
\text { farming community }\end{array}$ \\
\cline { 2 - 5 } & $\bullet \quad$ High level of interaction & Having contact with farmers \\
\cline { 2 - 5 } & Relevance for decision-making & $\begin{array}{l}\text { Information that provides relevant } \\
\text { agrometeorological indicators, e.g., onset date, length } \\
\text { of the season, dry spell occurrence, and other } \\
\text { information on agronomic practices, market } \\
\text { availability, input, etc. }\end{array}$ \\
\hline
\end{tabular}




\section{Chapter 4}

\begin{tabular}{|c|c|c|}
\hline \multirow[t]{3}{*}{ Legitimacy } & $\begin{array}{l}\text { - Farmers' involvement in } \\
\text { information creation }\end{array}$ & $\begin{array}{l}\text { Involvement of farmers in the creation of information } \\
\text { and incorporation of their feedback }\end{array}$ \\
\hline & - Respect for local values & $\begin{array}{l}\text { Has local content and reflects farmers' practices, } \\
\text { values, and beliefs }\end{array}$ \\
\hline & $\begin{array}{l}\text { - Continuity in the provision of } \\
\text { information }\end{array}$ & $\begin{array}{l}\text { Continuous delivery of information without } \\
\text { interruptions }\end{array}$ \\
\hline \multirow{3}{*}{$\begin{array}{l}\text { Spatial and } \\
\text { temporal } \\
\text { resolution }\end{array}$} & $\begin{array}{l}\text { - Timing/schedule delivery of } \\
\text { WIS }\end{array}$ & $\begin{array}{l}\text { Timely delivery of information that clearly specifies } \\
\text { when the weather condition should be expected }\end{array}$ \\
\hline & - Location-specific forecast & Provision of information for specific communities \\
\hline & $\begin{array}{l}\text { - Level of detail in the } \\
\text { explanation of the forecast }\end{array}$ & $\begin{array}{l}\text { Provides detailed explanation on all aspects of the } \\
\text { weather forecast }\end{array}$ \\
\hline \multirow[t]{3}{*}{$\begin{array}{l}\text { Predictive } \\
\text { skill }\end{array}$} & $\begin{array}{l}\text { - Communication } \\
\text { uncertainties }\end{array}$ & $\begin{array}{l}\text { Clear presentation of probability that farmers can } \\
\text { understand }\end{array}$ \\
\hline & - Reliability and accuracy & $\begin{array}{l}\text { Farmers' ability to have confidence that the weather } \\
\text { forecast corresponds to local knowledge and forecast }\end{array}$ \\
\hline & - Evidence-based information & $\begin{array}{l}\text { Information associated with field demonstrations on } \\
\text { how to apply it in farming }\end{array}$ \\
\hline \multirow[t]{7}{*}{ Accessibility } & $\begin{array}{l}\text { - Access of information to } \\
\text { diverse audience }\end{array}$ & $\begin{array}{l}\text { Available to different groups of farmers including } \\
\text { women, older persons, etc. }\end{array}$ \\
\hline & - Absence of language barriers & Provision of information in the local language \\
\hline & $\begin{array}{ll}\text { - Format and content of } \\
\text { information }\end{array}$ & $\begin{array}{l}\text { Simple presentation but rich in content and devoid of } \\
\text { information overload }\end{array}$ \\
\hline & $\begin{array}{l}\text { - Graphic presentation, symbols, } \\
\text { and terminologies }\end{array}$ & $\begin{array}{l}\text { Uses images, text, and words as symbols that enhance } \\
\text { understanding }\end{array}$ \\
\hline & - Multiple media delivery & $\begin{array}{l}\text { Uses a combination of ICTs for the delivery of } \\
\text { information }\end{array}$ \\
\hline & - Two-way information delivery & $\begin{array}{l}\text { Uses a delivery mode that permits two-way } \\
\text { communication }\end{array}$ \\
\hline & $\begin{array}{l}\text { - Accessible level and mode of } \\
\text { payment }\end{array}$ & Preference for prepaid or free access information \\
\hline
\end{tabular}

Source: Authors' construct based on field interviews

\subsubsection{Local embeddedness}

\section{Origin of the information}

Origin of WIS concerns the local presence/traceability of the WIS source in the farming community. This factor affected usable WIS, as farmers preferred to know the source of the information and how it was produced. Concerning this factor, farmers were suspicious of a forecast and distrusted it when they did not have any knowledge about its source (the information provider). This factor indicates that WIS usability was related to the information provider rather than to the information itself. It relates to the AEAs, the private weather forecaster, Radio Ada, and the farmerto-farmer WIS. Farmers explained that they were able to trace the sources of the aforementioned WIS in the study district. For example, a farmer stated that: "some information providers are here with us 24/7 and we can hold them accountable if they report any 'wrong' weather forecast".

\section{High level of interaction}

A high level of interaction refers to information providers' ability to have contact and communication with farmers. It is considered to affect WIS usability because explanations and discussions concerning the delivery of forecasts are perceived to be necessary before their uptake. With AEAs' WIS, farmers usually held in-depth discussions with the AEAs concerning a weather 
forecast and other agricultural issues on a one-to-one basis through home and farm visits or mobile phone calls. The private weather forecaster's WIS was also described as highly interactive because he took time to explain the forecast. The farmer-to-farmer WIS was also interactive because farmers discussed their observations about the weather during formal or informal gatherings. Women and young male farmers also consulted lead farmers to discuss their observations or inquire about the weather. The level of interaction was described as high because the weather was discussed at length based on questions such as: "What will the rainfall conditions be for the season or coming days?", "Is the current wind pattern or sky bearing rainfall clouds?", "Based on what we are seeing now, what will the length and intensity of rainfall be this season?", and so on. The Radio Ada WIS was also mentioned by a section of farmers as interactive because, at the beginning of the farming season, lead farmers, AEAs, and a host discussed pertinent questions about the seasonal forecast and farmers' observation. Afterwards, farmers were allowed to phone in and ask questions or contribute their ideas.

\section{Relevance for decision-making}

Relevance for decision-making relates to information that provides relevant agrometeorological indicators, e.g., onset date, length of the season, dry spell occurrence, and other information on agronomic practices, market availability, input, and so forth. These agrometeorological indicators are used for decision-making on when to plough, sow, apply agrochemicals, and harvest. Concerning this factor, WIS usability is also dependent on the provision of specific weather parameters like rainfall as well as bundled agricultural information (e.g., agronomic practices, market prices). Although all the identified WIS provided information on whether or not farmers should expect rainfall, the content of the private weather forecaster and the farmer-to-farmer WIS had some additional agrometeorological indicators, such as onset date, length of the season, and rainfall amount, which were relevant for farming. Bundled agricultural information such as agronomic advice in addition to the weather was also provided by agripreneurs, AEAs, and Radio Ada WIS. These relevant WIS helped to educate farmers on the variety of crops to select, soil moisture conservation strategies, the planting of cover crops, the time to start sowing, agrochemical application, and post-harvest loss management.

\subsubsection{Legitimacy}

\section{Farmers' involvement in information creation}

This factor refers to the involvement of farmers in the creation of information and the incorporation of their feedback. Farmers' involvement in information creation was a relevant factor associated with usable WIS. Farmers showed enthusiasm about being involved in information production and delivery. Hence, if information providers came to the farming communities only to assess their information needs, farmers did not become involved in information creation. This factor also involves the use of farmers' feedback to address actual needs. Among all the WIS identified, farmers mentioned that the AEAs, the private weather forecaster, and the Radio Ada WIS elicited their feedback or opinions.

\section{Respect for local values}

This factor implies that the WIS has local content and reflects farmers' practices, values, and beliefs. This factor is relevant for WIS usability in the context of farming in the Ada East District because it is an area noted for the production of food crops, vegetables, and some fruits for the urban market. The growing demand for some specific food crops in the urban market impedes changes in the cultivation of certain crops in response to a seasonal forecast. Therefore, farmers 


\section{Chapter 4}

expected information providers to understand their values, beliefs, socio-economic characteristics, and practices to tailor the information to their context. For example, they required WIS that would guide them in the selection of a variety of tomato suitable for a forecast rather than indicate a complete change in crop production. Also, they were of the view that, regardless of a weather forecast, its ultimate occurrence lay beyond human control. In this instance, WIS should not be provided to tell farmers to change their crops completely. This factor was met by Radio Ada, AEAs, and farmer-to-farmer WIS. The Radio Ada WIS was described as follows: "The programmes are from us, and presenters have knowledge about who we are and the programme is rooted in the culture of the people". AEAs' WIS was also mentioned as respecting farmers' local values because it took cognisance of their traditional crops and provided advice on how farmers could select varieties suited to a seasonal forecast rather than providing suggestions on complete changes in their cropping patterns. Discussions about AEAs' WIS usually started immediately after the celebration of Christmas (January) to enhance preparations for the farming season. A statement indicates: "Farmers have their values and ways of doing things, and so, they [referring to information providers] should not just provide the information to us as if we don't have any knowledge."

\section{Continuity in information provision}

Continuity in information provision refers to the continuous delivery of information without interruptions. Farmers attached relevance and trust to WIS delivered throughout the year and that also provided outlooks on changes that might occur. Farmers mentioned that the Radio Ada WIS was mostly provided at the onset of the farming season and then provided intermittently later in farming seasons (April-July or September-November). They expected information on outlook on intra-seasonal changes; but this rarely occurred, albeit that the WIS of the public TV, the private weather forecaster, GMet online, E-agricultural, agripreneurs, and farmer-to-farmer were continuously delivered daily. Continuity in information provision was a relevant factor because it influenced reliability and trust in a specific WIS. In this case, although the public radio, AEAs', and the Radio Ada WIS were useful, farmers found it difficult to rely on such information.

\subsubsection{Spatial and temporal resolution}

\section{Timing/schedule delivery of WIS}

The timing/schedule delivery of WIS is relevant for farming in the district, as some farmers showed interest in seasonal rainfall onset date and 1-14-day forecasts to determine when to apply fertiliser and agrochemicals, clear weeds, and harvest their farm produce. Another important temporal factor that affected WIS usability was the schedules attached to the delivery of the information (e.g., 7:00 pm daily). This was not appreciated by farmers, as they indicated that WIS should be provided with an outlook on changes in weather conditions whenever necessary. Agripreneurs' WIS was noted for providing daily information where the expected forecast was stated with terms such as "expect rainfall in the morning, afternoon, or evening". Another temporal aspect that affected WIS usability was the provision of scheduled information, which is the strict delivery of information at specified times. For instance, agripreneurs' WIS was provided at 8:00 am each day, whereas the public TV WIS was broadcast only during the evening news programme (7:00 $\mathrm{pm})$. The challenge with the scheduled delivery of these WIS was that certain farming decisions would have already been carried out before the information was delivered. 


\section{Location specificity of the forecast}

The provision of information for specific locations in the district also affects the usability of the information. According to farmers, a weather forecast ought to indicate the specific community where weather events are expected to occur, but this rarely happens. Agripreneurs' WIS was sometimes attuned to some specific locations in the district. Farmer-to-farmer WIS was also location specific because the indicators used for predicting the weather were in their communities. Public TV WIS covered the entire country and was delineated into three belts - the northern, middle, and coastal zones. Farmers were of the view that such delineations were too broad for them to know whether or not their district was part of the forecasts. They preferred information that made specific reference to their communities, and this need was sometimes met by the private weather forecaster's WIS.

\section{Level of detail in the explanation of the forecast}

The level of detail attached to the weather forecasts also influences their understandability and subsequent usability. With these criteria, farmers were referring to the need to provide detailed explanations of all aspects of the weather forecast rather than just stating a piece of information. The private weather forecaster's WIS provided a high level of detail by indicating the expected weather conditions, location, length of the expected conditions, and time. The farmer-to-farmer and AEAs' WIS were created around existing social structures, where face-to-face interactions took place and the information was in-depth. In this case, experiential knowledge, observed conditions, predictions, selection of crops, and other farm-related issues were discussed together. "Sometimes, when the rains are not coming, we hold meetings and then we discuss the changes we are observing. Sometimes, we advise each other on what to do....”. In contrast, other WIS provided little detail in their presentation or text. The public TV WIS was mentioned as a typical example where the presentation lasted for only 2-3 minutes. Agripreneurs' WIS was also automatically delivered via SMS with few texts, whereas the Radio Ada WIS allotted a limited time (15-20 minutes) for listeners and panel discussions.

\subsubsection{Predictive skill}

\section{Communication of uncertainties}

WIS are associated with uncertainty because of changes in atmospheric conditions and inadequacies in scientific models used for downscaling weather data to specific scales. Although this is expected, the communication of uncertainties in the WIS is relevant to enabled comprehension by farmers. Some farmers trusted and used certain WIS based on how they expressed probabilities related to local ways of thinking about uncertainties. Uncertainties were communicated differently in each WIS. In the case of public TV WIS, terms such as "likely" and "unlikely" were used, whereas agripreneurs' WIS specified uncertainty as: "It is likely to rain tomorrow", "it is not likely to rain today", "it will rain tomorrow". According to farmers, the use of these modifiers was not enough to adequately indicate the level of uncertainty in the forecast. The private weather forecaster's WIS was highlighted as providing an understanding of how farmers conceptualised probability. "In his information, he states the percentage and adds that, if God permits, we shall experience this condition. This tells that he is not God and the forecast can change anytime". The farmer-to-farmer WIS also identified probability based on observations about different indicators with cautions. These two types of WIS were identified as conceptualising uncertainties to match farmers' traditional way of thinking about the future, with cautions attached about the extent to which the information was reliable, because they attributed the final occurrence of an expected weather condition to the control of the supernatural (God). 


\section{Reliability and level of WIS accuracy}

Farmers' definition of a reliable weather forecast is when a scientific forecast matches their observation and local indicators. When a forecast is provided and it indicates similar predictions to farmers' local indicators and experience, it is considered to be highly reliable and accurate. Most farmers indicated that the farmer-to-farmer WIS was reliable and accurate compared to other WIS, to the extent that some ascribed $80 \%$ reliability and accuracy to it. However, none ascribed $100 \%$ reliability to the farmer-to-farmer WIS because "sometimes it fails". This is why they compared that forecast with other WIS. A farmer quote indicates: "we hear from the television and others, and then we compare it with our own". With regard to other WIS, farmers complained that "there are many times that I've listened to their weather [referring to other WIS], and nothing happened. Next time they tell me something, I will not believe". WIS reliability was also affected by the long information delivery chain to farmers, as reported by one farmer: "the information moves from one person to another and, before it reaches you, it can become like hearsay, or sometimes there is a divergence in what people are saying about the forecast.

\section{Evidence-based WIS with agricultural content for decision-making}

The provision of evidence-based WIS was a factor that affected usability, because farmers expected the information to be associated with field demonstrations on how to apply it. For example, they mentioned that, when a seasonal forecast indicated an intra-seasonal dry spell and it was associated with practical activities on soil moisture conservation, they usually adopted it. The provision of evidence-based WIS with agricultural content for decision-making was mostly delivered by AEAs' WIS. This type of WIS is associated with workshops, community meetings, and field demonstrations. Some evidence is attached to it in response to a forecast like a dry spell or heavy rainfall by carrying out demonstrations on the application of agrochemicals, water storage, and farm management practices. This type of WIS was usually provided through lead farmers who were willing to take the risk to apply the information and, if it worked, other farmers might decide to accept the information. In this instance, lead farmers served as intermediaries between AEAs' WIS and the rest of the farming community.

\subsubsection{Accessibility}

\section{Information access for a diverse audience}

The delivery of WIS should be accessible for all categories of people including youth, adults, men, women, persons with disabilities, children, literate and illiterate farmers. Young educated farmers were able to access any type of WIS because they could read and use most technologies. Farmers explained that only a few of them received AEAs' WIS directly through a home visit, mobile phone calls, workshops, and field demonstrations. Often, the invitation on AEAs' WIS to farmers to attend workshops and field demonstrations was limited to one member per household or to a lead farmer on the assumption that he would share the information; however, sometimes this was not the situation. With such selection criteria, women, young farmers, and other groups of farmers were prevented from accessing relevant WIS. A change in extension agents in some communities resulted in farmers having little idea about the existence of AEAs' WIS because it takes time for communal bonding with a new agent. The private weather forecaster's WIS was accessible directly to only a few farmers because the provider was unable to respond to their calls at all times. In the case of agripreneurs' WIS, farmers had to subscribe to a short code to receive the information, and this required training or some level of literacy; thus, it was used by few farmers. Lack of 'free time' because of engagement in various socio-economic activities affected women's access to WIS, especially when it pertained to scheduled information delivery on the radio or TV. Further, the 
accessibility of WIS for diverse groups of farmers was also dependent on the availability of a radio, mobile phones, television, internet, and electricity.

\section{Absence of a language barrier}

The absence of language barriers also enhanced the usability of certain WIS. According to farmers, most WIS were provided in English rather than in the Dangbe language, which is spoken in the Ada East District. Hence, some farmers, especially illiterate ones, were limited to the use of certain WIS like the farmer-to-farmer WIS. Of the 10 types of WIS found in the district, only half - the AEA, farmer-to-farmer, Radio Ada, private weather forecaster, and the public radio WIS were delivered in the local language. Public TV, GMet online, E-agricultural, agripreneurs', and online WIS were delivered in English, and this was a barrier for some farmers, as they were unable to understand the information. Some farmers had to depend on family members to translate the information, and this sometimes resulted in misinterpretations of facts.

\section{Format and content of information}

The format and content of information also enhanced the usability of information because, when WIS was presented at length, farmers were no longer able to remember all the information. The provision of WIS on the occurrence of rainfall was best recalled, whereas other aspects such as the level of uncertainty, location, and other expected conditions were rarely remembered. This was attributed to the presentation of the format and the content of the information. Farmers were of the view that a simple presentation but rich in content and devoid of information overload was appealing. The Radio Ada WIS was sometimes communicated in drama and it was deemed relevant for farming because farmers were able to comprehend the message. Agripreneurs' and online WIS were presented in formats such as: "rain likely, tomorrow, rain likely", "seasonal forecast", "above normal", "near normal".

\section{Graphic presentation, symbols, and terminologies}

The presentation of WIS with images, text, audios, symbols, and appropriate presentation of terminologies also affected the usability of WIS for farming, as these tended to enhance the understandability of information. The public TV WIS was presented with maps and symbols indicating sunlight, rainfall, cloudy conditions, thunderstorms, and so on. Although some farmers reported that they did not understand the meaning of all the symbols, it was still meaningful to them, especially when they observed the symbol for rainfall or sunlight. The terminologies used in WIS presentations were concepts that required some explanations even if the information was provided in the English language to make translation easy. Some WIS was packaged mostly as numbers and text. For example, agripreneurs' WIS was delivered in English, and the structure of the text message to symbolise the information was the same at all times to aid farmers' understanding.

\section{Multiple media for information delivery}

The use of multiple media, including voice-based, call centre facilities, mobile phones, radio, and text for the delivery of WIS, was considered to enhance or obstruct the usability of WIS. With this particular factor, we found that about $80 \%$ of farmers either owned mobile phones or had at least one household member who owned a phone through which they could access the information. Only $5 \%$ of the respondents had access to smartphones with an internet facility. Thus, many farmers were unable to access online WIS. Farmers had a clear preference for information received through voice mode: face-to-face interaction, telephone calls, or interactive voice response. Hence, AEAs, 


\section{Chapter 4}

the private weather forecaster, Radio Ada, and agripreneurs' WIS, which were provided through voice-based media, were suitable for farmers. WIS such as public TV, public radio, E-agricultural, GMet online, and online WIS were delivered through a single medium. Even so, some farmers emphasised the importance of the public radio and the Radio Ada WIS, as the radio could be operated with a battery, had wide coverage, was portable, and is also a component of mobile phones. The public TV was also appreciated by most farmers; however, the unavailability of electricity and frequent power outages affected accessibility to information. The use of interactive voice response and call centre facilities attached to agripreneurs' WIS was not promoted in the district.

\section{Two-way information delivery}

Two-way information delivery was mentioned by farmers as a factor that affected WIS usability for farming. The delivery of two-way information was considered important because it enabled farmers to verify their observations and discuss differences in the forecasts with information providers. The farmer-to-farmer, the private weather forecaster, and AEAs' WIS provided twoway information delivery through mobile phone and face-to-face interactions. This two-way WIS mode allowed farmers to ask questions and receive feedback.

\section{Accessible level and mode of payment}

Accessible level and mode of payment indicate farmers' preference for prepaid or free access WIS. In some instances, payment for WIS deterred some farmers from sourcing certain WIS. Except for public TV, public radio, Radio Ada, AEAs, and farmer-to-farmer WIS, which provided free information, other types of WIS involved some payment. The agripreneurs' WIS involved a deduction of 0.80 Ghana Pesewas (\$0.16) a day for an SMS. Although minimal, the payment discouraged some farmers from using such WIS. A farmer described his attitude towards payment of WIS as: "Last week, a group came, and they took our details so that they would give us the information. But actually, I didn't redeem it. I deleted their text because I am afraid that they will be taking my credit. I don 't want to pay." Farmers who used the online WIS had to purchase internet data/airtime, and this deterred them from frequently sourcing such information. Although the private weather forecaster WIS was free, it also required that farmers possess mobile phones with enough airtime. Farmers who were willing to pay for WIS mentioned conditions such as detailed, reliable, accurate, and evidence-based information for farming. 


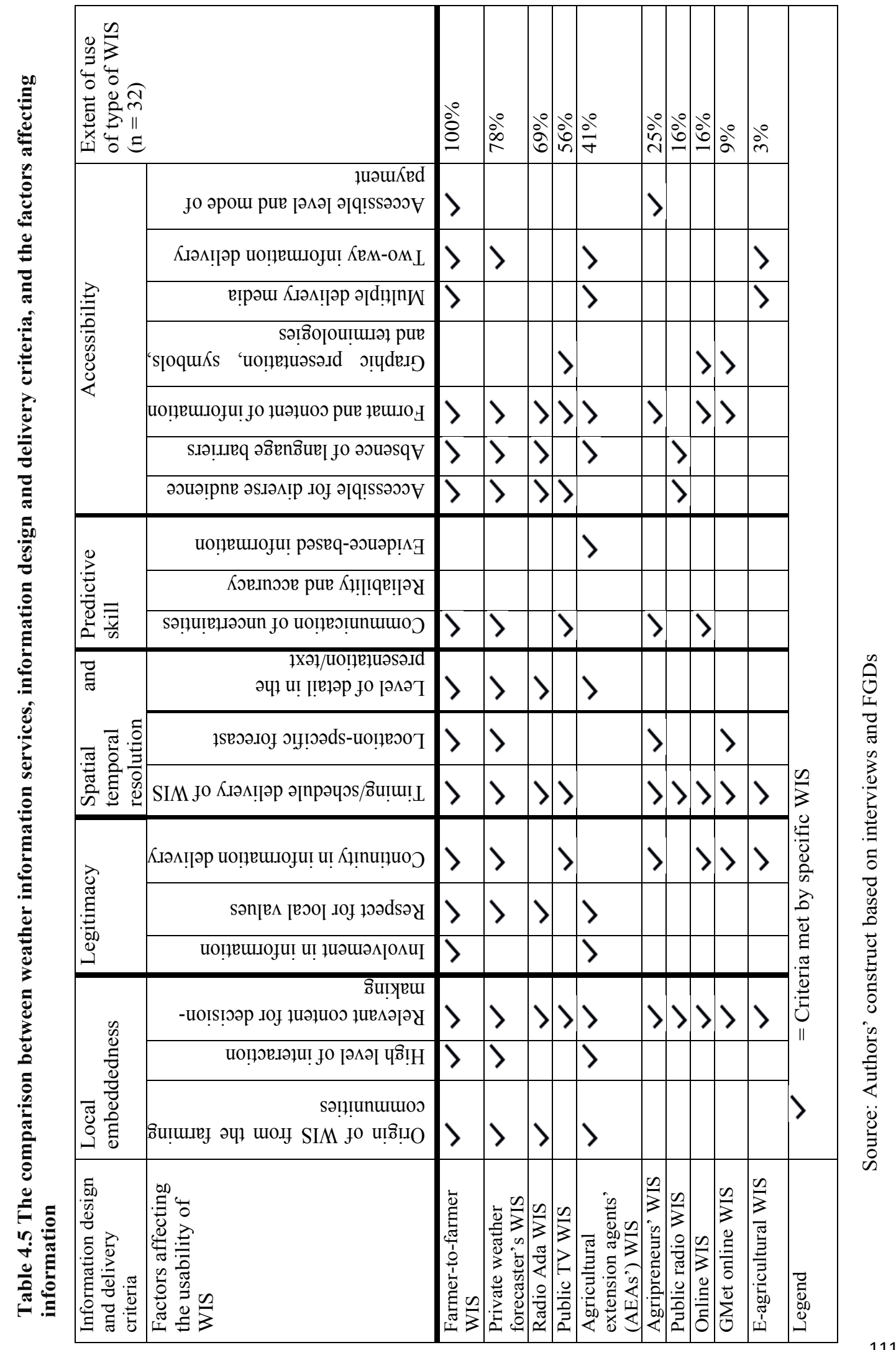




\section{Chapter 4}

\subsection{Discussion}

In this study, we identified 10 types of WIS for farming in the Ada East District, Ghana. On average, a farmer used at least two types of WIS. The farmer-to-farmer WIS was often used (see Table 4.1) in addition to other types of WIS, indicating a local way of integrating weather forecasts. This finding was also identified by some other studies, which mentioned that, despite the provision of scientific weather/climate information services through the radio, SMS, TV, agrometeorological bulletins, and so forth, farmers complemented this information with their local environmental observations (see for instance Slavova \& Karanasios, 2018; Nyamekye et al., 2019; Naab et al., 2019; Spear et al., 2019; Sarku et al., 2021). The main reason why farmers combined different WIS was the need for reliable and accurate forecasts, which seemed to be absent in a single WIS. Patt and Gwata (2002) and Nyadzi (2020) also observed that farmers' use of seasonal climate forecasts increased when they were combined and compared with local knowledge. The essence of this finding from the study conducted in the Ada East District is that there is an opportunity to coproduce WIS by integrating farmers' local knowledge with scientific forecasts to enhance their usability for farming. This idea is increasingly discussed theoretically in the climate information service literature. To achieve this aim, it is necessary to involve existing preferred WIS sources such as farmers, the private weather forecaster, AEAs, and Radio Ada, from the study district.

Furthermore, we identified new factors that affected WIS usability. These include the origin of information; continuity of information provision; schedule delivery of WIS; evidence-based information; format and content of information; graphic presentation, symbols, and terminologies; and accessible level and mode of payment. These new factors may be attributed to several issues, including climate change and increasing variability in weather conditions, exposure to different WIS and new ICTs, changes in farming practices, and intensive cultivation of crops in the study district, that may be playing multiple roles in triggering farmers to prefer certain factors to be inherent in WIS information design and delivery. We also identified other existing factors that affected WIS usability, including location-specific, reliable, and accurate forecasts; communication of uncertainties; language barriers; and two-way information delivery. These factors have also been identified in earlier studies in Ghana and other developing countries (see also Patt \& Gwata, 2002; Patt et al., 2005; Stone \& Meinke, 2006; Meinke et al., 2006; Nyadzi et al., 2018; Naab et al., 2019; Nyamekye et al., 2019). The findings on old and emerging factors indicate the need for information providers to make extra efforts to design and deliver WIS to decrease or even eliminate the WIS usability gap for farming.

In our study, we observed trade-offs from two perspectives that affected WIS usability for farming. The first refers to the information design and delivery criteria, where we observed trade-offs between predictive skill and spatial resolution. This is because, if they attain location-specific forecasts (high resolution), weather models tend to lose accuracy, and vice versa. Second, tradeoffs exist between pairs of factors that affect WIS usability for farming. We found a trade-off between a high level of interaction and accessibility for all audiences; as a result, only the farmerto-farmer and the private weather forecaster's WIS were not affected by these factors. The factor on WIS timing/schedule delivery did not complement evidence-based information. We also observed a trade-off between evidence-based WIS and accessibility for all audiences, because it was impossible to include every farmer in the district in practical WIS workshops. For online WIS sources, trade-offs existed between the format and content of information and the level of detail in the information. If WIS is detailed, the format and content that promote understandability will likely be lost. Also, there was no balance between factors such as access for all audiences and two- 
way information delivery. This is because if a specific WIS, for example the Radio Ada WIS, reaches out to a large audience, it is incapable of generating equal feedback from all its listeners. Trade-offs have been identified also in the literature (see Tall et al., 2018; Hansen et al., 2019), and they are inevitable in the provision of weather/climate information services. We recommend that information providers should engage farmers through workshops or training programmes to explain how trade-offs are associated with WIS. For example, issues on the provision of locationspecific and accurate forecasts need to be discussed with farmers to moderate their expectations. Alternatively, information providers can strategise with farmers on how to deal with certain tradeoffs. Additionally, information providers that find it difficult to generate feedback from farmers based on their mode of WIS delivery may consider using a selection strategy that enables different categories of farmers to be selected across the district to give their opinion about the WIS continually.

Furthermore, we found that the origin of WIS played an important role in WIS usability in the study district. The origin of WIS as defined by farmers was not about the physical space per se; rather, it was more about information providers and how they can establish personal bonds with farmers. This gave farmers some sense of security in the reception of WIS because they knew who to contact if the information 'failed'. In this instance, we observed preferential choices in WIS usability. If WIS comes from the farmer/farming community, the private weather forecaster, AEAs, and Radio Ada, it can be trusted and applied. Based on this finding, it can be inferred that, in the study district, if an information provider can position him/herself as a trusted person, this enhances WIS usability. This can be a positive characteristic, but it can equally pose a challenge when the provision of WIS is associated with an individual. This is because associating WIS usability with an individual bears the risk of creating dependencies that can destabilise the delivery of information in that person's absence. The private weather forecaster's WIS may not be sustainable in the long run, because the absence of the provider will bring an end to the delivery of this information. Similarly, the sustainability of AEAs' WIS could be affected by a change in extension staff. Farmer-to-farmer WIS may gradually disappear when experienced farmers are no longer present, given that their information is rarely documented but rather exists as tacit knowledge. We propose that the ideal is that information providers build farmers' trust towards a WIS rather than focusing on building personal bonds.

\subsection{Conclusion}

Our study examined farmers' perceptions about the usability of various types of WIS for farming, with a focus on the Ada East District in the Greater Accra Region, Ghana. From the literature, we developed five information design and delivery criteria - local embeddedness, legitimacy, spatial and temporal resolution, predictive skill, and accessibility - to attain the objective of the study. Using a combination of qualitative research methods such as semi-structured interviews and FGDs, our study identified that smallholder farmers had access to 10 different WIS. However, the extent to which each WIS was used varied, given that the farmer-to-farmer and the private weather forecaster's information were more used than the other services. The usability of the identified WIS for farming was affected by factors such as the origin of the information, the level of interaction, and relevant content, among others.

The analytical criteria applied in this study are novel because they aided in identifying factors that shaped WIS usability based on farmers' perspectives on how information providers were closing the usability gap. It also helped to show the trade-offs between the criteria and the factors. This 


\section{Chapter 4}

approach is novel, as we were able to illustrate the type of WIS that met a specific factor and information design and delivery criteria. This may serve as the basis to improve WIS usability for farming and other domains. There is a tendency for information providers to pay critical attention to the factors that obstruct the usability of WIS, but we recommend that they should find a balance between every factor that affects WIS usability.

We conclude by suggesting that information providers should establish sub-offices or employ field agents who have knowledge on agronomic principles and the communication of forecasts to support AEAs to respond promptly to farmers' information needs through monthly meetings or informal daily conversations. This may serve as a means to foster trust, legitimacy, reliability, and continuity in the provision of WIS. It could also enable WIS to reach larger audiences like women, older people, persons with disabilities, and illiterate people.

Further our findings suggest the need for information providers to use new ICTs in innovative ways to bridge the usability gap. This may include the application of ICT tools such as Facebook, WhatsApp audio recordings, call centre facilities, and interactive voice responses to facilitate interactions and the sharing of experience. Additionally, information providers may apply some of the abovementioned ICT tools to derive farmer-to-farmer WIS, which provides local environmental indicators, to support the delivery of reliable, accurate, and location-specific WIS. Also, new ICTs should not be applied merely in the delivery of WIS as a trending tool, as this may deepen the information divide among farmers. Instead, information providers should select ICTs that suit the needs of specific farmers, or they may apply new ICTs innovatively to serve the needs of farmers who rarely receive WIS because of their gender, human disabilities, socio-political influences, and institutions.

The policy on climate information services in Ghana should prioritise mainstreaming agro-WIS in its various components. This recommendation is made as a result of the finding on daily forecasts with limited provisions of evidence-based forecasts that contain relevant agrometeorological indices to support farmers' decision-making. Given that the policy on climate information services in Ghana is being formulated, it would be ideal to include some of the pertinent findings derived from this study. Also, drawing from the findings of the study, it seems that an increasing number of information providers are providing WIS, but there is no evidence of collaboration among them. Thus, it appears that, although a particular information provider was meeting a specific factor that could be assumed to be innovative, others were not applying such strategies. We recommend that the new government policy should institutionalise formal collaboration between information providers and different knowledge systems, and encourage the use of ICTs to ensure that different categories of farmers have access to WIS to support food production in Ghana. 
Assessing the usability of weather information services 


$$
5
$$




\section{Chapter 5}

\section{Coproducing Weather Forecast Information with and for Smallholder Farmers in Ghana: Evaluation and Design Principles}




\title{
Chapter 5
}

\begin{abstract}
Many West African farmers are struggling to cope with changing weather and climatic conditions. This situation limits farmers' ability to make optimal decisions for food and income security. Developing more useful and accessible weather and climate information services (WCIS) can help small-scale farmers improve their adaptive capacity. The literature suggests that such WCIS can be achieved if forecast information is produced jointly by farmers and scientists. To test this hypothesis and derive design requirements for effective WCIS, we evaluated the outcomes of an experimental coproduction of weather forecasts in Ada, Ghana. The experiment involved a userdriven design and testing of information and communications technology (ICT)-based digital (smartphones and apps) and rainfall monitoring tools by 22 farmers. They collected data and received weather forecasts during the 2018/2019 study period. The results showed a positive evaluation of the intervention, expressed by the level of engagement, the increase in usability of the tools and understanding of forecast uncertainty, outreach capacity with other farmers, and improved daily farming decisions. The success of the intervention was attributed to the iterative design process, as well as the training, monitoring, and technical support provided. We conclude that the application of modern technology in a coproduction process with targeted training and monitoring can improve smallholder farmers' access to and use of weather and climate forecast information.
\end{abstract}

Published as: Gbangou, T., Sarku, R., Slobbe, E.V., Ludwig, F., Kranjac-Berisavljevic, G. \& Paparrizos, S. (2020). Coproducing Weather Forecast Information with and for Smallholder Farmers in Ghana: Evaluation and Design Principles. Atmosphere, 11, 902. 


\subsection{Introduction}

Agriculture is a key source of food and income security in many sub-Saharan African countries (Rockström et al., 2015; Shimeles et al., 2018). However, the sector is heavily impacted by climate variability and change (Gbangou et al., 2018; Sultan et al., 2016, 2020). Future projections suggest significant risks to agriculture, even if global warming remains below the limits set by the Paris Agreement (IPCC, 2019; Sultan et al., 2020). Moreover, people involved in different agricultural water use systems throughout sub-Saharan Africa are unevenly impacted by climate variability and change (Jalloh et al., 2013; Atta et al., 2015). Climate variability and change prompted increased demand for early warning systems for weather and climate risks, especially in developing countries, where the climate is already highly variable and threatens food security, and where adaptation capacities are low (Gbangou et al., 2019; Sultan et al., 2020; Yobom et al., 2020). In West African countries like Ghana, where crop production depends largely on smallholder farming and rainwater, the need for better weather and climate information systems is significant (Cooper et al., 2008; Wani et al., 2009; Gbangou et al., 2019; Vaughan et al., 2019; Sultan et al., 2020). Although much effort is made by governments and other organizations to provide such information services to farmers and water managers, the resulting systems are often of limited usefulness for local smallholders (Masinde et al., 2012; Sultan et al., 2020). This is because many smallholder farmers in Africa need the information to be more tailored to their specific needs (Vogel et al., 2017; van der Burgt et al., 2020; Gbangou et al., 2020a). Among the climate information services currently available to West African farmers, the majority are hampered by information irrelevance, incompleteness, uncertainty, and the lack of user training for a better understanding of the required technology (Vaughan et al., 2019; Sultan et al., 2020). Hence, the design of information systems needs not only to be based on the provider's ideas and principles but also to integrate local farmers' needs and knowledge in a user-driven design approach (Masinde et al., 2012; Buytaert et al., 2014; Nyadzi et al., 2018).

The coproduction of information systems is a potential strategy for attaining adequate interaction between information producers and users, as well as to foster knowledge sharing (Byerlee et al., 2008; Lemos et al., 2018). Regarding weather and climate information systems, coproduction is increasingly recognized as a potential path to success, with several positive outcomes already documented (Masinde et al., 2012; Zebiak et al., 2019; van der Burgt et al., 2020). The current study uses the term "coproduction" to refer to participatory engagement between researchers and a group of farmers and extension agents in the design of tools and the production of weather data and forecasts (Vedeld et al., 2019). By definition, the coproduction process is built according to user engagement and needs and, thus, can facilitate the development of and access to climate services, i.e., the production, translation, and use of weather and climate information in a way that assists users in terms of decision-making and policy planning (Global Framework on Climate Services, 2020). Such services are crucial for smallholder farmers, who are particularly vulnerable to climate variability and change because of their reliance on rainfall for farming and their limited adaptive capacity (Gbangou et al., 2019; Sarku et al., 2020a).

Interactions with local farmers in Ada East District, Ghana (Figure 5.1) helped to define and predict relevant, tailor-made agrometeorological indices, such as the onset of the wet season, dry spell occurrence, and total seasonal rainfall, to support farming decision-making (Gbangou et al., 2019, 2020a). Previous research undertaken as part of the Waterapps project (www.waterapps.net) in Ada found that, due to the lack of location-specific information and limited understanding of modern forecasts (van der Burgt et al., 2018; Vaughan et al., 2019; Sultan et al., 2020), local farmers rely 


\section{Chapter 5}

on mainly on traditional knowledge for farming decisions. The coproduction of forecast knowledge with and for farmers can help foster trust and increase the local uptake of scientific model-based forecasting knowledge (Ingram et al., 2002). Furthermore, collecting and integrating local or traditional knowledge with scientific data can help increase credibility and improve access (Nyadzi et al., 2020; Gbangou et al., 2020). Good local information can help to the enhance usefulness and skills of model-based forecasts (Nyadzi et al., 2020). For instance, information about crop types, cropping calendars, and other local specific needs can be incorporated into models to derive relevant forecast information to enable adaptation to climate variability. Similarly, harnessing local forecasts can potentially be combined with the model's forecasts to synergize the accuracy of the combined weather and climate forecast information (Crane et al., 2010; Radeny et al., 2019; Nyadzi et al., 2020). As in many West African countries, Ghana's current climate information services are based on long-term modeled trends and resilience planning, regional agrometeorological bulletins, and weather forecasts at grid scales that are often too coarse to be useful for location-specific predictions (Gbangou et al., 2018,2019).

In this regard, modern digital technology offers opportunities for developing innovative climate information services. For example, information and communications technology (ICT) such as mobile phones, smartphones, apps, and the internet can serve as supportive tools at all stages of climate information service provision, including production, transfer, and use by end-users (van der Burgt et al., 2018; Sultan et al., 2020). The ICT interface can be designed with and for farmers to facilitate effective data collection, feedback, and interaction (Nyadzi et al., 2018). Farmers can also be engaged as citizen scientists to monitor daily and seasonal climate observations and share these with peer farmers and scientists (O'Grady et al., 2016; Rutten et al., 2017; Tinati et al., 2017; Turreira-García et al., 2018). Despite the overall limited use of ICT by local communities (Naab et al., 2019), there is evidence of a rapidly increasing digital literacy that indicates promise for ICT adoption in West Africa, particularly in Ghana (Zibi et al., 2009; Aker et al., 2010; Aker, 2011). The coproduction of weather and climate information services (WCIS) using digital tools could be an important means to enhance the adaptive capacity and resilience of smallholder farmers in the face of climate variability. Nonetheless, there is limited practical evidence on smallholder farmers' use of ICT-based technology in coproduction processes in West Africa (Beza et al., 2017; Phillips et al., 2018; Sultan et al., 2020). Practical evidence regarding the coproduction of climate information services could orient knowledge and policy to better support vulnerable smallholder farmers (Vaughan et al., 2019; Field, 2014).

This paper reports on an ICT-based weather information service coproduction process involving farmers, extension workers, and scientists in Ada East District, Ghana (Figure 5.1), on the testing of the codesigned WCIS and evaluation of the experiment's results. Based on the evaluation findings, design criteria for such services are proposed. Extracting the design principles will help improve future WCIS for smallholder farmers in Ghana and elsewhere. The current study focuses on aspects of WCIS implementation, particularly testing of design features and the associated training, monitoring, and support provided during the testing phase of the coproduction experiment. 


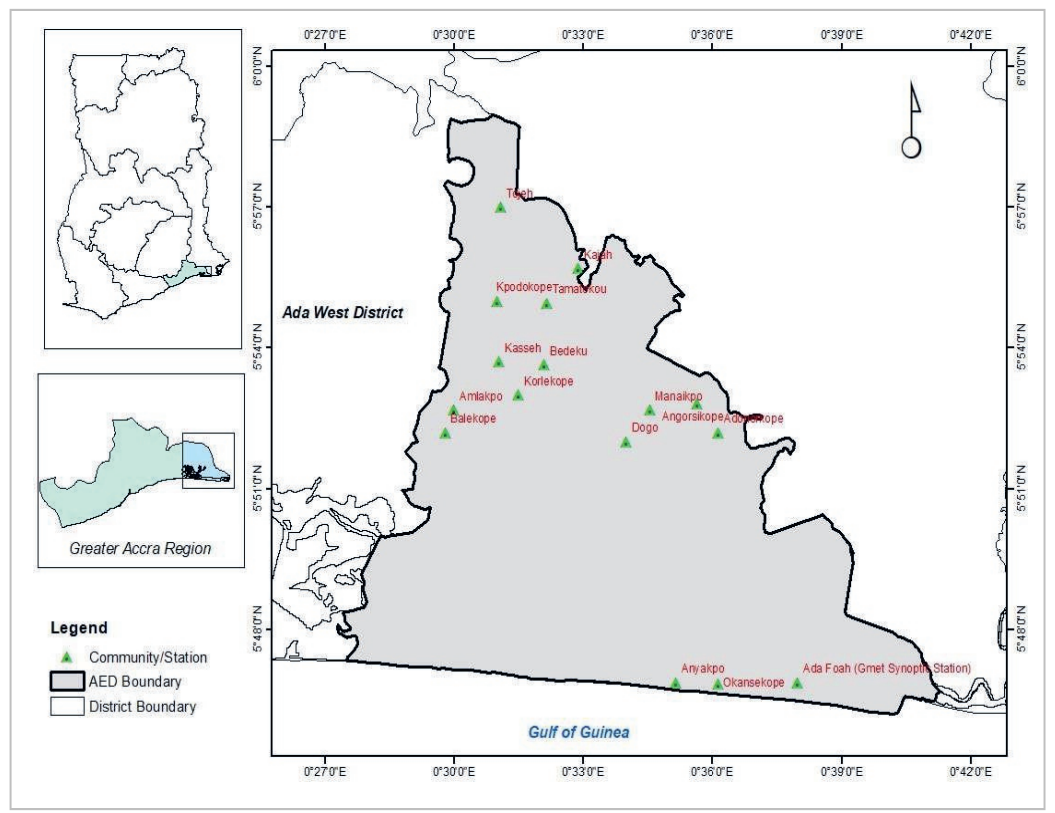

Figure 5.1. Map of the study area in the Greater Accra Region, Ghana, showing the various communities of Ada East District [29].

\subsection{Materials and Methods}

This section details the methodological approach for coproduction implementation, data collection, and analysis. Figure 5.2 presents a general methodological flowchart, including the participants, inputs, and processes, as well as the outcomes evaluated. The various components of the figure are addressed below. Other results from the field study, for instance, regarding local forecast performance and motivations and barriers for farmer participation, are presented elsewhere (Sarku et al., 2020b; Gbangou et al., 2020a) and, therefore, not included in the current paper. Similarly, before the design and testing phase, farmers' agrometeorological information needs and local forecasting indicators were assessed under the Waterapps project. Results of those pre-surveys were discussed in Reference (Gbangou et al., 2020a). 


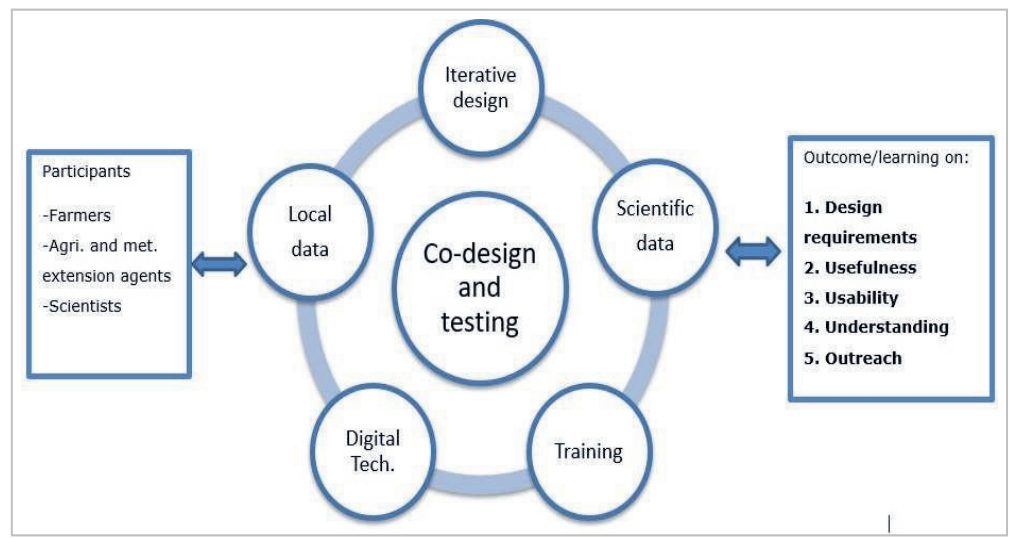

Figure 5.2. Codesign and testing of agrometeorological information services: methodological flowchart showing the cyclical and iterative process of knowledge development. Local data refer to farmers' forecasts (based on locally used biophysical indicators) and scientific data refer to model-based forecasts. Digital technology includes information and communications technology (ICT; smartphones, apps, and the internet) used for knowledge exchange and collection of rainfall monitoring data.

\subsubsection{Study Area and Participants}

Our study was carried out in the Ada East District (AED) of Ghana, which is a peri-urban district located in the Volta Delta, a coastal savanna subregion. The map in Figure 5.1 shows the location of communities with field study participants. In this region, crop growth is affected by changing climatic conditions, including greater variability in the onset date of the rainy season, more erratic total seasonal rainfall, and dry spells (Addo et al., 2018; Gbangou et al., 2019,2020a). Unpredictable early and late onset dates and dry spell occurrence affect AED farmers' decision-making strategies (Sarku et al., 2020a). Unlike many farmers in Northern Ghana, who have access to private weather forecast services in addition to national forecasts (Nyadzi et al., 2019; Nyamekye et al., 2020), AED farmers only occasionally receive (mainly via radio and television (TV)) daily national weather forecasts that are given for the entire coastal region and are, thus, too coarse for location-specific farming decisions (Jost et al., 2016; Limantol et al., 2016; Gbangou et al., 2019). Hence, local farmers in the area are among the most vulnerable to climate variability in Ghana. Crop production in the district mainly includes cassava, pepper, rice, maize, and tomato. These products represent an important source of food for urban markets, especially in nearby major cities like Accra and Tema in Ghana, as well as Lomé in Togo. The district's proximity to urban areas also suggests a potential for the adoption of ICT-based digital technology by farmers. Developing locationspecific, tailored ICT-based forecast information services could help farmers improve their daily farming decisions and adaptive capacity.

Study participants were selected using a purposive sampling method based on experience with local forecasts, availability, gender, and willingness to participate. A group of 22 farmers, five agricultural extension agents, and one meteorological extension agent was selected. This was considered representative and sufficient for the experiment in WCIS codesign and testing, which took place in 2018-2019. Figure 5.3 presents the socio-demographic characteristics of participants, including gender, age, and education levels. In our sample, there were 18 male 
and four female farmers. Participant ages ranged from 20 to over 60, thus including both young and older farmers. Education levels varied from no formal education to the high school level, with the majority of farmers having attended middle school. Extension agents were considered key participants, as they worked with farmers in different communities and, thus, had greater outreach potential. Although the extension agents did not collect primary data, they saw, shared, and interacted with the forecasts and data collected by the farmers and scientists. The extension agents were also asked to give their opinions in evaluating the coproduction experiment.

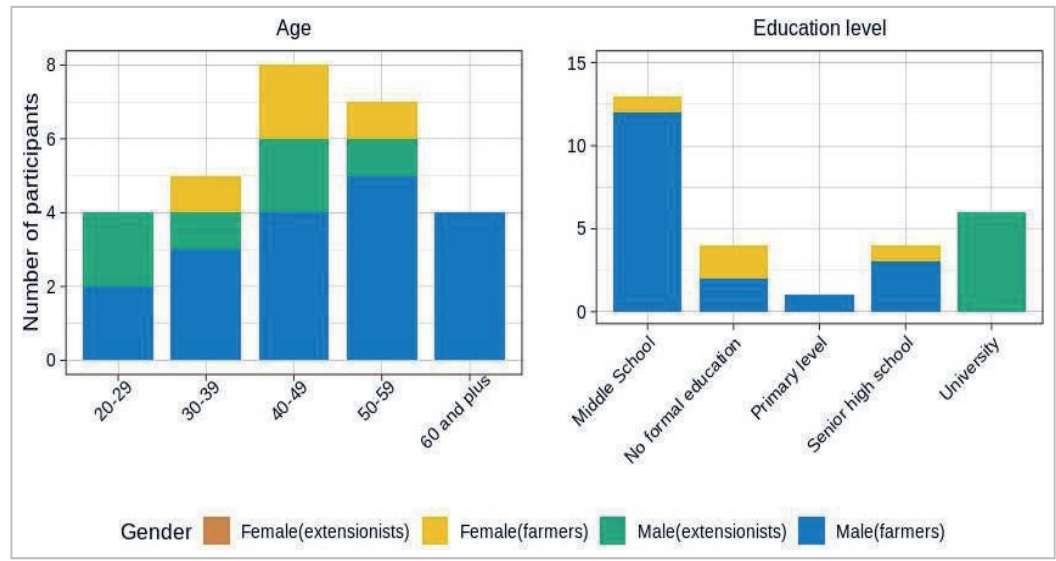

Figure 5.3. Age, education level, and gender of farmers and extension agents participating in coproduction experiment for weather and climate information in Ada East District, Ghana.

\subsubsection{Digital and Rainfall Monitoring Tools}

Modern technology, including web-connected smartphones, mobile applications (apps), and the internet, was used to facilitate the coproduction process. We provided a smartphone with an internet data bundle from a local telecommunication company to each of the 22 participating farmers and to extension agents who did not already have one (see Table $5 \mathrm{~g}, \mathrm{~h}$ of supplementary materials). Each phone contained (i) a weather app (http://waterappsweatherforecast.azurewebsites.net/Account/Login) for collecting local forecast indicators and rainfall observation data, and (ii) WhatsApp (a smartphone chat app) for disseminating forecasts prepared by scientists for farmers and to enable interaction among the participants (figure 5b-c of supplementary materials). Although this dual-app set-up was satisfactory for the coproduction experiment, future applications might seek ways to integrate data collection, dissemination, and interaction into one ICT tool. To measure daily rainfall, a total of 20 manual rain gauges were distributed to farmers from the 15 communities involved (see Figure 5.1). We ensured that each community had at least one rain gauge.

\subsubsection{Data Collection and Sharing}

Data collected by local farmers included daily local weather forecast indicators (see figure $5 \mathrm{~b}$. of Supplementary Materials) and daily rainfall observations (Table 5.1). Farmers collected these on a real-time basis, sharing them with the research team via the weather app. These data were then processed into daily forecasts (for details see Gbangou et al., 2020c) and shared with all participants via the WhatsApp group. Similarly, daily scientific model-based weather 


\section{Chapter 5}

forecasts (from www.meteoblue.com) were simplified and shared via the WhatsApp group. This sharing was done in real-time and on daily basis from April to July 2019.

Table 5.1. Summary of the data collected and shared via the digital tools.

\begin{tabular}{cl}
\hline \multicolumn{1}{c}{ Digital Tools } & \multicolumn{1}{c}{ Data collected and shared } \\
\hline $\begin{array}{c}\text { WeatherApp } \\
\text { (collection) }\end{array}$ & $\begin{array}{l}\text { Daily biophysical local forecast indicators as observed and reported by } \\
\text { farmers in their various locations (see also, Table 5i of supplementary } \\
\text { materials) }\end{array}$ \\
\hline $\begin{array}{c}\text { WhatsApp group } \\
\text { (sharing) }\end{array}$ & $\begin{array}{l}\text { Daily local forecasts based on the processed and aggregated local forecast } \\
\text { rain gauges }\end{array}$ \\
& $\begin{array}{l}\text { Daily local forecasts derived from scientific sources (e.g., meteoblue) } \\
\text { (Gbangou et al., 2020c) } \\
\text { Daily rainfall observations as measured with the provided rain gauges }\end{array}$ \\
\hline
\end{tabular}

\subsubsection{Workshops, Training, and Monitoring}

Several workshop sessions were conducted to learn from farmers what forecast indicators they typically used and to codesign the digital tool interface for the weather app. This was done following a user-driven design approach (Zulkafli et al., 2017). Hence, the researchers learned from farmers and extension agents and, with them, jointly defined and redefined features of the apps, including visuals, symbols, texts, and format. Farmers were also trained in the use of the digital tools, including smartphones, apps, internet handling, and installation and use of rainfall monitoring tools. They were also educated on the probabilistic nature of the forecasts shared via the WhatsApp group. Throughout the four-month data collection period (April to July 2019), monitoring was carried out, including field visits with farmers. A final evaluation of the whole experiment was conducted at the end of the rainy season, in July 2019. Figure 5.4 summarizes the chronology, activities, and methods used. Activities carried out in the rainy season of 2017 on local agrometeorological information needs and local forecasting indicators are outside the scope of the present study (details on these can be found in Reference Gbangou et al., 2020c). Nonetheless, this step is included in Figure 5.4 to show the flow of the project and the link to local information needs and forecasting indicators. 


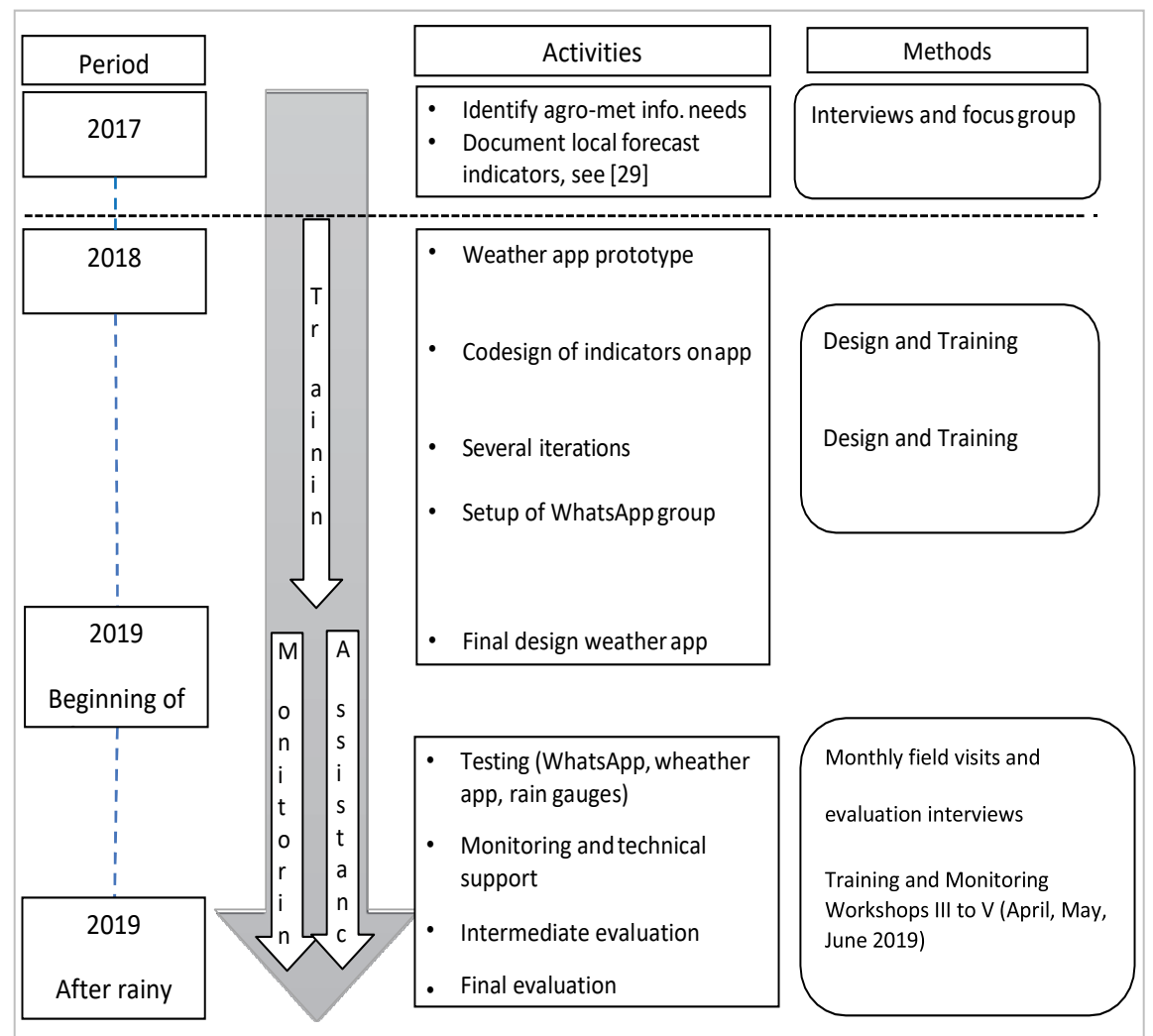

Figure 5.4. Chronology of the coproduction work carried out in Ada East District, Ghana. Activities and methods for the 2017 rainy season, above the horizontal dashed line, are covered in previous studies, as part of the Waterapps project. They are, therefore, not included in the present study.

\subsubsection{Analysis of Design and Lessons Learned}

Since the aim of this study was to improve the quality and effectiveness of weather and climate information services in the study area, an ex-post evaluation approach was adopted (Tall et al., 2019). This approach was deemed suitable for the actual intervention and sought to document and analyze participants' behavior and the impacts of climate information service delivery (Tall et al., 2019, Vaughan et al., 2019). Note that the focus of the current study was on evaluating farmers' engagement and the usability and usefulness of the weather information system introduced to them, not on examining the impacts of the intervention in terms of farming outcomes (like changes in cropping practices or yields). To determine the usability and usefulness of the WCIS and the extent to which farmers' understanding and daily management decisions improved or changed following access to the weather and climate information, we used answers to a set of descriptive questions (Table 5a of supplementary materials). These covered the ability of farmers to use the information service (i.e., its usability Collier \& Dercon, 2014), estimation of the potential relevance of the service for farmers (i.e., its usefulness Sonwa et al., 2017), and identification of elements of design 


\section{Chapter 5}

and implementation that could lead to better outcomes (i.e., design criteria (Collier \& Dercon, 2014; Sonwa et al., 2017). Although the research involved 22 farmers, 17 people participated in the evaluation workshop (see Table $5 \mathrm{j}$ of supplementary materials) because 3 farmers were not availability at the time while 2 farmers dropped out. All agricultural and meteorological extension agents participated throughout the research. The questionnaires for the evaluation exercise consisted of closed-ended questions with likert scale attached to some questions to enable scaling of responses. In the analysis of the evaluation survey, non-applicable (NA) refers to the number of farmers (4 out of 22) who were absent during the evaluation research. While "missing "not applicable"" represents responses on farmers who abstained from answering specific questions. Considering our small sample size, a binomial distribution approach was used to test the significance of the results. Expert (participant) observation (Bowden et al., 2016; Chandra et al., 2017) was also applied, to better understand differences between socio-demographic groups (age, gender, and literacy) in challenges encountered by farmers during the testing phase. Based on the evaluation results and expert judgments, design principles for an effective ICT-based weather information service coproduction process were derived.

\subsection{Results}

\subsubsection{Design Phase of the Digital and Rain Monitoring Tools}

The co-development process began in 2017, with an initial exploration, by researchers, of the forecast information needs and challenges faced by Ada East District farmers in using weather and climate information (Gbangou et al., 2019; Sarku et al., 2020a). ICT-based tools appropriate for the weather and climate information sharing and rainfall monitoring were then designed with and for farmers and extension agents in 2018. Table 5.2 presents design features, which were iteratively adjusted and refined by participants at design workshops. The main tools used were a web-based weather app, a WhatsApp group, and rain gauges (see Figure 5.5 for illustration).

The weather app was designed to be user-friendly and allow for the collection of local forecast observations and rainfall data from local farmers. These local observations included indicators that farmers typically paid attention to when assessing daily weather (see Reference Gbangou et al., 2020c and Table 5i of supplementary materials). These indicators were represented by symbols agreed upon with local farmers. The weather app also contained pictures illustrating various intensities of rainfall; these could be selected by participants (farmers) to record the amounts of rainfall observed at their locations. Each picture was complemented with a short descriptive text, as the majority of farmers could read (Figure 5.5a). The weather app required a login step for security purposes, although it offered the option of remembering the user's log-in details. Its interface offered an easy selection of options, scrolling, and submission of data with a confirmation message sent to verify successful data submission.

The WhatsApp mobile application was installed on participants' smartphones, and a WhatsApp chat group was created so they could receive both local and scientific forecasts and interact with one another (Table 5.2). Participants received training to help them understand and interpret the probability of rainfall occurrence represented by the simple pie charts that were shared (see Figure $5.5 \mathrm{~b}$ for illustration). Farmers could also write messages or use emojis to interact with other members of the WhatsApp group. Farmers unfamiliar with WhatsApp were trained in its aim and usage. Farmers were free to share their opinions on forecast quality. They could also share their rainfall data in the WhatsApp group to help others understand rainfall distribution across the 
district. Both apps required participants to use the mobile internet connection included in their smartphone subscription (e.g., they needed to be able to turn mobile data on and off).

Participants were also trained by a meteorological extension officer to install, read, and record rainfall data using the manual rain gauges provided (Figure 5.5c). Only farmers were asked to record daily rainfall at their locations, which they submitted via the weather app, the WhatsApp group, or notebook records. Farmers were asked to not only be attentive and report the rainfall amount and category (low, medium, and high; see Figure 5.5a) but also to note the beginning and end times of rainfall events when these occurred.

To summarize, the coproduction tools were designed with and for farmers to be user-friendly, and consensus on design features was sought with the study participants. The design features agreed upon with farmers in 2018 were tested in real-time during the rainy season of 2019, from April to July. At the end of the rainy season, in July 2019, an evaluation was carried out.

Table 5.2. Design aspects considered in coproduction of ICT-based digital and rain monitoring tools

\begin{tabular}{|c|c|c|}
\hline Digital Tools & Items & Important characteristics \\
\hline \multirow{4}{*}{$\begin{array}{l}\text { WeatherApp } \\
\text { (For collection daily } \\
\text { local rainfall forecasts } \\
\text { and daily rainfall } \\
\text { amount) }\end{array}$} & Images & $\begin{array}{l}\text { Symbolic images of the local forecast indicators } \\
\text { were defined and refined with farmers and } \\
\text { presented on the web application interface. }\end{array}$ \\
\hline & Symbols & $\begin{array}{l}\text { Several symbols were used to support farmers in } \\
\text { selecting different options including heavy, light, } \\
\text { low or no rain, confidence level, rainfall record } \\
\text { category levels, etc (see Figure 5a) }\end{array}$ \\
\hline & Text & $\begin{array}{l}\text { Since the majority of farmers could read (see } \\
\text { socio-demographic in Figure 5.3), short phrases } \\
\text { were used to describe for example indicators } \\
\text { with its signal, rainfall record level, farmers } \\
\text { forecasts, etc. }\end{array}$ \\
\hline & $\begin{array}{l}\text { App } \\
\text { Manipulation }\end{array}$ & $\begin{array}{l}\text { The App was designed to be easy to scroll, select } \\
\text { and submit with an end message confirming } \\
\text { whether the submission succeeded. The training } \\
\text { session helped farmers to quickly master it. }\end{array}$ \\
\hline \multirow[t]{2}{*}{$\begin{array}{l}\text { WhatsApp } \\
\text { (For sharing daily } \\
\text { local and scientific } \\
\text { rainfall forecasts, and } \\
\text { daily rainfall amount) }\end{array}$} & Forecast graphs & $\begin{array}{l}\text { To illustrate the probabilistic nature of both local } \\
\text { and scientific forecasts, simple pie charts were } \\
\text { used to show the percentage of for example yes } \\
\text { and no rain events expected (see illustration } \\
\text { Figure 5.5b). }\end{array}$ \\
\hline & Text & $\begin{array}{l}\text { Interactions among farmers, extension agents and } \\
\text { scientists required that each participant can read } \\
\text { and write. Since a large majority of farmers } \\
\text { could do so, this was facilitated. Those who were } \\
\text { low literate were assisted by their relatives at } \\
\text { home. }\end{array}$ \\
\hline
\end{tabular}




\begin{tabular}{lll}
\hline & $\begin{array}{l}\text { App } \\
\text { Manipulation }\end{array}$ & $\begin{array}{l}\text { Considering the majority of farmers have never } \\
\text { used this popular app, training were done to help } \\
\text { them find the app, start it, read and write } \\
\text { messages }\end{array}$ \\
\hline $\begin{array}{l}\text { Internet } \\
\text { (digital mode of } \\
\text { transmission of } \\
\text { weather forecasts and } \\
\text { data) }\end{array}$ & $\begin{array}{l}\text { Setup and } \\
\text { handling } \\
\text { Rain gauges } \\
\text { (For measuring daily } \\
\text { rainfall amount) }\end{array}$ & $\begin{array}{l}\text { Internet connection was preconfigured on each } \\
\text { mobile phone with a subscription from a local } \\
\text { internet provider company in Ghana. Farmers } \\
\text { were then trained on how to turn the data on and } \\
\text { off. }\end{array}$ \\
\hline $\begin{array}{ll}\text { Setup of the } \\
\text { manual rain } \\
\text { gauge }\end{array}$ & $\begin{array}{l}\text { An experienced meteorologist from Ghana } \\
\text { meteorological agency trained farmers to } \\
\text { conveniently set up the rain gauges in their farms } \\
\text { or near their housing (Figure 5.5c). }\end{array}$ \\
\cline { 2 - 3 } & $\begin{array}{l}\text { Recording of } \\
\text { daily rainfall }\end{array}$ & $\begin{array}{l}\text { Farmers were trained to record daily rainfall at } 9 \\
\text { AM and specify the start and end date and time } \\
\text { of each rainfall event }\end{array}$ \\
\cline { 2 - 3 } & $\begin{array}{l}\text { Reporting of } \\
\text { daily rainfall }\end{array}$ & $\begin{array}{l}\text { Data collected by farmers could be reported in } \\
\text { several ways including the WeatherApp, } \\
\text { WhatsApp, and notebook when the internet was } \\
\text { becoming unstable or when the battery of the } \\
\text { phones was off. }\end{array}$ \\
& &
\end{tabular}




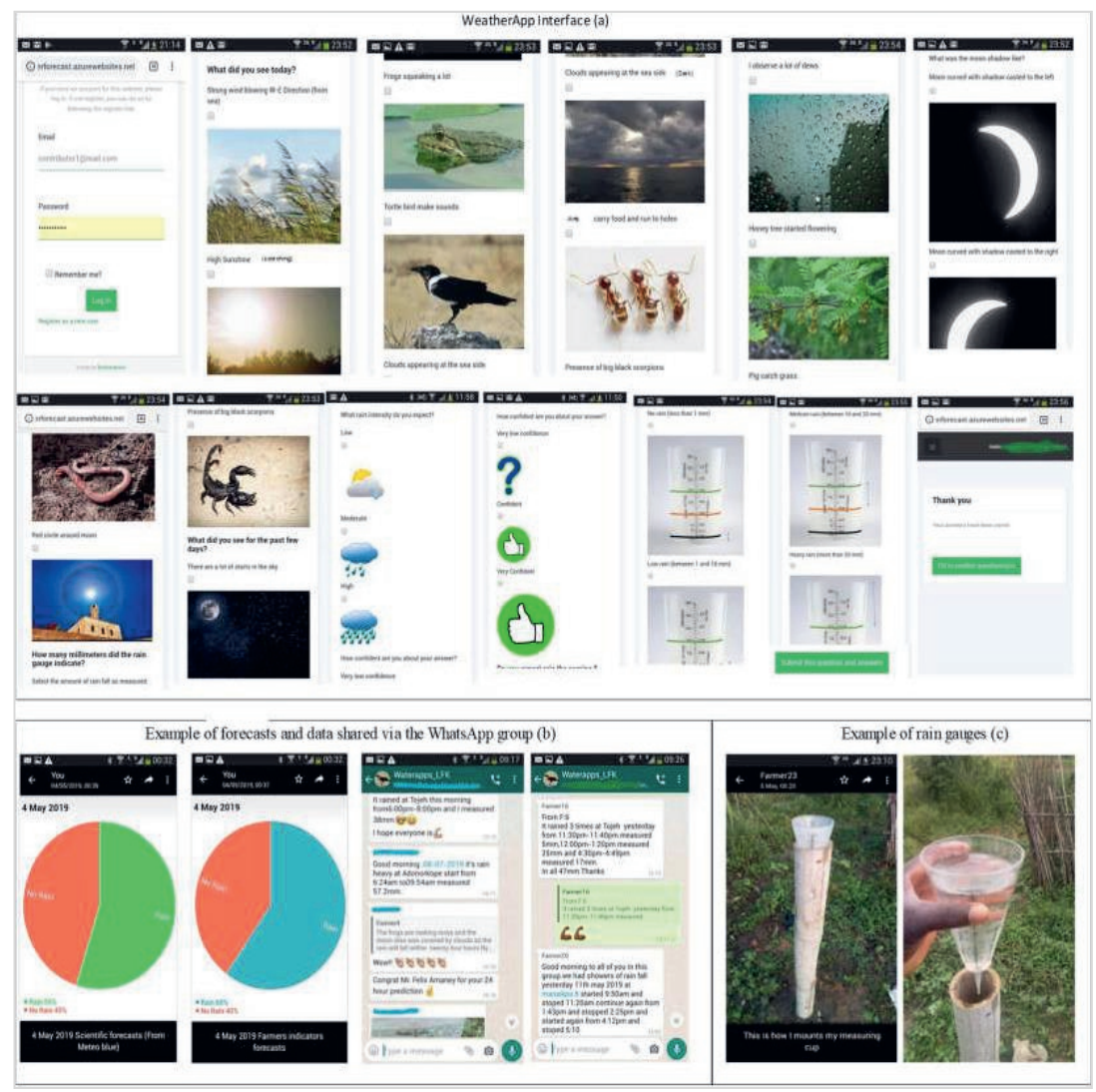

Figure 5.5. The mobile applications and rain gauges were used during the coproduction experiment. These included (a) a weather app used by farmers to collect real-time data on local forecast indicators and rainfall (see Table 5.2), (b) a WhatsApp group used by participants to share data on rainfall, as well as to disseminate both local and scientific forecasts in simple pie chart format and also to interact (see Table 5.2), and (c) manual rain gauges used by farmers to record rainfall amounts (see Table 5.2).

\subsubsection{Evaluation of the Testing Phase}

\subsubsection{Participant Engagement}

During the testing phase, from April to July 2019, the engagement of the farmers and extension agents varied in terms of their data inputs and participation (Figure 5.6). Based on the frequency of data collection and interaction, we ranked engagement levels into three categories: low $(<33 \%)$, medium, and high ( $>66 \%$ ). Some $76 \%$ of farmers fell into the medium to high range during the four-month testing period. The high-level engagement category grew over time. Extension agents' engagement remained constant over time, meaning that they were consistently active in monitoring activities, providing feedback, and sharing knowledge with farmers beyond those involved in the experiment. 


\section{Chapter 5}

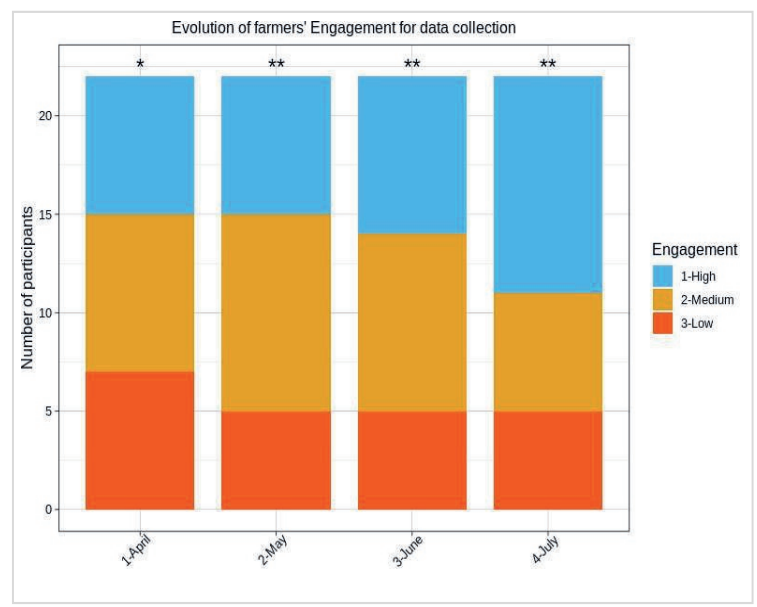

Figure 5.6. Evolution of participants' engagement based on their frequency of data collection and interaction via the digital and rain monitoring tools. Asterisks (* and **) indicate the significance of the results for the combined "medium and high engagement" category at, respectively, $p<0.05$ and $p<0.01$, based on a binomial distribution test.

\subsubsection{Usability of the Digital Technology}

Farmers' ability to use the digital and rain monitoring tools was evaluated throughout the testing phase. Figure 5.7 shows participants' assessments of the usability of the various tools, before and after four months of practice. The usability of all the tools improved considerably. Nonetheless, the figure indicates some design aspects that, although improved, still needed further refinement. These included the mobile internet connection, inputting text in WhatsApp, recording rainfall data, and submitting reports. A small percentage of farmers $(<23 \%)$ did not answer because they did not know or dropped out of the experiment due to low motivation or other barriers. 


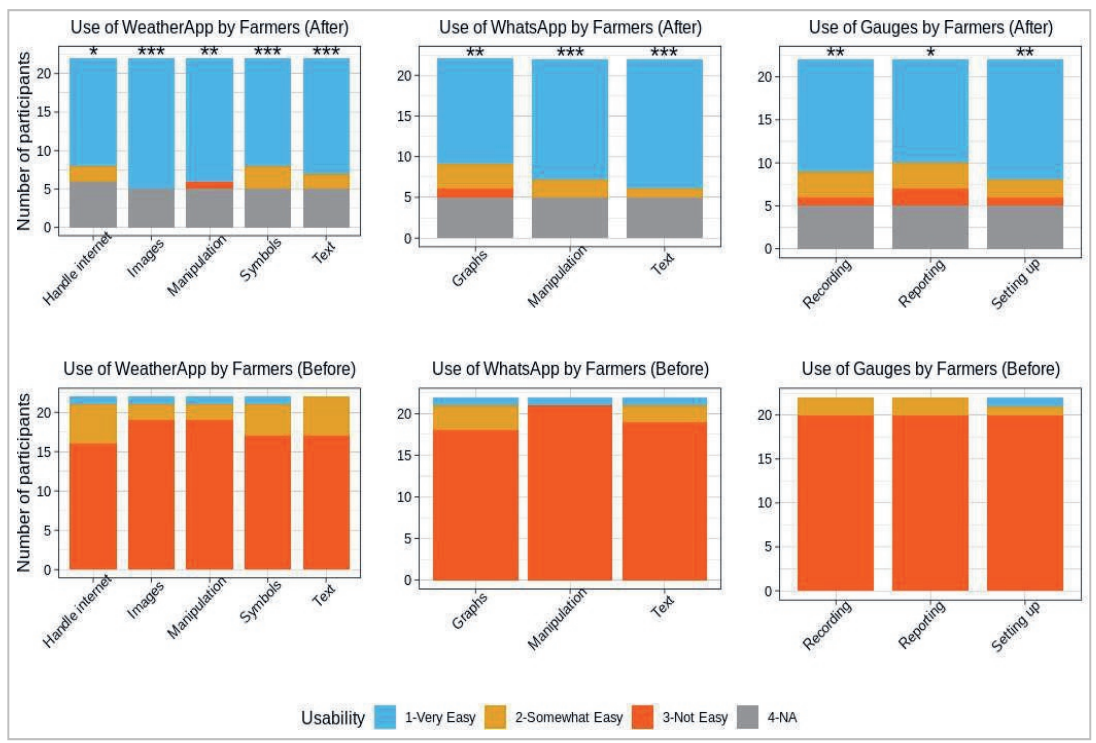

Figure 5.7. Usability of the digital and rain monitoring tools throughout the testing phase. "Not applicable (NA)" indicates participants who did not answer or dropped out of the experiment. Asterisks $(*, * *$, and $* * *)$ indicate the significance of the results for the combined "somewhat and very easy" category at, respectively, $p<0.05, p<0.01$, and $p<0.001$, based on a binomial distribution test.

\subsubsection{Usefulness of Tools, Weather Forecasts, and Data} The usefulness of the tools, weather forecasts, and data was also evaluated. Figure 5.8 presents farmers' and extension agents' opinions on the relevance of each component to farmers in the study area. Most participants confirmed that the design tools (i.e., mobile internet, the rain gauges, smartphones, the weather app, and WhatsApp) were at least somewhat relevant as communication tools for weather forecast information (compared to traditional channels like radio and TV). Similarly, the majority thought the local and scientific weather forecasts and data produced and shared were highly relevant to their daily farming decisions. However, some digital technology items (e.g., mobile internet) were less appreciated by participants. This was mainly due to the low internet coverage in remote locations of the study district, which prevented some participants from using the apps effectively.

Both farmers and extension agents observed that the experiment helped farmers improve their understanding of rainfall distribution and forecast uncertainties. Furthermore, farmers' decisionmaking was said to have improved, compared to previous years (see daily decisions in Table 51 of supplementary materials). Most participants noted that their understanding and decisions improved, at least somewhat (Figure 5.9).

In summary, although further improvements were still called for, the evaluation pointed to positive outcomes regarding engagement of farmers, usability and usefulness of the tools, understanding of the tools, and farming decisions. These results are significant at the $95 \%$ confidence level, 


\section{Chapter 5}

considering a binomial distribution for the medium and high response categories, except for the internet category (see details in Tables 5i, Supplementary Materials).
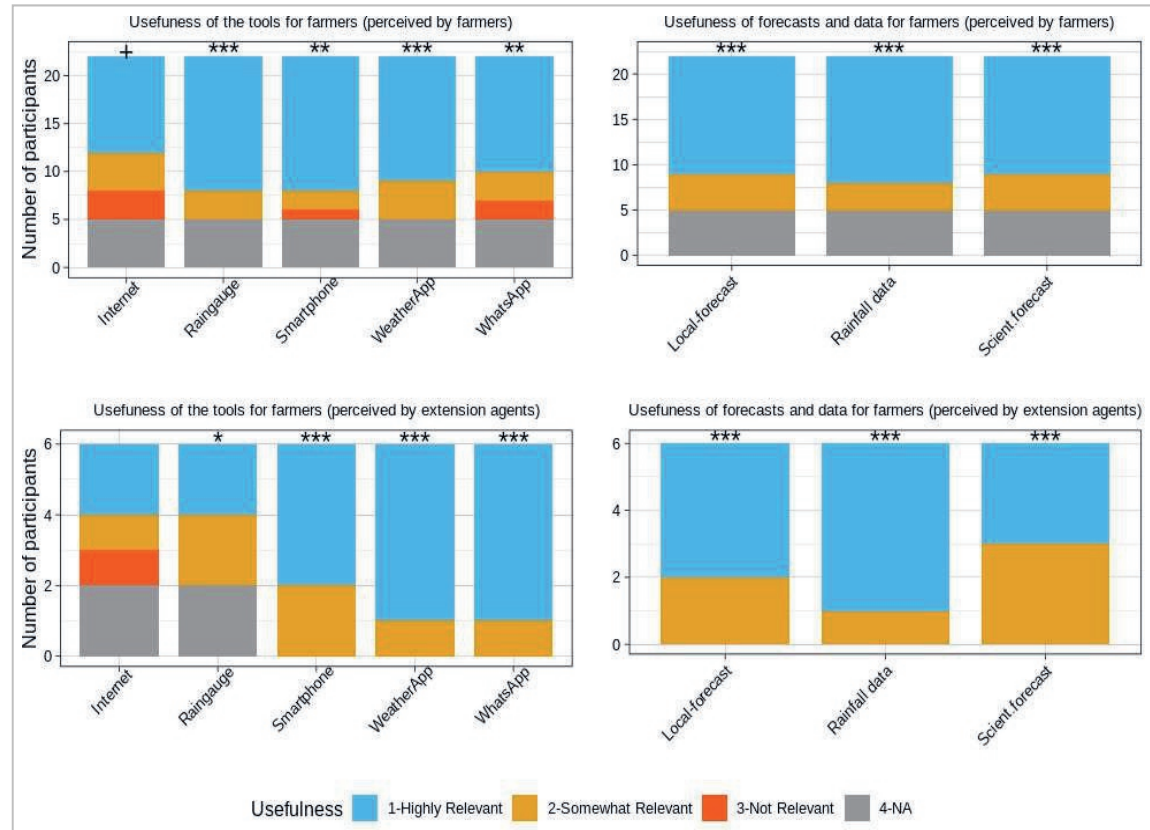

Figure 5.8. Farmers' perceptions of the relevance or usefulness of the digital tools and weather forecast information and data shared compared to channels formerly used for dissemination of forecast data. "NA" indicates the share of participants who abstained from answering the question or dropped out of the experiment. Farmers were asked how useful the tools and information were, while extension agents were asked to confirm this usefulness. Various symbols $(+, *, * *$, and ***) indicate the significance of the results for the combined "somewhat and highly relevant" category at, respectively, $p<0.1, p<0.05, p<0.01$, and $p<0.001$, based on a binomial distribution test. 


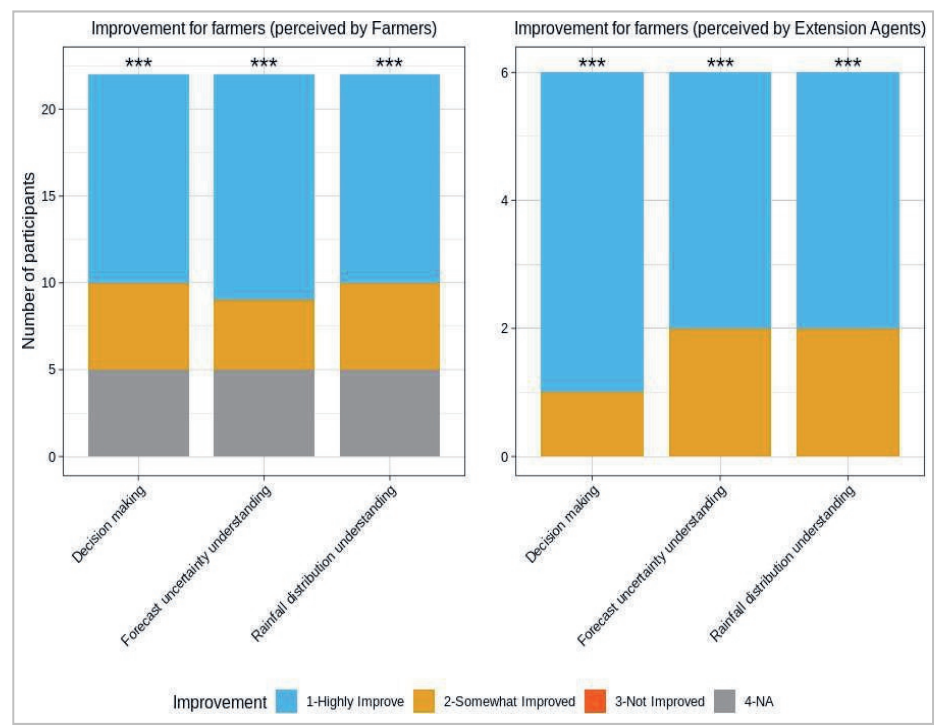

Figure 5.9. Perception of improvement in farmers' decision-making, as well as an understanding of forecast uncertainty and rainfall distribution, as compared to previous seasons. Farmers were asked if their decisions and understanding improved, while extension agents were asked if they perceived any such improvement. Asterisks $(* * *)$ indicate the significance of the result for the combined "somewhat and highly improved" category at $p<0.001$, based on a binomial distribution test.

\subsubsection{Outreach to Other Farmers}

The coproduction experiment reached more farmers in Ada East communities beyond those directly involved in the experiment. Table 5.3 presents the numbers of farmers with whom experiment participants (i.e., both farmers and extension agents) shared data and what they learned. In total, farmers indicated having shared their data and knowledge with more than 350 fellow farmers, while the extension agents, who were in constant contact with farmers throughout Ada East, indicated they reached out to more than 504 farmers. This implies that all participants can spread the knowledge coproduced. It also demonstrates the importance of involving agricultural and meteorological extension agents, as they have larger networks and can transmit the coproduced knowledge to many farmers not involved in the experiment.

Table 5.3. Numbers of farmers reached indirectly, via participants in the coproduction experiment (both farmers and extension agents).

\begin{tabular}{cll}
\hline & Farmers & $\begin{array}{l}\text { Extension } \\
\text { Agents }\end{array}$ \\
\hline $\begin{array}{c}\text { Number of participants in coproduction } \\
\text { experiment }\end{array}$ & 22 & 6 \\
\hline $\begin{array}{c}\text { Number of farmers with whom forecast } \\
\text { information and/or data were shared. }\end{array}$ & $350+$ & $504+$ \\
\hline
\end{tabular}




\section{Chapter 5}

\subsubsection{Monthly Monitoring and Assistance Activities}

Continuous monitoring was carried out during the testing phase to support farmers in their usage of the tools and to ensure the quality of the data collected. Table 5.4 lists several adjustments made during the process, alongside observations on lessons learned regarding design principles.

Primary adjustments were to increase the frequency of tool maintenance (e.g., replacing broken rain gauges and defective phone batteries), correcting rainfall recording and reporting techniques, and advising some farmers on how to work around internet instability. These activities generated a workload for scientists of a half-day per week and one full day each month on average.

We also observed differences between the socio-demographic categories of participants that helped us to adjust and target our monitoring and assistance efforts (Table 5.4). For example, older farmers had better knowledge of local forecast indicators (see Table 5i, supplementary materials) but faced more technical challenges in using the tools compared to younger farmers (Table 5o of supplementary materials). Moreover, literate farmers tended to have less difficulty in handling the tools. Female and male farmers invested similar levels of time and effort in their participation in the coproduction experiment activities.

As noted, mobile internet stability varied across the district, and this particularly affected data collection and interaction of farmers in the most remote communities. Adjustments were made to help them address the issue. For instance, they were advised to try to reconnect on an elevated surface or to use a notebook to record rainfall data and local forecast indicators, and to call one of the scientists to submit their data.

Both apps (the weather app and WhatsApp) were essential for data collection and participant interaction. However, the double tools generated increased workload for both the farmers and the scientists. For instance, farmers had to keep track of two separate tools, which effectively doubled the technical challenges some faced. Researchers, for their part, had to manually process the data input via the weather app for sharing on WhatsApp.

Table 5.4. Observations from the monitoring and assistance activities during the testing phase (April-July 2019).

\begin{tabular}{|c|c|c|}
\hline Period & $\begin{array}{l}\text { Monitoring and assistance (technical) to } \\
\text { participants during the testing phase }\end{array}$ & $\begin{array}{l}\text { Observations from the monitoring and } \\
\text { assistance during the testing phase }\end{array}$ \\
\hline $\begin{array}{l}\text { Monthly/ } \\
\text { Weekly }\end{array}$ & $\begin{array}{l}\text { Weekly coaching and support for } \\
\text { farmers facing technical issues } \\
\text { related to the digital tools (e.g., } \\
\text { smartphone repairs, replacement of } \\
\text { batteries and chargers, work- } \\
\text { arounds for internet and app } \\
\text { problems). } \\
\text { - Monthly field visits to check the } \\
\text { state of the rain gauges and issues } \\
\text { with their set-up, data recording, }\end{array}$ & $\begin{array}{l}\text { - In terms of workload, the field visits } \\
\text { generated about one day of work per } \\
\text { month for the scientists involved. } \\
\text { Providing the weekly technical } \\
\text { support/coaching generated about a } \\
\text { half-day of work per week. } \\
\text { Nonetheless, these monitoring and } \\
\text { assistance activities were essential to } \\
\text { ensure continuous functioning and } \\
\text { good use of the tools and to }\end{array}$ \\
\hline
\end{tabular}




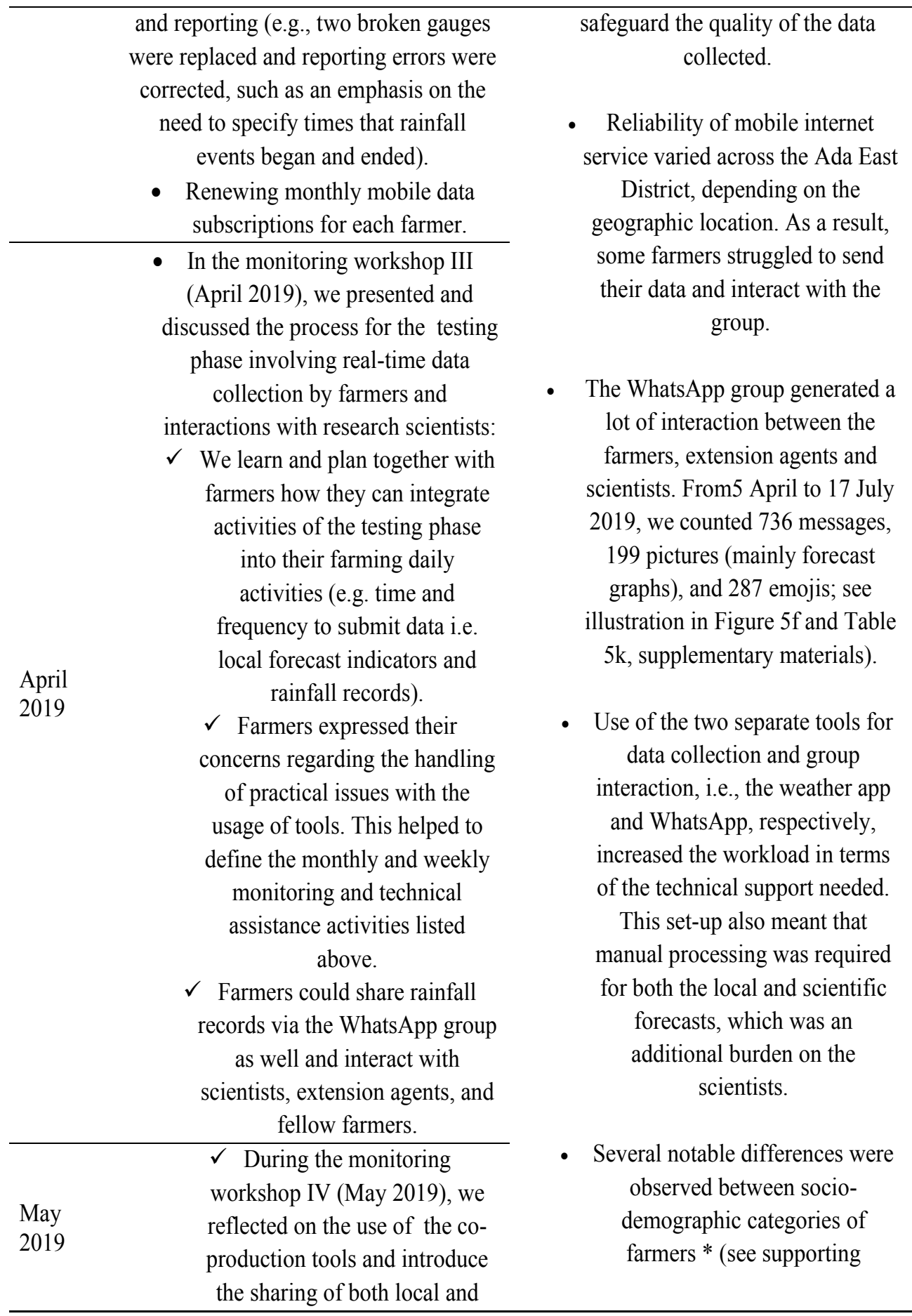




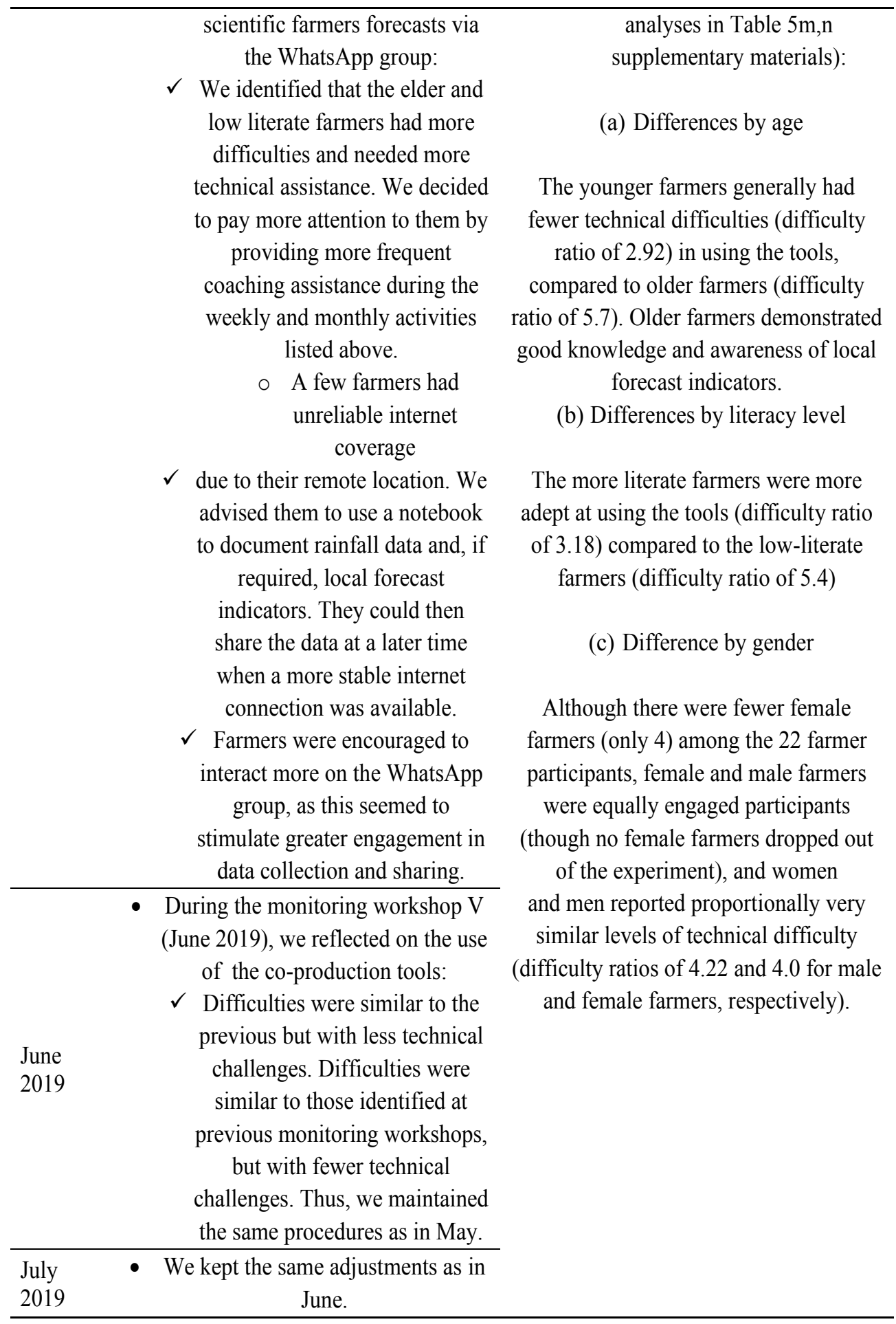


(*) These observations are based on expert (participant) observation during the workshops and analysis of technical issue reports.

\subsection{Discussion}

The objective of this study was to evaluate a coproduction experiment and extract lessons on design principles for an ICT-based WCIS that combines local and scientific forecasting knowledge and is tailored to the needs of smallholder farmers. This section discusses the evaluation results and draws lessons on design criteria. In our evaluation of the experiment, we drew on participants' engagement in the coproduction experiment, the usability and usefulness of the tools, the weather forecasts and data coproduced, and improvements in farmer decision-making and understanding of rainfall distribution and forecast uncertainty. Our focus was on the design process, as the aim was to define critical design criteria/principles for effective ICT-based WCIS. We did not evaluate impacts in terms of farming outcomes, like changes in cropping practices or yields.

\subsubsection{Evaluation of the Coproduction Experiment}

The results include the level of engagement (i.e., $76 \%$ of farmers with medium and high levels of engagement) and the usability of the designed tools that were found to increase over time. In addition, most farmers and extension agents expressed appreciation for the relevance of the features and functionality of the tools (i.e., the weather app, the WhatsApp group, and the rain gauges) and the coproduced information (i.e., weather forecasts and rainfall data). A large share of the participants indicated that their understanding of rainfall distribution, forecast uncertainty, and farm decisions improved. Moreover, the coproduction experiment reached many farmers beyond those directly involved. A next step could be to evaluate the impacts of the coproduction experiment, for example, in terms of changes in cropping practices and yields. This was beyond the scope of the current experiment, as it would require a longer-term intervention.

The capacity building proved to be a key factor in the success of the experiment, alongside the continuous monitoring and technical support provided throughout the design and testing phases. This includes the joint definition and refinement of the app interfaces with farmers during the design phase, as well as several adjustments made during the testing phase of the experiment (see Table 5.4).

The participants' engagement and interaction allowed the research team to identify and address challenges early and ensured the continuity of the experiment activities. Both farmers and scientists learned from each other as they defined the features and functionalities of the tools together. The scientists followed up by providing the participating farmers individualized coaching and technical assistance (see Table 5.4). Despite the intensive interactions between the scientists and farmers, a small portion of farmers still dropped out of the experiment.

At the start of the intervention, most of the participating farmers had no prior experience with mobile internet and smartphones, as they were still using basic mobile phone services, such as text alerts and voice messaging. The choice to use smartphones in our experiment meant that greater effort would be required to achieve the goals of the coproduction. However, the decision not to limit our experiment to the level of technology currently in use, but instead to jump ahead to the next level (smartphones) reflects our expectation of the fast development of digital technology in sub-Saharan Africa, and especially Ghana, in the near future (Zibi, 2009; Aker \& Mbiti, 2010; Aker, 2011). ICT services, including internet service providers and telecommunication companies, 


\section{Chapter 5}

have huge investments planned for the coming years in Ghana (Musters, 2017). The cost of mobile devices, including mobile data subscriptions, is also dropping, making them more accessible to peri-urban farmers and even to rural ones (Zibi, 2009; Intelligence, 2016; Smith, 2020). Digital devices like smartphones with mobile apps have much more power to generate interaction between scientists and farmers than short message service (SMS)-based alert services( David-West, 2011).

In line with our results, many previous studies found that coproduction is an efficient way to reach out to and engage smallholder farmers and build trust and user confidence (Byerlee et al., 2008; Lemos et al., 2018; Nyadzi, 2020). Consistent with the literature, our results suggest that capacity building is essential to the success of coproduction (Rao et al., 2015, Vogel et al., 2017; van der Burgt, 2020). Capacity building is particularly important for interventions involving the testing of an innovative approach (Rao et al., 2015; Gertler et al., 2016).

The application of our findings could add value to existing climate information systems in Ghana. Indeed, today's information systems in Ghana still apply a traditional top-down approach, referred to as "one-directional". In these first-generation climate information services, researchers create and transfer knowledge and/or technology to end-users (e.g., farmers) and assume that farmers will access, understand, and adopt the information provided for improved decision-making (Nyadzi et al., 2018; Musters, 2017). This applies to the forecast information provided by the Ghana Meteorological Agency and by private information services such as Esoko and Farmerline (Nyadzi et al., 2018; Nyamekye et al., 2020). Our study went beyond this traditional approach. It used a holistic or second-generation methodology that acknowledges farmers as active participants in the production of knowledge and the codesign of innovative technology (Nyadzi et al., 2018; Karpouzoglou et al., 2016). This approach additionally promotes processes of intense collaboration between researchers and dedicated groups of farmers and extension agents, to build a strong foundation for technology design, weather forecast production, and dissemination of knowledge to the wider community.

The concept of joint, intensive collaboration with farmers for the provision of location-specific knowledge is not new in West Africa (Kniveton et al., 2015; Tall et al., 2014). Nonetheless, our findings extend existing scholarship (Vaughan et al., 2019; Field, 2014) by providing practical evidence that coproduction of climate information services can advance science and policies on smallholder agriculture within and outside Ghana. Our experiment showed the codesign of ICTbased tools, which harness real-time local/traditional weather forecasting knowledge, to be a significant step forward, particularly in the development of climate services that integrate traditional forecasting systems and scientific model-based forecasts.

Availability of such combined services can foster acceptance and use of climate information by smallholder farmers (Roncoli et al., 2002, 2009). This could, in turn, enhance the adaptive capacity and resilience of smallholder agriculture in developing countries in the face of climate variability and change. Although implementing this approach requires efforts to build a strong collaboration with local farmers (especially during the development phase), once codesigned, the information service can be scaled up relatively quickly. Another limitation is the need for traditional forecasting knowledge to be local-specific, meaning that, while the information service designed may be good for the target community, it may not be wholly transferable to other regions within or outside Ghana. 
Our overall results suggest that the use of modern technology in a coproduction process, with targeted training, can improve access to and use of weather forecasts by smallholder farmers. Currently, such an approach is mainly applicable in peri-urban areas of Ghana, like the Ada East District, or rural areas with basic ICT infrastructure, particularly internet service and electricity. However, implementation in other remote rural communities will likely be possible in the near future, considering the fast growth of ICTs and internet access in Ghana and West Africa overall (Zibi, 2009).

\subsubsection{Design Criteria for Weather and Climate Information Services for Smallholders}

Our research demonstrates that digital and rainfall monitoring tools can be codesigned with userfriendly features (e.g., visualization with symbols, Table 5.5) and tailored to smallholder farmers' needs. It also highlights the importance of appropriate training and monitoring throughout the design and testing of information systems for farmers, particularly if target farmers differ in literacy levels, ages, and locations (see Figures 5.1 and 5.3). Our coproduction experiment's use of two different apps and multiple data sources proved to be hectic for both scientists and farmers. In the future, we recommend combining the functionality of the weather app and WhatsApp in a single app that offers users the ability to both record data and interact. An additional improvement would be to process the forecasts and data from both local sources and scientific models by algorithms integrated into the back-end design of the single app. This would reduce the data processing, training, and monitoring workload. Nonetheless, for the purpose of this experiment, and considering limitations of time, the current set-up was sufficient for learning design principles for an effective WCIS. Additionally, involving young farmers and balancing gender would seem important for sustainable knowledge sharing. Particularly, mixing age groups can foster knowledge transmission between generations.

In designing a WCIS, it is important to focus on a smaller but dedicated group of intensive users who will form the basis for wider dissemination in their communities. This is especially because of the workload and the cost related to tool training, monitoring, and assistance, which require the coproduction investments to be optimized to ensure sustainability in future applications. The focus can then be on a representative but optimal sample size of participants (especially farmers who are collecting the data, as well as extension agents) and with attention paid to the good use of tools and quality of the data (Table 5.5). Coproduction requires an investment of sufficient resources to allow for targeted technical support to ensure the continued engagement of participants and guarantee the quality of the data collected. The coproduced information can then be made publicly available in the district. Regarding outreach, the current study found that extension agents had bigger networks and were good disseminators of forecast information. Although "extension-to-farmer" outreach was higher than "farmer-to-farmer" outreach in our case, the latter remains an important channel for reaching other farmers in the community. Farmer-to-farmer dissemination has the potential to spread agricultural technologies among smallholder farmer communities (Kiptot et al., 2006). However, more research is needed to understand and determine the impact and effectiveness of the "farmer-to-farmer" dissemination route for weather and climate information.

The lessons drawn from the coproduction approach used in this experiment are transferable to other regions under certain conditions (Table 5.6). Internet availability is an important one, as the realtime collection of forecast indicators and rainfall data from remote locations requires reliable internet coverage. This was one of the reasons why we selected a peri-urban region as our study 


\section{Chapter 5}

area. Furthermore, the indicators used by farmers to forecast the weather and climate will differ depending on the region/district studied and, therefore, need to be adjusted for each.

Results from the current study advance research on the development and application of WCIS for smallholder farmers. Our coproduction experiment also contributes to other ongoing studies and mobile app development for smallholder farmers. It demonstrates how local or traditional forecasting knowledge can be harnessed in real time and combined with scientific model-based forecasts for Ada East District, Ghana (Sarku et al., 2020b). Additionally, the study helps to examine and understand the motivation and barriers to the engagement of local farmers for the same district in a follow-up study (see Reference Sarku et al., 2020b). Moreover, the design lessons learned from this coproduction experiment, combined with related research outputs, will help to further optimize the design of the two-way information systems within a single app, which is now under development and provisionally called "FarmerSupport" (http://www.waterapps.net/enus/ghana-updates/farmersupport-mobile-app- now-online/).

Defining a strategy to sustain the coproduction process was found to be a critical design principle (Table 5.6). In this regard, it is important to reflect on WCIS sustainability and inclusiveness. For example, together with local authorities, roadmaps that can be adapted to local needs can be developed for establishing coproduction processes even in the absence of external research-driven projects. In the present study, we sought, with the acquiesce of local stakeholders such as the district assembly, extension department, and farmers (EVOCA, 2019), to create a sustainable business model. This was another factor that prompted our selection of a target farming community in proximity to an urban market outlet. Similar initiatives could involve collaboration between farmers and social enterprises. Moreover, local enterprises could elaborate a win-win business model around the coproduction process, connecting with partners such as government institutions, universities, agricultural insurance companies, and nongovernmental organizations to ensure the sustainability of activities and outputs. However, this is not the only way to sustain the coproduction process. Prior research (Oxfam, 2015; Chandra et al., 2017) found that climateresilient field schools (CrFSs) provide a fruitful environment for the coproduction of locationspecific knowledge such as weather and climate information for smallholder farmers. CrFSs involve multilevel institutional actors (Chandra et al., 2017) that help to cover the costs of the coproduction process. However, barriers in terms of mismanagement and financial constraints need to be addressed for effective application of the farmer field school strategy (Chandra et al., 2017).

Table 5.5. Recommended design criteria or principles (development phase) for creating effective weather and climate information system (WCIS) with and for smallholder farmers, combining local and scientific-based forecasting knowledge

\begin{tabular}{ll}
\hline Items & Design criteria recommendations \\
\hline $\begin{array}{l}\text { (1) Goal of the co- } \\
\text { production of weather } \\
\text { information service }\end{array}$ & $\begin{array}{l}\text { Defining the goal of the WCIS is important for design tailoring. The } \\
\text { engagement with farmers, extension agents, and scientists to collect } \\
\text { local forecasts and weather indicators (with rainfall data for } \\
\text { validation), combined with scientific model-based forecasts and } \\
\text { group interaction. }\end{array}$ \\
\hline
\end{tabular}


(2) User interface of the application (front-end and back-end design)

The ICT-based tool should have a simple and clean design with an emphasis on visualization. Consensus and visual design facilitate understanding by low- literacy farmers. Additional voice messages can be used to further facilitate farmers' understanding. The twoway information sharing system (i.e., both sending and receiving data and forecasts) could be integrated within a single application that uses algorithms in the back-end design which automatically process and display forecasts.

(3) Capacity Building of Training is necessary to learn from farmers and ensure appropriate both farmers and design, good usage of tools, and the quality of the data collected. research scientists Training can be delivered through workshop sessions with farmers. During the development phase of the information service,

(4) Monitoring and technical assistance during the development phase

(5) Sample size of the coproduction participants monitoring and technical assistance are important to ensure the appropriate use of tools and quality of the local forecast knowledge and data, as well as coaching to keep the participants motivated. Monitoring and technical assistance also help in detecting problems and making the adjustments needed to solve the technical and nontechnical issues that arise.

The sample size is important. At least one farmer should be included from each community targeted. This will help achieve a good distribution of the dataset across the district or area considered. We also learned that availability, knowledge, and engagement are more important for the quality of data than having a large number of farmers. However, the coproduced information can be shared with a larger group of farmers in the district.

We learned that it is important to include both older and younger

(6) Socio-demographic characteristics of the co-production participants farmers in the coproduction process and to balance gender as much as possible. This facilitates knowledge harnessing, sharing, and transfer between generations. It is also important to include agricultural and meteorological extension agents in the coproduction process, as they are in contact with a large network of farmers and, thus, can boost sharing of the results.

Table 5.6. Recommendations on the design criteria or principles (upscaling phase) for an effective weather and climate information system with and for small scale farmers that combine local and scientific knowledge.

\begin{tabular}{ll}
\hline Items & Design criteria recommendations \\
\hline & $\begin{array}{l}\text { Costs are involved in the acquisition of tools (e.g., smartphones and } \\
\text { rain gauges), in providing training sessions, and in monitoring and }\end{array}$ \\
$\begin{array}{l}\text { (1) Trade-off between } \\
\text { linding assistance to farmers to ensure appropriate usage of tools } \\
\text { quality of intervention } \\
\text { and the quality of data and forecasts. To optimize these investments, } \\
\text { we recommend intensifying the coproduction intervention within a } \\
\text { limited but representative group of farmers and extension agents } \\
\text { (see notes on sample size and socio-demographic characteristics in } \\
\text { Table 5.5). This will help ensure the quality of the data and its }\end{array}$ \\
\hline
\end{tabular}




\begin{tabular}{|c|c|}
\hline & $\begin{array}{l}\text { continuous improvement. The coproduced information can be made } \\
\text { available and disseminated publicly in the targeted district. }\end{array}$ \\
\hline $\begin{array}{l}\text { (2) Dissemination of } \\
\text { weather and } \\
\text { climate } \\
\text { information }\end{array}$ & $\begin{array}{l}\text { This case study found that extension agents played a key role in the } \\
\text { dissemination of weather forecast information, as they were in } \\
\text { contact with a larger network of farmers. This demonstrates that } \\
\text { both farmers and extension agents involved in the experiment can } \\
\text { provide a base for sharing knowledge across the communities of the } \\
\text { district. }\end{array}$ \\
\hline $\begin{array}{l}\text { (3) Transferability of } \\
\text { the design criteria } \\
\text { to other areas }\end{array}$ & $\begin{array}{l}\text { The design principles can be applied to other areas where local or } \\
\text { traditional forecasting knowledge exists and can be used to boost } \\
\text { uptake of scientific model-based weather and climate information. } \\
\text { However, internet coverage is essential for real-time data collection. } \\
\text { Moreover, location-specific information needs have to be identified } \\
\text { first. Moreover, local forecast indicators will vary from place to } \\
\text { place and need to be identified for each new target community. }\end{array}$ \\
\hline $\begin{array}{l}\text { (4) Sustainability and } \\
\text { inclusiveness }\end{array}$ & $\begin{array}{l}\text { Regarding sustainability and inclusive development, it is } \\
\text { important to reflect on the way forward with local authorities } \\
\text { and to choose together an appropriate approach for scaling } \\
\text { up. For example, as a follow-up to this study, we decided } \\
\text { together with district authorities to create a business model } \\
\text { for the development of an app that combines the } \\
\text { functionalities of the two apps used in this experiment. That } \\
\text { app is now under development and provisionally called } \\
\text { "FarmerSupport" (http://www.waterapps.net/en-us/ghana- } \\
\text { updates/farmersupport-mobile-app- now-online/). } \\
\text { The coproduction process can be incorporated into the } \\
\text { "farmer field school system", which offers a location- } \\
\text { specific environment for intensive, technically rigorous } \\
\text { knowledge exchange [53]. Farmer field schools are often } \\
\text { supported by a multilevel institutional platform that } \\
\text { includes international, national, and sub- national actors. } \\
\text { Hence, they can provide a setting and resources for farmers } \\
\text { to coproduce and access weather and climate information } \\
\text { and related agrometeorological services. }\end{array}$ \\
\hline
\end{tabular}

\section{Conclusions}

This study evaluated an experimental coproduction process for ICT-based weather forecast information services developed with and for smallholder farmers in Ada East District, Ghana. It also identified several lessons for similar interventions in the future. In particular, our research yielded two main insights related to the value of coproduction and its implementation. Firstly, the research demonstrated that digital tools (smartphones and apps) and rainfall monitoring tools with simple interfaces, designed with and for smallholder farmers, can lead to useful and usable weather forecast information services. The tools employed offered a unique opportunity for farmers and researchers to collaborate, real-time collection of local or traditional forecasts and data, and for processing and combining local knowledge with scientific model-based forecasts. The Ada East 
case study further demonstrated that coproduction of a WCIS can facilitate farmers' access to and acceptance of weather and climate information and promote a better understanding of forecast uncertainties, leading to improved farming decisions. However, longer-term changes in yields and livelihood assessments are needed to prove the real effectiveness of the coproduced WCIS. Our findings suggest that a coproduced information service is more likely to be accepted and used by vulnerable smallholder farmers in the study district.

Secondly, our study advanced understanding of design principles for a new generation of climate information services tailored for smallholder farmers. Coproduction of an ICT-based WCIS was found to require intensive collaboration between scientists and a dedicated group of farmers and extension agents. Capacity building was needed, alongside continuous monitoring and technical support during the design and testing phases. If a WCIS is built on both local and scientific forecast knowledge, it has more chance to be accepted, understood, and used by smallholder farmers. Integrating WCIS into agricultural policies and decision-making would further enhance the adaptive capacity of smallholder farmers in developing countries. These findings will also be of interest to the growing research community studying the integration of traditional forecasting systems into modern climate information services.

Funding: This research is part of the WATERAPPS project (http://www.waterapps.net/) and is funded by the Netherlands Organization for scientific research (NWO/WOTRO) under the Urbanizing Deltas of the World (UDW) program, grant number W 07.69.204.

Acknowledgments: This research was fully funded by the Netherlands Organization for Scientific Research (NWO/WOTRO) under the urbanizing deltas of the world program (UDW) and WaterApps (www.waterapps.net) project. Our sincerest gratitude goes to the farmers of Ada East District communities who contributed to local data collection and are the holders and custodians of this information. We also thank the Agriculture and Development Unit, Ada East, Ghana for their facilitation of the coproduction set-up. 


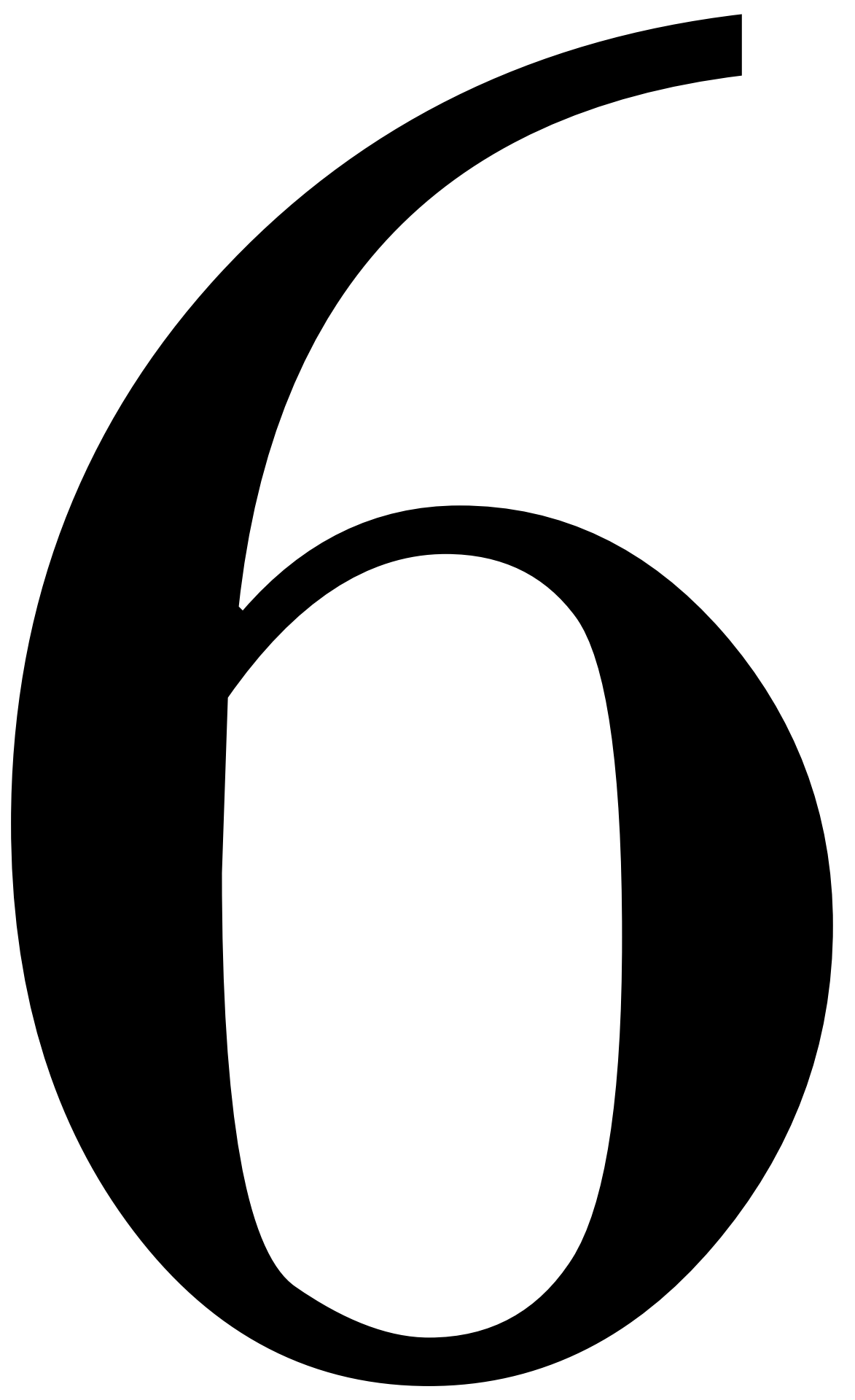




\section{Chapter 6}

Beyond 'experts knowledge': Locals and experts in a joint production of weatherApp and weather information for farming in the Volta Delta, Ghana 


\title{
Chapter 6
}

\begin{abstract}
Local knowledge about weather conditions is often crucial to farming practices in developing countries. It is potentially valuable when combined with scientific knowledge. Citizen science approaches rely on participatory environmental monitoring to source knowledge and information from citizens. The study examined the opportunities and challenges for tapping into local knowledge by using smartphone applications - this topic that is often discussed but less studied empirically. Based on an in-depth qualitative case study approach, involving interviews and workshops, a citizen science experiment involving 22 farmers in Ada-East District, Ghana was analysed. Farmers were handed smartphones to digitally enter their weather forecasts, their local indicators, and actual rainfall. The study found that the daily display of the forecast on whatsApp generated interaction and feedbacks among farmers and experts. The usability of the smartphones and digital applications for recording local information depends on an appropriate user-interface, language, cultural context, internet, and electricity coverage. The study also presents lessons on motivation of farmers, and the challenges of linking different knowledge system. Critical areas identified for future consideration include data ownership and the expansion of the project to reach numerous farmers.
\end{abstract}

Paper accepted: Sarku, R., Gbangou, T., Dewulf, A. \& Slobbe, V.E. (2020). Beyond 'experts knowledge': Locals and experts in a joint production of weatherapp and weather information for farming in the Volta Delta, Ghana. In: Leal Filho W., Luetz J., Ayal D. (eds) Handbook of Climate Change Management. Springer, Cham. https://doi.org/10.1007/978-3-030-22759-3_114-1 


\subsection{Introduction}

Citizen science has become a popular approach to generate scientific data. The approach offers the possibility of generating huge volumes of data on a large temporal and spatial scale with the aid of lay people (Buytaert et al., 2014) and is currently used as an approach to carry out research across scientific domains (Tinati et al., 2017). Citizen science approaches rely on participatory environmental monitoring to source information from participants for environmental and climate change management purposes. This includes observations of natural phenomena such as the weather and climate indicators by local residents who experience these phenomena and have considerable knowledge (Reyes-García et al., 2016). Participatory environmental monitoring is mostly used in tropical, Arctic and developing regions, where communities depend directly on natural resources (Danielsen et al. 2008). Participants in participatory environmental monitoring may derive several benefits, including conservation and development of natural resources (Danielsen et al., 2007b; Turreira-García et al., 2018). Despite its benefits, the application of participatory environmental monitoring in a developing country context has several challenges which affects engagement and motivations of participants (Costa et al., 2018; Kleinke et al., 2018). Empirical research has indicated that engagement and motivation can be enhanced when research goals are aligned with the pressing needs of participants (Pacha, 2015; West \& Pateman, 2016).

This chapter discusses research on the engagement and motivation of farmers who were involved in participatory environmental monitoring of the weather in rainfed farming areas in the Volta delta, specifically, the Ada East District near Accra in Ghana. In most parts of Ghana's Volta delta, farming is reliant on rainfall; however, rainfall varies on spatial and temporal scale across the district. An assessment of climatic conditions in the delta show variability and high-risk levels for cropland areas, particularly in the Ningo-Prampram and the Ada Districts (Deltas, vulnerability \& Climate Change: Migration \& Adaptation (DECCMA), 2017). Spatial and temporal variability in rainfall has several effects on farming. Citizen participatory environmental monitoring can engage farmers in observing and predicting weather conditions with the aid of Information Communication Technology (ICT). This study aims to examine the reasons why farmers are engaged and motivated to contribute data in participatory environmental monitoring on weather conditions.

\subsubsection{Rationale for and intended contribution of this research}

Climate change adaptation is a key strategy that enables vulnerable societies to respond to climate change and variability. Adaptation to climate change has become relevant due to the complexity and increasing effect of climate change on different sectors of societies including agriculture, health, water, among others. However, the agricultural sector is the most affected due to the dependence on water in various forms (Pesche et al., 2016; Nicholls et al., 2020). In developing regions such as Africa, agriculture is affected by climate change and variability, especially in sensitive socio-ecological regions such as the delta, coastal areas, islands, savanna belts, arid lands and so forth (van Berkum \& Dengerink, 2019; Nyadzi et al., 2018a). There are instances where too much rainfall results in flooding, increase in sea level and saltwater intrusion, thereby affecting the quality of water for farming (Luetz \& Havea, 2018). In other situations, the effects of climate change are evident in the form of drought or limited rainfall which affects the level of groundwater table and the amount of surface water that can support the growth of crops (Swe et al., 2015; Gopalakrishnan et al. 2019). Additional observations have also indicated false start, short rainy seasons, dry spell in-between seasons and low amount of rainfall which did not occur in the past (Chepkoech et al., 2017; Gbangou et al., 2019; Nnadi et al., 2019). 


\section{Chapter 6}

Given the relevance of agriculture in Africa, the application of weather information has become a crucial adaptation strategy to manage the effects of climate variability in sensitive socio-ecological regions (Hansen et al., 2019). Weather information services for farming include seasonal forecast, early warning systems for floods and/or droughts, irrigation scheduling, and daily and weekly forecasts for specific geographical location (Naab et al., 2019). Various scholars have highlighted the importance of weather information services because access to information forms the basis upon which farmers make crucial decisions regarding their farming activities. Information also builds the capacity of farmers to anticipate risks to their livelihoods (Vogel et al., 2017). Despite the existence of weather information services as an adaptation strategy, they are mostly not used by farmers in Africa due to: (1) misalignment between the weather information needs of farmers and the actual information that is being provided (Vaughan \& Dessai, 2014); (2) disconnection between farmers and weather information service providers (Changnon, 2004); and (3) inadequacy of the information, the medium and mode of dissemination and non-contextualization of information to suit farmers' needs (Dilling \& Lemos et al. 2011).

To solve these challenges, it is relevant that information providers and farmers interact and coproduce tailored weather information services (Kirchhoff et al. 2013). The co-production process is aimed at enabling farmers to interact with information providers. It also allows the production of weather information services iteratively to make room for changes (Jasanoff, 2010; Bremmer \& Meisch, 2017; Vincent et al., 2018). The proliferation of ICTs in Africa widens the opportunity to co-produce weather information services with farmers. It is estimated that for every household in Africa, at least one member uses a mobile phone (Aker et al., 2011; Food and Agriculture Organisation, 2017). ICTs such as mobile phones, the internet, computer, global position systems, and so forth provide opportunities for farmers, researchers, and information providers to exchange knowledge and data (Mahon et al., 2019).

The approach of co-producing weather information as an adaptation strategy is relevant in Ghana's Volta River delta region, due to the continual experiences of variability in climatic conditions annually and in-between seasons (see Ofori-Sarpong \& Annor, 2012; Teye \& Owusu, 2015; Mul et al., 2015; Gbangou et al., 2019). The Ada East District is mentioned as one of the vulnerable districts in the Volta delta due to experiences in climate variability and other environmental challenges (DECCMA, 2017). In most farming communities in Ghana including the Ada East District, the existing scientific weather information is mostly not used due to lack of location specific information, language and literacy barriers, limited ICT usage to access weather information from the internet, and untimely provision of relevant weather forecasts (Naab et al., 2019). As a result, farmers mostly apply their local knowledge to forecast the weather since they consider it to be more reliable and location specific than the formal scientific forecast. Even so, they have acknowledged that there are limitations in their indicators due to increasing variability in weather conditions, possibly attributed to climate change (Naab et al., 2019). Hence, although scientific and local knowledge have the potential to complement each other for the co-production of weather information, the two knowledge systems remain largely separated. The outcome is that, farmers in the Ada East District are in a dilemma in their decision-making on when and how to plough, sow seeds, apply fertilisers, herbicides or pesticides and harvest due to the variable weather conditions and inability to apply weather information in decision-making (Sarku et al., 2020a).

In this situation, the potential of ICT can be tapped to co-produce weather information with farmers through citizen science participatory environmental research. With this approach, the interface of 
ICTs can be designed with farmers to ensure effective data collection, feedback and interactions between farmers and information providers (Nyadzi et al., 2018a). Farmers can monitor daily or seasonal local weather indicators in their specific communities and share the observations and predictions onto a pre-designed domain where it can be integrated with scientific models to improve location-specific and accessible weather information (O'Grady et al., 2016). Hence, this study is motivated by the fact that participatory environmental monitoring research can contribute to the provision of location specific weather information in developing country contexts where the costs of installing automated ground weather stations in various communities is high. Several participatory environmental monitoring research have successfully applied this strategy with ICTs to collect data on local indicators for conservation and forest management in developing countries (see, for instance Evans \& Guariguat, 2008; Forest Compass, 2015; Brammer et al., 2016; Rutten et al., 2017; Tinati et al., 2017). However, these studies have provided little knowledge on the engagement and motivations of participants in their research (Turreira-Garcia et al., 2018). Additionally, despite the relevance of participatory environmental monitoring research and the increasing use of ICTs for this purpose, it has remained an understudied area in the climate change management and agricultural literature as co-production of weather information is relatively underdeveloped and still in its infancy (Hansen et al., 2019; Phillips et al., 2018; Beza et al., 2017). For this reason, the process of co-producing weather information with farmers' local knowledge through monitoring of environmental indicators was observed to examine their engagement and motivations in a citizen science participatory environmental monitoring research in the Ada East District, Ghana to provide lessons for future research on participatory environmental monitoring for climate change management.

The study addressed the following research questions: What motivates farmers to engage in participatory environmental monitoring of local weather indicators and what barriers affect their engagement? The sub-questions are: 1 . What is the engagement of farmers in the participatory environmental monitoring process? 2. What are the motivations of farmers to engage in participatory environmental monitoring of local weather indicators? 3. What barriers affect farmers' engagement in the collection of data? This study extends beyond previous studies (see for instance, Tarchiani et al., 2017; Etwire et al., 2017; Clarkson et al., 2019; Partey et al., 2019) by inviting farmers to use smartphones to digitally enter their weather forecasts, the local indicators associated with the forecasts and the actual rainfall amount recorded in their communities. The next section discusses the key concepts that will be used to structure the study and analyse the data. They include: citizen science and participatory environmental monitoring, engagement and motivation.

\subsection{Operationalising concepts in the study}

\subsubsection{Citizen science and participatory environmental monitoring}

Citizen science encompasses the involvement of individuals (lay people) in scientific research. Individuals may collect, analyse, categorise or transcribe scientific data (Bonney et al., 2009). The process of engaging laypeople to participate in various aspect of research make citizen science a participatory form of science (Buytaert et al., 2014). Citizen science methodology ranges across the spectrum of data contribution, collaboration and co-creation (Bonney et al., 2009). Participatory environmental monitoring is part of citizen science and it involves local people who monitor and collect data on their environment, with their local knowledge (Pacha, 2015; Turreira-García et al., 2018). In this study, participatory environmental monitoring involves local people who are users of the monitored resource, connects local and scientific knowledge, and monitors rapidly changing 


\section{Chapter 6}

environmental conditions such as the weather (Pacha, 2015). Monitoring involves the "systematic gathering and analysis of information to gauge if something is changing" (Evan \& Guariguat, 2008). Hence, information is collected at specified intervals depending on the resource that needs to be monitored (Evan \& Guariguat, 2008). The advent of ICTs (smartphones, SMS, social media, tablets, digital cameras, data logger, and the global positioning system) are enabling frequent and real-time data collection, processing, analyses and dissemination of results. ICTs have also been identified as motivating people to engage in monitoring their environment (Lewis \& Nkuintchu, 2012; Pratihast et al., 2014).

\subsubsection{Engagement of participants in participatory environmental monitoring}

The term engagement has varied definitions and meanings attached to it, depending on the research objective in question (Seymour \& Haklay, 2017). This study defines engagement in participatory environmental monitoring as the level and duration of involvement in the collection of data (Maslach, 2011). According to Seymour and Haklay (2017), engagement also bears an emotional aspect as it involves participants experiences, sense of relatedness, competence, social interactions and so forth (Curtis, 2018). These factors can motivate participants to engage in participatory environmental monitoring.

\subsubsection{Participant motivation in participatory environmental monitoring}

Motivation simply explains why people remain or are committed to a particular activity. Various approaches have been used to understand the motivation of individuals in participatory environmental monitoring. Motivations differ in amounts (levels of motivation) and kinds (orientation). Ryan and Deci (2000b) defined two kinds of motivations: intrinsic and extrinsic.

Intrinsic motivation involves participating in an activity to derive an inherent satisfaction (Ryan and Deci, 2000b). Intrinsic motivation is inherent because human beings are naturally curious and display the willingness to learn and explore new things without external incentives to do so (Baton et al., 2002). Intrinsic motivation exists as a relationship between an individual and an activity being performed. Although individuals are endowed with inherent tendencies to naturally engage in activities, most often, the propensity to act is expressed in a certain context or under certain conditions. Intrinsic motivation is enhanced in situations where individuals experience competence (the ability to overcome challenges), autonomy (self-direction) and relatedness (sense of belonging) (Ryan \& Deci, 2000a,b). A list of intrinsic motivation factors that are relevant to participatory environmental monitoring is illustrated in Table 6.1. Intrinsic motivation may serve as an initial driver to enable an individual to engage in an activity; however, it may also develop in the course of engaging in an activity (Frensley et al., 2017).

Extrinsic motivation involves the engagement of individuals in an activity in order to attain some external outcome (Ryan \& Deci, 2000b). When individuals are extrinsically motivated, their behaviour is driven by external factors which push them to engage in an activity with the expectation that they will earn an external reward (Batson et al., 2002). Extrinsic motivations are not initially appealing; hence, they are primarily promoted. Some relevant factors that drive extrinsic motivation are illustrated in Table 6.1. Intrinsic and extrinsic motivations can reinforce each other (Ryan \& Deci, 2000b). Individuals may possess both motivations throughout the participation cycle, and it can also be dynamic. Ryan and Deci (2000b), provided a continuum on human motivation where extrinsic and intrinsic motivations are at extreme opposite ends, while internalized and integrated factors drive behaviours that are extrinsically motivated to become more 
self-determined (intrinsic). There are four categories of extrinsic motivation based on the mechanism that drives them. These include: integrated regulation, identified regulation, introjected regulation, and external regulation (Table 6.1). The application of the framework to study motivations in citizen science project shows different forms of extrinsic motivations with classifications of motivational factors, sources and mechanisms (see Rutten et al., 2017). 


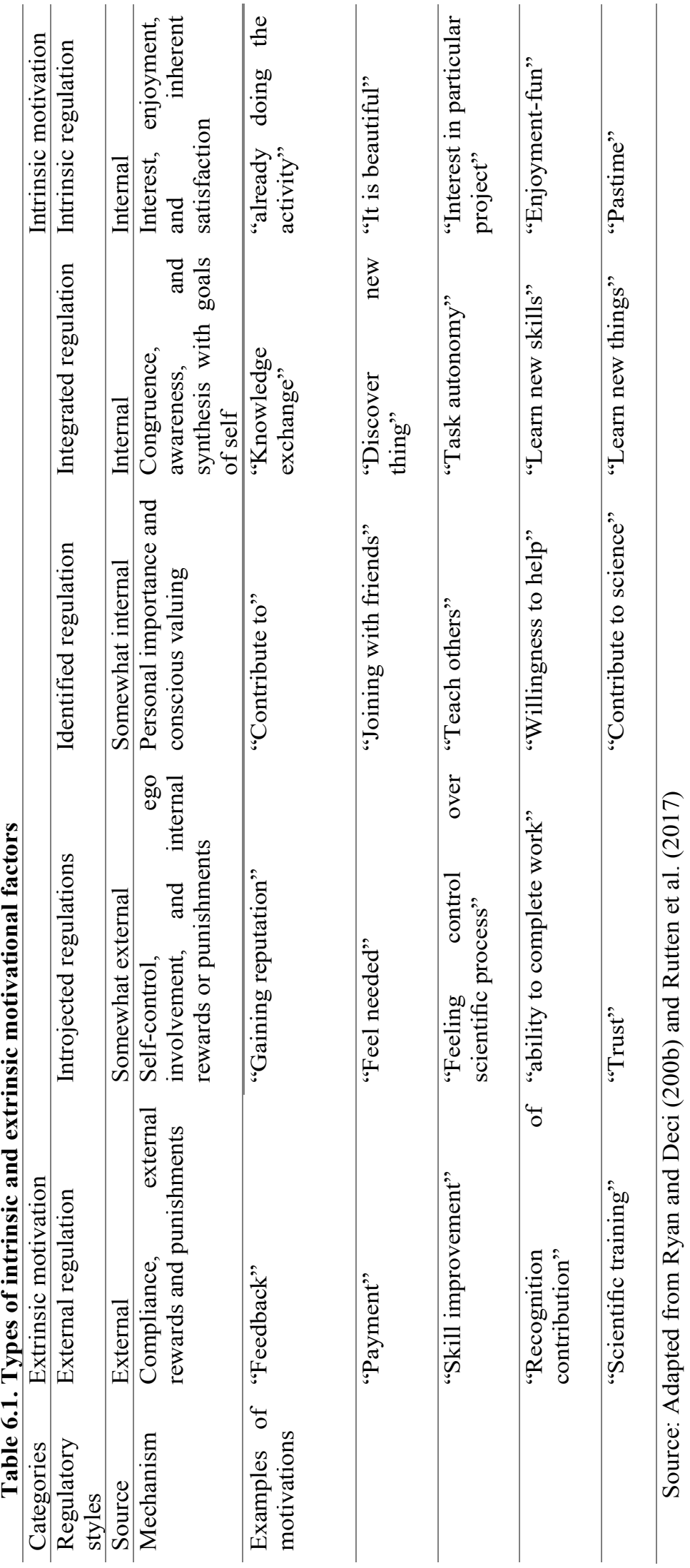




\subsubsection{Barriers that affect engagement in Participatory environmental monitoring research}

The motivation to participate in a monitoring activity can change at various stages, and it can affect an individual's engagement. Barriers that affect the engagement of participants in participatory environmental monitoring are varied (Rutten et al., 2017). Some of them are impersonal issues, lack of control or a feeling of incompetence. Specific examples identified from the literature on participatory environmental monitoring include:

- Lack of infrastructure, for example mobile network, inaccessible internet and availability of electricity (O'Grady, et al., 2016).

- Greater time investment in training participants on the use of ICTs and their reliance on facilitators for guidance (Pacha, 2015)

- Unfamiliarity with ICTs for data collection (Steinke, 2015).

- Susceptibility of ICTs to technical problems; frequent charging of phones, vulnerability of smartphones to damage (Bellfield et al., 2015; Forest Compass, 2015).

- Time commitment and fatigue on the part of participants (Frensley et al., 2017).

- Numeracy and literacy issues (West \& Pateman, 2016).

- High financial cost involving internet data, call credit, frequent repairs, chargers (Forest Compass, 2015; Pacha, 2015).

The above listed barriers can lead to gaps in monitoring data and it can reduce the overall engagement of participants (Forest Compass, 2015).

\subsection{Research methodology}

\subsubsection{Socio-economic and climatic conditions in the Volta delta, the Ada East District}

The Ada East District (Figure 6.1) is one of the nine administrative districts in the Volta Delta (Addo et al., 2017). Diverse economic activities are carried out in the district, but agriculture is the prominent source of food for neighbouring urban markets. Despite the relevance of agriculture in the district, climate related events such as rainfall variability, flooding from both marine and riverine sides, drought, sea-level rise, storm surge, and increased temperature have influenced the quality and quantity of water for farming (Addo et al., 2017; Roest, 2018). Since the 1970s, the West African region has undergone periods of changes in climatic conditions, marked by a series of severe droughts conditions, floods and a shift in rainfall regime (Owusu et al., 2008). This phenomenon also affects the Ada East District as variability in climate conditions is notable yearly and seasonally (Gbangou et al., 2019). The annual average total rainfall is lower than other agroecological and climatic regions in the country. Despite the bimodal rainy season, the area is the driest climatic and agroecological region in Ghana (Teye \& Owusu, 2015). Figure 6.2 shows the interannual variability in rainfall amount, onset dates, dry spell frequency, and dry spell lengths of weather conditions for the Ada area over the period 1981-2018. Onset is explained as the date when a given percentage of cumulative season rainfall is recorded and it accumulates in $25 \%$ of the normalized seasonal rainfall. It represents the secured date from which local farmers can start sowing seeds with low risk of crop failure due to soil moisture limitation. Dry spell length is the largest number of consecutive days during which the rainfall is less than $1 \mathrm{~mm} /$ day over the season considered. While dry spell frequency is the number of dry spells with a length of more than 5 days during which precipitation is less than $1 \mathrm{~mm} /$ day over the season. Seasonal rainfall indicated in figure 6.2 is the sum of rainfall over the season (Gbangou et al., 2019). Figure 6.2 highlights that 


\section{Chapter 6}

high variability of these weather indices is recorded during the major growing season in the Ada East District; that is, from March to May. The high variability shows the uncertain conditions under which farmers predict the weather and climate patterns for the farming seasons annually.

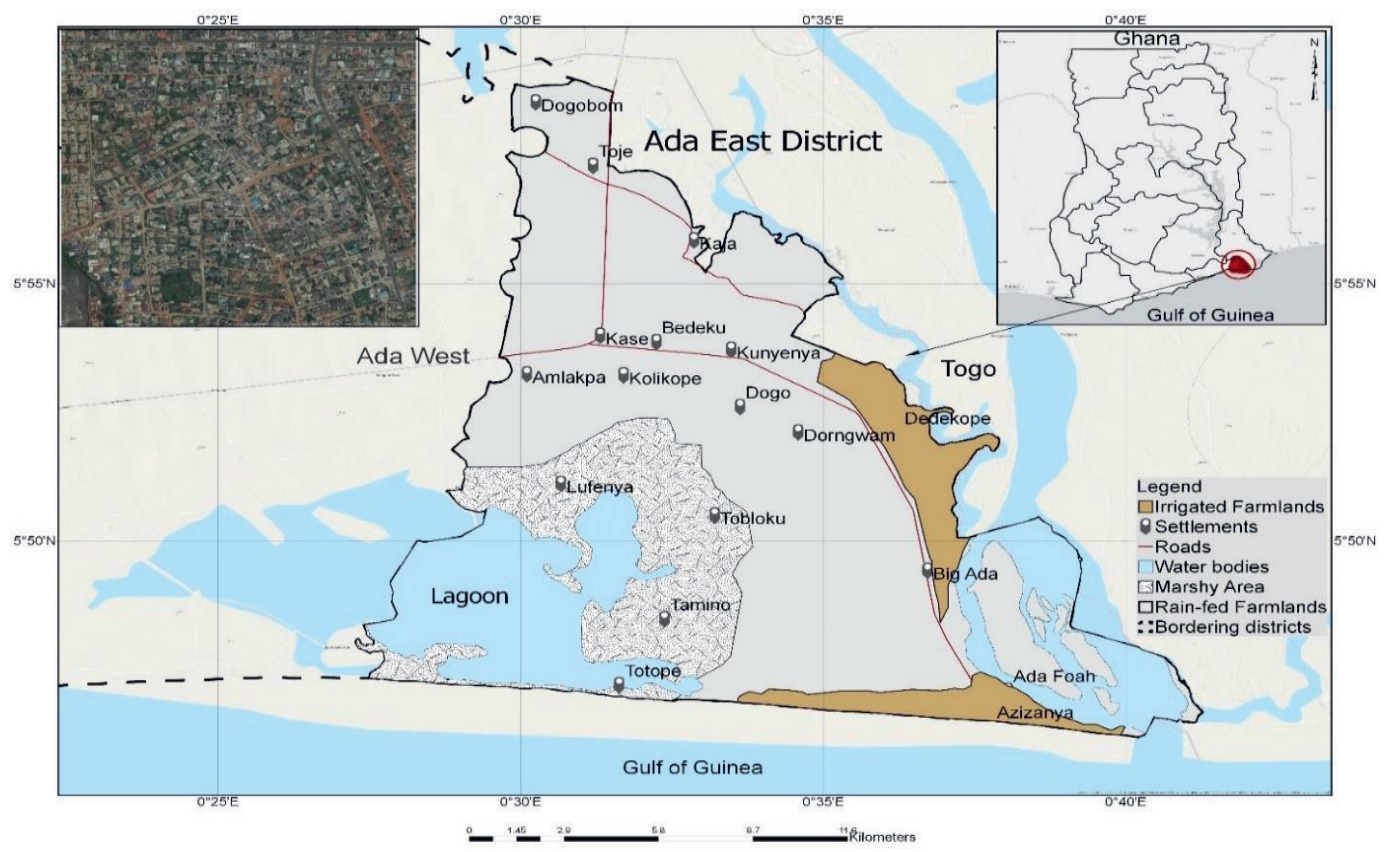

Figure 6.1. Study area showing Ada East District location

Source: Authors' construct, 2019
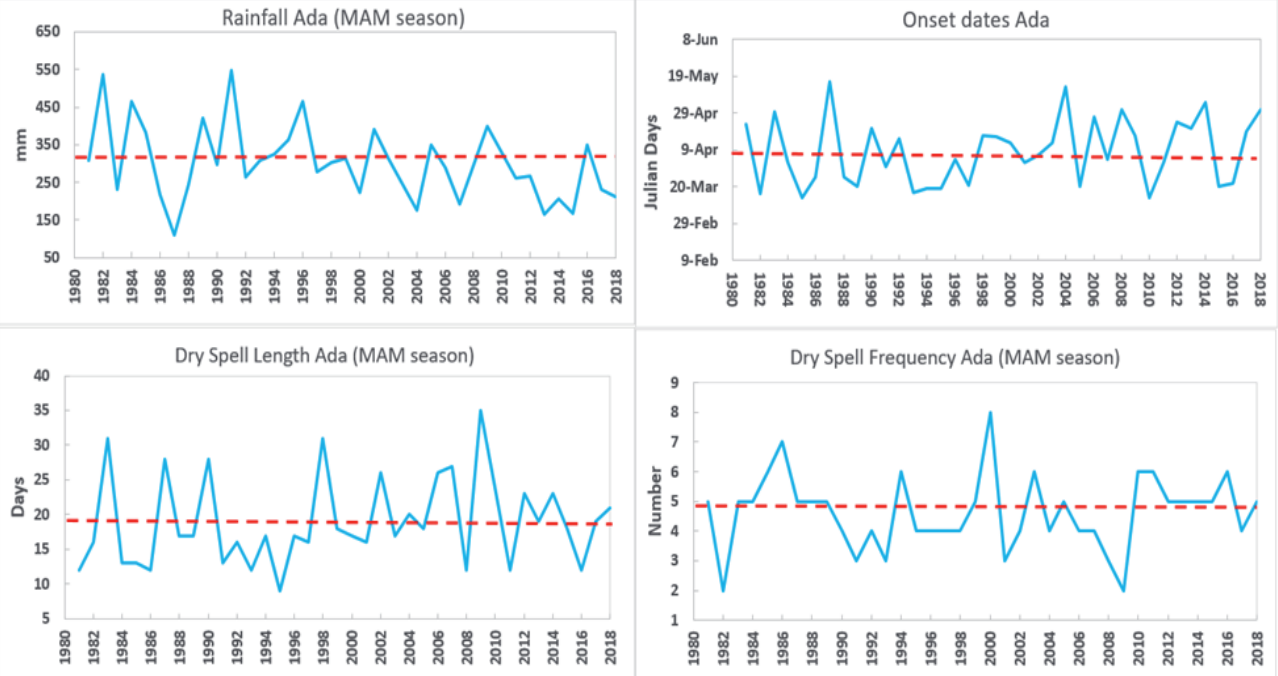
Figure 6.2. Interannual variability in seasonal rainfall, dry spell frequency, dry spell length and onset dates in the Ada Area from 1981-2018. The red-dashed line indicates the long-term mean of each weather indices; while MAM indicates March, April and May.

Figure 6.2. Interannual variability in seasonal rainfall, dry spell and onset dates in the Ada Area

Source: Authors' construct based on meteorological data from the Ghana Meteorological Agency

\subsubsection{Research Design, Methodology, and Data Collection}

Data for the study was collected with qualitative research methods through five steps. Participants in this study were identified during the initial research carried out in the Ada East District between 2017-2018 (see Sarku et al., 2020a). During this phase of the study, face-to-face discussions were carried out with some farmers on the idea of co-producing weather information with their local weather indicators on a daily basis. At the same time, data on farmers' local indicators were collected to produce a web-based app as the user-interface for collecting data. Farmers were made aware of the time commitment required, nature of data collection, the skills required, the nonpayment mode of the research and the opportunities involved, that is, the provision of feedback on their local weather indicators and scientific weather forecasts. The objective of the research was also discussed with experts (agricultural extension agents and a weather forecaster from the Ghana Meteorological Agency).

Farmers were selected from 18 communities from the three agricultural zones (Kasseh, Big Ada and Ada Foah) in the Ada East District. These zones were managed by 5 agricultural extension agents in the district. In each community, at least 1-2 farmers were selected to ensure wide data coverage throughout the district and to also aid in understanding variations in engagement. After the introduction of the idea on the collection of local weather indicators to co-produce weather information, numerous farmers were willing to participate in the study as the objective of the research was appealing. However, 22 farmers were purposively selected from the different communities based on gender, willingness to participate in the project, knowledge of local indicators, age, years of experience in farming and literacy and numeracy levels. In addition to the 22 farmers, 5 agricultural extension agents, and a weather forecaster were part of the study to provide their expertise.

Most of the farmers who participated in the study fell within the age range of 40-59 years while two farmers were between 20-29 years. Majority of the farmers (18) who participated in the research were male with only four females. The low participation of females in this study was due to the involvement of more men in farming while women are mostly engaged in agro-processing and trading in the district. Most farmers had attained different levels of education. The majority of participants have completed junior high school or middle school level of education in Ghana. Only four farmers had no formal education (Figure 6.3). 


\section{Chapter 6}

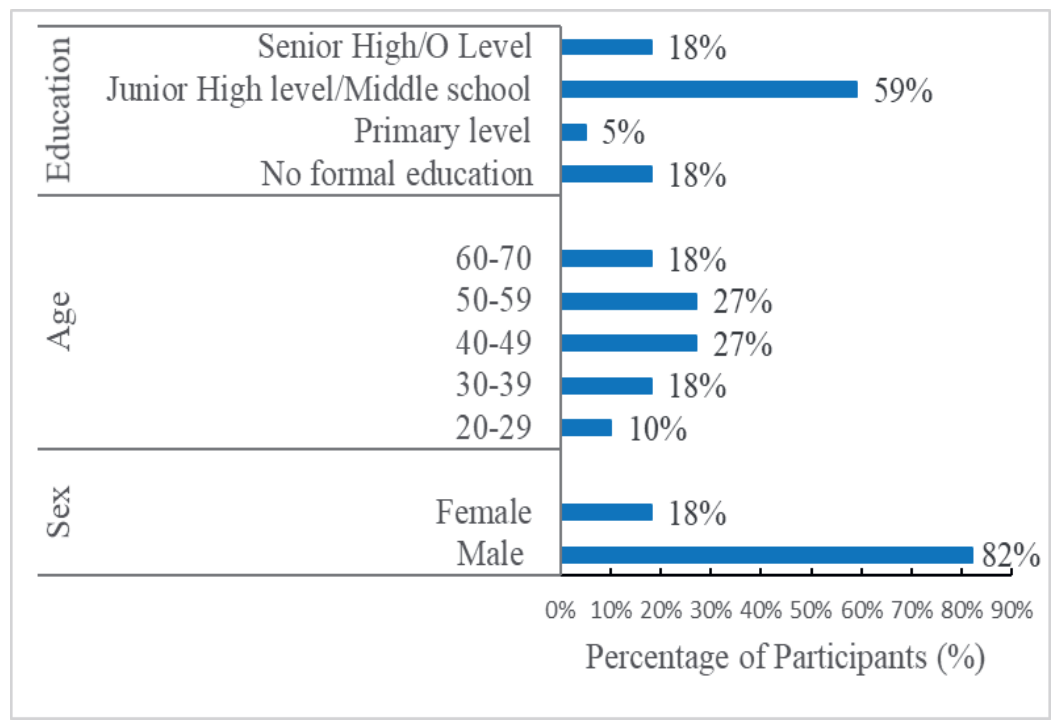

Figure 6.3 Characteristics of farmers who participated in the participatory environmental monitoring research

Source: based on authors' fieldwork, 2019

A workshop was conducted in August 2018 to show the weather app interface to farmers for necessary alterations to be made. The interface had images of farmers' local weather indicators (Figure 6.4). This was followed by 2 training workshops in September 2018 on the use of smartphones, the weather app, WhatsApp, rain gauge and record takings in fieldnote books (See Table 6.2). The user-interface of the weather app was simple to avoid literacy and numeracy challenges. 

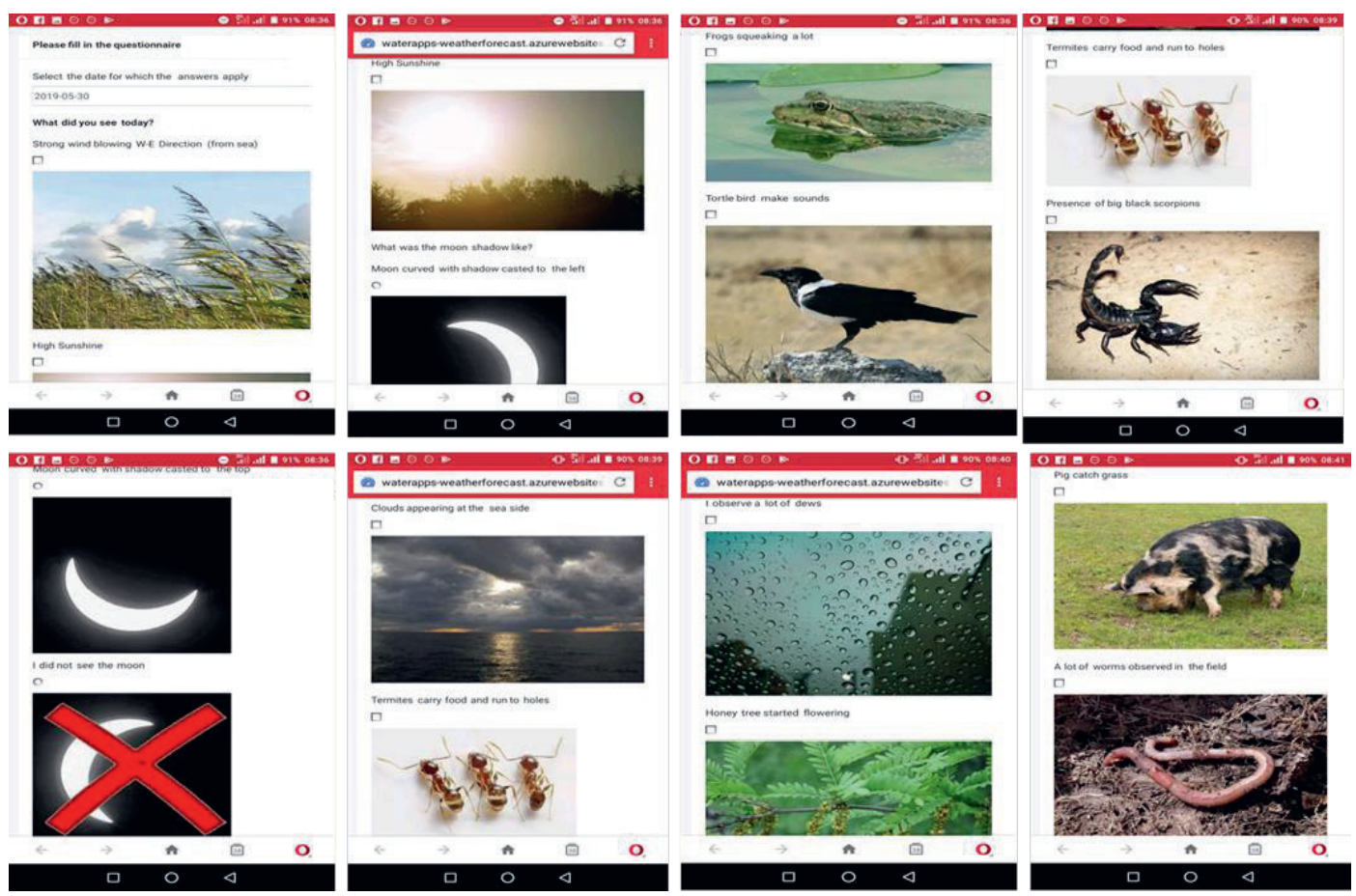

Figure 6.4 The interface of the weather app showing some images of local weather indicators and data collection procedure

Source: Authors' field data, 2019

At the onset of the main rainy season in March 2019, farmers were trained again on the use of the aforementioned technologies. Each farmer was assigned a code to conceal their identity during data collection and interactions in the WhatsApp group. After the training activities, the actual data collection started in April, 2019. Farmers were asked to first report an observation by selecting an accompanying picture and their predictions on daily basis. The rules on data collection, rainfall measurement and record keeping protocols were clearly set out at the workshop for all actors.

During the process, farmers' engagement, motivations, and barriers were monitored and notes were taken. They were also paid periodic home visits to inspect how they used the smartphones to collect data and also solved technical challenges. Additionally, mobile phone calls were made on weekly basis to check whether they had the necessary resources to collect data. All these activities were documented in fieldnotes.

Semi-structured interviews were conducted with farmers at the end of the main season in August 2019 to solicit their views on their engagement, motivations and barriers. The interviews were conducted with all the 22 farmers who were selected for the research. The use of a semi-structured interview guide enabled conversations to flow along topics emerging from the research. 


\section{Chapter 6}

Table 6.2 Outline of workshops and training programs organised

\begin{tabular}{|l|l|l|}
\hline Workshops & Time & Purpose \\
\hline $\begin{array}{l}\text { Introduction to } \\
\text { weather app } \\
\text { user-interface }\end{array}$ & August & $\begin{array}{l}\text { Discussion with farmers a suitable ICT } \\
\text { that can be used for data collection and } \\
\text { the user-interface }\end{array}$ \\
\hline $\begin{array}{l}\text { Training on } \\
\text { smartphone, } \\
\text { weather app and } \\
\text { rain gauge }\end{array}$ & September & $\begin{array}{l}\text { Testing of the app and training of } \\
\text { farmers on the use of smartphone }\end{array}$ \\
\hline $\begin{array}{l}\text { Inception } \\
\text { workshop for } \\
\text { the main season }\end{array}$ & April & $\begin{array}{l}\text { Recap training of farmers on the use of } \\
\text { smartphones with the weather } \\
\text { application and the introduction of } \\
\text { WhatsApp page }\end{array}$ \\
\hline $\begin{array}{l}\text { Mid-season } \\
\text { workshop }\end{array}$ & May & $\begin{array}{l}\text { To introduce scientific rain gauge, } \\
\text { identification of uncertainty with pie } \\
\text { chart, and record taking with notebook }\end{array}$ \\
\hline Fifth & $\begin{array}{l}\text { Training on the use of WhatsApp and } \\
\text { note taking on rainfall measurement }\end{array}$ \\
\hline
\end{tabular}

Source: Authors' field data 2019

Interviews were tape-recorded and transcribed, followed by a thorough examination of the transcripts, screenshots of WhatsApp messages, and fieldnotes. These were read several times to generate initial codes and themes. The initial review and preliminary analysis of all the data sources led to the identification of 3 broad themes that were used for the first round coding: (1) engagement (2) motivation and (3) barriers. The data was subsequently uploaded into the qualitative data analysis software package Atlas.ti for coding. Further exploration and iterative analysis revealed sub-themes that were connected to the broad themes. Iterative coding process was used to elicit categories of sub-codes for the broad themes by reflecting on the conceptual framework. For example, the broad theme (motivation) had sub-themes (intrinsic and extrinsic) and primary codes (e.g. "want to share"). This strategy was used to code the data due to the length and richness of the responses generated from the interview. The analysis was also supported by computing descriptive statistics from the demographic information collected through the interviews and fieldnotes. In order to understand the engagement of farmers, characteristics such as longevity and frequency were used (Curtis, 2018; Kleinke et al., 2018). Longevity refers to the length or duration that a person continues to be involved in a voluntary activity. Frequency refers to the number of times or regularity that participants collected data. A volunteer was considered to be a regular data collector if he/she submits data every week; Occasional participants submitted data with gaps in-between weeks for a particular month. This operational definition was used to assess the engagement of farmers from the field data. 


\subsection{Results}

6.4.1 Engagement of farmers in the monitoring of local weather indicators in the Ada East District

Not all farmers contributed to the data collection in a similar pattern during the period of the study. Farmers' engagement (frequency) were characterised into three categories, namely, regular participants, occasional and no-data collectors. Results showed that in the month of April, seven farmers collected data on a regular basis and the number increased (50\%) in July (figure 6.5), the number of non-data collectors were few throughout the period of the research. Overall, there was a gradual increase in the number of regular participants from April to July.

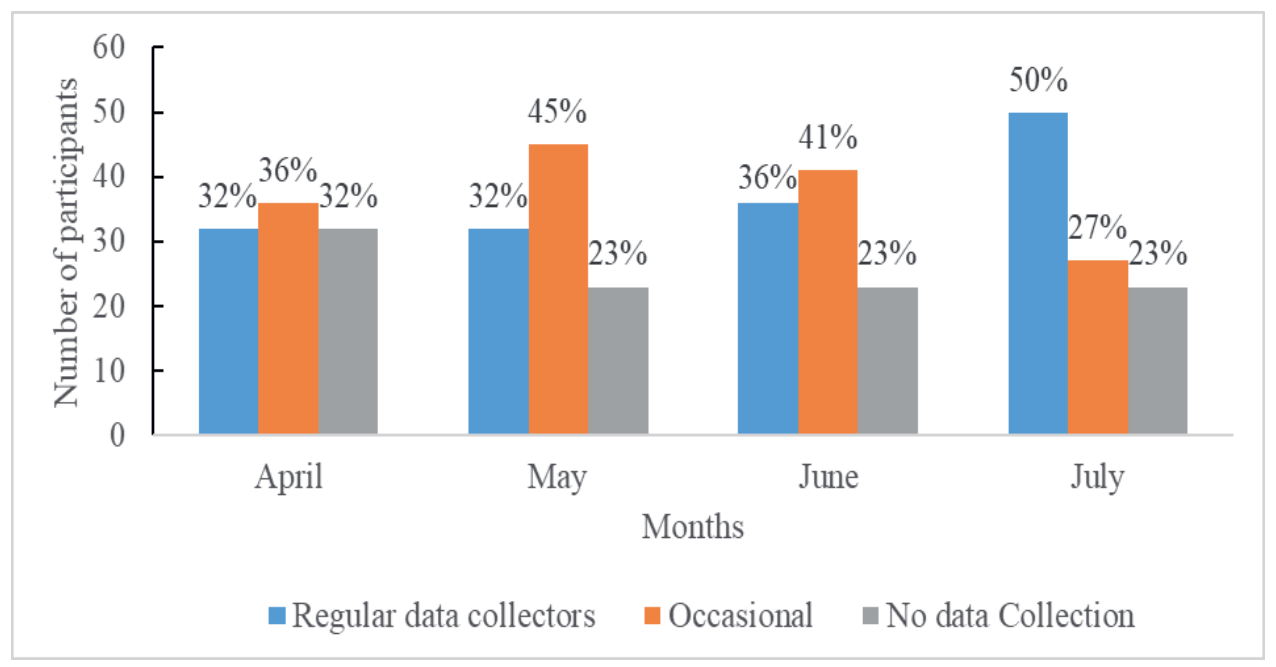

Figure 6.5. Frequency of farmers' data collection expressed in percentage

Source: Authors' construct base on fieldwork, 2019

Three different patterns were found in farmers' engagement overtime (figure 6.6). In pattern 1, some group of farmers were regular participants throughout the period of the research, with increasing engagement over time. Pattern 2 captures farmers who were occasional participants and pattern 3 consists of farmers who were irregular participants and finally dropped out before the end of the research. With the three patterns identified on the longevity of engagement, the group of farmers in pattern 1 form the largest group of participants. In summary, $77 \%$ of farmers collected data up to the end of the research while $23 \%$ dropped-out. Out of the $23 \%$ of farmers who droppedout, $9 \%$ never submitted any data. 


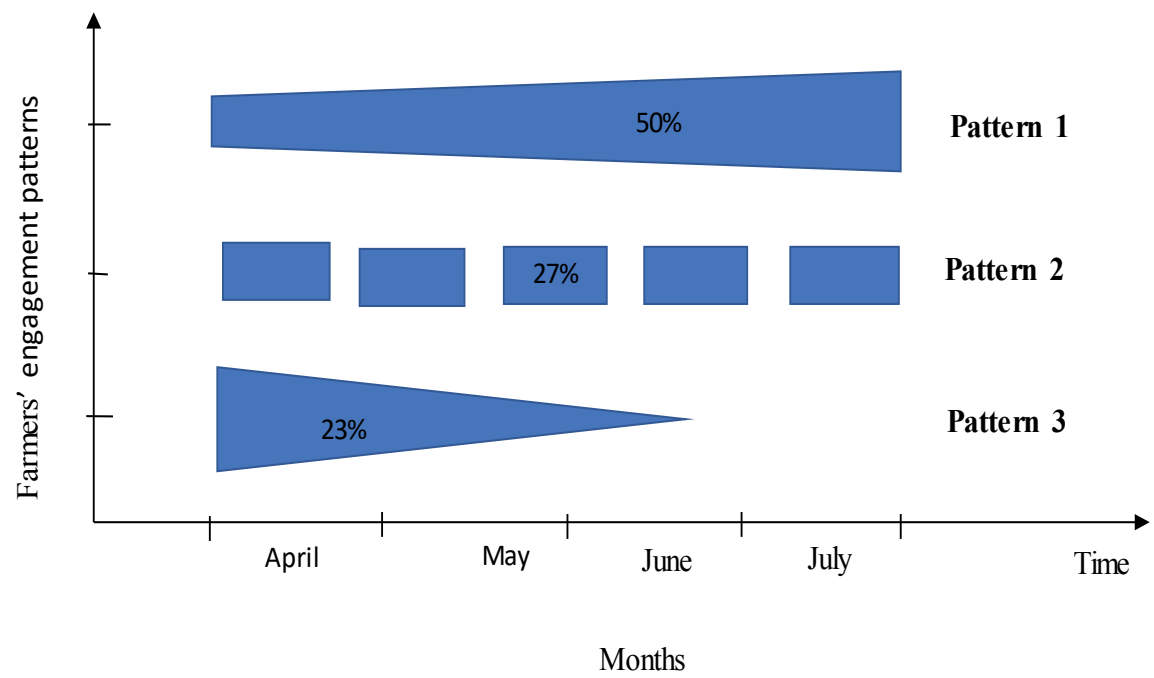

Figure 6.6. Pattern of farmers' longevity in the data collection Source: based on authors' fieldwork, 2019

6.4.2. Motivations of farmers for participating in participatory environmental monitoring of local weather indicators

This section analyses the motivations of farmers for collecting data on the local weather indicators. It involves responses from all the farmers who participated in the research. Findings on the motivations of farmers are presented under the sub-themes, intrinsic and extrinsic.

\subsubsection{Intrinsic motivations of participants who monitored local weather indicators}

The motivations of farmers who participated in this study was intrinsically regulated because they derive an inherent satisfaction from monitoring their environment on local weather indicators without any external factors influencing their behaviour. Findings show that all farmers were motivated to participate because they were interested in a research that connects directly to their livelihoods, especially farming. The fact that the research is about the weather, it motivated farmers to agree to participate in the data collection. For example, a participant said: "Farming is our main occupation here so anything that is about farming we are interested in it".....so my motivation for joining in this research is because it is interesting to find a research of this kind that want to produce weather information with farmers' local knowledge."

Also, all farmers indicated that their motivation to join in the data collection was because they were ("already doing it") monitoring the weather with local weather indicators to support their decisionmaking in farming. A testimony of a farmer states:

"What motivated me was that before the weather app project started, I am able to tell other farmers in this and other communities that it will rain and it happens. That is before the project o! So, when they are farming and it is becoming difficult and the rains are not coming, they consult me and ask, when is the rain coming again. Then I will observe the environment and respond that it may rain 
or not. So when the research team visited and told me about the idea, I was happy that I will be part of something that I had already been doing."

Farmers were also interested in experimenting with rainfall amounts by predicting and measuring the actual quantity with the rain gauge. Attached to this motivation was the fact that farmers were always interested in searching for two or three indicators to reinforce the certainty that a predicted weather condition would occur: "I don't just submit data that I have seen a bird as the sole indicator that it will rain! When I see that bird, I have to see two other indicators which have the same meaning before I submit my observations." The fact that farmers were already monitoring local weather indicators suggest that they had greater competence which also motivated them to collect the data.

Some groups of farmers in pattern 1 were motivated to collect data for the research because it was their hobby. Thus, when they were invited to join in the research, they saw it as "an opportunity to do more."

\subsubsection{Motivational factors that straddle between intrinsic and extrinsic motivation}

Findings from the study show that some motivations of participants were not fully intrinsic or extrinsic. Learning is one of the motivations which bolstered participants' competence to collect data for the study. Learning occurred in four different ways depending on when and where it evolved during the period of the research.

All farmers gained additional knowledge about local weather indicators and ways of monitoring the environment from their colleagues. With regards to this motivating factor, findings of the study show that before the research began, farmers had different levels of knowledge about local weather indicators. Specifically, $18 \%$ of farmers indicated that they had 'little' experience, $31 \%$ of farmers considered themselves to have 'average' experience and $50 \%$ of farmers mentioned that they were 'experienced' with the use of local weather indicators. The knowledge on monitoring the environment with regards to changes in weather conditions is another reason for accepting to participate in the research. Despite these levels of experience, each farmer expressed satisfaction about how they learnt new local weather indicators. One of the 'experienced' farmers mentioned that: "I joined to this project before I learnt that the linear pattern produced by the fumes of an aeroplane is an indicator for a likely rainfall for the next day or two."

Some farmers indicated that the new ideas they derived from their colleagues changed their assumptions about certain local weather indicators. It also motivated them to verify and reassess the reliability of the indicators on the weather app.

Learning about the science inherent in farmers' local weather indicators also boosted farmers' competence, which further enhanced their motivation for the research (see pattern 1 and 2 in table 6.4). They used to regard the act of using local weather indicators as "a normal thing" in the farming communities. Some statements of farmers indicate: "we have been doing this thing all the time but now, it seems new all over". "At first, we hadn't learnt most of these things about the local knowledge. We were just using the local knowledge just like that. We just took things in general but now we study the weather and get confirmations about our observations and predictions on the WhatsApp page”. The display of weather information from the two knowledge systems on the WhatsApp page aroused farmers' consciousness to always attach expectations to any indicator they 


\section{Chapter 6}

monitored. Hence, farmers tacit knowledge on 'usual' practices of forecasting with local weather indicators became explicit through the interaction with the formal scientific knowledge. Other events which stirred farmers' interest to continue to learn about the science inherent in their local weather indicators include the observation of repetitive patterns, occurrence of local indicators and observation of uncertainty in farmers' forecast and differences in rainfall amount across communities.

Additionally, the desire to understand formal scientific processes in weather forecasting during the occurrence of certain weather conditions also motivated groups of farmers in pattern 1. Specifically, some farmers realised that the patterns of rainfall differed across communities in the district. The desire to observe these patterns motivated them to collect data. Better still, this motivation can be described as curiosity to observe weather events in other communities. Some farmers identified that:

"In May-June, most farmers provided feedback that it had rain in their communities, but it did not rain in this community. We had two rainfalls in June. This made me realise that the rainfall differs and I also checked the amount and the time the rain started in other communities as reports in the WhatsApp page differed. I became more interested in the research so that I could observe these patterns, differences in time and amount recorded by other farmers."

"I want to get the scientific lessons on weather forecasting. At first, when I receive information on the radio that it will rain and it doesn't happen, usually, I do not understand why the rain did not fall as forecasted. So I use to disregard the scientific weather forecast and assumed that their information were not true. But now, I am learning the reasons why the forecast sometimes fails to come through in my community."

Another motivating factor linked to learning is the desire to learn new "things" introduced to farmers. The new "things" here include, the provision of technologies such as the smartphone, weather app, WhatsApp, the rain gauge, and record-keeping in fieldnote books. This factor was mentioned by all farmers as they indicated that it enhanced their sense of autonomy. In this regard, farmers made comments such as:

"I participated to learn", "The greatest benefit is the learning experience", "I wanted to learn new things". "When you go to the workshop and everyone is participating, it calls for the need to take the lessons seriously. As a result, I am motivated to join and be open-minded to learn something in the project."

The scientific training workshops organised for farmers also served as a motivating factor, due to the capacity building training programs which were provided. For instance at the workshops, farmers learnt about weather forecasting skills, the use of new technologies (smartphones, newly developed App, WhatsApp and rain gauge), and data collection approach. The scientific training also motivated them to conduct experiments with the new technologies. For instance, before the research began, only $32 \%$ of participants were using smartphones, while $68 \%$ were using nonsmartphones limited to receiving and sending calls (see Table 6.3). Farmers were strongly incentivised with the lessons they derived from the training and started using the internet. A farmer stated that: "As soon as the training was over at the workshop, I kept all the instructions and I learnt to use everything on my own. I even tried to use other apps and Facebook". Another farmer 
indicated that, "I was taught about the rain gauge as one of the topics when I was attending school but I have never used it to record rainfall until I was taught at the workshop." Two farmers who dropped out continued to attend the training workshops and considered themselves as part of the research group due to the scientific training provided on weather information and data collection: "Every training brings new knowledge. The capacity building aspect of the research motivated farmers to continually collect data as they expected that it will open doors to new information or opportunities.

Table 6.3. Type of mobile phones and usage among farmers before the participatory environmental monitoring project

\begin{tabular}{l|l|l} 
Activity & Number & Percentage (\%) \\
\hline Use of non-smartphones & 15 & $68 \%$ \\
\hline $\begin{array}{l}\text { Use of smartphones including social media and } \\
\text { internet }\end{array}$ & 7 & $32 \%$ \\
\hline
\end{tabular}

Application of functions of mobile phones

\begin{tabular}{l|l|l}
\hline Making calls & 22 & $100 \%$ \\
\hline Receiving calls & 22 & $100 \%$ \\
\hline $\begin{array}{l}\text { Number of farmers who are able to send/read text } \\
\text { messages with mobile phones }\end{array}$ & 13 & $59 \%$ \\
\hline $\begin{array}{l}\text { Number of farmers who unable to send/read text } \\
\text { messages with mobile phones }\end{array}$ & 9 & $41 \%$ \\
\hline
\end{tabular}

Source: Authors' construct based on field data, 2019

Additionally, a motivational factor which was mentioned by some group of farmers in pattern 1 was that they wanted to contribute to the provision of weather information for the farming community: "I want to contribute to the provision of weather information for farmers. When you go to the community, they now call me the weather man."

Besides, some farmers in pattern 1 also mentioned that they derived social recognition through sharing of knowledge on the local weather indicators and feedback in their communities and on WhatsApp (figure 6.7). Social recognition derived from this act was also a form of reward for these groups of farmers. Others also derived emotional satisfaction from the research as a farmer mentioned: "I am proud to tell others that I am part of this group and I always show them the smartphone with the weather information and digitised local weather indicators." This assertion was made by several other farmers and it is also indicative that they share the weather information with the farming community.

Furthermore, the desire to impart knowledge on the use of local weather indicators for forecasting was another motivational factor which was mentioned by some group of farmers. They reported that: "we have been doing this for several years in our communities and so it is time to also share the knowledge with other farmers." They hoped that the new generation (young farmers) who participated in the research will also gain some knowledge to enhance the continuity of the use of local weather indicators.

According to some group of farmers in pattern 1, the collection of data on local weather indicators were perceived as a way of 'showcasing' their local knowledge. Farmers were influenced to collect 


\section{Chapter 6}

data when they realised that their local indicators have been documented in a digitised form on a smartphone. They mentioned that their daily 'tales' have actually been captured on a phone and the information is shared with other farmers. From their perspective, they were motivated to collect data so as to prove the reliability and the validity of farmers' local knowledge.

The formation of the waterapp citizen science platform also created a community of practice for interaction. This factor motivated farmers to continue to engage in the research because they generated a sense of belong to a community where knowledge and information is exchanged. Farmers interacted during workshops, through phone calls and on the WhatsApp page. A farmer mentioned that: "I am interested in fellowship and sharing with others. So when we meet like that it is enough for me." This suggests that social interactions boosted farmers' sense of relatedness, which motivated groups of farmers in pattern 1 to collect data for the study.

Being part of self-organized groups, such as farmers' families, farming community and farmerbased organisations also motivated farmers to collect data. These self-organised groups have shared interest and expertise regarding the resources being monitored. Whether farmers selected for the research were experienced or not, they exchanged and discussed their observations with their family and colleague farmers before submitting data. The family and the community also played a role in motivating farmers to collect data because they helped to bridge the technical and language barriers to data collection. Some farmers' children or colleagues helped participants to write and read messages on the WhatsApp page, check technical challenges on the phones, renew airtime and internet bundle, measure rainfall, and switch on internet data. For instance, when training was carried out on the use of the technologies, farmers who knew how to operate it assisted others. A farmer also recounted that: "I wouldn't have been able to collect data on my own without the assistance of my colleague. When I need help, I consult him in the next village". Another farmer also mentioned that: "I don't know how to use everything on the phone, so I call my daughter to send the messages once I have made my observations. She also reads the information and then interprets it for me. I also instruct her to write messages on my behalf." This motivation factor was mentioned by farmers in patterns 1 and 2.

The motivations of farmers were also about the feeling of control over the data collection process. For instance, the entire research team agreed on some set rules concerning suitable times to collect data and report on the measurement of the rainfall (figure 6.7). Those who could not send information on the WhatsApp page wrote their records in their notebooks. This motivational factor implies that farmers had autonomy (opportunities for self-direction) over their role in the research.

The appealing nature of the data collection process and farmers' ability to complete tasks easily was due to the data collection mode which was introduced in the research as shown previously in figure 6.4. They indicated that the simple data collection method motivated them to complete various activities associated with this research (competence). A farmer describes the procedure of submitting information with the smartphone application as follows: "all you need to do is to click on the weather app icon and then you tap on the box with the image of the indicator and click on send." The same process applies to the measurement of rainfall. Another reported: "it does not even require in-depth knowledge about computers or smartphones as the same drawing on the rain gauge is on the app. So, it is a matter of knowing where the water had reached and then you also find it on the app and then you click send." 
Participants were motivated to collect data because they "didn't struggle to identify local weather indicators." The local weather indicators collected comprised of flowering of plants, animal behaviours, wind conditions, sunlight, stars, the shapes of the moon and others (see also figure 6.7). The nature of the local indicators and the geographic scale at which they existed motivated farmers to collect data for the research. For instance, a farmer mentions that:

"When I wake up in the morning, I just have to look into the sky and observe how the clouds have formed, the sunlight and the wind patterns. Then I can predict what will happen in the day."

"The assignment to collect data on the local indicators is not about going into the forest to search for weather indicators. It is about sending whatever indicator that you see around. So that is not a difficult task at all. And when it rains too, yours is to pick the rain gauge and then check the level of water on the recorder."

This implies that farmers do not need to travel to distant places in search of indicators. This resonates with a farmer's statement: "whatever I see is what I send." The life cycle of some plants or animals and duration of some atmospheric conditions such as the pattern of the wind coincided with the data collection period. These include the temporal patterns of migratory birds, the evolution cycle of flowering mango trees and other plants. The geographic scale, the wide range of indicators and their availability is related to accessibility and visibility. Farmers indicated that it was easy to identify the indicators (accessibility) as they can find it anywhere. For example, the sunshine, the clouds, moon, the wind pattern etc.

\subsubsection{Extrinsic motivations of participants for collecting data on local weather indicators}

This section presents findings on the extrinsic motivation (externally regulated) which is triggered by compliance to (social) norms and external rewards.

The reception of feedback in the form of weather information is an extrinsic motivational factor which was mentioned by all farmers. This was also one of the initial motivating factors which encouraged most farmers to accept the invitation to participate in the research. This motivating factor was reinforced by the relevance of rainfall for farming and other livelihoods in the area. Since farmers were dependent on rainfall, they were motivated to monitor their environment to identify indicators that showed whether or not there will be rainfall for the next day.

The use of rewards in the form of commendation and appreciation for collecting data also motivated farmers in pattern 1 and 2 to continue to engage in the research. Researchers awarded farmers by commending and thanking them for submitting data or for writing a post on the WhatsApp page. A farmer mentioned with excitement that: "on that day, I was the one they mentioned on the page that "Only one farmer submitted data for the day." This form of reward also promoted competition among farmers on the WhatsApp page especially at the peak of the main season (June). The competitive aspect was also a strong motivating factor as some farmers felt that they had to outdo their colleagues and they derived satisfaction from it, while some farmers also submitted data so that they were not left out. The feedback on farmers local weather indicators was also regarded as a form of reward because they felt that they gained 'something' in return for the time spent in monitoring their environment (figure 6.7). 


\section{Chapter 6}
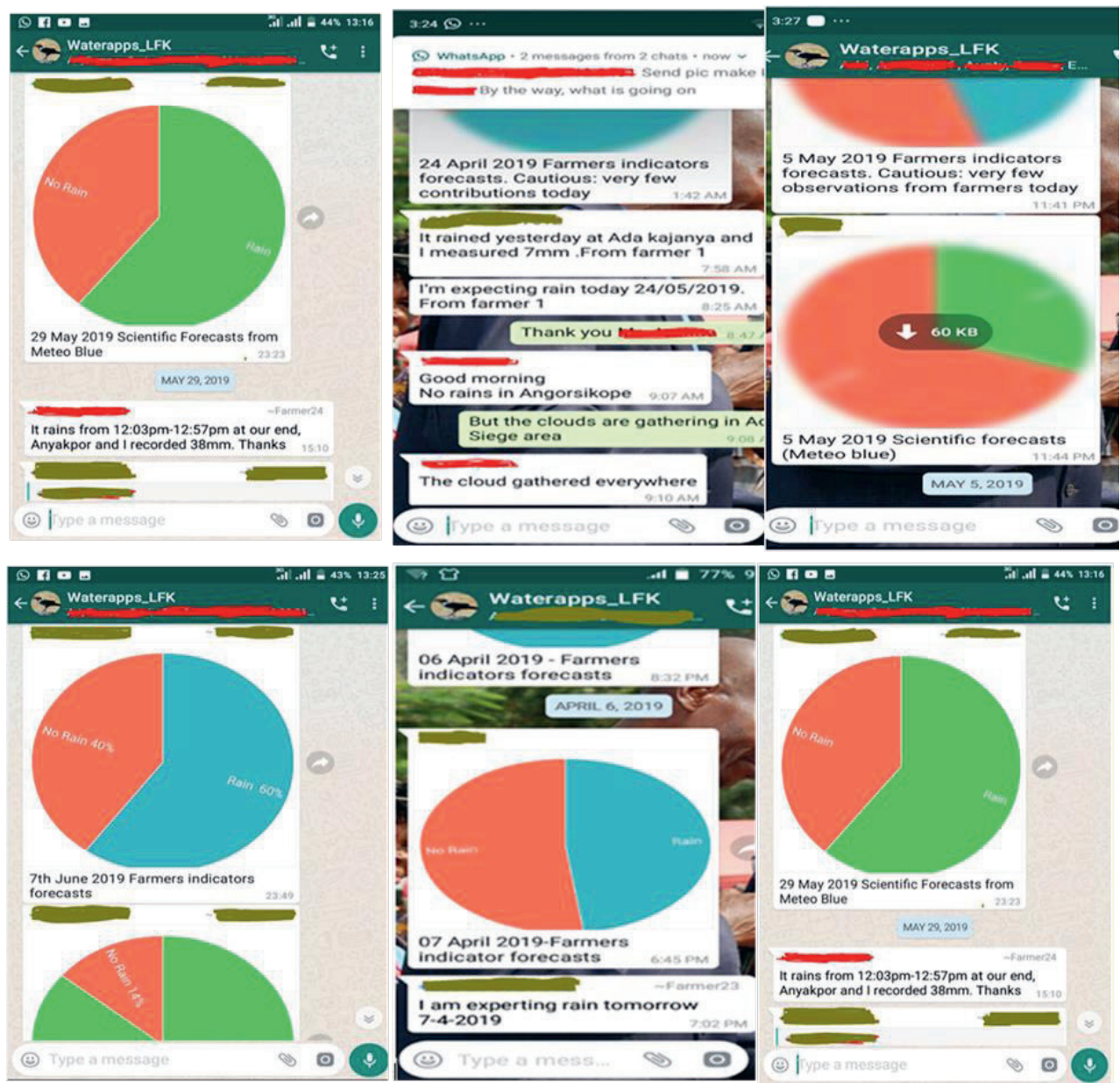

Figure 6.7 WhatsApp image showing interactions between farmers and researchers

Source: Authors' field data, 2019

The experts involved in the research also influenced farmers to contribute data as their presence at the training workshops sent a message of acceptance, legitimacy and a sense of purpose about the research (see table 6.4). In addition, field visits and phone calls were made to inquire about the general wellbeing of farmers and data collection processes. Farmers affirmed that it was useful to maintain close relations with experts because "that way I can call them quickly to discuss my problems or observations." An overview of findings on the different forms of motivation identified in the study is presented in Table 6.4. Despite the motivations of farmers to collect data, their engagement levels differed due to certain barriers. 


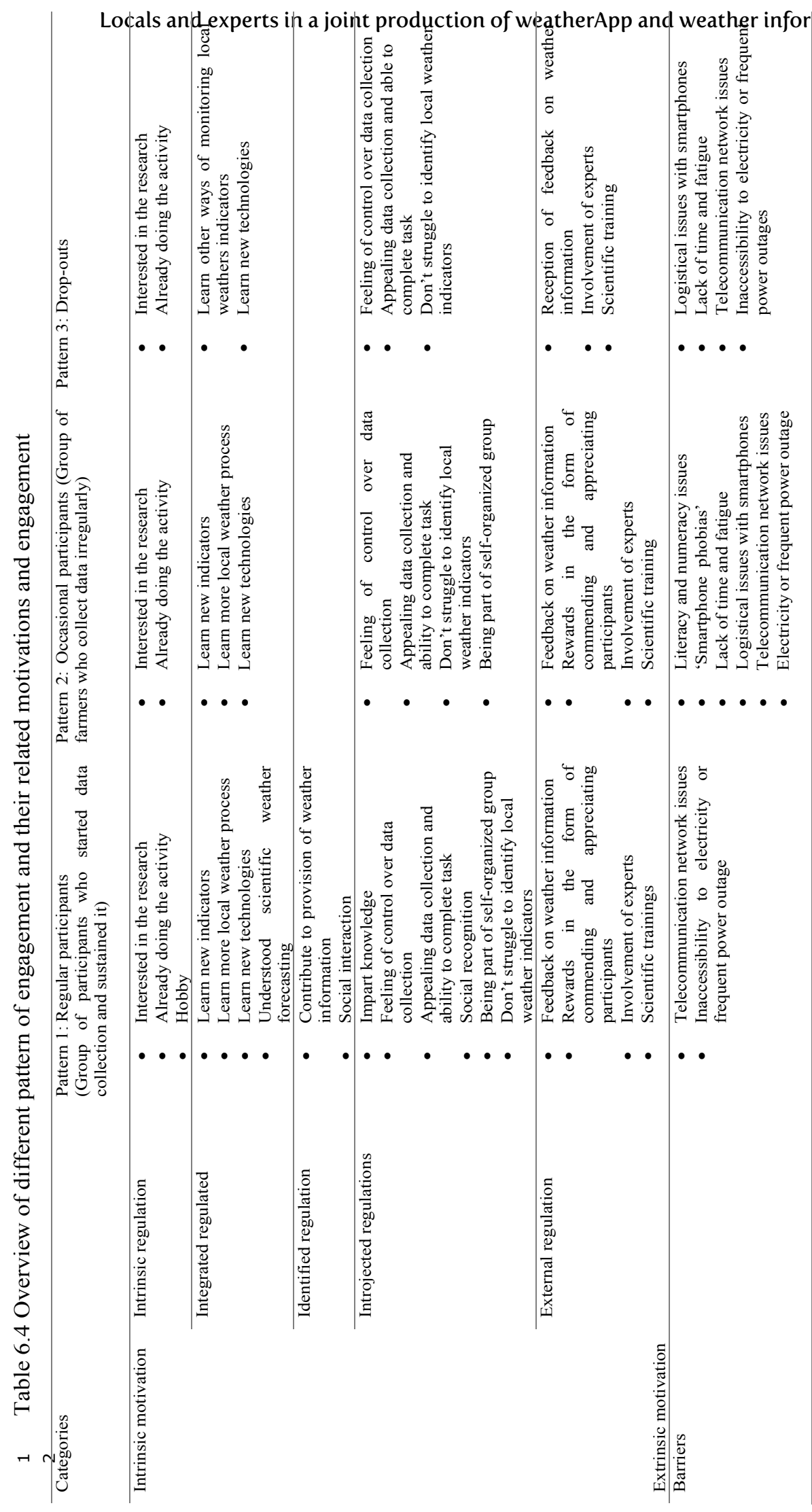




\section{Chapter 6}

6.4.3 Barriers that affected the engagement of farmers in the collection of data on local weather indicators

In this section, the barriers which constrained farmers' engagement in the collection of data in this research are discussed.

First, literacy and numeracy issues affected the continual collection of data by some group of farmers in pattern 2 and 3. Some farmers speak only the local language, Dangme; hence, they could not read the information disseminated in the English language. This hindered some of them from receiving feedback or being interactive on the WhatsApp platform. Where farmers depended on family members to submit data and also translate information, the absence of these dependants meant that no data was submitted.

Secondly, the behaviour of some farmers can be better described as 'smartphone phobias'. Some farmers made comments such as "as for me, if you hold my hands and teach me, I will still not be able to use it." This comment is indicative of the fact that some farmers were not ready to use the smartphones if no one was assisting them. Interestingly, these group of farmers submitted data with the weather app; however, they were unable to use WhatsApp, which had the same usability procedure. Also, since some farmers were using some components of smartphones for the first, it took some time for them to become familiar with switching on data, swiping, checking the internet data bundles, reading SMS on the expiration of internet data bundles and so on. The period of adjusting to the use of smartphones created some gaps in data collection for some farmers (see pattern 2 in Table 6.4).

Thirdly, the lack of time and fatigue also affected data collection. This barrier was recorded as data collection coincided with the main farming season, where farmers were involved in various aspects of farming activities. Hence, regular participants increased steadily from May-July as shown in figure 6.5. These barriers also accounted for pattern 2 and 3 in Table 6.4. In addition to their farming activities, most farmers held social positions or participated in communal activities such as funerals and so on. This issue was mentioned by several farmers because they were usually involved with "other things" and simply forget to monitor and submit data. Some farmers also migrated to nearby districts to farm at some period when the research was conducted. Few excerpts of the interviews are as follows:

"When I am in school, I am not able to send the indicators and I also have other responsibilities as well."

"The problem is all about the unavailability of time. I am always engaged and I have a lot of things to do. So, when I come home late in the evening, I get tired and then I forget to check the messages or even submit data."

"Data collection is not very difficult at all. But the only reason why I do not send information all the time is that, there are days that I am engaged with a lot of activities."

Additionally, logistical issues with smartphones such as the availability of airtime, cost of phone batteries, replacement of chargers and other miscellaneous issues affected engagement. Although smartphones and other equipment supplied to farmers were easily available, the provision of 22 farmers with weekly airtime, internet data, regular training and field visits had a substantial cost. 
Some of these logistical issues affected regular data collection as it required some days to respond to certain challenges and potentially led to gaps in data collection. For instance, 2 of the farmers dropped-out of the research because the screen of their smartphones got damaged beyond repairs. Whiles, a farmer reported the theft of the smartphone.

Furthermore, telecommunication network issues also affected data collection of all groups of farmers. Generally, the internet network connection is a challenge in most rural communities. In the Ada East District, some farmers had to relocate to specific areas before they could access the internet to submit data. The situation gets worse after a rainfall as the reception becomes poorer. A farmer expressed his grievance by indicating that: "If I will have to move in search of a suitable place to access the internet network, then it is a daunting task that prevents me from sending data regularly." Another farmer indicated that: "When the weather is not clear, it interrupts the network, so when you are sending a message, you have to try it several times and you can give up if you don't have time."

Lastly, some communities still do not have access to electricity while frequent power outages also affected all groups of farmers to submit data on a regularly. Farmers who had no electricity supply in their communities had to charge their phones in neighbouring communities; hence, they submitted data at their convenience.

\subsection{Discussion}

The study found two types of engagement associated with farmers' data collection on local weather indicators. The first is the frequency of data collection by farmers which varied for various months but increased towards the end of the main season (June-July). Secondly, the longevity of farmers' data collection in the study also varied. This finding is similar to a study conducted on participatory environmental monitoring in Ghana where varying levels of monitoring were also recorded in the Mole National park (Burton, 2012). This finding implies that participants in a participatory environmental monitoring research do not contribute data at the same time even when equal resources are provided. Tinati et al. (2017) also indicated that engagement varies in most citizen science projects and it can be relative depending on the objective of the research. The frequency and longevity of engagement recorded in this study can be attributed to the introduction of a new approach to data collection (participatory environmental monitoring research) and the technologies (smartphones, newly developed App, WhatsApp and rain gauge) which required time for farmers to gain experience in their use. The two types of engagement recorded in this study can also be ascribed to the fact that farmers might have taken some time to evaluate the perceived efficacy and ease of use of the new data collection approach and technologies. They might have also assessed the relative advantage of the technologies, its compatibility, complexity and effects with existing tools and procedures of data collection before they engaged more in the research. Also, the fact that some farmers were able to use the technologies at the early stages of the research might have inspired others to also engage in the data collection. Therefore, though continual interactions, training and early involvement of participants are mentioned as relevant strategies to sustain engagement in participatory environmental monitoring research (see, Sheil, 2001; Danielsen et al., 2003, 2005b), it is important to also consider the characteristics of individuals and their technology adoption strategies as well.

The longevity of farmer's engagement in the collection of data was in three patterns: regular participants, occasional participants, and drop-outs. Generally, the number of regular participants 
was high with few drop-outs during the period of the study. Farmers who were occasional participants in April and May, became regular participants until the end of the research (see pattern 2 in figure 6.5). This finding contributes to knowledge on participatory environmental monitoring as it identified the participation of farmers in the collection of data in different patterns. The patterns of engagement mimics a continuum where we found occasional participants straddling between regular participants and drop-outs. This finding explains that it is a common trend to identify different engagement or "participation inequality" in citizen science research such as, mobile phone data collections, web platforms, Open StreetMapping as well as offline and nonICT environmental volunteering projects (Seymour \& Haklay, 2017). Yet, the difference between this finding and other studies is that the identified longevity of regular and occasional participants is high compared to other studies where dropout rate were high (Curtis, 2018). Findings on the longevity of farmers' engagement in the three patterns identified in this study provide important insight into climate change management projects to consider the behaviour of participants. It can also be useful for planning the frequency of data collection (e.g., should farmers collect data daily, weekly or monthly) and the type or length of time allocated to a task (e.g., single event, short-term or long-term project) (Ponciano \& Brasileiro, 2014).

Overall, the analytical approach used in characterising motivation (intrinsic and extrinsic) of farmers with self-determination theory (Ryan \& Deci, 2000a,b) was useful. Indeed, Rutten et al. (2017) also used this approach to categorise the motivations of participants in citizen science research from a systematic literature review perspective. This research applied the theory to interrogate different types of intrinsic and extrinsic motivational factors instead of broadly mentioning the motivations of farmers. Motivational factors were grouped under different categories as: external regulation, introjected regulations, identified regulation, integrated regulation and intrinsic regulation. From Table 6.4, intrinsic regulated motivations were: "interest in the research" and "already doing the activity". These factors were identified by all groups of farmers except "hobby" which was mentioned by regular participants. Interestingly, identified regulation was only mentioned by regular participants as their motivation. These include "contribution to the provision of weather information" and "social interaction". Finally, external regulation such as "feedback on weather information", "rewards in the form of commending and appreciating participant", and "scientific training" was mentioned by all participants. This finding contributes to the knowledge on different motivational factors of participants in participatory environmental monitoring research for climate change management. Again, the study demonstrated the types of motivational factors as a continuum. As shown in Table 6.4, all group of farmers held some specific type of motivation except for identified regulation motivational factor which was peculiar to regular participants. This finding calls for further research to compare and identify new and similar motivational factors that can exist in other participatory environmental monitoring research. This analytical approach can be viewed as valuable in assisting practitioners who are involved in climate change management with farmers to understand the relation between engagement patterns and types of motivational factors that may evolve. It also serves as an indicator to understand whether or not an individual's motivation is externally or internally regulated. As indicated in Table 6.4, most of the motivational factors of farmers exist between intrinsic and extrinsic regulation. Thus, knowledge gained from this analytical approach can help to ensure the provision of resources or create opportunities that can help align the engagement of participants with their motivation. 
Also, findings of the study on the ease of monitoring local weather indicators in farming communities underscored the relevance of the availability of local environmental resources in supporting participatory environmental monitoring research. As indicated in other studies, the use of local weather indicators served as motivation to collect data in farming communities (see Chang'a et al., 2010; Shoko \& Shoko, 2013; Gwenzi et al., 2016; Balehegn et al., 2019). Yet, local knowledge and indicators exist as tacit knowledge which are part of the routine practices of farmers. The training conducted in this study helped to socialise farmers on the use of scientific knowledge which is assumed to be explicit and codifiable. This approach helped to transform farmers' tacit knowledge to explicit ('new knowledge') and they learned to value it. As indicated by Nonakata and Krogh (2009), knowledge creation is an ongoing process of socialisation, externalisation, combination and internalisation between tacit and explicit knowledge. In this instance, we can infer that the continual engagement of farmers in the collection of data is not solely as a result of their experience in monitoring local weather indicators. Rather, it is also a factor of the interconnection between two knowledge systems which gave rise to the formulation of a new knowledge. This phenomenon contributed to motivations on learning: "I want to know more" "learn more". The finding on the interconnections between the two knowledge systems had consequences on how farmers were able to learn about uncertainties in the forecast and the inadequacies in each type of knowledge system. Farmers learned to appreciate probabilistic forecasting more than the usual demand for deterministic forecasts. The integration of the two knowledge systems in the research also had implications on building trust in scientific forecasts and enabled farmers to appreciate variations in the occurrence of weather forecasts in-between communities.

The context of the research comprised of farmers who were involved in multiple socio-economic activities. This became a barrier which affected the engagement of some farmers and was captured in Table 6.4 as "lack of time and fatigue". Due to this factor, the engagement of farmers in the collection of data in May was less compared to subsequent months. While it is possible that this phenomenon may be as result of issues pertaining to other barriers as enumerated in Table 6.4, some farmers specifically mentioned the "lack of time and fatigue" as reason for occasional data collection. They explained that the period of the study corresponded with the main farming and rainfall season concurrently. During the main season, farmers were mostly involved in arranging for tractors, labour and the mobilisation of other resources to aid in farming. While towards the end of the season (June-July), most farmers had ample time to engage in other tasks including data collection.

Despite the finding that some farmers were engaged in multiple socio-economic activities, others described themselves as hobbyists and wished to pass free time by monitoring and collecting local weather indicators for the research. The socio-economic context in which the study was conducted differed from other participatory environmental monitoring research where participants were mostly hobbyists or conservationists and offered their free time to monitor their environment. This finding resonates with West et al.'s (2020) study on citizen science monitoring of air pollution in informal settlements in Nairobi, Kenya. Their study also recorded that participants had varieties of jobs which affected the time they spent on data collection. Findings on how farmers' involvement in multiple socio-economic activities affected their engagement in this study suggests that the effectiveness of participatory environmental monitoring research also hinges on the broader socioeconomic context. In this instance where farmers are constrained by "lack of time and fatigue", they are likely to prioritise their socio-economic tasks above the collection of data even when the 


\section{Chapter 6}

task of monitoring is easy. Further, the abovementioned factor can be considered as a perceived barrier instead of being real. This assertion is made because people may perceive that volunteering is a task which requires extra effort and time. On this note, finding on barriers such as, "lack of time and fatigue" as identified in a farming context is a useful knowledge since it helps in explaining the level of importance some participants attach to participatory environmental monitoring research.

Additionally, though different groups of farmers identified specific barriers which affected their engagement, the unavailability of electricity and frequent power outages and poor internet connections affected all participants. Frequent power outages resulted in smartphones not being charged often, and to do so, some farmers had to visit nearby communities. While erratic internet connections affected the collection of data especially after rainfall. Experiences of poor internet coverage in this study appears to indicate that the ICT growth and penetration is perhaps limited to urban areas. Research conducted on citizen science seed experiment with farmers in Honduras also mentioned poor internet coverage in rural communities compared to urban areas (Steinke, 2015). Findings on how erratic supply of relevant infrastructures affected data collection is also recorded in participatory environmental monitoring research in some developing countries (see for instance Pacha, 2015; Beza et al., 2017). Participants in pattern 2 and 3 also experienced logistical issues with smartphones and literacy and numeracy issues. These challenges have also been identified in other participatory environmental monitoring research which focused on the use of digital tools for data collection (see for instance, Evan \& Guariguat, 2008; Forest Compass, 2015; Brammer et al., 2016). A study conducted on citizen science research in East Africa also identified that institutional, social and language factors can serve as barriers to engagement (Pocock et al. 2018). These contextual issues constantly change with time but they can be relevant in participatory environmental monitoring research that focuses on the use of digital tools for data collection to ensure the sustainability of the initiative. Thus, it is essential to first gain a thorough understanding of the contextual setting in which the research is embedded, since these aspects can strongly affect its design, implementation, outcomes and impact (Gharesifard et al., 2019).

Reflecting on the method used for data collection in this study, the purposeful selection of 22 farmers in the Ada East District to collect data on the local weather indicators is not representative of all farmers in Ghana. Therefore, findings from this study cannot be generalised; however, it provides key insight for research on climate change management that focuses on co-production of weather information with farmers. Secondly, the selection of 22 farmers with various socioeconomic backgrounds is minimal. However, since participatory environmental monitoring research and technologies were new to farmers, it was a management strategy to start with few farmers and understand their engagement, motivations and barriers. Furthermore, in most participatory environmental monitoring research, data ownership is one of the issues discussed between scientists and participants. At the time farmers were recruited for the study, they were informed about how their knowledge on local weather indicators will be used to aid in co-producing weather information. Feedback was provided by sharing daily weather information on farmers' local weather indicators and scientific weather forecast concurrently (see figure 6.6). Also, the collection of local weather indicators was not perceived as sensitive personal data by farmers. Instead, it was rather seen as a means to preserve their local knowledge by documenting it. In addition, the interpretation and feedback on the local weather forecast was left to farmers to decide on what to do with the information. Since it was communal data which was generated from farmers, they also shared the feedback with their family and the farming community. In some instances, cautions were attached to the feedback by indicating the number of farmers who provided data on 
a specific day. Data classification was also set with a specific colour indicating farmers' forecast (see figure 6.6). The identity of farmers was also protected by ascribing codes: for example farmer 1. Some of the strategies used for sharing data with farmers have also been applied in other participatory environmental monitoring studies (see for instance, Sabogal, 2015; Torres et al., 2014; Bellfield et al., 2015). Therefore, in this form of citizen science research, issues of data ownership was not a challenged as the collection of data on local indicators was considered a communal resource and for the preservation of local knowledge.

6.5.1 Implications for community-based intervention in climate change management

Based on the aforementioned findings, the study provides lessons for the up-scale and sustainability of this form of research in other contexts as follows.

First, the task which will be required of participants should be made explicit at the onset of research to enhance their motivation. Participants should be involved in identifying local indicators, designing and testing the interface of a selected ICT tool, and setting of rules for data collection. The study also suggests that farmers who have challenges with literacy and numeracy issues should be given periodic training, follow-ups and a booklet with images that describes the procedure for data collection.

Secondly, the use of interactive ICTs for data collection and sharing is relevant since the interactive component of ICTs played major roles in motivating some groups of farmers in this study. Interactive ICTs for data collection and sharing can include 'Sapelli', sound recordings, online weather apps, SMS, and so forth. These tools can be adapted to focus on illiterates and 'ICT phobias'. In addition, the interface should be attractive, easy to navigate, and the procedure should be short and clear.

Also, poor telecommunication networks, inaccessibility to electricity and frequent power outages affected the engagement of most farmers in this study. This was unforeseen as it was perceived that the study area had access to the necessary infrastructure that is needed to support data collection with smartphones: yet, several technical challenges were encountered. In such instances, power banks can be supplied to participants depending on the budget and the amount of funding available. Alternatively, ICTs such as voice recordings on WhatsApp pages, the use of 'emojis' in SMS, phone calls, and Open Data Kits can be used offline. Fieldnote books can also be used to record observations and predictions as well. To encourage the engagement of groups of farmers who lack time and require constant reminders, auto-mated voice messages, peep calls, and alert systems can be used to support the facilitation process.

For future research and practical application in climate change management, it is relevant to identify and work with self-organized groups, experts and other relevant actors as it creates legitimacy for the research process, build trust, and also bridges language gaps. Additionally, a large number of participants from different communities can be recruited through agricultural events, farmers' markets, seed fairs and so on. The engagement of occasional participants or drop outs can also be enhanced by drawing on the testimonies of regular participants in the research.

Furthermore, the socio-economic context in which participants operate requires that the goals of the research is aligned with their livelihood development. Therefore, feedback on data collection is useful for decision-making in climate change management research. Additionally, recharge of 


\section{Chapter 6}

farmers' airtime, provision of bundle agricultural information on crop insurance, and market and agronomic information can be useful incentives. This form of citizen science has more to offer the business sector such as mobile network operators, ICT companies and other service providers as their presence can result in a significant business case development.

\subsubsection{Research limitations and Opportunities for Future Research}

In this study farmers who were recruited to participate in data collection had different demographic characteristics; however, more men were involved than women. Since women were not readily available to participate in the research, gendered perspective on the level of engagement of men and women and their motivations. The research recommends that future studies should integrate gender disaggregation into the research design and its findings. Another short coming was that the study did not correlate different demographics (sex, age, literacy, education level) with level of engagement and motivations. This will be an interesting knowledge gap that can be filled in a future research on participatory environmental monitoring research on climate change management. Additionally, the research was conducted for a short period (4 months), hence, the study did not provide enough insight on farmers' level of engagement and motivations for a long term. A research can also be designed with the aim to understand how participants' motivation changes over time can be added to the literature on participatory environmental monitoring research in weather and climate information sector. Future research can also focus on randomised control trials to compare findings on the level of engagement, retention rate and the motivations between control and experimental farmer groups.

\subsection{Conclusion}

This chapter has examined the engagement, motivations and barriers in a citizen science participatory environmental monitoring research in the Ada East District, Ghana. By doing so, the study provided an example of the process of co-producing weather information with farmers' local knowledge through monitoring of environmental indicators. The study found three patterns of engagement with explanations on the motivations of participants and the barriers which affected their engagement. Since the study was carried out in a context where participants had no idea about participatory environmental monitoring research as a data collection approach with the application of new technologies, low engagement of farmers should have been recorded. However, a reverse situation was noted as the retention rate was higher than the number of drop-outs. This occurrence was facilitated by some social factors and contextual issues emphasizing their relevance in participatory environmental monitoring research in climate change management. Furthermore, while some barriers can be considered to be real, others such as lack of time and the inability to use smartphones can be regarded as perceived challenges.

The growth in ICTs, including internet and (non)smartphone usage is remarkable in a developing country such as Ghana. All participants in the study had knowledge on the use of (non)smartphones. Yet, the variations in their competences and the unavailability of infrastructures can limit data collection and also affect the realisation of the full potentials of ICTs in a participatory environmental monitoring research. This form of participatory environmental monitoring research in a developing country context such as Ghana required training of farmers and field visits which were costly in terms of time and financial resources. It is, therefore, necessary for local, national and international communities to adopt ICT literacy strategies that can enhance the full usage of technologies, especially in rural farming communities in developing countries. 
A key lesson that can be drawn from this study is that engagement of participants can vary in terms of frequency and longevity as determined by the objective of the study. The motivation of participants also varies and each individual may initially have a sole motivational factor which can either accumulate to include other factors or their motivations may change completely. The main barriers which can affect engagement are logistical issues with ICTs and availability of infrastructures such as electricity, internet and telecommunication network.

Finally, the study concludes by emphasising that participatory environmental monitoring research in climate change management has the potential to aid in the provision of location-specific weather information, build partnership between information providers and farmers, build trust in local and scientific weather information for decision-making; and provide lessons on uncertainties and challenges in weather forecasting among farming communities. Consequently, this form of research can be replicated in other developing country contexts or better still, it can be expanded to other geographic areas in Ghana. 


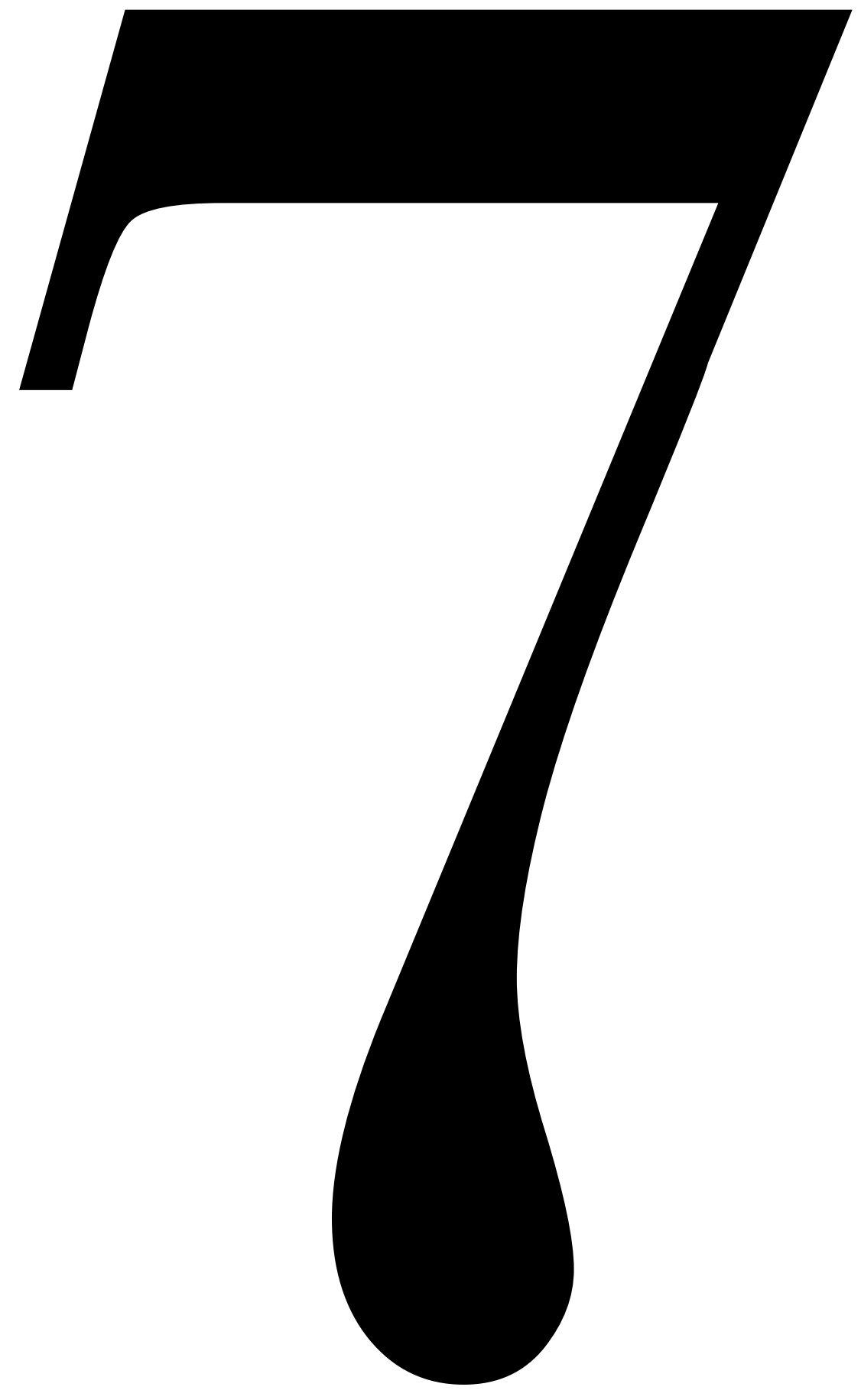




\section{Chapter 7}

Synthesis 


\subsection{Introduction}

Farming in developing countries is constrained by numerous environmental conditions such as water scarcity; soil, water, and nutrient depletion; pest and disease infestation; among other conditions. The environmental conditions constraining farming are connected mostly to the occurrence of climate change and climate variability. In Africa, climate change and climate variability are projected to affect farming because of the sector's dependence on rainfall for food crop production (Schlenker \& Lobell, 2010; Niang et al., 2014; Rockström et al., 2014; Salack et al., 2016). Currently, changing weather conditions, especially erratic rainfall patterns and a rise in temperature in most regions including West Africa, have affected the farming calendar and planting patterns (Salack et al., 2016; Gbangou et al., 2020b; Nyadzi et al., 2019; Atiah et al., 2019). The variations in rainfall pattern, including changes in rainy season onset date and rainfall duration and early cessation of rainy seasons, have significant effects on farmers' decisions (Nyamekye, 2020).

The same situation as experienced globally pertains in local rainfed farming contexts like the coastal savanna agroecological zone, including the Ada East District in the Volta Delta in Ghana where changes in rainfall and temperature create uncertainty in farming. In this region, vegetables, fruits, and other crops are intensively cultivated for export and urban markets, amidst limited rainfall and irrigation facilities. Under uncertain and variable weather conditions and limited availability of water, farmers make decisions on whether or not to plough, sow seeds, apply fertiliser and agrochemicals, and harvest, guided by the use of weather or seasonal forecasts. However, the uptake of weather information services (WIS) for farming is low for a variety of reasons attributed mostly to the dominance of information providers in the production and delivery of information. In recent times, there has been an increasing call to shift from science-driven to user-driven provision of weather and climate information services through collaboration between scientists, information providers, and users to co-produce usable information to enhance adaptivity in decision-making in farming (Vogel et al., 2016; Daly \& Dilling, 2019; Dewulf et al., 2020). This thesis is situated within this notion and it seeks to answer the question: What makes weather information services usable for adaptive decision-making in farming within an informational governance context? I engaged farmers and information providers in an empirical study in the Ada East District, Ghana, for four years to provide answers to the research question.

In this chapter, I present findings on the research sub-questions formulated to address the overarching research question of this thesis. It comprises five sections, starting with an introduction section. In section 7.2, I provide answers to the research sub-questions and discuss their empirical, theoretical, and methodological contributions to debates in the literature. Afterward, the findings of the main research question are discussed in section 7.3. In section 7.4, I present a discussion on the limitations of the thesis and suggestions for future research, and in section 7.5 I provide recommendations for WIS design, policy, and practice.

\subsection{Answering the research sub-questions and contributions to literature}

As stated, the main research question of this thesis is formulated as follows: What makes weather information services usable for adaptive decision-making in farming in an informational governance context?

The main research question is divided into four research sub-questions (RQs) as follows: RQ1: Through which hybrid informational arrangements are weather information services provided, and with what effects? 
RQ2: What flexible or robust decision-making strategies are applied to deal with uncertain weather conditions in farming?

RQ3: To what extent are existing weather information services usable for farming and what is required to enhance their usability?

RQ4: How can WIS be co-produced through the integration of scientific and local knowledge and what motivates farmers to participate in co-producing WIS?

The five empirical chapters of this thesis contribute to answering these RQs.

\subsubsection{Hybrid informational governance arrangements for the provision of weather information services}

This section focuses on providing answers to RQ1: Through which hybrid informational governance arrangements are weather information services provided, and with what effects? To provide an answer to RQ1, in Chapter 2 of this thesis, I introduced the hybrid informational governance framework based on the integration of ideas from three theories, that is, informational governance, hybrid governance, and hybrid organisation. In the framework, I distinguished three forms of hybrid governance: 1) multiplicity, when multiple information services are provided in a complementary manner by government, business, and civil society organisations (CSOs); 2) intertwinement, when information services are jointly provided by organisations from two or three sectors; 3) coalescence, when there is a merger of roles, practices, and institutional logic from organisations from different sectors to form a new innovative entity or organisation.

- Provision of WIS through multiplicity

With the aid of ICTs like mobile phones, interactive voice response (IVR), short message service (SMS), television, call centre facilities, and other tools, different information providers deliver varied WIS for farming. The WIS are parallelly provided by different organisations from the government, business, and CSOs, which was not the situation formally. Also, ICTs and other factors have changed the number and nature of WIS provided.

\section{- Provision of WIS through intertwinement}

In addition to generating competition or separate provision of WIS among information providers, ICTs have engendered intertwinement among government, business, and CSOs. Some organisations have evolved towards joint delivery of WIS by using a combination of technologies including radio, mobile telephony, SMS, call centres, and IVR.

\section{- Provision of WIS through coalescence}

Furthermore, ICTs have played roles in coalescence in the provision of WIS by creating hybrid organisations that combine key characteristics from different organisational sectors. In this regard, some business-oriented information providers such as agripreneurs provide WIS, with business models and altruistic motives guiding their practices and institutions. Government organisations like the Ghana Meteorological Organisation (GMet) and CSOs such as Radio Ada also tend to adopt business models instead of providing information for free.

As a result of these identified governance arrangements, WIS can flow across scales. WIS provision ranges from international non-state organisations to farming communities without the scrutiny and control of national and district-level government organisations. Non-state organisations such as agripreneurs, Radio Ada, a private weather forecaster, among others, fill the gaps unaddressed by 


\section{Chapter 7}

government organisations, by providing WIS and other farming-related information such as market prices, agronomic advice, insurance, and details of markets for farm produce. The provision of this information in addition to WIS is designed to steer farmers' decision-making.

\section{Contribution to informational governance theory}

This thesis makes three contributions to informational governance theory. First, although the theory envisages and stipulates a redefinition of the role of the state as a result of the entrance of new actors (business and CSOs) as one of the four factors that contribute to the emergence of informational governance (Mol, 2006), the theory provides limited ideas about how this phenomenon may transform the organisations involved and whether or not to expect hybrid arrangements. Findings from RQ1 contribute to informational governance theory by indicating that governing through information and institutional change resulting from weather information flow leads to the emergence of hybrid governance and hybrid organisations. The thesis indicates that new actors (business and CSOs) not only emerge to fill gaps unaddressed by government organisations, but also collaborate towards the delivery of WIS. The actors may be individuals (e.g., private weather forecaster) and not necessarily organisations.

Another contribution to the theory is the finding on the dominant role of government organisations in an informational governance context. In essence, the theory predicts the decreasing role of the state consequent to ICT and globalisation (Mol, 2006). However, applying the informational governance theory to study WIS provision for farming shows that government authorities still play a significant role or are still in charge of the provision of information. Glin et al. (2019) indicated that, despite the occurrence of informational governance in a certain context, the role of a government organisation or the state's control may remain unchanged if the state derives large benefits from a specific sector (e.g., the cocoa sector in Ghana). Findings from RQ1 emphasise that informational governance may occur in certain sectors of an economy because of the role of ICTs and other factors (Mol, 2006). However, when the specific sector is crucial to the economy of the state, government organisations (e.g., GMet) will remain as key players. Hence, one should not expect an automatic decrease in the state's role as a result of ICT or the entrance of non-state actors, because context, space, and sector differ.

Informational governance as a theoretical framework has been applied mostly in research in developed countries (see for instance Toonen, 2013; Hoefnagel et al., 2013; Soma et al., 2016c). This thesis is the first to apply the informational governance theory in a developing country context to examine WIS provision for farming in Ghana. The application of the theory in the farming sector in Ghana in this thesis is also distinct from other studies that applied the theory to study environmental governance issues in developed countries. By so doing, I have illustrated the emergence of new and numerous information providers in response to the demand for information for farming and provided knowledge on how ICTs restructure WIS governance and cause changes in actors' roles, practices, and institutions. Also, by applying the theory in a developing country context, I have indicated how international development actors bypass government authorities to provide WIS to farmers at the local level with ICT and by collaborating with CSOs or business organisations in farming communities.

\section{Contribution to the weather and climate information service research field}

The findings from RQ1 contribute to the weather and climate information service discipline by providing knowledge on the new actors providing WIS in the study district. They show that WIS 
provision is no longer the exclusive domain of government organisations (Chapter 2). They also demonstrate the patterns of weather information flows by showing the current sources of information and how individuals, with ICTs, can generate information from the global scale to farming communities. Furthermore, this thesis contributes to the weather and climate information service discipline by illustrating the changing character of government, businesses, or CSOs through either the adoption of business models and/or altruistic motives. Finally, these findings have demonstrated the relevance of considering the entire landscape of weather and climate information services instead of focusing on a single service.

\subsubsection{Application of flexible and robust decision-making strategies in farming}

This section aims to examine the flexible and robust decision-making strategies applied by farmers under uncertain weather conditions (Chapter 3). This is guided by RQ2: What flexible or robust decision-making strategies are applied to deal with uncertain weather conditions in farming?

Uncertainties experienced in the farming context in the Ada East District consist of variability and unpredictability in rainfall conditions. The variability in rainfall conditions as identified in 2017 includes abnormal, above normal, below normal, and normal rainfall conditions. The occurrence of these conditions differed from farmers' local knowledge and past experience. Given the uncertainties under which farmers operate, three adaptive strategies based on flexibility and three strategies based on robustness were observed during the three farming seasons, namely, pre-season (January-March), main season (April-July), and minor season (September-November).

The three flexible adaptive decision-making strategies identified are as follows.

1. Switching dates by a wait-and-see or delay strategy was adopted by farmers concerning ploughing or sowing seeds during the farming seasons, on the assumption that further observation would provide enough information to understand the consequences of selecting a particular crop.

2. Muddling through the farming season by adopting additional options involved the application of various options (e.g., application of agrochemicals, weeding, soil moisture conservation) without specific knowledge about how they would perform.

3. Alternative irrigations strategies involved a substitute supply of water from other sources to support the growth of crops when the below normal rainfall condition was experienced.

Following this, I identified three robust adaptive decision-making strategies applied to deal with uncertain conditions.

1. Farmers selected a portfolio strategy of transplanting seedlings in batches by transplanting seedlings of the same crop (e.g., tomato or pepper) on multiple dates in order to cater for changes in weather conditions.

2. Robust (hardy) crops or varieties were selected, as these were perceived as able to withstand abnormal or below normal rainfall condition and provide an adequate yield under varied weather conditions.

3. Intercropping/diversification of drought resistant crops involved choosing multiple crops or varieties of the same crop in light of a prevailing variable weather condition during the farming seasons.

\section{Contribution to adaptive decision-making theory}

This thesis makes two contributions to adaptive decision-making theory. First, the findings from RQ2 refined the definition of adaptive decision-making, beyond the definitions of Nyamekye et al. 
(2018) and Robert et al. (2016a). Nyamekye et al. (2018) defined the concept as choosing nonstandard decision options in response to circumstances that are considered abnormal or unexpected, whereas Robert et al. (2016a) defined adaptive decision-making as adjustments in agricultural systems in response to actual or expected stimuli through changes in practices, processes, and structures and their effects or impacts on moderating potential modifications and benefitting from new opportunities. To advance the idea, I defined adaptive decision-making as a pattern of decisions characterised by the application of decision options that are flexible, robust, or both, in response to uncertain socio-technical-environmental conditions. Hence, in this thesis, four distinctions are made regarding the definition of adaptive decision-making theory:

- First, the selection of options (farming practices) is specified or characterised as either a flexible or a robust strategy.

- Second, the selection of flexible options should leave room for adjustment or a reversal over time when additional information becomes available, and robust options should be effective under uncertain conditions.

- Third, a flexible or a robust option must be responsive under uncertain conditions.

- Fourth, flexible or robust options can be applied on a temporal basis as either a reactive or a proactive strategy.

Secondly, flexibility and robustness are concepts used mostly as characteristics of long-term adaptation planning in the infrastructural sector (see for instance Lempert \& Schlesinger, 2000; Lempert et al., 2006; Groves \& Lempert, 2007; Lempert \& Collins, 2007; Hallegatte, 2009; Colombo \& Byer, 2012; Hallegatte et al., 2012; Haasnoot et al., 2013; Bhave et al., 2016; Yousefpour \& Hanewinkel, 2016). However, in the conceptualisation of flexibility and robustness in this thesis, I attuned the definitions to local and individual level decision-making. Hence, the findings from RQ2 provided knowledge and evidence on the possibility of applying the theory to the temporal (reactive and for a short timescale) and the spatial (localised farming setting and individual level) dimension of adaptive decision-making in response to uncertain conditions.

\section{Methodological contribution}

To answer RQ2, I developed a methodology and data collection tool to identify farmers' adaptive decision-making strategies. This was necessary because of the limited information in the research literature on how to analyse adaptive decision-making in a farming context. The methodology entailed multi-stage qualitative research methods (interviews, observations, and focus group discussions) to generate information that was used to construct a decision-making table (Chapter 3). The decision-making table presents a selection of farming practices, ranging from ploughing to harvesting, arranged in accordance with the months of the year and the rainfall amount recorded for a specific month. A decision-making strategy can be deduced by observing the rainfall record for a specific month and the farming practices undertaken in that month. With the decision-making table, a flexible strategy can be identified by observing the adjustment or reversals of different strategies (farm practices) applied during the farming season with different farm practices. On the other hand, a robust strategy can be identified from the decision-making table when an initial option selected is effective and hence requires no changes under a wide range different rainfall conditions during the farming season. The decision-making table was used as a data analysis tool to generate information on farmers' decision-making in 2017. The methodology including the decision-making table can be applied in decision-making analysis under uncertain conditions either on a short-term or a longitudinal basis. 


\subsubsection{Usability of existing weather information services for farming}

This section analyses the third RQ of the thesis, which states: To what extent are existing weather information services usable for farming and what is required to enhance their usability? To answer this question, this thesis distinguished between useful information and usable information (Lemos et al., 2012) by indicating that useful information is information that is potentially relevant for decision-making. However, because users may not be familiar with it or may have unrealistic expectations about how it fits their decision-making, they may choose to ignore it. Usable information, on the other hand, is information that is readily applicable by users in the formulation of strategies (Lemos et al., 2012). Hence, although all forms of information are in principle useful, they are not always usable, unless users and producers take specific steps to ensure that they are applied (Buizer et al., 2010; Dilling \& Lemos, 2011).

Regarding the first part of RQ3, I found 10 different WIS provided in the Ada East District by the government, business, CSOs, and individuals. The types of WIS found include public TV, public radio, GMet online, E-agriculture platform, private weather forecaster, Radio Ada, farmer-tofarmer, agripreneurs, and online WIS. However, I found differences in the extent to which they were used, with the farmer-to-farmer and the private weather forecaster's WIS more used. Also, WIS such as Radio Ada, public TV, and agricultural extension agents' WIS were moderately used by farmers. Other information, such as the public radio, agripreneurs, online, GMet online, and Eagricultural WIS, was rarely used.

The different categorisations of the extent to which WIS was used indicated a usability gap between farmers and information providers. This gap arose because information providers were unable to respond to certain information design and delivery criteria (Chapter 4). The criteria include local embeddedness, legitimacy, spatial and temporal resolution, predictive skill, and accessibility.

a) Farmers perceive WIS as locally embedded when information originates from the farming community. Furthermore, a locally embedded WIS is highly interactive and provides relevant content such as agrometeorological indicators, agronomic advice, market prices, and so on.

b) A legitimate WIS enhanced WIS usability for farming in the case of the Ada East District. A WIS is considered legitimate when farmers' views are involved in the production of the information. WIS legitimacy also involves respect for farmers' local values, such as considerations on farming practices in the district and continuity in information delivery.

c) Another way to enhance the usability of WIS for farming is by designing the spatial and temporal resolution of information to suit farmers' needs. This is achieved by some information providers through timely delivery of WIS (e.g., daily forecast, 1 week-1 month provision of information), location-specific forecasts, and detailed presentation of information.

d) The predictive skill of the WIS takes into consideration the communication of uncertainty and its conformity to farmers' traditional ways of conceptualising probability; for example, expression of uncertainty in terms like percentages or with words that indicate that conditions are likely to change. A WIS with predictive skill is also reliable and accurate, and the inclusion of evidence-based information with practical demonstrations on how to 
apply the information in situations where forecasts indicate expected dry spell conditions makes WIS usable.

e) Finally, accessibility of information is another criterion that can enhance the usability of WIS for farming. With this criterion, information providers ought to make the WIS more accessible for diverse audiences; for example, women, illiterate people, persons with disabilities, and so on. Also, there should be no language barriers; the format and content of information should be simply presented along with meaningful graphics, symbols, and terminologies. Accessibility criteria can be met through multiple media, two-way information delivery, and an accessible level and mode of payment.

In summary, the findings from RQ3 indicate that, despite the availability of numerous information sources (10 WIS) in the Ada East District, only a few WIS were applied in farming. Most of all, the selected WIS were challenged by several factors, especially the reliability and accuracy of the information. Hence, farmers were integrating weather information to enhance the reliability and accuracy of a forecast by deriving information from various sources. One of the conclusions drawn from RQ3 is that WIS usability could be enhanced if scientific forecasts and farmers' local forecasts were integrated (Chapter 4). The question that then arises is how a new WIS can be produced with the findings derived from RQ1-RQ3. The answer to this question is provided in RQ4, which aimed to co-design and co-produce a new WIS through the integration of scientific forecasts and local forecasts.

\section{Contribution to the weather and climate information service research field}

The findings from RQ3 contribute to the weather and climate information service discipline firstly by providing evidence on how farmers are integrating scientific forecast with local knowledge and experience to enhance the reliability and accuracy of weather forecasts. This finding is relevant, as it provides evidence of the need to integrate scientific forecasts and local weather forecasts into the weather and climate information design and delivery process.

Secondly, the answers derived for RQ3 led to findings on specific factors that enhance or obstruct the usability of WIS for farming. Some of the factors that were specific to the farming context in the Ada East District include the origin of information, schedule delivery of WIS, level of detail in the presentation/text, evidence-based information, access to information for a diverse audience, and accessible level and mode of payment. This finding is relevant to the weather and climate information service discipline because it indicates that, under conditions of uncertainty as well as farmers' exposure to development and changes of all kinds, new factors can evolve to enhance or obstruct usable WIS. The contribution of this knowledge is that a strict focus on certain criteria or factors, for example, skill or downscaling models to specific areas to the detriment of other factors, renders the information unusable. Instead, a holistic approach is required in information design and delivery taking into account the push-side (information production) and the pull-side (users' context). This contribution has implications for the development of new strategies, methodologies, and approaches to facilitate access to usable weather and climate information services in different contexts.

\subsubsection{Co-production of weather information services with scientific and local knowledge}

The fourth RQ addresses the co-design process and design principles for co-producing usable WIS with farmers using the citizen science method (Chapter 5). RQ4 states: How can WIS be co- 
produced through the integration of scientific and local knowledge and what motivates farmers to participate in co-producing WIS? To answer the question, I draw knowledge from the findings of previous empirical chapters. For instance, lessons were drawn about the role of ICT in the provision of multiple WIS and hybrid informational governance arrangements (Chapter 2). Chapter 3 provided insight on how to plan the co-production of a new WIS along with farmers' decisionmaking strategies. In Chapter 4, the factors that affected the usability of WIS for farming were drawn upon in the co-design process.

The first aspect of RQ4 focuses on the co-design process and design principles for co-producing WIS through the integration of scientific forecasts and local knowledge. This involved the recruitment of farmers, agricultural extension agents, and a meteorologist as relevant actors in the co-design process because they know about the production of weather information with local knowledge and indicators. Farmers' local knowledge such as bird migration, flowering of plants, wind patterns, shape of the moon, croaking of frogs, sunshine intensity, among other environmental indicators were identified. Farmers' local knowledge also included their own predictions on whether or not there would be rainfall, the confidence level attached to such predictions, and the expected amount of rainfall. The local indicators, the probability of the occurrence of rainfall, and the level of confidence attached to the forecast were digitalised into a weather app, which was installed on smartphones. The weather app was designed to be user-friendly, as it had images, short text descriptions, and emojis to aid in data collection in the farming communities. The main tools farmers used for data collection were a web-based weather app, a WhatsApp group page, and rain gauges. Feedback on farmers' local weather forecasts and scientific forecasts were presented as a pie chart on a daily basis on a WhatsApp page. Different shades of colours were used on the pie chart, with percentages to indicate the certainty attached to the scientific and the farmers' local forecasts. Farmers also used the WhatsApp platform as a medium to share their opinions on observations about expected conditions, forecast quality, and rainfall data.

The second aspect of RQ4 explored farmers' motivation to participate in the co-production of a new WIS, especially data collection on local weather indicators. Given the strong link between the research topic and livelihood development, farmers' motivation differed substantially from studies conducted in Western countries where participants usually engage in such exercises as a leisure activity or pastime. Overall, the need to contribute to the co-production of WIS, generation of feedback, learning, and the ease of data collection were the important motivational factors; albeit I found that some farmers participated in data collection because it was their "hobby" or they were "already doing the activity" in the community. I used the self-determination theory and illustrated participants' motivation (Ryan \& Deci, 2000b). I found that farmers' motivation mimicked a continuum ranging from externally to internally regulated motivations. Some farmers' motivation was intrinsically regulated, implying that their drive to participate in data collection was fully internal with no consideration for external factors (e.g., hobby). Second, farmers were motivated by integrated regulations. That is, their motivations were fully internalised simultaneously with their personal needs (e.g., to learn about new local weather indicators). Motivational factors such as the need to contribute to the provision of weather information and social interaction also contributed to identified regulation. Furthermore, the motivations of some farmers were introjected regulations (e.g., the need to impart local knowledge to other participants). Finally, some farmers' motivation was externally regulated, based on external rewards; for example, being provided with smartphones and a rain gauge. 


\section{Contribution to the weather and climate information service research field}

The findings from RQ4 (Chapters 5 and 6) contribute to knowledge on participants' motivations to co-produce weather and climate information. Alexander and Dessai (2019) noted that knowledge on users' motivation to co-produce weather and climate information is required in the scholarly debate on the co-production of usable information. In this regard, the categorisation of farmers' motivations on a continuum from intrinsically regulated to extrinsically regulated proved relevant. This knowledge points to the need for researchers or information providers to engage farmers and transform their external regulations ("provision of materials" or "payments") or introjected regulations (social recognition) towards internalisation (e.g., inherent satisfaction) by complementarily enhancing their competence (the ability to overcome challenges), autonomy (selfdirection), and relatedness (sense of belonging) (Ryan \& Deci, 2000a, b). If users' (farmers') motivation to co-produce a weather and climate information service is internalised, it will be relevant from a developmental perspective, where users can contribute their resources towards coproducing information and rely less on the provision of material resources and funding from external actors. This notion is relevant because studies have provided evidence that the provision of financial or material incentives usually causes a clash with participants' intrinsic motivations (Tinati et al., 2017). In this instance, if the reward is not substantial, then performance is likely to be worse than when no reward is offered. This knowledge is useful in supporting the sustainability of the co-production of usable weather and climate information, especially when citizen science methods are applied by making provision for the motivation of different groups of participants. Besides, when participants' motivations are more intrinsically driven, this may lead to a reduction in the required investment of resources and time.

\section{Methodological contribution to citizen science participatory environmental monitoring}

This study contributes to citizen science in farming and the weather and climate information sector. It is relevant to indicate that citizen science methods are widely known and applied in several domains such as environmental monitoring on air pollution, biodiversity, water quality, disaster management, natural resources management, human wildlife management, among other natural resource issues (Rotman et al., 2014; Gharesifard \& Wehn, 2016; Rutten et al., 2017; Wehn \& Almomani, 2019; Gharesifard et al., 2019). However, the application of the citizen science participatory environmental monitoring methodology to co-produce weather and climate information services in the farming sector is less explored (Phillips et al., 2016; Beza et al., 2019; Nyadzi, 2020). Hence, the application of the methodology to answer RQ4 is novel and serves as a proof of concept to demonstrate how farmers were involved in selecting local weather indicators, co-designing the weather app interface, collecting data on local weather indicators, and providing feedback on the integration of scientific forecasts and local forecasts in the co-production process. The methodology applied in RQ4 (Chapters 5 and 6) makes the thesis unique compared with other citizen science research where participants were involved only in data collection or only in an aspect of the research process. Given the strong demand for water for farming in most regions globally, there is increasing interest in methodologies that can facilitate the engagement of larger numbers of volunteers to enable a scientific and societal course. Hence, the answers to RQ4 are relevant, as they provide knowledge on how to co-design and engage a large number of farmers to co-produce weather and climate information and upscale it using the citizen science methodology.

\section{Contribution to theory on co-production}

Because of the need to make WIS usable to support users' (farmers') decision-making, several typologies of co-production have evolved over the years in the weather and climate information 
service discipline, with different levels of engagement (Alexander \& Dessai, 2019). Nonetheless, a gap has persisted, in that information co-production is still typically science-led and dictated by scientific and technological capabilities (Lemos et al., 2012; Meadow et al., 2015; Djenontin \& Meadow, 2018; Vincent et al., 2018; Hansen et al., 2019). The findings from RQ4 indicate a response to the call for transformative change from the existing paradigm and a move beyond the current dominance of the science-driven approach, which focuses on tailoring existing services for users. This thesis has actualised the call to integrate scientific forecasts with local forecasts to enhance usability. In the RQ4 investigation process, farmers were regarded as co-producers in most aspects of the information design, production, and delivery, and this created opportunities for the creation of a pure, user-led innovation.

\subsection{Answering the main research question}

To address the usability gap between information providers and farmers to support the uptake of WIS for adaptive decision-making in farming, a knowledge gap needs to be filled. The knowledge gap is captured in the main research question of the thesis: What makes weather information services usable for adaptive decision-making in farming within an informational governance context?

To answer the overall question, I distinguished different context layers and identified the factors contributing to the usability of WIS in each of these layers. The context layers include:

- Farmer decision-making context

- Farmer information context

- Weather information service delivery context

- Informational governance context

- Overall weather information service design

The context layers illustrated in Figure 7.1 are interconnected. The farmer decision-making context is about the conditions existing in the farming communities that drive the need to apply WIS for adaptive decision-making, and this is linked to the farmer information context, which focuses on farmers' sources of, and access to, information. The weather information service delivery context identifies the types of WIS and how they meet the information design and delivery criteria, and the informational governance context provides a broader view concerning how the existing governance arrangement to a large extent determines the kind of WIS provided for farmers and how it is delivered. Finally, the overall weather information service design cuts across all the layers, and it shows the process of designing WIS, which should consider key factors embedded in all the aforementioned interconnected layers. The factors contributing to the usability of information in the interconnected layers are elaborated further in subsequent sub-sections (7.3.1-7.3.5) and summarised in Table 7.1. 


\section{Chapter 7}

Figure 7.1 Interconnected context layers relevant to answering the main research question on how weather information can be made usable for farming

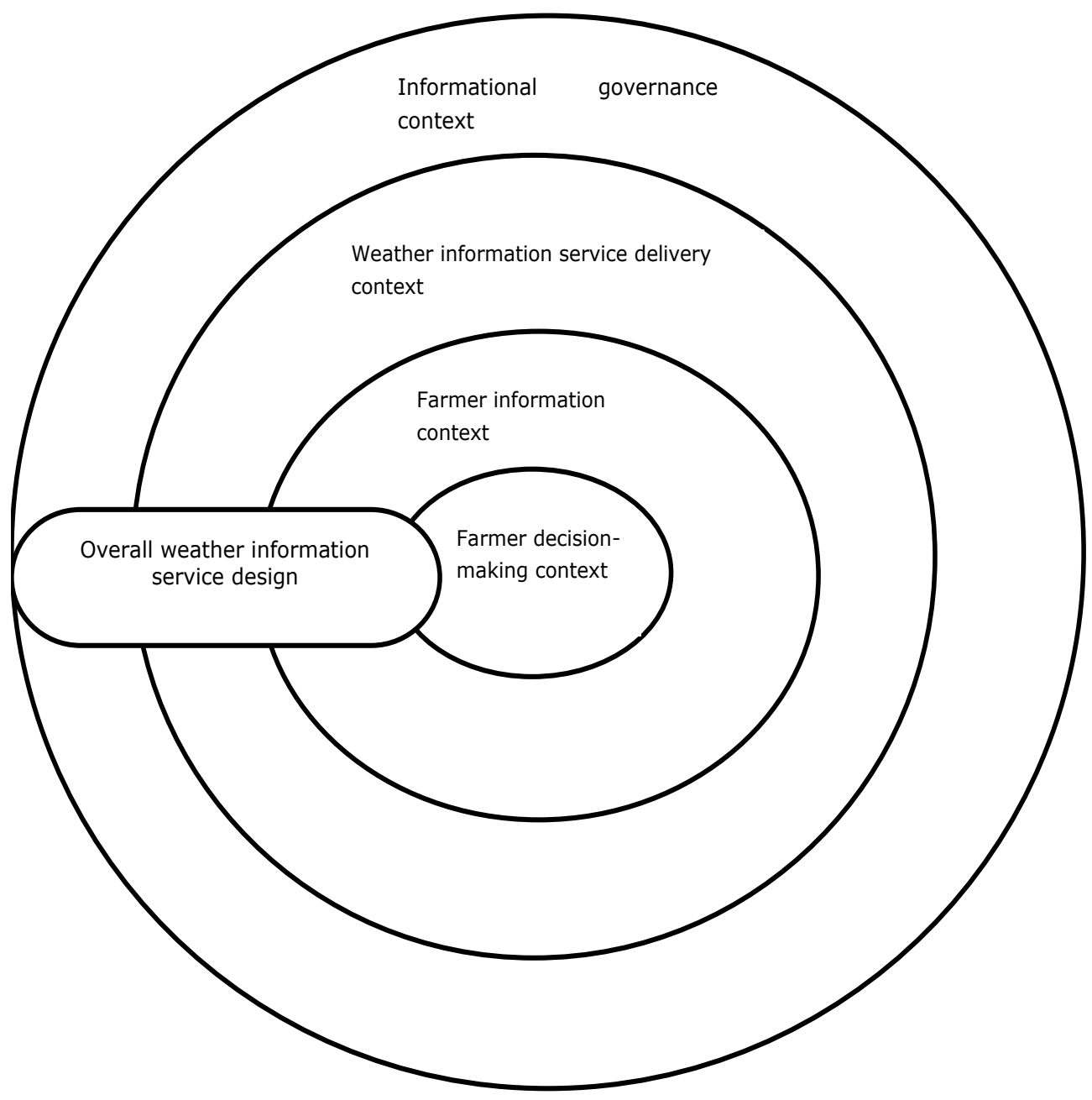

Source: Authors' construct, 2020

\subsubsection{Farmer decision-making context}

In the farmer decision-making context, I argue that WIS usability is enhanced when uncertainties about weather conditions affect farming practices. The uncertainty in weather conditions includes experiences of abnormal, below normal, above normal, and normal rainfall conditions at different periods of the farming seasons when farmers least expect such conditions to occur (Chapter 3). As a result of the effect of uncertainties in weather conditions on farmers' decision-making patterns, 
WIS application has become necessary to support decision-making on when to start farming, the crop or variety to select, when to apply agrochemicals, and when to harvest. From the findings in this thesis, I argue that in instances where farmers do not depend on the weather, or where seasonal weather patterns are not variable, WIS may be less usable. This finding resonates with Yaro's (2013) study, which indicates that small-scale food crop farmers in the coastal savanna are more in need of WIS than commercial farmers, because of the effect of unpredictability of rainfall conditions on their crops. In the case of commercial farmers in the forest zone, Yaro (2013) has indicated that they feel the effects of variable rainfall conditions less, because, even if rainfall is variable, it is able to sustain the growth of a range of crops in the area. In resonance with the finding of this thesis, Feldman and Ingram (2009) also noted that, under uncertain conditions, people are likely to apply weather and climate information if they have previous experience and perceptions of being vulnerable to similar conditions.

Another factor that can enhance WIS usability in the farmer decision-making context is the availability of flexible and/or robust options. In Chapter 3 of this thesis, I illustrated how farmers use flexible or robust strategies to deal with uncertain weather conditions at different stages in the farming season. For instance, farmers were able to select a flexible option such as transplanting tomato or pepper seedlings in batches when their local knowledge and experience indicated a variable seasonal weather condition. Similarly, the availability of robust options such as the selection of hardy crops (e.g., okra or cassava) was exploited in the pre-season during an abnormal weather condition. On the basis of this finding, I argue that the availability of flexible and/or robust options can make weather information usable. I make this assertion because, even when a forecast has a high certainty of occurring and the information is made available to all farmers but they do not have decision options to respond to the expected conditions, the information is unusable.

\subsubsection{Farmer information context}

In the farmer information context, WIS becomes usable when farmers share and discuss weather information among one another. The weather information is shared and discussed in the local language, through face-to-face interactions, and it is associated with deliberations on decision strategies that should be selected, given the forecast. Through sharing and discussing the weather information in the farming communities, farmers pass on the information to a diverse audience, and trust is built regarding the forecast because farmers reach a common agreement on their observations, including scientific sources. This results in a situation where farmers consider the forecast as reliable and legitimate (Chapter 4). This finding resonates with other studies that have also indicated that the practice of sharing and discussing weather information in farming communities contributes to the usability of the information for farming (see for instance Nidumolu et al., 2018; Clarkson et al., 2019; Nyamekye et al., 2019).

Further, WIS becomes usable when ICTs are in everyday use in farming communities, because ICTs aid in the availability of information, the accessibility of different types of information, and the reach of information to a diverse audience of farmers. For instance, the availability of a radio in farming communities helps to make WIS usable in farming because a radio is easy to carry, has a wide coverage, and has a strong oral culture. Mobile phone ownership is also widespread, and mobiles are used to access weather information from different information providers. Findings from this thesis also suggest that farmers are inclined to use ICTs that offer opportunities for oral communication (Chapter 2). Slavova and Karanasios (2018) reported a similar finding: that farmers' strategy of combining technologies with oral communication approaches supports the 
usability of agricultural information because it is associated with a high level of interaction and it instils trust in the information.

\subsubsection{Weather information service delivery context}

In the WIS delivery context, information providers respond to the information design and delivery criteria to make information usable for farming. I elaborate briefly on how each criterion contributes to WIS usability for farming as follows.

Local embeddedness supports WIS usability for farming because information providers are connected with, or integrated into, the farming community. Hence, they are able to design and deliver information that fits farmers' needs. This criterion is applied by agricultural extension agents, Radio Ada, and the private weather forecaster, because they are situated in the farming community. Here, there is a trade-off, as information providers cannot be embedded in each community as this will lead to prohibitive WIS costs. Hence, a certain measure of embeddedness is needed, but for efficiency reasons it may not meet all farmers' exact needs.

Legitimacy enhances WIS usability because the information design and delivery conform to farmers' interests, values, concerns, and perspectives, thereby resulting in acceptability. With this criterion, a WIS that respects farmers' values will be applied by farmers because they consider the information to connect to their context and needs.

Temporal and spatial resolution are relevant criteria that support the usability of WIS for farming because farmers require a forecast that indicates when and where a weather condition is likely. The ability of information providers to deliver weekly to monthly forecasts, including onset date, cessation dates, rainfall duration, and a list of specific communities where conditions are expected to occur, enables farmers to determine when to plough, sow seeds, or select crop varieties. However, between these two factors there is also a trade-off, because the more local the forecast is, the lower its predictive skill.

Predictive skill also enhances WIS usability because this criterion focuses on the communication of uncertainty inherent in the forecasts. When information providers are able to communicate uncertainty with various strategies to the understanding of farmers, this supports the usability of information because farmers are interested in knowing the extent of the expected weather condition that is likely to occur, in order to store water and adopt irrigation and soil moisture conservation strategies, among other decisions.

The accessibility criterion supports WIS usability in the absence of barriers and when there is ease in the flow of information to all farmers. With regard to this criterion, in instances where information providers deliver WIS in the local language, adopt two-way information delivery strategies to enhance feedback generation, use ICTs that are user-friendly, and apply other relevant communication strategies, the information is usable for farming. This is because it addresses the needs of farmers' age, literacy level, gender, and other socio-economic characteristics.

\subsubsection{Hybrid informational governance context}

The informational governance context supports WIS usability based three factors. 
First, multiplicity in hybrid informational governance contributes to WIS usability, as it results in a variety of information for farmers to choose for their decision-making. If a sole information source like the public WIS, which is broadcast only in the evenings, is provided to the farming community, it may be inaccessible to diverse groups of farmers for decision-making. Another implication is that farmers can combine different information to ascertain the reliability and accuracy of a forecast (Chapters 2 and 4). This aspect gives farmers more confidence to apply WIS in adaptive decision-making because their forecast corroborates other sources.

Second, intertwinement in hybrid informational governance contributes to WIS usability because it leads to the provision of joint information through multiple ICTs, leading to improved access to different types of WIS information. Also, information providers are able to add value to the weather information in the form of the inclusion of market prices, agronomic advisories, loans, and so forth. Intertwinement reinforces mutual obligations between the government, business, and civil society actors rather than undermining the relevance of a specific sector, especially government actors.

Thirdly, coalescence in hybrid informational governance supports WIS usability for farming because the involvement of the practices and institutions of different organisations results in the provision of innovative information specifically for farming areas that are underserved with weather information. Coalescence also makes WIS usable because it can strengthen organisations' ability to continue WIS provision through innovations and cost sharing among actors from different sectors.

\subsubsection{Overall weather information service design}

The weather information service design context is about the requirement for producing usable information.

In this context, WIS usability is improved when diverse groups of actors (farmers, agricultural extension agents, meteorologists, and scientists) are involved in designing the WIS. This results in the production and delivery of a WIS that matches the needs of each actor, especially farmers, because their knowledge and information needs are incorporated into the information design. For example, farmer involvement, especially throughout the co-design process, the daily collection of data on local indicators, and the provision of feedback, supported WIS usability (Chapter 5).

Secondly, the integration of local knowledge and scientific forecasts in the WIS design context is found to boost the usability of WIS for adaptive decision-making because farmers' acceptance and the usability of scientific forecasts increase when they are provided as part of local forecasts. This approach also results in ownership of the information, and the information is considered reliable. On this note, Grothmann and Patt (2005) found that farmers' acceptance and usability of scientific forecasts increased when they were provided as part of the local forecasts.

The application of tailor-made ICTs also supports WIS usability to enhance adaptive decisionmaking in farming because the tools/technologies are attuned to farmers' socio-economic characteristics. For instance, the co-production of a new WIS involving a tailor-made ICT through the use of symbols or images of local indicators; indicators of rainfall amount specified as heavy, medium, and low; the probability of the occurrence of rainfall; confidence levels in the weather app; and the use of emojis in WhatsApp made the WIS usable for diverse groups of farmers. 
Table 7.1 Summary on the factors that make a weather information service usable to support adaptive decision-making in farming

\begin{tabular}{|c|c|c|c|c|}
\hline $\begin{array}{l}\text { Farmer } \\
\text { decision- } \\
\text { making } \\
\text { context }\end{array}$ & $\begin{array}{l}\text { Farmer information } \\
\text { provision context }\end{array}$ & $\begin{array}{l}\text { Weather information } \\
\text { service provision context }\end{array}$ & $\begin{array}{l}\text { Informational governance } \\
\text { context }\end{array}$ & $\begin{array}{l}\text { Overall } \\
\text { weather } \\
\text { information } \\
\text { service design }\end{array}$ \\
\hline $\begin{array}{l}\text {-Uncertainty } \\
\text { in weather } \\
\text { conditions } \\
\text {-Availability } \\
\text { of flexible } \\
\text { and/or robust } \\
\text { options }\end{array}$ & $\begin{array}{l}\text {-Sharing and } \\
\text { discussing weather } \\
\text { information } \\
\text {-Everyday use of } \\
\text { ICTs in the farming } \\
\text { communities }\end{array}$ & $\begin{array}{l}\text {-Local embeddedness } \\
\text {-Legitimacy } \\
\text {-Temporal and spatial } \\
\text { resolution } \\
\text {-Predictive skill } \\
\text {-Accessibility }\end{array}$ & $\begin{array}{l}\text {-Multiplicity in hybrid } \\
\text { informational governance } \\
\text {-Intertwinement in hybrid } \\
\text { informational governance } \\
\text {-Coalescence in hybrid } \\
\text { informational governance }\end{array}$ & $\begin{array}{l}\begin{array}{l}\text {-Involvement } \\
\text { of diverse } \\
\text { groups }\end{array} \\
\text {-Integrating } \\
\text { local } \\
\text { knowledge } \\
\text { and scientific } \\
\text { forecast } \\
\text {-Tailor-made } \\
\text { ICTs }\end{array}$ \\
\hline
\end{tabular}

\subsection{Limitations and suggestions for future research}

This thesis examined, explained, and provided knowledge on what makes WIS usable for adaptive decision-making in farming within an informational governance context. However, it has also identified gaps that require further research investigations. Although additional recommendations on questions that require further research are linked to the individual chapters (Chapters 2-6), here, I reflect on five general issues that are relevant and relate to multiple chapters.

In this thesis, I generated information from a small population of farmers. Certainly, the selection of a large number of farmers could have provided varied insights on adaptive decision-making through flexible or robust strategies, the factors that affect the usability of existing WIS, and farmers' engagement and motivation. However, as these concepts were applied in a new context, there was a need to derive in-depth knowledge on their applicability and the empirical knowledge that can be deduced with a qualitative approach. With the citizen science co-production approach, issues about availability of time and funding, inability to train large groups of farmers, and other resource constraints resulted in the selection of a few farmers; nonetheless, participants were selected from different communities. On this note, future research could focus on increasing the number of participants in the study by recruiting people who are already using smartphones, given the expansion in smartphone use and internet coverage. Likewise, studies could focus on a largescale survey to enable the generalisation of findings on adaptive decision-making strategies and the factors that affect WIS usability for farming. An increase in the number of participants would also support analysis of the variations in, and similarities of, results within and between communities.

Secondly, more male than female farmers were involved in the thesis. This is because farming in the Ada East District is male dominated, with women involved in trading or agro-processing activities. Hence, although I generated interesting findings, I treated most of the responses as the homogenous views of all farmers in the Ada East District. Thus, investigating the level of engagement and motivations from a gendered perspective would have provided interesting results that could be useful in strengthening the citizen science method to co-produce WIS in a developing 
country context. A gendered perspective on adaptive decision-making and the usability of weather and climate information for farming would also be useful for informing policy. This theme is relevant considering that rural communities have differing access to resources. Further research is also required on the correlation between socio-economic characteristics (e.g., age, level of education, household size) and adaptive decision-making or factors that affect the usability of weather and climate information services.

Thirdly, the studies comprising each chapter of the thesis were undertaken in different phases for three years in the study district. The research on decision-making in farming was conducted for a year, as well as the co-design and co-production of new weather information. This implies that the duration of each phase of the investigation of the core themes was relatively short. This limited the continual observation of farmers' decision-making; a longer observation period would have yielded more results on the application of flexible and robust decision-making under uncertain conditions. Also, if the experiment on data collection on local weather indicators for the co-production of WIS had been conducted over a longer period, new dimensions of findings could have emerged on the level of participants' engagement and motivations, thereby potentially allowing for stronger claims and generalisation of results. Nevertheless, I catered for this shortfall by engaging the same group of farmers as in the initial phase of the study to participate in the co-production of weather information. With this approach, I established cordial relationship through home visits, workshops, and several interview phases. Future studies could extend the duration of the study or possibly undertake a longitudinal study to provide insights on the patterns of decision-making and factors affecting the usability of WIS and/or engagement and motivations in the co-production of weather and climate information. The collection of data on a long-term basis would also provide an opportunity to understand how farmers learn from previous experience of applying flexible or robust adaptive decision-making strategies and how, in subsequent farming seasons, they apply lessons learned about dealing with uncertain weather conditions.

This thesis has focused on examining what makes WIS usable for adaptive decision-making in farming, but the co-production of new WIS through the integration of scientific forecasts and local knowledge was not followed by an analysis of the real-life decision-making strategies adopted by farmers. This is a limitation, because the evaluation in Chapter 5 did not ascertain the outcome of the usable WIS in supporting adaptive decision-making in terms of the selection of flexible or robust strategies or the amount of yield derived from farming in view of the application of a new WIS. However, the findings in this thesis have contributed to the development of a support app (provisionally called FarmerSupport app) through a business challenge and a proposed testing of the app to ascertain how it can support farmers' decision-making in real-life in Kulna, Bangladesh (see figure $5 \mathrm{p}$ of supplementary materials). This knowledge gap could also be an area for future research to quantify or establish the extent to which the application of usable WIS affects decisionmaking in farming. This should be markedly different from doing a normative evaluation of the outcome of the co-production process. In doing this, it is important to note that farmer decisionmaking is complex and may be based on interconnecting social, cultural, and economic factors. Hence, I propose that future research should design an approach including the application of the decision-making table (see Chapter 3) to examine participants' real-life decision-making during the co-production of WIS.

Furthermore, I applied qualitative single case study research methods (interviews, focus group discussions, participatory workshops) throughout the thesis. These methods were relevant for 
providing in-depth knowledge on various issues in the empirical chapters of the thesis. This obviously has implications for data reliability and the ability to generalise results to a wider population of farmers in Ghana. Therefore, in order to make stronger claims and be able to generalise findings, I propose that studies should be carried out on a large scale, focusing on a survey approach to allow for more statistical analysis in order to draw explanatory variables. Future research could also focus on a randomised control trial or apply a comparative case study design to compare findings on the level of engagement, motivations, and adaptive decision-making between communities that use generic WIS and communities that use co-produced WIS.

\subsection{Recommendations for policy and practice}

The findings of this thesis offer a basis for rethinking the production and delivery of usable weather and climate information services to support adaptive decision-making in farming. Therefore, several recommendations for policy and practice derived from the cross-cutting themes require discussion.

\subsubsection{Recommendations on the design of weather information services}

In this section, I provide recommendations for the design of usable weather information by considering factors that can ensure its scalability and sustainability in different contexts.

First, I recommend that the application of ICT tools for the provision of weather information should encapsulate ideas embedded in the provision of services rendered in places like a restaurant where customer satisfaction is paramount. Here, I seek to draw attention to the fact that information providers need to apply ICT tools and deliver information in a way that provokes cognitive and emotional responses from users and does not focus just on the attractiveness of the tools. In this instance, the weather information should have colours, signs, short texts, and symbols. The tool should be attractive and easy to navigate, and the procedure should be short and clear. In a farming context, interactive ICTs like the abovementioned FarmerSupport app, IVR, call centres, and so forth can be used for two-way delivery of information, as users may prefer to discuss the forecast with the formation provider. For instance, the FarmerSupport app (http://www.waterapps.net/enus/ghana-updates/farmersupport-mobile-appnow-online/) to which this thesis has contributed comprises two-way mobile information systems with a single smartphone app. This mobile app has an interface for: 1) colourful local weather indicators, 2) pie charts indicating local and scientific forecasts, 3) an integrated forecast, 4) audio settings, and 5) agronomic advisories. It is embedded in a citizen science model where users can submit data on local weather indicators. It is also designed with symbols, short texts, and audio features for communicating information. Furthermore, the app helps to corroborate certainty in the different forecast systems.

Secondly, alternative strategies can be adopted to deal with technical challenges, such as internet connectivity, inaccessibility to electricity, and frequent power outages, during the co-production of weather information. In this instance, power banks can be supplied to participants depending on the availability of funding. Alternatively, open data kits and apps that enable data collection offline but can synchronise upon internet availability may be used as suitable options. Also, non-literate people can be engaged in interactions and the provision of feedbacks through the use of emojis in SMS, phone calls, IVR, and voice recording. Fieldnote books can also be used to record observations and predictions. To support user engagement in data collection during the coproduction process, tools such as automated voice messages, peep calls, and alert systems can be applied to remind users to collect data. 
Thirdly, the involvement of diverse participants in co-producing weather information is crucial for the upscaling and the sustainability of usable WIS. With regard to this factor, it is important to deal with power structures that can lead to the exclusion of certain groups of users, especially women. Hence, in the design of WIS, ideas for including diverse audience groups can be integrated into the selection of participants/users. For example, young men and women, elderly men and women, persons with disabilities, (non)literate persons, among other socio-economic classifications, are required to be involved in the process. Also, it is relevant to identify and work with self-organised groups and experts, as this creates legitimacy, builds trust, and also bridges 'language' gaps. Although the involvement of certain actors with formal scientific knowledge is relevant, their knowledge should not dominate the process. Instead, their role should focus mainly on facilitating and guiding users in the co-production process. It is necessary also to include organisations that may become lead players in driving and developing a scaling-up strategy for the co-production of the WIS.

Fourth, information providers should have knowledge about users' context to enhance the delivery of usable weather and climate information. This aspect is relevant because it can enable information providers to design the information to fit specific contexts by considering users' language, farming practices, and socio-economic and cultural practices. With regard to this factor, it is important that information providers focus on dedicated group of intensive users who will form the basis for wider dissemination of the information in the communities. Alternatively, as the use of smartphones is increasing, the co-production of weather information with users' local knowledge may target volunteers who already use smartphones, and then the mobile app may be installed. This approach may help to reduce the workload and cost related to training, the provision of data collection tools, and monitoring activities. Furthermore, the co-production process should ensure that elements such as participants' competence (e.g., feeling capable of doing something), autonomy (e.g., control over the process), and relatedness (e.g., a sense of belonging) are met to enhance volunteers' intrinsic motivation.

\subsubsection{Recommendations for policy}

The findings of this thesis have practical implications for policy interventions also. I elaborate on a few core areas that require policy attention.

First, given the relevance of local knowledge in this thesis, I recommend that it should be given policy attention. Specifically, it is necessary for local and national authorities to document and conserve local knowledge and its related indicators. Observations from fieldwork suggest that there are instances where local knowledge is regarded as primitive, unchristian, and superstitious. Hence, currently, the knowledge is applied by adults or experienced farmers and it exists in an oral form. In this instance, the passing of such knowledge holders could imply a possible extinction of some relevant local knowledge in their farming communities. To support the sustainability of this important resource, strategies should be developed to institutionalise and document local knowledge. This may take the form of the establishment of a national database that documents local knowledge through approaches like citizen science. Also, biological species that are used for forecasting should be protected through community wildlife conservation programmes, because urbanisation, climate change, and other human development could threaten their existence. Additionally, local knowledge could be mainstreamed into academic curriculum activities including climate change adaptation modules and climate science disciplines. 
Second, the application of citizen science to co-produce weather and climate information by integrating scientific forecasts and local forecasts in the weather and climate information service sector in this thesis points to a new course of action concerning the design and framework of weather and climate information services in a developing country context. The thesis has provided evidence on what is required to co-design, co-produce, and sustain volunteers' motivation for continual data collection, given the extent of smartphone adoption and the expansion in ICT infrastructures like the telecommunication services in developing countries. This knowledge is useful for organisations that require detailed location-specific weather data from local communities in order to consider the integration of scientific forecasts and local knowledge in WIS production. The application of information design and delivery criteria such as local embeddedness, legitimacy, spatial and temporal aspects, predictive skill, and accessibility could also be a useful analytical and evaluation tool that could be applied to assess farmers' (users') information needs in order to support the formulation of specific strategies that can improve the usability of weather and climate information services.

Third, considering the relevance of WIS for farming and for the development of other sectors, the knowledge derived from this thesis contributes to the call for a weather and climate information policy in Ghana (see also Naab et al., 2019). Given the existence of numerous actors providing weather and climate information services, it is worth devising a policy that focuses on multiscale stakeholder collaboration (government agencies, local radio, individual specialist, community knowledge). To eliminate the fragmented provision of weather and climate information for farming, this thesis furthermore recommends that the weather and climate information policy should indicate the coordinating organisation that should be responsible for leading this initiative. Further, the design of the policy to produce and deliver WIS should be anchored on the principles of participation and power balance and be user-driven.

Fourth, it is necessary to integrate ideas of adaptive decision-making into the pattern of decisionmaking in farming, given the uncertain weather patterns. This idea is relevant for information providers like agricultural extension agents, agripreneurs, input dealers, and other actors to strategise the use of flexible and robust strategies in farming to alter risk-averse behaviour among farmers under uncertain weather conditions. This idea may be integrated into farmer field schools on weather and climate information with a facilitator to guide farmers to participatorily select adaptive strategies in line with a given weather or seasonal forecast. The idea of adaptive decisionmaking can also be included in agricultural extension field guidelines, given the variability in weather and climatic conditions that is being experienced in most farming area. The Ministry of Food and Agriculture, agri-input dealers, radio channels, and the farming community can collaborate to provide relevant farming resources like seeds, irrigation facilities, and other farm inputs, based on adaptive decision-making and patterns of decision-making in a specific farming context. Also, it is relevant that government programmes like the distribution of seeds and agrochemicals are planned according to the forecasts for the farming season to avoid too late or too early distribution of farm inputs. 


\section{References}

Abdul-Razak, M. \& Kruse, S. (2017). The adaptive capacity of smallholder farmers to climate change in the Northern Region of Ghana. Climate Risk Management, 17, 104-122. doi.org/10.1016/j.crm.2017.06.001

Adaba, G.B. \& Ayoung, D. A. (2017). The development of a mobile money service: an exploratory actor-network study. Information Technology for Development, 23(4), 668-686. doi: $10.1080 / 02681102.2017 .1357525$

Addo, A.K., Nicholls, R.J., Codjoe, S.N.A., \& Abu, M. (2018). A biophysical and socioeconomic review of the Volta delta, Ghana. Journal of Coastal Resources, 34(5), 1216-1226 doi:10.2112/JCOASTRES-D-17-00129

Addo, K.A. (2015). Assessment of the Volta Delta shoreline change. Journal of Coastal Zone Management, 18(408). doi:10.4172/2473-3350.1000408.

Adjei, P.O.W., Cazcarro, I., Arto, I., Ofori-Danson, P.K., Asenso, J.K., Codjoe, S.N. et al. (2018). Biophysical and Socioeconomic State of the Volta Delta Region of Ghana from the Perspectives of Gender and Spatial Relations. Journal of Sustainability 10, 893. doi:10.3390/su10030893.

Agyekumhene, C., de Vries, J.R., van Paassen, A., Macnaghten, P., \& Schut, M. (2018). Digital platforms for smallholder credit access: The mediation of trust for cooperation in maize value chain financing [Special issue]. Wageningen Journal of Life Sciences, 86-87, 77-88. doi.org/10.1016/j.njas.2018.06.001

Aker, J.C., Ghosh, I., \& Burrell, J. (2016). The promise (and pitfalls) of ICT for agriculture initiatives. Journal of Agricultural Economics 47, 35-48. doi.org/10.1111/agec.12301

Aker, J.C. (2011). Dial "A" for agriculture: A review of information and communication technologies for agricultural extension in developing countries. Journal of Agricultural Economics 42, 631-647. doi.org/10.1111/j.1574-0862.2011.00545.x

Aker, J.C. \& Mbiti, I.M. (2010). Mobile phones and economic development in Africa. Journal of Economic Perspective, 24(3) 207-232. doi/pdfplus/10.1257/jep.24.3.207

Akudugu, M.A., Guo, E., \& Dadzie, S.K. (2012). Adoption of modern agricultural production technologies by farm households in Ghana: What factors influence their decisions. Journal of $\begin{array}{llll}\text { Biology, Agriculture } \quad \text { Healthcare, } & \text { 2(3) }\end{array}$ https://www.iiste.org/Journals/index.php/JBAH/article/view/1522

Alexander, M. \& Dessai, S. (2019). What can climate services learn from the broader services literature? Climatic Change, 157, 133-149. doi.org/10.1007/s10584-019-02388-8.

Alexander, C., Bynum, N., Johnson, E., King, U., Mustonen, T., Neofotis, P., et al. (2011). Linking Indigenous and Scientific Knowledge of Climate Change. BioScience, 61(6), 477-484. doi.org/10.1525/bio.2011.61.6.10 
Alhassan, R.M., Egyir, I.S., \& Abakah, J. (2013). Farm household level impacts of information communication technology (ICT)-based agricultural market information in Ghana. Journal of Development Agricultural Economics, 30(5),161-167. doi: 10.5897/ JDAE12.143

Allotey, G.A. (2019). Wageningen University, partners launch apps to transform agricultural landscape. Citi newsroom. https://citinewsroom.com/2019/06/wageningen-university-partnerslaunch-apps-to-transform-agricultural-landscape/

Amegnaglo, C.J., Asomanin, K., \& Mensah-Bonsu, A. (2017). Contingent valuation study of the benefits of seasonal climate forecasts for maize farmers in the Republic of Benin, West Africa. Climate Services, 6, 1- 11. doi.org/10.1016/j.cliser.2017.06.007

Amekudzi, L.K., Yamba, E.I., Preko, K., Asare, E.O., Aryee, J., Baidu, M., \& Codjoe, S.NA. (2015). Variabilities in rainfall onset, cessation and length of rainy season for the various agroecological zones of Ghana. Journal of Climate, 3(2), 416-434. doi.org/10.3390/cli3020416

Amisigo, B., McCluskey, A., \& Swanson, R. (2015). Modeling impact of climate change on water resources and agriculture demand in the Volta basin and other basin systems in Ghana. Sustainability 7(6), 6957-6975. doi:10.3390/su7066957.

Anderies, J.M., Janssen, M.A., \& Ostrom, E. (2004). A framework to analyze the robustness of social-ecological systems from an institutional perspective. Ecology and Society, 9(1). doi.org/10.5751/es-00610- 090118

Andreini, M., van de Giesen, N.C., van Edig, A., Fosu, M., \& Andah, W. (2000). Volta Basin water balance. ZEF- Discuss Papers Dev Policy. 21, 29. https://www.zef.de/uploads/tx_zefportal/Publications/zef-dp21-00.pdf.

Appeaning-Addo, K., Nicholls, R.J., Codjoe, S.N.A., \& Abu, M. (2018). A Biophysical and Socioeconomic Review of the Volta Delta, Ghana. Journal of Coastal Research 34(5), 1216-1226. doi.org/10.2112/JCOASTRES-D-17-00129.1

Anthony, E.J., Almar, R., \& Aagaard, T. (2016). Recent shoreline changes in the Volta river delta, West Africa: the roles of natural processes and human impacts. African Journal of Aquatic Science, 41(1), 81-87. doi:10.2989/16085914.2015.1115751.

Archie, K.M., Dilling, L., Milford, J.B., \& Pampelf, F.C. (2014). Unpacking the 'information barrier': Comparing perspectives on information as a barrier to climate change adaptation in the interior mountain West. Journal of Environmental Management, 133, 397-410. doi.org/10.1016/j.jenvman.2013.12.015

Armah, F.A, Yengoh, G.T., Luginaah, I., Chuenpagdee, R., Hambati, H., \& Campbell. G. (2015). Monitored versus experience-based perceptions of environmental change: evidence from coastal Tanzania. Journal of Integrated Environmental Science, 12(2), 119-152. doi:10.1080/1943815X.2015.1017505. 
Armah, F.A., Odoi, J.O., Yengoh, G.T., Obiri, S., Yawson, D.O., \& Afrifa, E.K.A. (2011). Food security and climate change in drought sensitive savanna zones of Ghana. Mitigation and Adaptation Strategies for Global Change, 16(3), 291-306. doi.org/10.1007/s11027-010-9263-9

Armitage, C.J. \& Conner, M. (2001). Efficacy of the theory of planned behaviour: a meta analytic review. British Journal of Social Psychology, 40(4), 471-499. doi.org/10. 1348/014466601164939.

Asante, F.A., \& Amuakwa-Mensah, F. (2014). Climate Change Variability Ghana: Stocktaking. Climate, 3(1), 78-99. doi.org/10.3390/cli3010078

Asenso-Okyere, K., \& Mekonnen, D. A. (2012). The Importance of ICTs in the Provision of Information for Improving Agricultural Productivity and Rural Incomes in Africa (WP 2012-015) United Nations Development Program, Regional Bureau of Africa. http://www.africa.undp.org/content/rba/en/home/library/working-papers/icts-provisioninformation/

Atta, S., Ly, M., Salack, S., \& George, D.A. (2015). Adapting to climate variability and change in smallholder farming communities: A case study from Burkina Faso, Chad and Niger. Journal of Agricultural Extension and Rural Development, 7, 16-27. doi.org/10.5897/JAERD14.0595

Atiah, W.A., Amekudzi, L.K., Quansah, E. \& Preko, K. (2019). The spatiotemporal variability of rainfall over the agro-ecological zones of Ghana. Journal of Atmosphere, 9(527), 44. doi.org/10.3390/atmos11080859

Asingizwe, D., Murindahabi, M.M., Koenraadt, C.J.M., Poortvliet, P.M., van Vliet, A.J.H., Ingabire, C.M. et al. (2019). Co-Designing a Citizen Science Program for Malaria Control in Rwanda. Sustainability, 11, 24. doi.org/10.3390/su11247012

Ajzen, I., Sparks, P., \& Hall, T. (2002). Perceived behavioral control, self-efficacy, locus of control, and the theory of planned behavior. Journal of Applied Social Psychology, 32(4), 665-683. doi.org/10.1111/j.1559-1816.2002.tb00236.x

Awadzi, T.W., Ahiabor, E., \& Breuning-Madsen, H. (2008). The soil-land use system in a sand spit area in the semi-arid coastal savanna region of Ghana-development, sustainability and threats. West African Journal of Applied Ecology, 13(1), 132-143. doi:10.4314/wajae.v13i1.40573.

Banoeng-Yakubo, B.K., Akabzaa, M., Hotor, V., \& Danso, S.K. (2006). Application of Electrical Resistivity Techniques in Delineation of Saltwater-Freshwater in Keta Basin, Ghana. In Y. Xu \& B. Usher, (eds.), Groundwater Pollution in Africa (193-202). Taylor \& Francis.

Baidu, M., Amekudzi, L.K., Aryee, J., \& Annor, T. (2017). Assessment of long term spatiotemporal rainfall variability over Ghana using wavelet analysis. Journal of Climate 5, 30. doi.org/10.3390/cli5020030 
Bailey, M., Bush, S.R., Miller, A., \& Kochen, M. (2016). The role of traceability in transforming seafood governance in the global South. Current Opinion in Environmental Sustainability, 18, 25 32. doi.org/10.1016/j.cosust.2015.06.004

Balaji, V., \& Craufurd, P. (2011). Using information and communication technologies to disseminate and exchange agriculture-related climate information in the Indo Gangetic Plains. CGIAR Research Program on Climate Change, Agriculture and Food Security (CCAFS), Project Report. https://hdl.handle.net/10568/21720

Balehegn, M., Balehey, S., Fu, C., \& Liang, W. (2019). Indigenous weather and climate forecasting knowledge among Afar pastoralists of north eastern Ethiopia: Role in adaptation to weather and climate variability. Journal of Pastoralism 9(8). doi.org/10.1186/s13570-019-0143-y

Barron, J. (2004). Dry Spell Mitigation to Upgrade Semi-arid Rainfed Agriculture: Water Harvesting and Soil Nutrient Management for Smallholder Maize Cultivation in Machakos. [Published Doctoral thesis]. Stockholm University. https://www.divaportal.org/smash/get/diva2:200763/FULLTEXT01.pdf

Bassi, A. (2014). Hybrid Organizations and the Third Sector: Challenges for Practice, Theory and Policy. Nonprofit Policy Forum, 5(2), 395-401. doi.org/10.1515/npf-2014-0015

Battilana, J., \& Dorado, S. (2010). Building Sustainable Hybrid Organizations: The Case of Commercial Microfinance Organizations. Academy of Management Journal, 53(6), 1419-1440.

https://www.jstor.org/stable/29780265

Batson, C.D., Ahmad, N., \& Tsang, J.A. (2002). Four motives for community involvement. Journal of Social Issues, 58(3), 429-45. doi/pdf/10.1111/1540-4560.00269

Bazile, R., Boucher, M., Perreaul, L. \& Leconte, R. (2017). Verification of ECMWF System 4 for seasonal hydrological forecasting in a northern climate. Journal of Hydrology and Earth System Sciences, 21, 5747-5762. doi.org/10.5194/hess-21-5747-2017

Beach, D., \& Pedersen, R.B. (2016). Causal case study methods: Foundations and guidelines for comparing, matching and tracing. University of Michigan Press, Michigan. doi.org/10.3998/mpub.6576809

Bellfield, H., Sabogal, D., Goodman, L., \& Leggett, M. (2015). Case report case study report: community-based monitoring systems for REDD+ in Guyana. Journal of Forests, 6(1), 133-156. doi:10.3390/f6010133.

Bennett, W.L., \& Segerberg, A. (2012). The logic of connective action: digital media and the personalization of contentious politics, information. Journal of Information, Communication and Society, 15, 739-768. doi.org/10.1080/1369118X.2012.670661.

van Berkum, S., \& Dengerink, J. (2019). Transition to sustainable food systems: the Dutch circular approach providing solutions to global challenges. Wageningen, Wageningen Economic Research, Report 2019-082. https://library.wur.n1/WebQuery/wurpubs/fulltext/495586 
Beza, E., Steinke, J., van Etten, J., Reidsma, P., Fadda, C., Mittra, S., et al. (2017). What are the prospects for citizen science in agriculture? Evidence from three continents on motivation and mobile telephone use of resource-poor farmers. PLoS One, 12(5). doi.org/10.1371/journal.pone. 0175700

Berliner, L.M. (2003). Uncertainty and climate change. Statistical Science, 18(4), 430-435. https://projecteuclid.org/download/pdf_1/euclid.ss/1081443227

Bertilsson, T.M. (2004). The elementary forms of pragmatism: on different types of abduction. European Journal of Social Theory, 7(3), 371-389. doi.org/10.1177/1368431004044199

Bhaskar, R. (1998). The possibility of naturalism: a philosophical critique of the contemporary human sciences ( $3^{\text {rd }}$ ed.). Routledge, London.

Bhatasara S., \& Nyamwanza, A. (2018). Sustainability: a missing dimension in climate change adaptation discourse in Africa? Journal of Integrative Environmental Science, 15(1), 87-102. doi:10.1080/1943815X.2018.1450766.

Bhave, A.G., Conway, D., Dessai, S., \& Stainforth, D.A. (2016). Barriers and opportunities for robust decision making approaches to support climate change adaptation in the developing world. Climate Risk Management, 14, 1-10. doi.org/10.1016/j.crm.2016.09.004

Bièvre, B. De, Clark, J., Hannah, D.M., \& Shaheed, S. (2017). User driven design of decision support systems for polycentric environmental resources management. Environmental Modelling \& Software, 88, 58-73. doi.org/10.1016/j.envsoft.2016.10.012

Billis, D. (2010). Towards a theory of hybrid organizations. In D. Billis (Ed), Hybrid Organisations and the Third Sector: Challenges for practice, theory and policy (pp. 46-69). Palgrave Macmillan.

Boege, V.M., Brown, A.M., \& Clements, K.P. (2009). Hybrid Political Orders, Not Fragile States. Peace Review, 21(1), 13-21. doi.org/10.1080/10402650802689997

Bohensky, E.L., \& Maru, Y. (2011). Indigenous knowledge, science, and resilience: What have we learned from a decade of international literature on "integration"? Ecology and Society, 16(4). doi.org/10.5751/ES-04342- 160406

Bonney, R., Phillips, T.B., Ballard, H.L., \& Enck, J.W. (2016). Can citizen science enhance public understanding of science? Public Understanding of Science, 25(1), 2-16. doi.org/10.1177/0963662515607406

Bonney, R., Cooper, C.B., Dickinson, J., Kelling, S., Phillips, T., Rosenberg, K.V., \& Shirk, J. (2009). Citizen Science: A Developing Tool for Expanding Science Knowledge and Scientific Literacy. BioScience, 59(11), 977-984. doi.org/10.1525/bio.2009.59.11.9

Bonney, R., Ballard, H., Jordan, R., McCallie, E., Phillips, T., Shirk, J., Wilderman, C.C. et al. (2009). Public participation in scientific research: Defining the field and assessing its potential for 
informal science education. A CAISE Inquiry Group Report. Washington, DC: Center for Advancement of Informal Science Education (CAISE). http://www.birds.cornell.edu/citscitoolkit/publications/CAISE-PPSR-report-2009.pdf.

Boubacar, B., Obuobie, E., Andreini, M., Andah, W., \& Pluquet, M. (2005). The Volta River basin. The Volta River Basin. p. 190.

http://www.iwmi.cgiar.org/assessment/files_new/research_projects/river_basin_development_an d_management/VoltaRiverBasin_Boubacar.pdf

Bovaird, T., Van Ryzin, G.G., Loeffler, E., \& Parrado, S. (2015). Activating citizens to participate in collective coproduction of public services. Journal of Social Policy, 44(1), 1-23. doi:10.1017/S0047279414000567

Bowden, A., \& Ciesielska, M. (2016). Ecomuseums as cross-sector partnerships: Governance, strategy and leadership. Public Money Management, 36, 23-30. doi.org/10.1080/09540962.2016.1103414

Brandsen, T., \& Karré, P.M. (2011). Hybrid Organizations: No Cause for Concern? International Journal of Public Administration, 34(13), 827-836. doi: 10.1080/01900692.2011.605090

Brammer, J.R., Brunet, N.D., Burton, A.C., Cuerrier, A., Danielsen, F., Dewan, K. et al. (2016). The role of digital data entry in participatory environmental monitoring. Journal of Conservation Biology, 30(6), 1277-1287. doi: 10.1111/cobi.12727.

Bremer, S., \& Meisch, S. (2017). Co-production in climate change research: reviewing different perspectives. Wiley Interdisciplinary Reviews: Climate Change, 8(6), 482. doi.org/10.1002/wcc.482

Brown, P.R., Hochman, Z., Bridle, K.L., \& Huth, N.I. (2015). Participatory approaches to address climate change: perceived issues affecting the ability of South East Queensland graziers to adapt to future climates. Journal of Agricultural and Human Values, 32, 689-703. doi 10.1007/s10460015-9584-0

Brownlee, J. (2007). Satisficing, Optimization, and Adaptive Systems. Complex Intelligent Systems, Technical Report 070305A, 1-5. https://pdfs.semanticscholar.org/baf6/e9e5b2b6e6b d728ac4d070293fbde124d286.pdf

Briley, L., Brown, D., \& Kalafatis, S.E. (2015). Overcoming barriers during the co-production of climate information for decision-making. Climate Risk Management, 9, 41-49. doi.org/10.1016/j.crm.2015.04.004

Brugnach, M., Dewulf, A., Pahl-Wostl, C., \& Taillieu, T. (2008). Toward a relational concept of uncertainty: About knowing too Little, knowing too differently, and accepting not to know. Ecology and Society, 13(2). doi.org/10.5751/ES-02616-130230.

Bryman, A. (2004). Social Research Methods (2 $\left.{ }^{\text {nd }} e d.\right)$. Oxford University Press, Oxford. 
Buizer, J., Jacobs, K., \& Cash, D. (2010). Making short-term climate forecasts useful: Linking science and Action. Proceedings of the National Academy of the United States of America, 113(17), 4597-4602. doi. org/10.1073/pnas.0900518107

van der Burgt, F., van Pelt, S., \& Lobbrecht, A. (2018). Mobile Weather Services for Small-Scale Farmers. Available online:https://www.weatherimpact.com/wpcontent/uploads/2019/10/MobileWeatherServicesforSmallScaleFarmers_WeatherImpact.pdf.

Burgess, M.M. (2014). From "trust us" to participatory governance: deliberative publics and science policy. Public Understand of Science, 23, 48-52. doi: 10.1177/0963662512472160.

Burton, A.C. (2012). Critical evaluation of a long-term, locally-based wildlife monitoring program in West Africa. Journal of Biodiversity Conservation, 21, 3079-3094. doi 10.1007/s10531-0120355-6

Buytaert, W., Vuille, M., Dewulf, A., Urrutia, R., Karmalkar, A ., \& C élleri, R . (2010). Uncertainties in climate change projections and regional downscaling in the tropical Andes: implications for water resources management. Hydrology and Earth System Sciences, 14(7), 1247 1258. doi.org/10.5194/hess-14-1247-2010, 2010.

Byerlee, D., De Janvry, A., Sadoulet, E., Townsend, R., \& Klytchnikova, I. (2008). World Development Report 2008: Agriculture for Development. The World Bank, Washington, DC.

Cafer, A.M \& Rikoon J.S. (2018). Adoption of new technologies by smallholder farmers: the contributions of extension, research institutes, cooperatives, and access to cash for improving tef production in Ethiopia. Agricultural and Human Values, 35(3), 685-699. doi:10.1007/s10460018-9865-5.

Caine, A., Dorward, P., Clarkson, G., Evans, N., Canales, C. \& Stern, D. (2015). Review of Mobile Applications that Involve the Use of Weather and Climate Information: their use and potential for Smallholder Farmers. CCAFS Working Paper no.150. www.ccafs.cgiar.org

Carter, B, \& New, C. (2004). Introduction: realist social theory and empirical research. In, B. Carter, \& C. New, (eds.), Making realism work: realist social theory and empirical research (120). Routledge.

Cash, D.W., Adger, W., Berkes, F., Garden, P., Lebel, L., Olsson, P. et al. (2006). Scale and crossscale dynamics: governance and information in a multilevel world. Ecology and Society 11(2), 8. doi.org/10.5751/ES-01759-110208.

Cash, D.W. \& Buizer, J. (2005). Knowledge-action systems for seasonal to interannual climate forecasting: summary of a workshop. Report to the Roundtable on Science and Technology for Sustainability. Washington, DC: National Research Council of the National Academies, National Academies Press, 32 pp. 
Cash, D.W., Clark, W.C., Alcock, F., Dickson, N.M., Eckley, N., Guston, D.H. et al. (2003). Knowledge systems for sustainable development. Proceedings of the National Academy of Sciences, 100(14), 8086-8091. doi.org/10.1073/pnas.1231332100

Cash, D., Clark, W. C., Alcock, F., Dickson, N. M., Eckley, N., \& Jäger, J. (2002). Salience, credibility, legitimacy and boundaries: linking research, assessment and decision making. KSG Working Papers Series.

Cazcarro, I., Arto, I., Hazra, S., Bhattacharya, R. N., Adjei, P. O.-W., Ofori-Danson, P. K., et al. (2018). Biophysical and socioeconomic state and links of deltaic areas vulnerable to climate change: Volta (Ghana), Mahanadi (India) and Ganges-Brahmaputra-Meghna (India and Bangladesh). Sustainability, 10(3), 893. doi.org/10.3390/su10030893.

Chapman, R., Blench, R., Kranjac-Berisavljevic, G. \& Zakariah, A.B. (2003). Rural Radio in Agricultural Extension: the Example of Vernacular Radio Programmes on Soil and Water Conservation in N. Ghana. Agricultural Research \& Extension Network: Network Paper 127(2).

Chandra, A., Dargusch, P., McNamara, K.E., Caspe, A.M., \& Dalabajan, D. (2017). A study of climate-smart farming practices and climate-resiliency field schools in Mindanao, the Philippines. World Development, 98, 214-230. doi: 10.1016/j.worlddev.2017.04.028

Changnon, D. (2004). Improving outreach in atmospheric sciences: assessment of users of climate products. American Meteorological Society, 85(4), 601-606. doi.org/10.1175/ BAMS-85-4-601.

Chang'a, L.B., Yanda, P.Z. \& Ngana, J. (2010). Indigenous knowledge in seasonal rainfall prediction in Tanzania: A case of the South-western Highland of Tanzania. Journal of Geography and Regional Planning, 3(4), pp. 66-72. http://hdl.handle.net/10625/48748

Chepkoech, W., Mungai, N.W., Stöber, S., Bett, H.K. \& Lotze-Campen, H. (2018). Farmers' perspectives impact of climate change on African indigenous vegetable production in Kenya. International Journal of Climate Change Strategies and Management, 10(4), 551-579. doi.org/10.1108/IJCCSM-07-2017-0160

Christensen, T., \& Laegreid, P. (2011). Complexity and hybrid administration: Theoretical and empirical challenges. Public Organization Review, 11, 407-423. doi.org/ 10.1007/s11115-0100141-4

Cieslik K.J., Leeuwis, C, Dewulf, A.R.P.J., Lie, R., Werners, S.E., van Wessel, M., Feindt, P. \& Struik, P.C. (2018). Addressing socio-ecological development challenges in the digital age: Exploring the potential of Environmental Virtual Observatories for Connective Action (EVOCA). NJAS - Wageningen Journal of Life Sciences 86-87, 2-11. doi.org/10.1016/j.njas.2018.07.006

Clarkson, G., Dorward, P., Osbahr, H., Torgbor, F., \& Kankam-Boadu, I. (2019). An investigation of the effects of PICSA on smallholder farmers' decision making and livelihoods when implemented at large scale - The case of Northern Ghana. Journal of Climate Services 14, 1-14. doi.org/10.1016/j.cliser.2019.02.002 
Collier, P., \& Dercon, S. (2014). African agriculture in 50 years: Smallholders in a rapidly changing world? World Development, 63, 92-101. doi.org/10.1016/j.worlddev.2013.10.001

Colona, F., \& Jaffe, R. (2016). Hybrid Governance Arrangements. European Journal of Development Research, 28(2), 175-183. doi: 10.1057/ejdr.2016.5

Colombo, A.F., \& Byer, P.H. (2012). Adaptation, flexibility and project decision-making with climate change uncertainties. Impact Assess Project Appraisal. 30(4), 229-241. doi:10.1080/14615517.2012.731189.

Cooper, P.J.M., Dimes, J., Rao, K.P.C., Shapiro, B., Shiferaw, B., \& Twomlow, S. (2008). Coping better with current climatic variability in the rain-fed farming systems of sub-Saharan Africa: An essential first step in adapting to future climate change? Agriculture, Ecosystems and Environment, 126(1-2), 24-35. doi.org/10.1016/j.agee.2008.01.007

Córdoba-Pachón, J.R., \& Paucar-Caceres, A. (2019). The Unfolding and Resurfacing of Information Systems Knowledge over the Last 25 Years: A Systemic Perspective. Systems Research and Behavioral Science, 36(4), 445-460. doi: 10.1002/sres.2558

Costa, D.C., Pereira, H.S., Marchand, G.A.E.L. \& Silva, S.C.P. (2018). Challenges of participatory community monitoring of biodiversity in protected areas in Brazilian Amazon. Journal of Diversity, 10(61). doi:10.3390/d10030061.

Crane, T.A., Roncoli, C., Paz, J., Breuer, N., Broad, K., Ingram, K.T. \& Hoogenboom, G. (2010). Forecast skill and farmers' skills: Seasonal climate forecasts and agricultural risk management in the south eastern United States. Journal of Weather, Climate and Society, 2, 44-59. doi.org/10.1175/2009WCAS1006.1.

Creswell, J.W. (2014). Research design: qualitative, quantitative and mixed methods approaches. (4th ed.). Sage, Thousand Oaks.

Crowston, K \& Fagnot, (2018). Stages of motivation for contributing user-generated content: A theory and empirical test. International Journal of Human-Computer Studies 109, 89-101. https://doi.org/10.1016/j.ijhcs.2017.08.005

Climate services Partnership. (2011). What are Climate Services? Available online: https://climateservices.org/about-us/what-are- climate-services/

Curtis, V. (2018). Patterns of participation and motivation in Folding@home: The contribution of hardware enthusiasts and overclockers. Citizen Science. Journal of Theory and Practice, 3(1), 114. doi: https://doi.org/10.5334/cstp.109.

Cvitanovic, C., Hobday, A.J., van Kerkhoff, L., \& Marshall, N.A. (2015) Overcoming barriers to knowledge exchange for adaptive resource management; the perspectives of Australian marine scientists. Marine Policy 52, 38-44. https://doi.org/10.1016/j.marpol.2014.10.026 
Danermark, B., Eckström, M., Jakobsen, L., \& Karlsson, J.C. (2002). Explaining society: an introduction to critical realism in the social sciences. Routledge, London.

Danielsen, F., Mendoza, M.M., Alviola, P., Balete, D.S., Enghoff, M., Poulsen, M.K., \& Jensen, A.E. (2003). Biodiversity monitoring in developing countries: what are we trying to achieve? Oryx: The International Journal of Conservation, (34)7, 407-409. doi.org/10.1017/S0030605303000735

Danielsen, F., Burgess, N.D., \& Balmford, A. (2005a). Monitoring matters: examining the potential of locally-based approaches. Journal of Biodiversity Conservation, 14, 2507-2542. doi $10.1007 / \mathrm{s} 10531-005-8375-0$

Danielsen, F., Mendoza, M.M., Tagtag, A., Alviola, P. A., Balete, D. S., Jensen, A. E. et al. (2007b). Increasing conservation management action by involving local people in natural resource monitoring. Journal of Human Environment, 36(7), 566-570. doi: 10.1579/00447447(2007)36[566:icmabi]2.0.co;2

Danielsen, F., Burgess, N.D., Balmford, A., Donald, P.F., Funder, M., Jones, J.P.G. et al. (2008). Local participation in natural resource monitoring: a characterization of approaches. Journal of Conservation Biology, Society for Conservation Biology, 23(1), 31-42. doi: 10.1111/j.15231739.2008.01063.x

Daly, M., \& Dilling, L. (2019). The politics of "usable" knowledge: examining the development of climate services in Tanzania. Climatic Change, 157(1), 61-80. doi.org/10.1007/s10584-01902510-w

Dapilah, F., Nielsen, J.Ø. \& Friis, C. (2020). The role of social networks in building adaptive capacity and resilience to climate change: a case study from northern Ghana. Journal of Climate and Development, 12(1), 42-56. doi: 10.1080/17565529.2019.1596063

Dapilah, F. \& Nielsen, J.Ø. (2019). Climate change extremes and barriers to successful adaptation outcomes: Disentangling a paradox in the semi-arid savanna zone of northern Ghana. Journal of the Human Environment, 49, 1437-1449. doi.org/10.1007/s13280-019-01275-x

David-West, O. (2011). Esoko Networks: Facilitating agriculture through technology. GIM Case Study, B061. http://growinginclusivemarkets.org/media/cases/esoko_summary.pdf

Deltas, Vulnerability \& Climate Change: Migration \& Adaptation (DECCMA) (2017). The Volta Delta: understanding the present state of climate change, adaptation and migration. Policy brief. http://generic.wordpress.soton.ac.uk/deccma/wp-content/uploads/sites/181/2017/10/68439-A4DECCMA-VD_final_web.pdf

Derbile, E.K., Jarawura, F.X., \& Dombo, M.Y. (2016). Climate Change, Local Knowledge and Climate Change Adaptation in Ghana. In Adaptation to Climate Change and Variability in Rural West Africa. Springer International Publishing, 83-102. doi.org/10.1007/978-3-319-31499-0_6

Dewulf, A., Klenk, N., Wyborn, C., \& Lemos, M.C. (2020). Usable environmental knowledge from the perspective of decision-making: the logics of consequentiality, appropriateness, and 
meaningfulness. Current Opinion in Environmental Sustainability, 42, 1-6. https://doi.org/10.1016/j.cosust.2019.10.003

Dewulf, A., \& Biesbroek, R. (2018). Nine lives of uncertainty in decision-making: strategies for dealing with uncertainty in environmental governance. Policy and Society, 37(4), 441-458. doi:10.1080/14494035.2018.1504484

Dewulf, A., \& Termeer, C.J.A.M. (2015). Governing the future? The potential of adaptive delta management to contribute to governance capabilities for dealing with the wicked problem of climate change adaptation. Journal of Water and Climate Change, 6(4), 759-771. doi.org/10.2166/wcc.2015.117

Delmas, M.A., \& Young, O.R. (2009). Governance for the Environment: New Perspectives. Public Administration, 89(2), 701-704. doi/epdf/10.1111/j.1467-9299.2011.01935_3.x

Dilling, L., \& Lemos, M.C. (2011). Creating usable science: opportunities and constraints for climate knowledge use and their implications for science policy. Global Environmental Change, 21, 680-689. doi.org/10.1016/j.gloenvcha.2010.11.006

Dinku, T., Thomson, M.C., Cousin, R., del Corral, J., Ceccato, P., Hansen, J., et al. (2018). Enhancing national climate services (ENACTS) for development in Africa. Climate Development, 10, 664-672. doi: 10.1080/17565529.2017.1405784

Dinku, T., Hailemariam, K., Maidment, R., Tarnavsky, E. \& Connor, S. (2014). Combined use of satellite estimates and rain gauge observations to generate high-quality historical rainfall time series over Ethiopia. International Journal of Climatology, 34, 2489-2504. doi: 10.1002/joc.3855

Dittrich, R., Wreford, A., \& Moran, D. (2016). A survey of decision-making approaches for climate change adaptation: are robust methods the way forward? Ecological Economics. 122, 79-89. doi:10.1016/j.ecolecon.2015.12.006.

DiJohn, J. (2008). Conceptualising the Causes and Consequences of Failed States: A Critical Review of the Literature. Working Paper no. 25. London, Crisis States Research Centre, London School of Economics. https://www.files.ethz.ch/isn/57427/wp25.2.pdf

Doherty, B., Haugh, H., \& Lyon, F. (2014). Social Enterprises as Hybrid Organizations: A Review and Research Agenda. International Journal of Management Reviews, 16, 417-436. doi: 10.1111/ijmr.12028

Dow, K., Murphy, R.L. \& Carbone, G. (2009). Consideration of user needs and spatial accuracy in drought mapping. Journal of the American Water Resources Association 45, 187-197. doi.org/10.1111/j.1752-1688.2008.00270.x

Dorward, P.T., Shepherd, D., \& Wolmer, W. (1997). Developing farm management type methods for participatory needs assessment. Agricultural System, 55(2), 239-256. doi.org/10.1016/s0308$521 \times(97) 00009-7$. 
Drafor, I. (2016). Access to Information for Farm-Level Decision-Making. Journal of Agricultural \& Food Information, 17(4), 230-245. doi/pdf/10.1080/10496505.2016.1213170?needAccess=true

Drafor, I., \& Atta-Agyepong, K. (2005). Local Information Systems for Community Development in Ghana. In J. Dixon, H. Wattenbach, \& C. Bishop-Sambrook (Eds.), Improving Information flows to the rural community (pp. 5-19). Agricultural Management, Marketing And Finance Occasional Paper, Food And Agricultural Organisation.

Drummond H. (2014). Escalation of commitment: when to stay the course? Academy of Management Perspectives, 28(4), 430-446. doi:10.5465/amp.2013.0039.

Duncombe, R. (2016). Mobile phones for agricultural and rural development: a literature review and suggestions for future research. The European Journal of Development Research, 28(2) $213-$ 235. doi.org/10.1057/ejdr.2014.60.

Duncombe, R.A. (2014). Understanding the Impact of Mobile Phones on Livelihoods in Developing Countries. Development Policy Review 32(5), 567-588. doi/pdf/10.1111/dpr.12073

Djenontin, I.N.S. \& Meadow, A.M. (2018). The art of co-production of knowledge in environmental sciences and management: lessons from international practice. Journal of Environmental Management, 61, 885-903. doi.org/10.1007/s00267-018-1028-3

Elia, E.F., Mutula, S., \& Stilwell, C. (2014). Use of Indigenous knowledge in seasonal weather forecasting in semi-arid central Tanzania. South African Journal of Libraries and Information Science, 80(1). doi.org/10.7553/80-1-1395

Etwire, P.M., Buah, S., Ouédraogo, M., Zougmoré, R., Partey, S.T. \& Martey, E. (2017). An assessment of mobile phone-based dissemination of weather and market information in the Upper West region of Ghana. Journal of Agricultural Food Security, 1(8). doi 10.1186/s40066-016-0088$\mathrm{y}$

Evans, K., \& Guariguat M.R. (2008). Participatory monitoring in tropical forest management: a review of tools, concepts and lessons learned. Jakarta, Center for International Forestry Research. http://www.cifor.org/publications/pdf_files/Books/BGuariguata0801.pdf.

Fafchamps M. (1993). Sequential labor decisions under uncertainty: an estimable household model of West-African farmers. Econometrica. 61, 1173-1197. doi.org/10.2307/2951497

Feleke, H.G. (2015). Assessing weather forecasting needs of smallholder farmers for climate change adaptation in the Central Rift Valley of Ethiopia. Journal of Earth Science and Climatic Change, 6, 312. doi.org/10.4172/2157-7617.1000312

Field, C.B. (2014). Climate Change 2014-Impacts, Adaptation and Vulnerability: Regional Aspects; Cambridge University Press, Cambridge. 
Fleming, G. (2008). Service delivery and public weather services-an overview. World Meteorological Orgainsation Bulletin, 57, 208-212. https://public.wmo.int/en/bulletin/servicedelivery-and-public-weather-services $\% \mathrm{E} 2 \% 80 \% 94$-overview

Fletcher, A.J. (2017). Applying critical realism in qualitative research: methodology meets method. International Journal of Social Research Methodology, 20(2),181-194. doi.org/10.1080/13645579.2016.1144401

Flyvbjerg, B. (2006). Five misunderstandings about case-study research. Qualitative Inquiry, 12(2), 219-245. doi.org/10.1177\%2F1077800405284363

Flyvbjerg, B., Skamris, H.M.K., \& Buhl, S.L. (2004). What causes cost overrun in transport infrastructure projects? Transport Reviews, 24(1), 3-18. doi.org/10.1080/0144164032000080494a

Forest Compass. (2015). Community-based forest monitoring in North Rupununi, Guyana. $\mathrm{http}$ :/forestcompass.org/case-studies/community-based-forest-monitoring-north-rupununiguyana.

Food and Agriculture Organization. (2017). Information and Communication Technology (ICT) in Agriculture A Report to the G20 Agricultural Deputies. Food and Agriculture Organization of the United Nations Rome.

Fosu-Mensah, B.Y., Vlek, P.L.G., \& MacCarthy, D.S. (2012). Farmers' perception and adaptation to climate change: a case study of Sekyedumase district in Ghana. Environment, Development and Sustainability, 14(4), 495-505. doi.org/10.1007/s10668-012-9339-7

Frank, E., Eakin, H., \& Lopez-Carr, D. (2011). Social identity, perception and motivation in adaptation to climate risk in the coffee sector of Chiapas, Mexico. Global Environmental Change 21, 66-76. doi.org/10.1016/j.gloenvcha.2010.11.001.

Frensley, T., Crall, A., Stern, M., Jordan, R., Gray, S. Prysby, M., et al. (2017). Bridging the benefits of online and community supported citizen science: A case study on motivation and retention with conservation-oriented volunteers. Journal of Citizen Science: Theory and Practice, 2(1)4, 1-14. doi.org/10.5334/cstp.84

Gbangou, T., Ludwig, F., Slobbe, E.V., Greuell, W. \& Kranjac-Berisavljevic, G. (2020a). Rainfall and dry spell occurrence in Ghana: trends and seasonal predictions with a dynamical and a statistical model. Journal of Theoretical and Applied Climatology, 141(527). doi.org/10.1007/s00704-020-03212-5

Gbangou, T., Sarku, R., Slobbe, E.V., Ludwig, F., Kranjac-Berisavljevic, G. \& Paparrizos, S. (2020b). Coproducing Weather Forecast Information with and for Smallholder Farmers in Ghana: Evaluation and Design Principles. Atmosphere, 11, 902. doi:10.3390/atmos11090902

Gbangou, T., Slobbe, E.V., Ludwig, F., Kranjac-Berisavljevic, G. \& Paparrizos, S. (2020c). Harnessing local forecasting knowledge on weather and climate in Ghana: Documentation, skills 
and integration with scientific forecasting knowledge. Weather, Climate, and Society, 1-14. doi.org/10.1175/WCAS-D-20-0012.1

Gbangou, T., Ludwig, F., Slobbe, V.E., Hoang, L. \& Kranjac-Berisavljevic G. (2019). Seasonal variability and predictability of agrometeorological indices: tailoring onset of rainy season estimation to meet farmers' needs in Ghana. Journal of Climate Service, 14, 19-30. doi.org/10.1016/j.cliser.2019.04.002

Gbangou, T., Sylla, M.B., Jimoh, O.D., \& Okhimamhe, A.A. (2018). Assessment of projected agro-climatic indices over Awun river basin, Nigeria for the late twenty-first century. Climate Change, 151,445-462. doi.org/10.1007/s10584-018-2295-y

Gharesifard, M., Wehn, U., \& van der Zaag, P. (2017). Towards benchmarking citizen observatories: Features and functioning of online amateur weather networks. Postprint of Journal of Environmental Management, 193(15), 381-393. doi.org/10.1016/j.jenvman.2017.02.003

Gharesifard, M., Wehn, U., \& van der Zaag, P. (2019). Context matters: a baseline analysis of contextual realities for two community-based monitoring initiatives of water and environment in Europe and Africa, Journal of Hydrology, 579, 124-144. doi.org/10.1016/j.jhydrol.2019.124144

Gampson, E.K., Nartey, V.K., Golow, A.A., Akiti, T.T., Sarfo, M.A, Salifu, M., et al. (2015). Physical and isotopic characteristics in peri-urban landscapes: A case study at the lower Volta River Basin, Ghana. Applied Water Science, 7(2), 729-744. doi 10.1007/s13201-015-0286-y

Ghana Statistical Services. (2014). Population and housing census. District analytical report. Ada East District. Ghana Statistical Service. [accessed 2017 Sept 28]. https://s3.amazonaws.com/ndpcstatic/CACHES/PUBLICATIONS/2016/06/06/Ada+East.pdf

Ghana Statistical Services. (2014). Population and housing census: District analytical report. Ada East District. Ghana Statistical Service.

https://web.archive.org/web/20171215123257/http://www.statsghana.gov.gh/docfiles/2010_Distri ct_Report/Greater\%20Accra/Ada\%20East.pdf

Ge, 1., \& Brewster, C.A. (2016). Informational institutions in the agrifood sector: meta-information and meta-governance of environmental sustainability. Current Opinion in Environmental Sustainability, 18, 73-81. doi.org/10.1016/j.cosust.2015.10.002

Gerrits, L. M., \& Verweij, S. (2013). Critical realism as a meta-framework for understanding the relationships between complexity and qualitative comparative analysis. Journal of Critical Realism, 12, 166-182. doi.org/10.1179/rea.12.2.p663527490513071

Gertler, P.J., Martinez, S., Premand, P., Rawlings, L.B., \& Vermeersch, C.M. (2016). Impact Evaluation in Practice; The World Bank.

Geertz, C. (2008). Thick description: toward an interpretive theory of culture. In The Cultural Geography Reader, (pp. 41-51). Routledge. 
Global Framework on Climate Services. (2016). Development and Delivery of Climate Services Research Dialogue.

https:/unfccc.int/files/science/workstreams/research/application/pdf/part2.1_wmo_dilley.pdf

Glin, L.C., Oosterveer, P., \& Mol, A.J.P. (2015). Governing the organic cocoa network from Ghana: towards hybrid governance arrangements? Journal of Agrarian Change, 15(1), 43-64. doi.org/10.1111/joac.12059

Global System for Mobile Association (2019). The Mobile Economy: Sub-Saharan Africa. https://www.gsma.com/mobileeconomy/wpcontent/uploads/2020/03/GSMA MobileEconomy20 20 SSA Eng.pdf

Goodfellow, T., \& Lindemann, S. (2013). The clash of institutions: traditional authority, conflict and the failure of 'hybridity' in Buganda. Journal of Commonwealth and Comparative Politics, 51(1). doi.org/10.1080/14662043.2013.752175

Gonzalez, Y.S., Dijkxhoorn, Y., Koomen, I., Maden, E.V, Herms, S., Joosten, F. \& Mensah, S.A. (2016). Vegetable Business Opportunities in Ghana: 2016. Vegetable Business Opportunities in Ghana: 2016. GhanaVeg Sector Reports. Wageningen UR. https://vdocuments.mx/vegetablebusiness-opportunities-in-ghana-2016-ghanaveg-.html

Gopalakrishnan, T., Hasan, M.K. Haque, A.T.M.S., Jayasinghe, S.L. \& Kumar, L. (2019). Sustainability of Coastal Agriculture under Climate Change. Journal of Sustainability, 11, 7200. doi:10.3390/su11247200.

Gifford, R. (2011). The dragons of inaction: psychological barriers that limit climate change mitigation and adaptation. American Psychology, 66(4), 290-302. doi. org/10.1037/a0023566.

Gigerenzer, G., \& Selten, R. (2002). Bounded rationality: The adaptive toolbox. MIT press, Massachusetts

Goldmann, K. (2005). Appropriateness and consequences: The logic of neo-institutionalism. Governance, 18(1), 35-52. doi.org/10.1111/j.1468-0491.2004.00265.x

Graham, R., Visman, E., Wade, S., Amato, R., Bain, C., Janes, T., et al. (2015). Scoping, Options Analysis and Design of a 'Climate Information and Services Programme' for Africa (CIASA): Literature Review. doi.org/10.12774/eod_cr.may2015.grahamr

Groves, D.G., \& Lempert, R.J. (2007). A new analytic method for finding policy-relevant scenarios. Global Environmental Change, 17, 73-85. doi:10.1016/j.gloenvcha.2006.11.006

Güth, W., \& Kliemt, H. (2004). Perfect or Bounded Rationality? Analyse \& Kritik, 26(2), 364-381. doi.org/10.1515/auk-2004-0203

Guillaume, S., Bruzeau, C., Justes, E., Lacroix, B., \& Bergez, J.E. (2016). A conceptual model of farmers' decision- making process for nitrogen fertilization and irrigation of durum wheat. European Journal of Agronomy, 73, 133-143. doi:10.1016/j.eja.2015.11.012. 
Gwenzi, J., Mashonjowa, E., Mafongoya, P.L., Rwasoka, D.T., \& Stigter, K. (2016). The use of indigenous knowledge systems for short and long range rainfall prediction and farmers' perceptions of science-based seasonal forecasts in Zimbabwe. International Journal of Climate Change Strategic Management, 8, 440-462. doi.org/10.1108/IJCCSM-03-2015-0032.

Gyampoh, B.A, Asante, W.A., Rose, D.J., Adu-Acheampong, G., Assimeng, T., Gyamfi, A.O. (2011). Mapping and documenting indigenous knowledge in climate change adaptation in Ghana. Technical report, Africa Adaptation Programme and United Nations Development Programme Project. doi:10.13140/RG.2.1.4818.6640.

Haigh, N., Walker, J., Bacq, S., \& Kickul, J. (2015). Hybrid Organizations: Origins, Strategies, Impacts, and Implications. California Management Review, 57(3), 5-12. doi.org/10.1525/cmr.2015.57.3.5

Hallegatte, S., Shah, A., Lempert, R., Brown, C., \& Gill, S. (2012). Investment decision making under deep uncertainty - application to climate change. Policy Research Working Papers, 6193. doi:10.1596/ 1813-9450-6193.

Hammersley, M., \& Atkinson, P. (2007). Ethnography: Principles in practice (3rd ed.). Routledge, London.

Hansen, J.W., Vaughan, C., Kagabo, D.M, Dinku, T., Carr, E.R., Körner, J., \& Zougmoré, R.B (2019). Climate Services Can Support African Farmers' Context-Specific Adaptation Needs at Scale. Frontiers of Sustainability Food System, 3(21). doi: 10.3389/fsufs.2019.00021

Van Der Haar, G, \& Heijke, M. (2013). Conflict, governance and institutional multiplicity: Parallel governance in Kosovo and Chiapas, Mexico. In D. Hilhorst (ed.), Disaster, Conflict and Society in Crises: Everyday politics of crisis response, Humanitarian Studies Series, Routledge.

Haasnoot, M., Kwakkel, J.H., Walker, W.E., \& ter Maat, J. (2013). Dynamic adaptive policy pathways: A method for crafting robust decisions for a deeply uncertain world. Global Environmental Change, 23(2), 485-498. doi.org/10.1016/j.gloenvcha.2012.12.006

Haasnoot, M., \& Middelkoop, H. (2012). A history of futures: a review of scenario use in water policy studies in the Netherlands. Environmental Science and Policy, 19-20, 108-120. doi.org/10.1016/j.envsci.2012.03.002

Haasnoot, M., Middelkoop, H., Offermans, A., van Beek, E., \& van Deursen, W.P.A. (2012). Exploring pathways for sustainable water management in river deltas in a changing environment. Climate Change, 115(3-4), 795-819. doi:10.1007/s10584-012-0444.

Haklay, M., (2013). Citizen science and volunteered geographic information - overview and typology of participation. In D.Z. Sui, S. Elwood, \& M.F. Goodchild (Eds.), Crowdsourcing Geographic Knowledge: Volunteered Geographic Information (VGI) in Theory and Practice (pp. 105-122). Springer. 
Heeks, R. (2009). The ICT4D 2.0 Manifesto: Where Next for ICTs and International Development? Development Informatics, working paper Paper No. 42. Manchester: Centre for Development Informatics, The University of Manchester. doi.org/10.1016/0736-5853(84)90003-0

Hesselbein , G., Golooba-Mutebi , F., \& Putzel , J. (2006). Economic and Political Foundations of State Making in Africa: Understanding State Reconstruction. Working Paper 3, Series 2. Crisis States Research Centre, London School of Economics.

Hewitt, C., Simon, M., \& David, W. (2012). The Global Framework for Climate Services. https://core.ac.uk/download/pdf/288437099.pdf

Hiwasaki, L., Luna, E., Syamsidik, \& Shaw, R. (2014). Process for integrating local and indigenous knowledge with science for hydro-meteorological disaster risk reduction and climate change adaptation in coastal and small island communities. International Journal of Disaster Risk Reduction, 10, 15-27. doi.org/10.1016/j.ijdrr.2014.07.007

Hihn, H., Gottwald, S. \& Braun, D.A. (2018). Bounded Rational Decision-Making with Adaptive Neural Network Priors. Artificial Neural Networks in Pattern Recognition, 213-225. doi.org/10.1007/978-3-319-99978-4_17

Hoang, M.H., Namirembe, S., van Noordwijk, M., Catacutan, D., Öborn, I., Perez-Teran, A.S. et al. (2014). Farmer portfolios, strategic diversity management and climate-change adaptation implications for policy in Vietnam and Kenya. Climate Development 6(3), 216-225. doi:10.1080/17565529.2013.857588.

Hoefnagel, E., Vos, B., \& Buisman, E. (2013). Marine informational governance, a conceptual framework. Journal of Marine Policy, 42, 150-156. doi.org/10.1016/j.marpol.2013.02.006

Holm, P., \& Soma, K. (2016). Fisher's information in governance a matter of trust. Current Opinion Environment Sustainability, 18, 115-121. doi.org\%2F10.1016\%2Fj.cosust.2015.12.005

Hounkonnou, D., Kossou, D., Kuyper, T.W., Leeuwis, C., Nederlof, E.S., Röling, N. et al. (2012). An innovation systems approach to institutional change: Smallholder development in West Africa. Agricultural Systems, 108(1), 74-83. doi.org/10.1016/j.agsy.2012.01.007

Hyett, N., Kenny, A., \& Dickson-Swift, V. (2014). Methodology or method? A critical review of qualitative case study reports. International journal of qualitative studies on health and well-being, 9(1), 23606. doi.org/10.3402/qhw.v9.23606

Iizumi, T., \& Ramankutty, N. (2015). How do weather and climate influence cropping area and intensity? Global Food Security, 4, 46-50. doi.org/10.1016/j.gfs.2014.11.003

Ingram, K., Roncoli, M., \& Kirshen, P. (2002). Opportunities and constraints for farmers of West Africa to use seasonal precipitation forecasts with Burkina Faso as a case study. Agricultural System, 74, 331-349. doi.org\%2F10.1016\%2FS0308-521X(02)00044-6

Global System for Mobile Communications Association. (2016). The Mobile Economy Africa 
2016; GSM Association: London, UK. https://data.gsmaintelligence.com/api-web/v2/researchfile-download?id=28999719\&file=The\%20Mobile\%20Economy\%202017.pdf

IPCC (2018). Global Warming of $1.5^{\circ} \mathrm{C}$. An IPCC Special Report on the impacts of global warming of $1.5^{\circ} \mathrm{C}$ above pre-industrial levels and related global greenhouse gas emission pathways, in the context of strengthening the global response to the threat of climate change, sustainable development, and efforts to eradicate poverty [Masson-Delmotte, V., P. Zhai, H.-O. Pörtner, D. Roberts, J. Skea, P.R. Shukla, A. Pirani, W. Moufouma-Okia, C. Péan, R. Pidcock, S. Connors, J.B.R. Matthews, Y. Chen, X. Zhou, M.I. Gomis, E. Lonnoy, T. Maycock, M. Tignor, and T. Waterfield (eds.)]. IPCC, Geneva.

IPCC (2018). Summary for Policymakers. In: Global Warming of $1.5^{\circ} \mathrm{C}$. An IPCC Special Report on the impacts of global warming of $1.5^{\circ} \mathrm{C}$ above pre-industrial levels and related global greenhouse gas emission pathways in the context of strengthening the global response to the threat of climate change, sustainable development, and efforts to eradicate poverty [Masson-Delmotte, V., P. Zhai, H.-O. Pörtner, D. Roberts, J. Skea, P.R. Shukla, A. Pirani, W. Moufouma-Okia, C. Péan, R. Pidcock, S. Connors, J.B.R. Matthews, Y. Chen, X. Zhou, M.I. Gomis, E. Lonnoy, T. Maycock, M. Tignor, and T. Waterfield (eds.)]. IPCC, Geneva.

Jain, P., Nfila, R., Lwoga, E. T., Stilwell, C., \& Ngulube, P. (2011). Access and use of agricultural information and knowledge in Tanzania. Library review, 60(5), 383-395. doi.org\%2F10.1108\%2F00242531111135263

Jalloh, A., Nelson, G.C., Thomas, T.S., Zougmoré, R.B., \& Roy-Macauley, H. (2013). West African Agriculture and Climate Change: A Comprehensive Analysis. International Food Policy Research Institute. doi.org/10.2499/9780896292048

Jasanoff, S. (2010). A new climate for society. Theory, Culture and Society, 27, 2-3. doi.org/10.1177/0263276409361497.

Jasanoff, S. (2004). States of knowledge: the co-production of science and the social order $\left(1^{\text {st }} \mathrm{ed}.\right)$. Taylor \& Francis, London.

Jasanoff, S. \& Wynne, B. (1998). Science and decision making. In S. Raynor \& E.L. Malone (Eds.), Human choice and climate change (pp. 1-87). Batelle Institute. https://hdl.handle.net/11245/1.141789

Jost, C., Kyazze, F., Naab, J., Neelormi, S., Kinyangi, J., Zougmore, R. et al. (2016). Understanding gender dimensions of agriculture and climate change in smallholder farming communities. Climate Development, 8, 133-144. doi.org/10.1080/17565529.2015.1050978

Jiri, O., Mafongoya, P.L., \& Chivenge, P. (2015). Indigenous knowledge systems, seasonal "quality" and climate change adaptation in Zimbabwe. Climate Research, 66(2), 103-111. doi.org/10.3354/cr01334 
Karpouzoglou, T., Zulkafli, Z., Grainger, S., Dewulf, A., Buytaert, W., \& Hannah, D.M. (2016). Environmental Virtual Observatories (EVOs): prospects for knowledge co-creation and resilience in the Information Age. Current Opinion in Environmental Sustainability, 18, 40-48. doi.org/10.1016/j.cosust.2015.07.015

Keshavarz M, Karami E. 2014. Farmers' decision-making process under drought. J Arid Environ. 108:43-56. doi:10.1016/j.jaridenv.2014.03.006.

Klein, G. (2003). The power of intuition: how to use your gut feelings to make better decisions at work. Knopf Doubleday, New York.

Kranjac-Berisavljevic, G., Abdul-Ghanyu, S., Gandaa, B.Z., \& Abagale, F.K. (2014). Dry Spells Occurrence in Tamale, Northern Ghana- Review of Available Information. Journal of Disaster Research, 9(4).

https://pdfs.semanticscholar.org/f3d6/312713e749738905fa27799f2bc81c75f01e.pdf

Kirchhoff, C. J., Carmen Lemos, M., \& Dessai, S. (2013). Actionable Knowledge for Environmental Decision Making: Broadening the Usability of Climate Science. Annual Review of Environment and Resources, 38(1), 393-414. doi.org/10.1146/annurev-environ-022112-112828

Kickert, W.J. (2001). Public management of hybrid organizations: governance of quasiautonomous executive agencies. International Public Management Journal, 4(2),135-150. doi: 10.1016/s1096-7494(01)00049-6

Kiptot, E., Franzel, S., Hebinck, P., \& Richards, P. (2006). Sharing seed and knowledge: Farmer to farmer dissemination of agroforestry technologies in western Kenya. Agroforest System, 68, 167-179. doi 10.1007/s10457-006-9007-8

Kleinke, B., Prajzner, S., Gordon, C., Hoekstra, N., Kautz, A., \& Gardiner, M. (2018). Identifying barriers to citizen scientist retention when measuring pollination services. Journal of Citizen Science: Theory and Practice, 3(1) 2, 1-10. doi.org/10.5334/cstp.99

Kniveton, D., Visman, E., Tall, A., Diop, M., Ewbank, R., Njoroge, E. et al. (2015). Dealing with uncertainty: Integrating local and scientific knowledge of the climate and weather. Disasters, 39, 35-53. doi: $10.1111 /$ disa. 12108

Kobrin, S.J. (2001). Territoriality and the Governance of Cyberspace. Journal of International

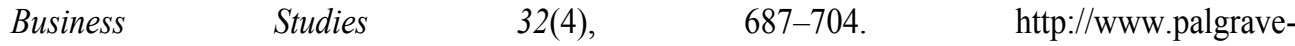
journals.com/jibs/journal/v32/n4/pdf/8490990a.pdf

Kwakkel, J. H., Haasnoot, M., \& Walker, W.E. (2016). Comparing Robust Decision-Making and Dynamic Adaptive Policy Pathways for model-based decision support under deep uncertainty. Environmental Modelling \& Software, 86, 168-183. doi.org/10.1016/j.envsoft.2016.09.017

Kwakkel, J.H., Walker, W.E., \& Haasnoot, M. (2016). Coping with the wickedness of public policy problems: Approaches for decision making under deep uncertainty. Journal of Water Resources Planning and Management, 142(3), 1-5. doi.org/10.1061/(ASCE)WR.1943-5452.0000626 
Lang, D.J., Wiek, A., Bergmann, M., Stauffacher, M., Martens, P., Moll, P., Swilling, M., \& Thomsa, C.J. (2012). Transdisciplinary research in sustainability science: Practice, principles and challenges. Sustainable Science, 7, 25-43. doi 10.1007/s11625-011- 0149-x.

Lazar, A.N., Nicholls, R.J., Payo, A., Adams, H., Mortreux, C., Suckall, N. et al. (2015). A method to assess migration and adaptation in deltas: A preliminary fast track assessment. DECCMA Working Paper, Deltas, Vulnerability and Climate Change: Migration and Adaptation, IDRC, 107642. www.deccma.com

Lawson, E.T., Alare, R.S., Salifu, A.R.Z., \& Thompson-Hall, M. (2019). Dealing with climate change in semi-arid Ghana: understanding intersectional perceptions and adaptation strategies of women farmers. GeoJournal, 85, 439-452. doi.org/10.1007/s10708-019-09974-4

Lemos, M.C., Arnott, J.C., Ardoin, N.M., Baja, K., Bednarek, A.T., Dewulf, A. et al. (2018). To co-produce or not to co-produce. Nature Sustainability, 1(12), 722-724. doi.org/10.1038/s41893018-0191-0

Lemos, M.C. (2015). Usable climate knowledge for adaptive and comanaged water governance. Current Opinion in Environmental Sustainability, 12, 48-52. doi.org/10.1016\%2Fj.cosust.2014.09.005

Lemos, M.C., Kirchhoff, C.J., \& Ramprasad, V. (2012). Narrowing the climate information usability gap. Nature Climate Change, 2(11), 789-794. doi.org/10.1038/nclimate1614

Lemos, M.C. \& Rood, R. (2010). Climate projections and their impact on policy and practice. WIRes. Climate Change 1, 670-682. doi.org/10.1002/wcc.71

Lemos, M.C. (2008). What influences innovation adoption by water managers? Climate information use in Brazil and the US. Journal of the American Water Resources Association, 44, 1388-1396. doi.org/10.1111/j.1752-1688.2008.00231.x

Lemos, M.C. \& Dilling, L. (2007). Equity in forecasting climate: can science save the world's poor? Science and Public Policy, 34(2), 109-116. doi: 10.3152/030234207x190964

Lemos, M.C., \& Agrawal, A. (2006). Environmental governance. Annual Review of Environmental Resources, 31, 297-325. doi: 10.1146/annurev.energy.31.042605.135621

Lemos, M.C., \& Morehouse, B.J. (2005). The co-production of science and policy in integrated climate assessments. Global Environmental Change: Human and Policy Dimensions, 15(1), 57 68. doi.org/10.1016/j.gloenvcha.2004.09.004

Lempert, R.J., \& Groves, D.G. (2010). Identifying and evaluating robust adaptive policy responses to climate change for water management agencies in the American west. Technological Forecasting and Social Change, 6(77), 960-974. doi.org/10.1016/j.techfore.2010.04.007

Lempert, R.J., Groves, D.G., Popper, S.W., \& Bankes, S.C. (2006). A general, analytic method for generating robust strategies and narrative scenarios. Management Science, 52(4), 514-528. doi:10.1287/mnsc. 1050.0472 . 
Lempert, R.J., \& Schlesinger, M.E. (2000). Robust strategies for abating climate change. Climate Change, 45(3-4), 387-401. doi.org\%2F10.1023\%2FA\%3A1005698407365

Leeuwis, C., Cieslik, K.J., Aarts, M.N.C., Dewulf, A.R.P.J., Ludwig, F., Werners, S.E., \& Struik, P.C. (2018). Reflections on the potential of virtual citizen science platforms to address collective action challenges: Lessons and implications for future research. NJAS - Wageningen Journal of Life Sciences, 86-87, 146-157. doi.org/10.1016/j.njas.2018.07.008

Lewis, J, \& Nkuintchu, T. (2012). Accessible technologies and FPIC: independent monitoring with forest communities in Cameroon. In IIED Biodiversity and culture: exploring community protocols, rights and consent. Participatory Learning and Action (No. 65). https://pubs.iied.org/pdfs/G03408.pdf.

Leeuwis, C., \& van den Ban, A. (2004). Communication for rural innovation: Rethinking agricultural extension (3rd ed.). Blackwell, Oxford.

Leister, C., \& Chiappin, J.R.N. (2010). Bounded and adaptive rationality, decision processes and problem solving in H.A. Simon. Sao Paulo, 7(1), 26-42. https://revistas.pucsp.br/cognitio/article/view/2901

Lie, R., \& Servaes, J. (2015). Disciplines in the Field of communication for development and social change. Communication Theory, 25(2), 244-258. doi.org/10.1111/comt.12065

Limantol, A.M., Keith, B.E., Azabre, B.A., \& Lennartz, B. (2016). Farmers' perception and adaptation practice to climate variability and change: A case study of the Vea catchment in Ghana. SpringerPlus, 5, 830. doi.org/10.1186/s40064-016-2433-9

Lipshitz, R., \& Strauss, O. (1997). Coping with uncertainty: a naturalistic decision-making analysis. Organisational Behaviour Human Decision Process, 69(2), 149-163. doi.org/10.1006/obhd.1997.2679

Logah, F.Y., Obuobie, E., Ofori, D., \& Kankam-Yeboah, K. (2013). Analysis of rainfall variability in Ghana. International Journal of Latest Research in Engineering and Computing, 1(1), 1-8. http:/iijlrec.com/index_files/Download/Vol\%201,\%20Issue\%201/1-F.\%20Y\%20Logah.pdf

Lourenço, T.C., Swart, R., Goosen, H., \& Street, R. (2016). The rise of demand driven climate services. Nature Climate Change, 6(1) 13-14. doi.org/10.1038/nclimate2836

Luetz, J., \& Havea, P.H. (2018). "We're not refugees, we'll stay here until we die!"-climate change adaptation and migration experiences gathered from the Tulun and Nissan Atolls of Bougainville, Papua New Guinea. In W. Leal Filho (ed.), Climate Change Impacts and Adaptation Strategies for Coastal Communities, Climate Change Management. Springer.

Lunenburg, F.C. (2010). The power of intuition: how to use your gut feelings to make better managerial decisions. International Journal Management Business Administration, 13(1). http://www.nationalforum.com/Electronic\%20Journal\%20Volumes/Lunenburg,\%20Fred\%20C. 
Maddison, D.J. (2007). The perception of and adaptation to climate change in Africa. World Bank Policy Research Working Paper No. 4308.

Mahona, R., Greene, C., Cox S., Guido, Z., Gerlak. A.K., Petriea, J. et al. (2019). Fit for purpose? Transforming National Meteorological and Hydrological Services into National Climate Service Centers. Journal of Climate Services, 13, 14-23. doi.org/10.1016/j.cliser.2019.01.002

March, J.G., \& Olsen, J.P. (2011). The logic of appropriateness in the Oxford handbook of political science. Oxford. doi:10.1093/oxfordhb/9780199604456.013.0024.

March, J.G. (1994). A primer on decision making: how decisions happen. The Free Press, New York.

March, J.G., \& Olsen, J.P. (2004). The logic of appropriateness. ARENA Working Papers WP 04/09. doi: 10.1093/oxfordhb/9780199548453.003.0034

March, J.G. (1991). How decisions happen in organizations. Human Computer Interaction, 6, 95117. doi/pdf/10.1207/s15327051hci0602_1?

Mafongoya, P.L., \& Ajayi, O.C. (2017). Indigenous knowledge and climate change: Overview and basic propositions. In Indigenous knowledge systems and climate change management in Africa (pp. 17-28). CTA, Wageningen -Netherlands.

Marfo, K.A., Dorward, P.T., Craufurd, P.Q., Ansere-bioh, F., Haleegoah, J., \& Bam, R. (2008). Identifying seed uptake pathways: the spread of Agya amoah rice cultivar in southwestern Ghana. Experimental Agriculture, 44, 257-269. doi.org/10. 1017/S0014479708006170.

Maslach, C. (2011). Engagement research: Some thoughts from a burnout perspective. European Journal of Work and Organizational Psychology, 20(1), 47-52. doi.org/10.1080/13594 $32 X .2010 .537034$

Mason, J. (2002). Qualitative researching (2nd ed.). Sage, London.

Masinde, M., Bagula, A., \& Muthama, N.J. (2012). The role of ICTs in downscaling and up-scaling integrated weather forecasts for farmers in sub-Saharan Africa. Proceedings from Fifth International Conference on Information Communication Technology Development, ACM, 122129.

Manzanas, R., Amekudzi, L.K., Preko, K., Herrera, S., \& Gutiérrez, J.M. (2014a). Precipitation variability and trends in Ghana: An intercomparison of observational and reanalysis products. Climatic Change, 124(4), 805-819. doi.org/10.1007/s10584-014-1100-9

Manzanas, R., Gutiérrez, J.M., Fernández, J., Frías, M.D., Cofiño, A.S., Sánchez, E., Voces, J. \& Rodríguez, E. (2012). European provision of regional impact assessment on a seasonal-to-decadal 
timescale: Report on assessment and combination of S2D predictions. http://www.euporias.eu/ system/files/D32.1_Final.pdf. ——,

McNamara, P., Dale, J., Keane, J., \& Ferguson, O. (2014). Strengthening Pluralistic Agricultural Extension in Ghana: A MEAS Rapid Scoping Mission. Modernizing extension and advisory services discussion paper, USAID. 2014. (No. AID-OAA-L-10-00003). The United States Agency for International Development.

https://reliefweb.int/sites/reliefweb.int/files/resources/MEAS\%20Country\%20Report\%20GHAN A\%20-\%200ct\%202012.pdf

McNie, E.C. (2013). Delivering climate services: Organizational strategies and approaches for producing useful climate-science information. Weather, Climate, and Society, 5(1), 14-26. doi.org/10.1175/WCAS-D-11- 00034.1

McNie, E.C. (2007). Reconciling the supply of scientific information with user demands: an analysis of the problem and review of the literature. Environmental Science Policy, 10(1), 17-38. doi.org/10.1016/j.envsci.2006.10.004.

Meadow, A.M., Ferguson, D.B., Guido, Z., Horangic, A., Owen, G. \& Wall, T. (2015). Moving toward the deliberate co-production of climate science knowledge. Weather Climate and Society, 7(2), 179-191. doi.org/10.1175/WCAS-D-14-00050.1

Meagher, K. (2014). Smuggling ideologies: From criminalization to hybrid governance in African clandestine economies. Journal of African Affairs African Affairs, 113(453), 497-517. doi.org/10.1093/afraf/adu057

Meagher, K. (2012). The strength of weak state? Non-state security forces and hybrid governance in Africa. Journal of Development and Change 43(5), 1073-1101. doi: 10.1111/j.14677660.2012.01794.x

Meinke, H., Nelson, R., Kokic, P., Stone, R.C., Selvaraju, R., \& Baethgen, W. (2006). Actionable climate knowledge-from analysis to synthesis. Climate Research, 33, 101-110. doi: $10.3354 / \mathrm{cr} 033101$

Meinke, H., \& Stone, R. C. (2005). Seasonal and inter-annual climate forecasting: the new tool for increasing preparedness to climate variability and change in agricultural planning and operations. Climate Change, 70, 221-253. doi.org\%2F10.1007\%2F1-4020-4166-7_11

Merot, A., Bergez, J.E., Capillon, A., \& Wery, J. (2008). Analysing farming practices to develop a numerical, operational model of farmers' decision-making processes: an irrigated hay cropping system in France. Agricultural Systems, 98(2), 108-118. doi:10.1016/j.agsy.2008.05.001.

Mittal, S. (2016). Role of Mobile Phone enabled Climate Information Services in Gender-inclusive Agriculture. Gender, Technology and Development 20(2), 200-217. doi: $10.1177 / 0971852416639772$

Mol, A.P.J. (2009). Environmental governance through information: China and Vietnam. Singapore Journal of Tropical Geography 30, 114-129. doi:10.1111/j.1467-9493.2008.00358.x 
Mol, A.P.J. (2008). Environmental Reform in the Information Age-The Contours of Informational Governance. Cambridge University Press, Cambridge.

Mol, A.P.J. (2006b). Environmental Governance in the Information Age: The Emergence of Informational Governance. Environment and Planning C: Government and Policy, 24(4), 497514. doi.org/10.1068/c0508j

Mol., A.P.L. (2006a). The Environmental State and Informational Governance. Journal of Nature and Culture, 1(1), 36-62. doi.org/10.3167/155860706780272033

Morss, R., Wilhelmi, O., Downton, M., \& Gruntfest, E. (2005). Flood risk, uncertainty and scientific information for decision making: lessons from an interdisciplinary project. Bulletin of American Meteorological Society, 86, 1593-1601. doi.org\%2F10.1175\%2FBAMS-86-11-1593

Munthali, N., Leeuwis, C., van Passen, A., Lie R., Asare, R., van Lammeren, R., \& Schut, M. (2018). Innovation intermediation in a digital age: Comparing public and prevate new-ICT platforms for agricultural extension in Ghana. Wageningen Journal of Life Sciences 86-87, 30-30. doi.org/10.1016/j.njas.2018.05.001

Mul, M., Obuobie, E., Appoh, R., Kankam, K., Bekoe-obeng, E., Amisigo, B. et al. (2015). Water resources assessment of the Volta River Basin. Colombo, Sri Lanka: International Water Management Institute. IWMI Working Paper 166, p. 78. doi:10.5337/ 2015.220.

Murphy, A.H. (1993) What is a good forecast? An essay on the nature of goodness in weather forecasting. Weather Forecast, 8, 281-293. doi.org/10.1175/15200434(1993)008\%3C0281:WIAGFA\%3E2.0.CO;2

Musters, D. (2017). An Innovation Systems Approach to Examine the Organization of ICT-Based IPs for Extension Services in Ghana [Master's Thesis, Wageningen University and Research].

Naab, F.Z., Abubakari, Z., \& Ahmed, A. (2019). The role of climate services in agricultural productivity in Ghana: The perspectives of farmers and institutions. Climate Services, 13, 24-32. doi.org/10.1016/j.cliser.2019.01.007

Nalley, L.L., Barkley, A., Watkins, B., \& Hignight, J. (2009). Enhancing farm profitability through portfolio analysis: the case of spatial rice variety selection. Journal of Agricultural and Applied Economic 41(3), 641-652. doi.org/10.1017/S1074070800003126

National Communication Authority. (2017). Quarterly statistical bulletin on communications in Ghana. Communication for Development, 2(3), 1-54.

https://www.nca.org.gh/assets/Uploads/stats-bulletin-Q3-2017.pdf

Nicholls, R.J., Neil A.W., Hutton, C.W., \& Hanson, S.E. (2020). Delta Challenges and Trade-Offs from the Holocene to the Anthropocene. In R.J. Nicholls, R.J., Adger, W.N., Hutton, C.W. \& S.E. Hanson (ed.), Deltas in the Anthropocene. Palgrave Macmillan. 
Nicholls, R.J., Kebede, A.S., Allan, A.A., Arto, I., Cazcarro, I., Fernandes, J.A. et al. (2017). The DECCMA Integrated Scenario Framework: A Multi-Scale and Participatory Approach to Explore Migration and Adaptation in Deltas. DECCMA Working Paper,Deltas, Vulnerability and Climate Change: Migration and Adaptation, IDRC Project Number 107642.

Nidumolu, U., Lim-Camacho, L., Gaillard, E., Haymand, P., \& Howden, M. (2018). Linking climate forecasts to rural livelihoods: Mapping decisions, information networks and value chains. Weather and Climate Extremes 27, 100-174. doi.org/10.1016/j.wace.2018.06.001

Nin-Pratt, A., \& McBride, L. (2014). Agricultural intensification in Ghana: Evaluating the optimist's case. Food Policy, 48, 153-167. doi.org/10.1016/j.foodpol.2014.05.004

Ndamani, F., \& Watanabe, T. (2015). Farmers' perceptions about adaptation practices to climate change and barriers to adaptation: a micro-level study in Ghana. Journal of Water, 7, 4593-4604. doi:10.3390/ w7094593.

Ndamani, F., \& Watanabe, T. (2014). Rainfall variability and crop production in Northern Ghana: The case of Lawra District. doi.org\%2F10.13140\%2F2.1.2343.7125

Neuendorf, K.A. (2016). The content analysis guidebook. Sage, London. doi.org/10.4135/9781071802878

Nnadi, O.I., Liwenga, E.T. Lyimo, J.G., \& Madukwe, M.C. (2019). Impacts of variability and change in rainfall on gender of farmers in Anambra, Southeast Nigeria. Journal of Heliyon, 5, 2085. doi: 10.1016/j.heliyon.2019.e02085

Nonaka, I., \& von Krogh, G. (2009). Tacit Knowledge and Knowledge Conversion: Controversy and Advancement in Organizational Knowledge Creation Theory. Journal of Organization Science 20(3), 635-652. doi.org\%2F10.1287\%2Forsc. 1080.0412

Nubuor, S.A. (2017). The Privatization Conundrum in Ghana: Lessons from Golden Tulip Hotel in Accra. International Journal of Innovation and Economic Development, 3(2), 56-69. doi.org/10.18775/ijied.1849-7551-7020.2015.32.2005

Nulman, E., \& Özkula. S.M. (2016). Environmental nongovernmental organizations' digital media practices toward environmental sustainability and implications for informational governance. Current Opinion Environmental Sustainability, 18, 10-16. doi.org/10.1016\%2Fj.cosust.2015.04.004

Nyamekye, A.B., Dewulf, A., Van Slobbe, E., \& Termeer, K. (2019). Information systems and actionable knowledge creation in rice-farming systems in Northern Ghana. African Geographical Review, 1-18. doi.org/10.1080/19376812.2019.1659153

Nyamekye, A.B., Dewulf, A., Van Slobbe, E., Termeer, K., \& Pinto, C. (2018a). Governance arrangements and adaptive decision-making in rice farming systems in Northern Ghana. NjasWageningen Journal of Life Sciences, 86-87, 39-50. doi:10.1016/j.njas.2018.07.004 
Nyantakyi-Frimpong, H. (2019). Combining feminist political ecology and participatory diagramming to study climate information service delivery and knowledge flows among smallholder farmers in northern Ghana. Applied Geography 112, 102079. doi.org/10.1016/j.apgeog.2019.102079

Nyadzi, E. (2020). Best of both worlds: Co-Producing Climate Services that Integrate Scientific and Indigenous Weather and Seasonal Climate Forecast for Water Management and Food Production in Ghana [Doctoral dissertation, Wageningen University]. https://research.wur.nl/en/publications/best-of-both-worlds-co-producing-climate-services-thatintegrate-

Nyadzi, E, Werners, S.E., Biesbroek, R., Phi, L.H., Franssen, W.H.P., \& Ludwig, F. (2019). Verification of Seasonal Climate Forecast Towards Hydro-Climatic Information Needs of Rice Farmers in Northern Ghana. Journal of Weather, climate and society 11(1), 127-142. doi/pdf/10.1175/WCAS-D-17-0137.1

Nyadzi, E., Nyamekye, A.B., Werners, S.E., Biesbroek, R.G., Dewulf, A., Slobbe, E., et al. (2018). Diagnosing the potential of hydro-climatic information services to support rice farming in northern Ghana. Wageningen Journal of Life Sciences 86-87, 51-63. doi.org/10.1016/j.njas.2018.07.002

O'Brien, K.L., \& Vogel, C. (2003). Coping with climate variability : the use of seasonal climate forecasts in Southern Africa. Climatic Change, 103, 537-554. doi 10.1007/s10584-009-9771-3

Ofori-Sarpong, E., \& Annor J. (2001). Rainfall over Accra, 1901-90. Journal of Weather, 56(2), 55-62. doi:10.1002/ j.1477-8696.2001.tb06535.x.

Ochola,W., \& Kerkides, C.P. (2003). A Markovchain simulation model for predicting critical wet and dry spells in Kenya: analysing rainfall events in the Kanoplains. Irrigation and Drainage, 52, 327-342. doi.org\%2F10.1002\%2Fird.94

Ofori-Sarpong, E. \& Annor, J. (2012). Rainfall over Accra, 1901-90. Journal of Weather, 56(2), 55-62. doi/pdf/10.1002/j.1477-8696.2001.tb06535.x.

O'Grady, M.J., Muldoon, C., Carr, D., Wan, J., Kroon, B, Gregory, M.P. et al. (2016). Intelligent sensing for citizen science: Challenges and future directions. (2016). Mobile Networks and Application, 21, 375-385. doi 10.1007/s11036-016-0682-z

Ogutu, G.E.O., Franssen, W.H.P., Supit, I., Omondi, P., \& Hutjes, R.W.A. (2017). Skill of ECMWF system-4 ensemble seasonal climate forecasts for East Africa. International Journal of Climatology, 37(5), 2734-2756. doi.org/10.1002/joc.4876

Onyx, J., Coventry, L., Kenny, S., \& Fanany, I. (2018). Third Sector Governance in Asia: Tracking Hybridity. Cosmopolitan Civil Societies: an Interdisciplinary Journal, 10(3), 1-18. doi. org/10.5130/ccs.v10i3.5922

Orlove, B., Roncoli, C., Kabugo, M., \& Majugu, A. (2010). Indigenous climate knowledge in southern Uganda: The multiple components of a dynamic regional System. Climatic Change,100(2), 243-265. doi.org/10.1007/s10584-009-9586-2 
Orlove, B.S., Broad, K., \& Petty, A.M. (2004). Factors that influence the use of climate forecasts — Evidence from the 1997/98 El Niño event in Peru. Bulletin of American Meteorological Society, 85, 1735-1743. doi.org\%2F10.1175\%2FBAMS-85-11-1735

Ouedraogo, I., Diouf, N.S., Ouédraogo, M., Ndiaye, O., \& Zougmoré, R.B. (2018). Closing the gap between climate information producers and users: Assessment of needs and uptake in Senegal.Climate,6(1). doi.org/10.3390/cli6010013

Ouédraogo, M., Zougmoré, R., Barry, S., Somé, L., \& Grégoire, B. (2015). The value and benefits of using seasonal climate forecasts in agriculture : evidence from cowpea and sesame sectors in climate-smart villages of Burkina Faso. CCAFS Info Note, September, 1-4.

Owusu, K., \& Waylen, P. (2009). Trends in spatio-temporal variability in annual rainfall in Ghana (1951-2000). Weather 64, 115-120. doi.org/10.1002/wea.255

Owusu, K., Waylen, P., \& Qiu, Y. (2008). Changing rainfall inputs in the Volta Basin: implications for water sharing in Ghana. Geo Journal, Springer, 71, 201-210. doi 10.1007/s10708-008-9156-6

Oxfam. (2015) Community-Based Climate Change Action Grants (CBCCAG) Program Activity Completion Report. Oxfam in The Philippines Quezon City. https://www.google.com/url?sa=t\&rct=j\&q=\&esrc=s\&source=web\&cd=\&ved=2ahUKEwiC6p OSj5nuAhXPDOwKHdX_DSUQFjAAegQIARAC\&url=https\%3A\%2F\%2Fwww.aph.gov.au \%2FDocumentStore.ashx\%3Fid\%3Dab661301-80d4-4527-9801ec3a842c7a97\&usg=AOvVaw2TeMg4tkVRZOM2_AefM8z9

Teye, J.K., \& Owusu, K. (2015). Dealing with climate change in the coastal Savannah Zone of Ghana: in situ adaptation strategies and migration. In F. Hillmann, M. Pahl, B. Rafflenbeul, H. Sterly (Eds), Environmental change, adaptation and migration (pp. 223-244). Palgrave Macmillan.

van de Giesen, N., Liebe, J., \& Jung, G. (2010). Adapting to climate change in the Volta Basin, West Africa. Current Science, 98(8). http://racines-sahel.org/bibliothequenumerique/files/original/80aa0820645971a45016750958d799a0.pdf

Osborne, S.P., \& Strokosch, K. (2013). It takes two to tango? Understanding the co-production of public services by integrating the services management and public administration perspectives. British Journal of Management, 24, 31-47. doi.org/10.1111/1467-8551.12010

Pacha, M.J. (2015). Community-based monitoring, reporting and verification know-how: sharing knowledge from practice. WWF, SilvaCarbon, Global Canopy Programme. http://wwf.panda.org/?239457/Community-based-Monitoring-Reporting-and-Verification-Knowhow\#.

Pahl-Wostl, C., Sendzimir, j., Jeffrey, p., Aerts, J., Berkamp, G., \& Cross, K. (2007). Managing change toward adaptive water management through social learning. Ecology and Society 12(2), 30. http://www.ecologyandsociety.org/vol12/iss2/art30/ 
Pahl-Wostl, C., Mostert, E., \& Tàbara, D. (2008). The growing importance of social learning in water resources management and sustainability science. Ecology and Society 13(1), 24. http://www.ecologyandsociety.org/ vol13/iss1/art24/

Parker, A., \& Tritter, J. (2006). Focus group method and methodology: current practice and recent debate. International Journal of Research \& Method in Education, 29(1), 23-37. doi.org/10.1080/01406720500537304

Partey, S.T., Dakorah, A.D., Zougmoré, R.B., Ouédraogo, M., Nyasimi, M., Nikoi, G.K., \& Huyer, S. (2020). Gender and climate risk management: evidence of climate information use in Ghana. Climatic Change, 1-15. doi.org/10.1007/s10584-018-2239-6

Partey, S.T., Nikoi, G.K., Ouédraogo, M., \& Zougmoré, R.B. (2019). Scaling up climate information services through public-private partnership business models: An example from northern Ghana. CCAFS Info note. https://hdl.handle.net/10568/101133

Patt, A., Suarez, P. \& Gwata, C. (2005). Effects of seasonal climate forecasts and participatory workshops among subsistence farmers in Zimbabwe. Bulletin of American Meteorological Society, 102(35), 12623-12628. doi.org/10.1073/pnas.0506125102

Patt, A., \& Gwatab, C. (2002). Effective seasonal climate forecast applications: examining constraints for subsistence farmers in Zimbabwe. Global Environmental Change 12, 185-195. doi.org/10.1016/S0959-3780(02)00013-4

Payne, J.W., Bettman, J.R., \& Johnson, E.J. (1993). The adaptive decision maker. Cambridge University Press, Cambridge.

Pesche, D., Losch, B., \& lmbernon, J. (2016). A new emerging rural world: An overview of rural change in Africa. In Atlas for the NEPAD: Rural Futures Programme (2 ${ }^{\text {nd }}$ ed.). NEPAD Agency. https:/www.nepad.org/caadp/publication/new-emerging-rural-world-overview-rural-changeafrica

Phillips, C., Walshe, D., O'Regan, K., Strong, K., Hennon, C., Knapp, K. et al. (2018). Assessing citizen science participation skill for altruism or university course credit: A case study analysis using cyclone center. Citizen Science: Theory and Practice, 3(1), 1-13. doi: https://doi.org/10.5334/cstp.111

Phillips, S. D. (1997). Toward an expanded definition of adaptive decision making. The Career Development Quarterly, 45(3), 275-287. doi/10.1002/j.2161-0045.1997.tb00471.x

Pickard, A. J. (2013). Research methods in information (2nd ed.). Neal-Schuman, New York.

Pocock, M.J.O., Roy, H.E., August, T., Kuria, A., Barasa, F., Bett, J. et al. (2019). Developing the global potential of citizen science: Assessing opportunities that benefit people, society and the environment in East Africa. Journal of Applied Ecology, 56, 274-281. doi.org/10.1111/13652664.13279 
Ponciano, L., Brasileiro, F., Simpson, R., \& Smith, A. (2014). Volunteers' Engagement in Human Computation Astronomy Project. Computing in Science \& Engineering 16(6), 52-59. doi.org/10.1109/ MCSE.2014.4

Ponelis, S.R. (2015). Using interpretive qualitative case studies for exploratory research in doctoral studies: A case of Information Systems research in small and medium enterprises. International Journal of Doctoral Studies, 10, 535-550. http://ijds.org/Volume10/IJDSv10p535550Ponelis0624.pdf

Pot, W.D., Dewulf, A., Biesbroek, G.R., Vlist, M.J. van der, \& Termeer, C.J.A.M. (2018). What makes long-term investment decisions forward looking: A framework applied to the case of Amsterdam's new sea lock. Technological Forecasting and Social Change, 132, 174-190. doi.org/10.1016/j.techfore.2018.01.031

Pielke, R.A. jr (2007). The honest broker. Making sense of science in policy and politics. Cambridge University Press, Cambridge.

Pratihast, A.K., De Vries, B., Avitabile, V., de Bruin, S., Kooistra, L., Tekle, M. et al. (2014). Combining satellite data and community-based observations for forest monitoring. Journal of Forests, 5(10), 2464-89. doi:10.3390/f5102464.

Radeny, M., Desalegn, A., Mubiru, D., Kyazze, F., Mahoo, H., Recha, J., Kimeli, P., \& Solomon, D. (2019). Indigenous knowledge for seasonal weather and climate forecasting across East Africa. Climate Change, 156, 509-526. doi.org/10.1007/s10584-019-02476-9

Raddick, M.J., Bracey, G., Gay, P.L., Lintott, C.J., Murray, P., Schawinski, K., Szalay, A.S., \& Vandenberg, J. (2013). Galaxy Zoo: Motivations of citizen scientists. https://arxiv.org/ftp/arxiv/papers/1303/1303.6886.pdf

Raddick, M. J., Bracey, G., Gay, P. L., Lintott, C. J., Murray, P., Schawinski, K., Szalay, A.S., \& Vandenberg, J. (2010). Galaxy Zoo: Exploring the Motivations of Citizen Science Volunteers. Astronomy Education Review, $\quad 9(1), \quad 10103-10118$. doi.org\%2F10.3847\%2FAER2009036\&v=55066437

Raddick, M.J., Bracey, G., Carney, K., Gyuk, G., Borne, K., Wallin, J., et al. (2009). Citizen science: Status and research directions for the coming decade. The Astronomy and Astrophysics Decadal Survey, Position Papers, no. 46. http://adsabs.harvard.edu/abs/2009astro2010P..46R

Rao, K., Hansen, J., Njiru, E., Githungo, W.N., \& Oyoo, A. (2015). Impacts of Seasonal Climate Communication Strategies on Farm Management and Livelihoods in Wote, Kenya. CCAFS Working Paper;137. https://hdl.handle.net/10568/68832

Reyes-García, V., Fernández-Llamazares A., Guèze M., Garcés, A., Mallo, M., Vila-Gómez, M., \& Vilaseca, M. (2016). Local indicators of climate change: The potential contribution of local knowledge to climate research. Wiley Interdisciplinary Reviews on Climate Change, 7(1), 109124. doi:10.1002/wcc.374. 
Risbey, J., Kandlikar, M., Dowlatabadi, H., \& Graetz, D. (1999). Scale, context, and decision making in agricultural adaptation to climate variability and change. Mitigation and Adaptation Strategies for Global Change, 4(2), 137-165. doi.org/10.1023/A:1009636607038

Robert, M., Thomas, A., Sekhar, M., Raynal, H., Casellas, E., Casel, P. et al. (2018). A dynamic model for water management at the farm level integrating strategic, tactical and operational decisions. Environmental Modell Software, 100, 123-135. doi:10.1016/j.envsoft.2017.11.013.

Robert, M., Thomas, A., Sekhar, M., Badiger, S., Ruiz, L., Raynal, H., \& Bergez, J.E. (2017). Adaptive and dynamic decision-making processes: a conceptual model of production systems on Indian farms. Agricultural Systems, 157, 279-291. doi.org/10.1016/j.agsy.2016.08.001

Robert, A. (2017). A river in peril: human activities and environmental impacts on the lower mekong river and its delta. Environment: Science and Policy for Sustainable Development, 59(6), 30-40. doi:10.1080/00139157.2017.1374794.

Robert, M., Thomas, A., \& Bergez, J.E. (2016a). Processes of adaptation in farm decision-making models. A review. Agronomy for sustainable development, 36(4), 64. doi:10.1007/s13593-0160402-x.

Robert, M., Dury, J., Thomas, A., Therond, O., Sekhar, M., Badiger, S. et al. (2016b). CMFDM: A methodology to guide the design of a conceptual model of farmers' decision-making processes. Agricultural Systems 148, 86-94. doi.org/10.1016/j.agsy.2016.07.010

Rockström, J., \& Falkenmark, M. (2015). Agriculture: Increase water harvesting in Africa. Nature, 519, 283.

https://www.nature.com/news/polopoly_fs/1.17116!/menu/main/topColumns/topLeftColumn/pdf/ 519283a.pdf

Roesch-McNally, G.E., Arbuckle, G.J., \& Tyndall, J.C. (2017). What would farmers do? Adaptation intentions under a Corn Belt climate change scenario. Agricultural Human Values, 34(2), 333-346. doi:10.1007/s10460-016-9719-y

Roest, L.W.M. (2018). The coastal system of the Volta delta, Ghana Opportunities and strategies for development. TU Delft Delta Infrastructures and Mobility Initiative (DIMI). http://resolver.tudelft.nl/uuid:6d859f80-e434-407e-b0bc-41f574ff8b6f

Roncoli, C., Jost, C., Kirshen, P., Sanon, M., Ingram, K.T., Woodin, M. et al. (2009a). From accessing to assessing forecasts: An end-to-end study of participatory climate forecast dissemination in Burkina Faso (West Africa). Climatic Change, 92(3-4), 433-460. doi.org/10.1007/s10584-008-9445-6

Roncoli, C., Ingram, K., \& Kirshen, P. (2002). Reading the rains: Local knowledge and rainfall forecasting in Burkina Faso. Society \& Natural Resources, 15, 409-427. doi.org/10.1080/08941920252866774. 
Roncoli, C., Ingram, K., \& Kirshen, P. (2001). The costs and risks of coping with drought: livelihood impacts and farmers responses in Burkina Faso. Climate Research, 19, 119-132. doi.org\%2F10.3354\%2Fcr019119

Rosas, G., Gubler, S., Oriaa, C., Acuña, D., Avalos, G., Begert, M. et al. (2016). Towards implementing climate services in Peru - The project CLIMANDES. Climate Services, 4, 30-41. doi.org/10.1016/j.cliser.2016.10.001

Roudier, P., Muller, B., d'Aquino, P., Roncoli, C., Soumaré, M. A., Batté, L., \& Sultan, B. (2014). The role of climate forecasts in smallholder agriculture: Lessons from participatory research in two communities in Senegal. Climate Risk Management, 2, 42-55. doi.org/10.1016/j.crm.2014.02.001

Nel, J.L., Roux, D.J., Driver, A., Hill, L., Maherry, A.C. et al. (2016). Knowledge co-production and boundary work to promote implementation of conservation plans. Conservation Biology, 30(1),176-188. doi.org/10.1111/cobi.12560

Rutten, M., Minkman, E., \& van der Sanden, M. (2017). How to get and keep citizens involved in mobile crowd sensing for water management? A review of key success factors and motivational aspects. Wiley Water, 7(4), 1218. doi: 10.1002/wat2.1218

Ryan, R.M., \& Deci, E.L. (2000a). Self-determination theory and the facilitation of intrinsic motivation, social development and well-being. Journal of American Psychologist, 55(1), 68-78. doi.org/10.1037/0003066X.55.1.68

Ryan, R.M., \& Deci, E.L. (2000b). Intrinsic and extrinsic motivations: Classic definitions and new directions. Contemporary Educational Psychology, 25, 54-67.doi:10.1006/ceps.1999.1020

Sabogal, D. (2015). Data sharing in community-based forest monitoring: lessons from Guyana. Global Canopy Programme. Forest Compass. http://forestcompass.org/how/resources/datasharing-community-based-forest-monitoring-lessons-guyana .

Sarku, R., van Slobbe, E., Siwale, A., Chudaska, R., Teermer, K. \& Dewulf, A. (2021). Tracing hybridity in the provision of ICT-enabled agricultural weather information services in Ghana. Journal of Agricultural and Food Information. doi.org/10.1080/10496505.2021.1874388

Sarku, R., Gbangou, T., Dewulf, A. \& Van Slobbe, E. (2020b). Beyond 'experts knowledge': Locals and experts in a joint production of weatherapp and weather information for farming in the Volta Delta, Ghana. Springer Nature, Handbook of Climate Change Management: Research, Leadership, Transformation. doi.org/10.1007/978-3-030-22759-3_114-1

Sarku, R., Dewulf, A., Slobbe, V.E, Termeer, K., \& Kranjac-Berisavljevic, G. (2020a). Adaptive decision-making under conditions of uncertainty: the case of farming in the Volta delta, Ghana, Journal of Integrative Environmental Sciences, 17(1), 1-33. doi:10.1080/1943815x.2020.1729207

Sarewitz, D., \& Pielke, R.A. (2007). The neglected heart of science policy: reconciling supply of and demand for science. Environmental science \& policy, 10,5 - 5 . doi.org/10.1016/j.envsci.2006.10.001 
Saldaña, J. (2013). An Introduction to Codes and Coding. In The coding manual for qualitative researchers (2nd ed.). SAGE, London.

Schneider, C.Q., \& Wagemann, C. (2010b). Standards of good practice in qualitative comparative analysis (qca) and fuzzy-sets. Comparative Sociology, 9(3), 397-418. doi.org/10.1163/156913210X12493538729793

Schulz, M. (2014). Logic of consequences and logic of appropriateness. Palgrave Encyclopedia of Strategic Management, 1-6. doi.org/10.1111/j.1468-0491.2004.00265.x

Scholz, R.W., Lang, D.J., Wiek, A., Walter, A.I., \& Stauffacher, M. (2006). Transdisciplinary case studies as a means of sustainability learning: historical framework and theory. International Journal of Sustainability of Higher Education, 7, 226-251. doi.org/10.1108/14676370610677829

Seymour, V., \& Haklay, M. (2017). Exploring engagement characteristics and behaviours of environmental volunteers. Journal of Citizen Science: Theory and Practice, 2(1), 1-13. doi.org/10.5334/cstp.66

Shoko, K., \& Shoko, N. (2013). Indigenous Weather Forecasting Systems: A Case Study of the Abiotic Weather Forecasting Indicators for Wards 12 and 13 in Mberengwa District Zimbabwe. Journal of Sustainable Development in Africa, 14(2). doi.org\%2F10.5539\%2Fass.v9n5p285

Singh, C., Dorward, P., \& Osbahr, H. (2016). Land use policy developing a holistic approach to the analysis of farmer decision-making : implications for adaptation policy and practice in developing countries. Land Use Policy, 59, 329-343. doi:10.1016/j.landusepol.2016.06.041.

Singh, C., Daron, J., Bazaz, A., Ziervogel, G., Spear, D., Krishnaswamy, J. et al. (2018). The utility of weather and climate informationfor adaptation decision-making: current uses and future prospects in Africa and India. Climate and Development, 10(5), 389-405. doi.org/10.1080/17565529.2017.1318744

Silvertown, J. (2009). A new dawn for citizen science. Trends in Ecology and Evolution, 24(9), 467-471. doi.org/10.1016/j.tree.2009.03.017

Siebenhuner, B. (2004). Social learning and sustainability science: Which role can stakeholder participation play? International Journal of Sustainable Development 7(2), 146-163. doi: 10.1504/IJSD.2004.005368

Smith, D. (2014). Internet use on mobile phones in Africa predicted to increase 20-fold. Guardian. http://www.theguardian.com/world/2014/jun/05/internet-use-mobile-phones-africapredicted- increase-20-fold

Smit, B., \& Wandel, J. (2006). Adaptation, adaptive capacity and vulnerability. Global Environmental Change, 16(3), 282-292. doi.org/10.1016/j.gloenvcha.2006.03.008 
Spear, D., Selato, J.C., Mosime, B., \& Nyamwanza, A.M. (2019). Harnessing diverse knowledge and belief systems to adapt to climate change in semi-arid rural Africa. Climate Services 14, 31 36. doi.org/10.1016/j.cliser.2019.05.001

Spruijt P., Knol A.B., Vasileiadou E., Devilee J., \& Lebret, E. (2014). Roles of scientists as policy advisers on complex issues: a literature review. Journal of Environmental Science Policy, 40(46), 16-25. doi.org/10.1016/j.envsci.2014.03.002

Sheil, D. (2001). Conservation and biodiversity monitoring in the tropics: realities, priorities, and distractions. Journal of Conservation Biology, 15, 1179-1182. doi.org/10.1046/j.15231739.2001.0150041179.x

Shikuku, K.M., Winowiecki, L., Twyman, J., Eitzinger, A., Perez, J.G., Mwongera, C., \& Läderach, P. (2017). Smallholder farmers' attitudes and determinants of adaptation to climate risks in East Africa. Climate Risk Management, 16, 234-245. doi.org/10.1016/j.crm.2017.03.001

Shirky, C. (2008). Here Comes Everybody: the Power of Organizing Without Organizations. Penguin Books, London.

Slavova, M., \& Karanasios, S. (2018). When Institutional Logics Meet Information and Communication Technologies: Examining Hybrid Information Practices in Ghana's Agriculture. Journal of the Association for Information Systems, 19(9), 775-812. doi: 10.17705/1jais.00509

Soares, M.A, \& Dessai, S. (2016). Barriers and enablers to the use of seasonal climate forecasts amongst organisations in Europe. Climatic Change, 137, 89-103. doi.org/10.1007\%2Fs10584016-1671-8

Soma, K., Termeer K., \& Opdam, P. (2016a). Informational Governance-a systematic literature review of governance for sustainability in the Information Age. Journal of Environmental Science Policy, 56, 89-99. doi.org/10.1016/j.envsci.2015.11.006

Soma, K., Termeer, K., \& Opdam P. (2016a). Informational Governance-a systematic literature review of governance for sustainability in the Information Age. Journal of Environmental Science Policy, 56, 89-99. doi.org/10.1016/j.envsci.2015.11.006

Soma, K., Onwezen, M.C., Salverda, I.E., \& van Dam, R.I. (2016b). Roles of citizens in environmental governance in the information age - four theoretical perspectives. Journal of Current Opinion in Environmental Sustainability, 18, 122-130. doi.org/10.1016/j.cosust.2015.12.009

Soma, K., MacDonald, B.H., Termeer, C.J.A.M., \& Opdam, P. (2016c). Introduction article: informational governance and environmental sustainability. Journal of Current Opinion in Environmental Sustainability, 18, 131-139. doi.org/10.1016/j.cosust.2015.09.005 
Soma, K., Termeer, C.J.A.M., \& Opdam, P. (2016). Informational governance - A systematic literature review of governance for sustainability in the Information Age. Environmental Science \& Policy, 56, 89-99. doi.org/10.1016/j.envsci.2015.11.006

Sonwa, D.J., Dieye, A., El Mzouri, E.H., Majule, A., Mugabe, F.T., Omolo, N. et al. (2017). Drivers of climate risk in African agriculture. Climate and Development, 9, 383-398. doi.org/10.1080/17565529.2016.1167659

Stepenuck, K.F., \& Green, L. (2015). Individual and community level impacts of volunteer environmental monitoring: a synthesis of peer-reviewed literature. Journal of Ecology and Society, 20(3), 19. dx.doi.org/10.5751/ES-07329-200319

Steinke, J. (2015). Citizen science with resource-poor farmers as a new approach to climate adaptation and food security: Evidence from Honduras [Master's thesis, Humboldt University of Berlin]. https://edoc.huberlin.de/bitstream/handle/18452/14906/steinke.pdf?sequence=1\&isAllowed=y

Stone, R.C., \& Meinke, H. (2006). Weather, climate, and farmers: an overview. Meteorological. Application, 7-20. doi:10.1017/S1350482706002519

Stone, R.C., \& Meinke, H. (2006). Weather, climate, and farmers: An overview. Meteor. Appl., 13 (S1), 7-20. doi.org/ 10.1017/S1350482706002519.

Stevens, M., Vitos, M., Altenbuchner, J., Conquest, G., Lewis, J., \& Haklay, M. (2014). Taking Participatory Citizen Science to Extremes [Special Issue]. IEEE Pervasive Computing , 13(2), 2029. 10.1109/MPRV.2014.37.

Stokols, D. (2011). Transdisciplinary Action Research in Landscape Architecture and Planning: Prospects and Challenges. Landscape Journal: design, planning, and management of the land, 30(1), 1-5. doi.org\%2F10.3368\%2Flj.30.1.1

Stokols, D. (2006). Toward a Science of Transdisciplinary Action Research. American Journal of Community Psychology, 38, 63-77. doi 10.1007/s10464-006-9060-5

Sullivan, B.L., Wood, C.L., Iliff, M.J., Bonney, R.E., Fink, D., \& Kelling, S. (2009). eBird: A citizen-based bird observation network in the biological sciences. Biological Conservation, 142(10), 2282- 2292. doi.org/10.1371/journal.pbio.1001220

Sultan, B., \& Janicot, S. (2003). The West African monsoon dynamics. Part II: The "preonset" and "onset" of the summer monsoon. Journal of Climate, 16, 3407-3427. https://doi.org/10.1371/journal.pbio.1001220

Swe, L.M.M., Shrestha, R.P., Ebbers, T., \& Jourdain, D. (2015). Farmers' perception of and adaptation to climate-change impacts in the Dry Zone of Myanmar. Journal of Climate and Development, 7(5), 437-453. doi:10.1080/17565529.2014.989188.

Sylla, M.B., Nikiema, P.M., Gibba, P., \& Kebe, I. (2017). Climate Change over West Africa: Recent Trends and Future Projections. In J.A. Yaro \& J. Hesselberg (eds.), Adaptation to Climate 
Change and Variability in Rural West Africa. Springer Nature. doi.org\%2F10.1007\%2F978-3-31931499-0_3

Tall, J., Coulibaly, Y., \& Diop, M. (2018). Do climate services make a difference? A review of evaluation methodologies and practices to assess the value of climate information services for farmers: Implications for Africa. Climate Services 11, 1-12. doi.org/10.1016/j.cliser.2018.06.001

Tall, A., Hansen, J., Jay, A., Campbell, B., Kinyangi, J., Aggarwal, P.K., \& Zougmoré, R. (2014). Scaling up Climate Services for Farmers: Mission Possible. Learning from Good Practice in Africa and South Asia. CCAFS Report;13. https://hdl.handle.net/10568/42445

Tall, A. (2013). What do we mean by climate services [Special issue]? World Meteorological Organisation Bulletin, 62, 7-11. https://public.wmo.int/en/bulletin/what-do-we-mean-climateservices

Tall, A. (2010). Climate Forecasting to Serve Communities in West Africa. Procedia Environmental Sciences, 1, 421-431. doi.org/10.1016/j.proenv.2010.09.030

Tarchiani, V., Rossi, F., Camacho, J., Stefanski, R., Augustin, K. et al. (2017). Smallholder farmers facing climate change in West Africa: decision-making between innovation and facing climate change in West Africa: decision-making between innovation and tradition. Journal of Innovation Economics \& Management, 3(24), 151-176. doi 10.3917/jie.pr1.0013

Teye, J. K., \& Owusu, K. (2015). Dealing with Climate Change in the Coastal Savannah Zone of Ghana: In Situ Adaptation Strategies and Migration. In F. Hillmann, M. Pahl, B. Rafflenbeul, \& H. Sterly (Eds.), Journal of Environmental Change, Adaptation and Migration (pp. 223-244. Palgrave Macmillan.

Tinati, R., Luczak-Roesch, M., Simperl, E., \& Hall, W. (2017). An investigation of player motivations in Eyewire, a gamified citizen science project. Computers in Human Behavior, 73, 527-540. doi.org/10.1016/j.chb.2016.12.074

Torres, A.B., Acuña, L.A.S., \& Vergara, J.M.C. (2014). Integrating CBM into land-use based mitigation actions implemented by local communities. Journal of Forests, 5(12), 3295-3326. doi:10.3390/f5123295.

Toonen, H.M. (2013). SEA@SHORE: Informational governance in marine spatial conflicts at the North Sea [Doctoral dissertation, Wageningen University]. https://edepot.wur.nl/282909

Tosun, J., Koos, S., \& Shore, J. (2016). Co-governing common goods: Interaction patterns of private and public actors. Journal of Policy and Society, 35(1), 1-12. doi: 10.1016/j.polsoc.2016.01.002

Tripathi, A., \& Mishra, A.K. (2017). Knowledge and passive adaptation to climate change: An example from Indian farmers. Climate Risk Management, 16, 195-207. doi.org/10.1016/j.crm.2016.11.002 
Trujillo, P., Piroddi, C., \& Jacquet, J. (2012). Fish Farms at Sea: The Ground Truth from Google Earth. PLOS ONE 10(7), 0134745. doi.org/10.1371/journal.pone.0134745

Turreira-García, N., Lund, J.F., Domínguez, P., Carrillo-Anglés, E., Brummer, M.C., Duenn P., \& Reyes-García, V. (2018). What's in a name? Unpacking "participatory" environmental monitoring. Ecology and Society 23(2), 24. doi.org/10.5751/ES-10144-230224.

Usher, J., Phiri, C., Linacre, N., O’Sullivan, R., \& Qadir, U. (2018). Climate Information Services Market Assessment and Business Model Review. USAID-supported Assessing Sustainability and Effectiveness of Climate Information Services in Africa project. Washington, DC, USA.

Vincent, K., Daly, M., Scannell, C., \& Leathes, B. (2018). What can climate services learn from theory and practice of co-production? Climate Services, 12, 48-58. doi.org/10.1016/j.cliser.2018.11.001

Vaughan, C., Hansen, J., Roudier, P., Watkiss, P., \& Carr, E. (2019). Evaluating agricultural weather and climate services in Africa: Evidence, methods, and a learning agenda. Wiley Advance Review, 10(4), 1-33. doi.org/10.1002/wcc.586

Vaughan, C., \& Dessai, S. (2014). Climate services for society: Origins, institutional arrangements, and design elements for an evaluation framework. Wiley Interdisciplinary Reviews: Climate Change, 5(5), 587-603. doi.org/10.1002/wcc.290

Vedeld, T., Mathur, M., \& Bharti, N. (2019). How can co-creation improve the engagement of farmers in weather and climate services (WCS) in India. Climate Services, 15, 100-103. doi.org/10.1016/j.cliser.2019.100103

Vining, A.R., \& Weimer, D.L. (2016). The challenges of fractionalised property rights in publicprivate hybrid organisations: The good, the bad, and the ugly. Journal of Regulation and Governance, 10, 161-178. doi.org/10.1111/rego.12086

Visser, L. (2004). Challenging coasts: transdisciplinary excursions into integrated coastal zone development, Amsterdam. Amsterdam University Press, Amsterdam.

Vogel, C., Steynor, A., \& Manyuchi, A. (2019). Climate services in Africa: Re-imagining an inclusive, robust and sustainable Service. Climate Services, 15, 100-107. doi.org/10.1016/j.cliser.2019.100107

Vogel, J., Letson, D., \& Herrick, C. (2017). A framework for climate services evaluation and its application to the Caribbean Agrometeorological Initiative. Climate Services, 6, 65-76. doi.org/10.1016/j.cliser.2017.07.003

Vogel, C., \& O' Brien, K.O. (2006). Who can eat Information? Examining the effectiveness of seasonal climate forecasts and regional climate-risk management strategies. Climate Research, 33, 111-122. doi.org\%2F10.3354\%2Fcr033111 
Walker, W.E., Haasnoot, M., \& Kwakkel, J.H. (2013). Adapt or perish: A review of planning approaches for adaptation under deep uncertainty. Sustainability, 5(3), 955-979. doi.org/10.3390/su5030955

Walsham, G. (2006). Doing interpretive research. European Journal of Information Systems, 15(3), 320-330. doi.org/10.1057/palgrave.ejis.3000589

Wani, S.P., Rockström, J., \& Oweis, T.Y. (2009). Rainfed Agriculture: Unlocking the Potential; CABI.

http://www.iwmi.cgiar.org/Publications/CABI_Publications/CA_CABI_Series/Rainfed_Agric ulture/Protected/Rainfed_Agriculture_Unlocking_the_Potential.pdf

Wehn, U., \& Almomani, A. (2019). Incentives and barriers for participation in community-based environmental monitoring and information systems: A critical analysis and integration of the literature. Environmental Science \& Policy, 101, 341-357. doi.org/10.1016/j.envsci.2019.09.002

West, S.E., Büker, P., Ashmore, M., Njoroge, G., Welden, N., Muhoza, C. et al. (2020). Particulate matter pollution in an informal settlement in Nairobi: Using citizen science to make the invisible visible. Journal of Applied Geography 114,102-133. doi.org/10.1016/j.apgeog.2019.102133

West, S., \& Pateman, R. (2016). Recruiting and retaining participants in citizen science: What can be learned from the volunteering literature? Journal of Citizen Science: Theory and Practice, 1(2)15, 1-10. doi: https://doi.org/10.5334/cstp.8

Wetterhall, F., Winsemius, H., Dutra, E., Werner, M., \& Pappenberger, E. (2015). Seasonal predictions of agro-meteorological drought indicators for the Limpopo basin. Hydrology and Earth System Sciences 19(6), 2577-2586. doi.org\%2F10.5194\%2Fhess-19-2577-2015

Wiek, A. (2009). Analysing, evaluating and designing participatory research in sustainability science. Working paper, School of Sustainability, Tempe, Arizona State University.

Wiid, N, \& Ziervogel G. (2012). Adapting to climate change in South Africa: commercial farmers' perception of and response to changing climate. South African Geographic Journal, 94(2),152173. doi:10.1080/ 03736245.2012.742783.

Williams, B.K, \& Brown, D. (2014). Adaptive management: from more talk to real action. Journal of Environmental Management, 53, 465-479. doi:10.1007/s00267-013-0205-7.

Williams, L.J., Grünbühel, C.M., \& Brown, P.R. (2013). A social science framework to guide multiscale research into climate change adaptation strategies in agricultural communities. Australia: CSIRO. Retrieved from https:// publications.csiro.au/rpr/download?pid=csiro:EP12615\&dsid=DS5.

Woodroffe, C.D., Nicholls, R.J., Saito, Y., Chen, Z.Y., \& Goodbred, S.L. (2006). Landscape variability and the response of Asian mega deltas to environmental change. In N. Harvey (ed.), 
Global change and integrated coastal management: the Asia-pacific region (pp. 277-314). Springer Nature.

Wolf, A., \& Baehler, K.J. (2018). Learning transferable lessons from single cases in comparative policy analysis. Journal of Comparative Policy Analysis: Research and Practice, 20(4), 420-434. doi.org/10.1080/13876988.2017.1399578

World Meteorological Organisation. (2016). Report of the stakeholder workshop to implement the WMO strategy for service delivery Accra, Ghana.

https://www.wmo.int/pages/prog/amp/pwsp/documents/Finalreport_WMOServiceDelivery_Wor kshopGhana2016.pdf

Wynn, D., \& Williams, C.K. (2012). Principles for conducting critical realist case study research in information systems. Management information system quarterly, MIS Quarterly, 36(3), 787810. doi.org/10.2307/41703481

Yaro, J.A. (2013). The perception of and adaptation to climate variability/change in Ghana by small-scale and commercial farmers. Regional Environmental Change, 13(6), 1259-1272. doi:10.1007/ s10113-013-0443-5.

Yengoh, G.T., Armah, F.A., \& Svensson, M.G. (2009). Technology adoption in small-scale agriculture: the case of Cameroon and Ghana. Science Technology Innovation Studies, 5(2),111131. https://portal.research.lu.se/portal/en/publications/technology-adoption-in-smallscaleagriculture--the-case-of-cameroon-and-ghana(6d3dbf89-2135-4f04-a2e4-07d0deed8047).html

Yobom, O. (2020). Climate change and variability: Empirical evidence for countries and agroecological zones of the Sahel. Climate Change, 159, 365-384. doi.org/10.1007/s10584-01902606-3

Yousefpour, R., \& Hanewinkel, M. (2016). Climate change and decision-making under uncertainty. Current Forestry Reports, 2, 143-149. doi:10.1007/s40725-016-0035-y.

Yousefpour, R., Temperli, C., Jacobsen, J.B., Thorsen, B.J., Meilby, H., Lexer, M.J. et al. (2017). A framework for modeling adaptive forest management and decision making under climate change. Ecology and Society, 22(4). 40. doi.org/10.5751/ES-09614-220440

Yidana, S.M. \& Chegbeleh, L.P. (2013). The hydraulic conductivity field and groundwater flow in the unconfined aquifer system of the Keta Strip, Ghana. Journal of African Earth Sciences, 86, 4552. doi.org/10.1016/j.jafrearsci.2013.06.009

Yin, R.K. (2003). Case Study Research. Sage Publications. Thousand Oaks.

Yin, R.K. (2009). Case study research: design and methods (4 ${ }^{\text {th }}$ ed.). Sage, London

Zebiak, S.E. (2019). International Conference on Climate Services-5-An introduction. Elsevier, Amsterdam. 
Zheng, Y., Hatakka, M., Sahay, S. \& Andersson, A. (2018). Conceptualizing development in information and communication technology for development (ICT4D). Journal of Information Technology for Development, 24(1), 1-14. doi:10.1080/02681102.2017.1396020

Zibi, G. (2009). The African mobile phone market: Beyond the boom phase, between the promise and uncertainty of maturity. Private Sector Development, 4, 3-6. https://blog.private-sector-anddevelopment.com/2009/12/14/african-mobile-phone-market-beyond-boom-between-promise/

Ziervogel, G., van Garderen, E.A., \& Price, P. (2016). Strengthening the knowledge-policy interface through co-production of a climate adaptation plan: leveraging opportunities in Bergrivier Municipality, South Africa. Environment \& Urbanization, 28(2), 455-474. doi: $10.1177 / 0956247816647340$

Zulkafli, Z., Perez, K., Vitolo, C., Buytaert, W., Karpouzoglou, T., Dewulf, A. et al. (2017). Userdriven design of decision support systems for polycentric environmental resources management. Environmental Modelling \& Software, 88, 58-73. doi.org/10.1016/j.envsoft.2016.10.012

Zsambok, C.E, \& Klein, G. (2014). Naturalistic decision making (2nd ed.). Psychology Press, Sussex. 
Supplementary materials 
The text, figures, and tables in the supplementary material section is from published articles which have been adjusted to suit the $\mathrm{PhD}$ thesis format (e.g., the numbering, formatting). This includes editorial changes for consistency in the presentation of the $\mathrm{PhD}$ thesis chapters. The published versions of the supplementary materials are available online with the published articles.

\section{Supplementary Material-A}

Belonging to Chapter 2: Tracing hybridity in the provision of ICT-enabled agricultural weather information services in Ghana

\section{Appendix 2a: Interview guide for an information provider}

Introduction to the interview

- Note down: date and time of interview \& name of the interviewee

- Brief explanation of the research topic

- Ask for consent to record the interview

- Give a short outline of the interview structure (questions and time)

Water-related information provision

- Could you tell me about yourself and the service that you (or your organization) provide to farmers?

- Which type of water-related information do you provide?

$\circ$ E.g. weather information, cropping, technology, water management, and irrigation...

- How often is it updated?

- Frequency, quality of information

- Where do you receive your information from?

$\circ$ Effects/Impact of the information service

- How large is the outreach of your service?

- Users, revenue...

- How do farmers get to know about your service?

- Do you think that the information you are providing is useful for farmers? Why?

- What difference does your information make for the farmers?

- What effects have you observed/heard of?

- Can you give an example?

- How do you make the information accessible/understandable for farmers?

o How do you achieve uptake of the information or the adoption of certain practicess?

o Which factors increase/decrease the uptake of information?

- What difficulties do you face in the distribution of the information?

- Keywords: institutional bottlenecks, language, policies

- What do you know about the users of your information service?

- Do you receive feedback or communicate with the users? Do you evaluate your service?

- If yes, please elaborate.

- How do you adjust your information to farmer's information needs?

- Can you tell me more about farmers' information-seeking behavior?

Thank you for your time 
Appendix 2b: List Of Interviewees (Information providers)

\begin{tabular}{|c|c|c|c|}
\hline Name of organisation & Type of organisation & Location & $\begin{array}{ll}\text { Number } & \text { of } \\
\text { interview } & \\
\text { participants } & \\
\end{array}$ \\
\hline e-agriculture platform & $\begin{array}{l}\text { Governmental - } \\
\text { extension services }\end{array}$ & \multirow[t]{4}{*}{ Accra } & 3 \\
\hline Farmradio International & NGO/development & & 1 \\
\hline Farmerline & Agripreneurs & & 1 \\
\hline CSIR & Governmental- Research & & 1 \\
\hline Radio Ada & Broadcasting & $\begin{array}{|lr|}\text { Ada } & \text { East } \\
\text { District } & \\
\end{array}$ & 3 \\
\hline $\begin{array}{l}\text { Ghana Broadcasting } \\
\text { Corporation }(\mathrm{GBC})\end{array}$ & Government- Broadcasting & \multirow[t]{3}{*}{ Accra } & 1 \\
\hline Ignitia & Agripreneurs & & 1 \\
\hline $\begin{array}{l}\text { Ghana Meteorological } \\
\text { Agency (GMet) }\end{array}$ & Government- & & 1 \\
\hline 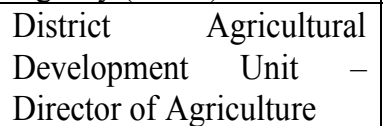 & Government & \multirow[t]{2}{*}{$\begin{array}{ll}\text { Ada } & \text { East } \\
\text { District } & \end{array}$} & 1 \\
\hline $\begin{array}{ll}\text { District } & \text { Agricultural } \\
\text { Development } & \text { Unit - } \\
\text { Agricultural } & \text { extension } \\
\text { officer } & \\
\end{array}$ & Government & & 1 \\
\hline $\begin{array}{l}\text { Ministry of Food and } \\
\text { Agriculture- Greater Accra } \\
\text { Regional office }\end{array}$ & Government & \multirow[t]{5}{*}{ Accra } & 2 \\
\hline $\begin{array}{l}\text { Private weather forecaster; } \\
\text { retired from GMet }\end{array}$ & Volunteer & & 1 \\
\hline $\begin{array}{ll}\text { mFarms } & \text { (Image-AD } \\
\text { Ghana) } & \\
\end{array}$ & Agripreneurs & & 3 \\
\hline Ministry of Information & Government & & 1 \\
\hline Esoko & Agripreneurs & & 1 \\
\hline
\end{tabular}




\section{Supplementary Material-B}

Belonging to Chapter 3: Adaptive decision-making under conditions of uncertainty: the case of farming in the Volta delta, Ghana

Appendix 3a: semi-structured interview guide for farmers

Introduction to the interview

- Note down: date, time and place of interview

- Brief explanation of the research topic

- Ask for consent to record the interview

\section{A. WATER AVAILABILITY CHALLENGES AND UNCERTAINTIES IN FARMING}

1. Getting to know the farmer: What crops do you grow?

- How long have you lived in this community?

- How long have you been farming?

2. How do you use water for farming? o Irrigation/Hand irrigation/Rain-fed

3. What uncertainty conditions do farmers face in farming in this community?

4. Can you describe how each of the uncertain conditions you mentioned occur in your community?

- Example, water availability situation such as rainfall condition and irrigation facilities, variability in-between years, months, and days

5. What is the most important parameter of water availability do you take cognizance of during the farming season?

6. What knowledge do you use in making decisions concerning the availability of water for farming under uncertain situations?

\section{B. THE USE OF INFORMATION IN DECISION-MAKING IN FARMING}

7. What type of crops do you cultivate?

8. Can you describe how you take decisions before and during the farming season?

9. Which of the decisions is influenced by the (non)availability of water such as rainfall conditions?

10. Can you describe the strategies that are applied under uncertain weather conditions such as too little rainfall, dry spell conditions etc.

11. What strategies can be (un)changed when uncertain weather conditions are evident?

12. Do you change decision strategies if it does not produce the expected results under uncertain weather conditions?

- Probe for explanations and real life stories

13. What are the effect(outcome) of the decisions strategies

14. What accounts for the failure or success of the decisions strategies

15. In what ways can farmers improve their decision-making in relation to water management?

\section{BACKGROUND OF FARMER}

- Can I ask you a few questions about yourself (age, education, occupation, etc.)? 
- If you have a family, can you tell me about them (family size, age of children, gender, etc)?

Thank you

\section{Appendix 3b: Focus group discussion with farmers}

Introduction to the interview

- Note down: date, time and place of interview

- Brief explanation of the research topic

- Ask for consent to record the interview

A. WATER AVAILABILITY CHALLENGES AND FARMING IN THE DISTRICT

1. What are the key environmental changes occurring in this area?

2. Can you tell me about farming and the use of water in this area?

- Obtain stories about incidences and the periods when they experienced water availability challenges

3. What are the local knowledge and perception about water availability conditions in the area?

4. How does water availability conditions affect farming decisions?

B. WATER-RELATED DECISION-MAKING IN FARMING UNDER WATER AVAILABILITY CONDITIONS

5. What water-related decisions are taken in this community to deal with uncertainties in water availability situation?

- Probe for stories about reactive water-related decision-making in farming

6. What are the sequences of farming decisions that are taken annually (farming seasons) under the perception of water availability condition?

- Ask discussants to share experiences about decision-making and the rainfall pattern for 2017.

7. What strategies are used to support decision-making under uncertain weather conditions. Probe for strategies that are applied during:

- Late onset of rainfall

- Early onset of rainfall

- False start of the rainfall season

- Increased rainfall amounts during the farming season

- Erratic or poor rains during the farming season

- Occurrence of dry spells during the farming season

- Early cessation of rainfall

Appendix 3c: Interview with agricultural extension agents

Introduction to the interview

- Note down: date, time and place of interview

- Brief explanation of the research topic

- Ask for consent to record the interview

A. GENERAL INFORMATION ABOUT FARMING IN THE AREA 
1. Can you tell me about the characteristics of farmers in the district?

Example, gender, age, level of formal education, income sources

2. What are the farming practices?

Example, farm sizes, crop types, rainfed or irrigation, marketing/supply of crops etc.

B. WATER AVAILABILITY CHALLENGES AND FARMING IN THE DISTRICT

3. What uncertainties do farmers face in farming?

4. What are the water availability conditions in this area?

Probe for the nature of variability in water availability conditions and some observed changes

5. Are farmers aware of the changing trends in water availability conditions?

6. What is the important parameters of water availability conditions considered by farmers?

7. What are the effects of water availability condition on farming in the district?

\section{WATER INFORMATION SERVICES FOR DECISION-MAKING}

8. What is the important source of water-related information?

Example, personal experiences and observation, television, radio etc.

9. What sort of information about water availability do extension workers and farmers have access to in this district?

10. What are the perceptions about the use of formal information among farmers?

Can you estimate the number of farmers who use scientific information?

11. Which of these is often used by farmers and why do farmers use more of a particular type of information than others?

12. How many organisations are currently providing ICT water-related information services to farmers in the district?

$\circ$ What is their scope of operation (type of forecast information, temporal, geographical focus, means of providing information and quality of information)?

- What ICT tool is used to transmit water-related information services to farmers?

- Can the availability of different ICT tools improve the relevance of formal information about water availability to farmers?

13. What local information do farmers have about water availability for farming?

○ Talk about daily, seasonal, annual indicators

14. How does this knowledge and ability to identify these elements affect their daily decisionmaking?

15. What will likely influence farmers to adopt and use scientific information about water availability to support farming decision-making?

\section{THE USE OF INFORMATION IN DECISION-MAKING IN FARMING}

16. What are the sequences of decisions carried out by farmers throughout the farming seasons? 
17. Which people (social networks) do farmers consult when they want to make decisions about farming?

○ Example, confer with elders, farmer groups, family members, community

- How do they influence farmers decision-making?

18. What advice do you provide to farmers during uncertain water availability conditions?

19. What farming decisions are easily changed by farmers during water availability conditions?

20. Which decisions are irreversible during water availability crises?

\section{E. BACKGROUND OF INTERVIEWEE}

- Name of interviewee and his or her organisation

- Interviewees position within the organisational structure

- Can you please tell me a bit about yourself (age, education, gender etc.)?

- How long have you been working with farmers in this district?

Any other comments?

THANK YOU FOR YOUR TIME

Appendix 3d List of interviewees

\begin{tabular}{|c|c|c|c|c|c|c|}
\hline $\begin{array}{l}\text { Agricultural } \\
\text { Extension } \\
\text { Agents } \\
\text { (AEA) }\end{array}$ & $\begin{array}{l}\text { Interviews } \\
\text { under } \\
\text { Extension } \\
\text { Agents }\end{array}$ & Date & Name of Community & Gender & Irrigation/rainfed & $\begin{array}{l}\text { Purpose of } \\
\text { farm } \\
\text { production }\end{array}$ \\
\hline \multirow[t]{12}{*}{ AEA 1} & II 1.1 & \multirow[t]{2}{*}{$19 / 6 / 2017$} & \multirow[t]{2}{*}{ Attortorkope } & Male & \multirow[t]{2}{*}{ Both } & Commercial \\
\hline & II 1.2 & & & Male & & Commercial \\
\hline & II 1.3 & $16 / 7 / 2017$ & \multirow[t]{4}{*}{ Dogo } & Male & \multirow[t]{4}{*}{ Rainfed } & $\begin{array}{l}\text { Semi- } \\
\text { commercial }\end{array}$ \\
\hline & II 1.4 & \multirow[t]{3}{*}{$21 / 06 / 2017$} & & Male & & $\begin{array}{l}\text { Semi- } \\
\text { commercial }\end{array}$ \\
\hline & II 1.5 & & & Male & & $\begin{array}{l}\text { Semi- } \\
\text { commercial }\end{array}$ \\
\hline & II 1.6 & & & Male & & $\begin{array}{l}\text { Semi- } \\
\text { commercial }\end{array}$ \\
\hline & II 1.7 & $26 / 9 / 2017$ & MacCarthykope & Male & Both & Commercial \\
\hline & II 1.8 & $21 / 06 / 2017$ & Adornorkope & Male & Both & Commercial \\
\hline & II 1.9 & $15 / 06 / 2017$ & Tovie & Female & Rainfed & $\begin{array}{l}\text { Semi- } \\
\text { commercial }\end{array}$ \\
\hline & II 1.10 & $18 / 6 / 2017$ & Angorsekope & Male & Irrigation & Commercial \\
\hline & II 1.11 & \multirow[t]{2}{*}{ 29/8/2017 } & Wasakuse & Male & \multirow[t]{2}{*}{ Rainfed } & $\begin{array}{l}\text { Semi- } \\
\text { commercial }\end{array}$ \\
\hline & II 1.12 & & Wasakuse & Female & & Subsistence \\
\hline \multirow[t]{2}{*}{ AEA 2} & II 2.1 & $12 / 07 / 2017$ & \multirow[t]{2}{*}{ Kajanya } & $\begin{array}{l}\text { Male \& } \\
\text { Female }\end{array}$ & \multirow[t]{2}{*}{ Rainfed } & Subsistence \\
\hline & II 2.2 & $13 / 07 / 2017$ & & Male & & Commercial \\
\hline
\end{tabular}




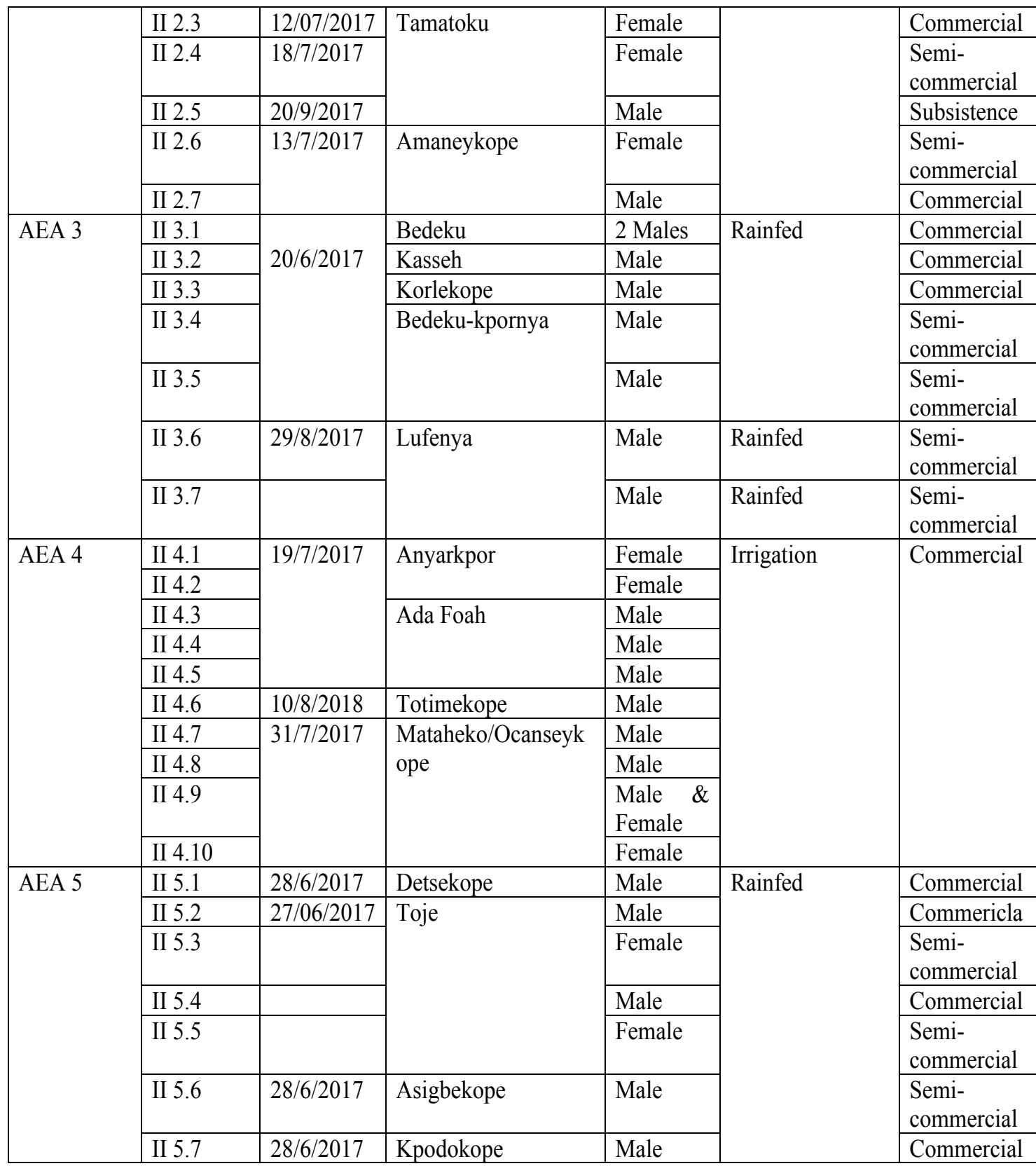

Appendix 3e. Code list

\begin{tabular}{|l|l|}
\hline Codes & Answers the question: \\
\hline Seasons & $\begin{array}{l}\text { Periods for the cultivation of crops and it coincides } \\
\text { with the occurrence of the rainfall }\end{array}$ \\
\hline Preseason & \\
\hline
\end{tabular}




\begin{tabular}{|c|c|}
\hline $\begin{array}{l}\text { Main season } \\
\text { Minor season }\end{array}$ & \\
\hline Rainfall conditions & Descriptions of the occurrence of rainfall \\
\hline $\begin{array}{l}\text { Above normal } \\
\text { Normal } \\
\text { Below } \\
\text { Abnormal }\end{array}$ & $\begin{array}{l}\text { Rainfall condition comprising of more than } 15 \text { rainy } \\
\text { days in a month } \\
5-14 \text { rainy days in a rainy season } \\
\text { When } 0-3 \text { rainy days is recorded in a rainy season } \\
\text { The record of rainy days in a dry season or month }\end{array}$ \\
\hline $\begin{array}{l}\text { Bad weather } \\
\text { Good weather }\end{array}$ & $\begin{array}{l}\text { The occurrence of above or below rainfall condition } \\
\text { Normal rainfall conditions in the farming seasons }\end{array}$ \\
\hline $\begin{array}{l}\text { Crop selections } \\
\text { Preseason crop selections } \\
\text { Main season crop selections } \\
\text { Minor season crop selections }\end{array}$ & $\begin{array}{l}\text { Decision-making on type of crops selected for the a } \\
\text { specific season }\end{array}$ \\
\hline Option & $\begin{array}{l}\text { Collections of usual decision-making for the farming } \\
\text { seasons }\end{array}$ \\
\hline Ploughing & Eg. Use of tractors to plough the land \\
\hline Harrowing & \\
\hline Land preparation & Eg. Burning of weeds and tree stumps \\
\hline Sowing of seed & \\
\hline Nursery & \\
\hline Transplanting & \\
\hline Irrigation strategies & Eg. Carrying water to the farm \\
\hline Application of $1^{\text {st }}, 2^{\text {nd }}, 3^{\text {rd }}$ Fertilisers & Eg. N.P.K, Ammonia or Urea \\
\hline Thinning & \\
\hline Weed control & \\
\hline Pest control & \\
\hline Spraying & Eg. Application of fruit boosters or insecticides \\
\hline Soil moisture conservation & Eg. Application of cow dung or manure \\
\hline Harvesting & \\
\hline $\begin{array}{l}\text { Flexible decision-making strategy } \\
\text { Decision-making strategy: Muddling } \\
\text { through } \\
\text { Decision-making strategy: Irrigation } \\
\text { Decision-making strategy: Wait-and- } \\
\text { see/delay }\end{array}$ & $\begin{array}{l}\text { What plans do you make after the rainfall or when } \\
\text { there is no rainfall in the season? }\end{array}$ \\
\hline
\end{tabular}




\begin{tabular}{|c|c|}
\hline Robust decision-making strategy & $\begin{array}{l}\text { Type of plan used by a farmer to support growth of } \\
\text { crops during too much or too little or dry spell } \\
\text { condition }\end{array}$ \\
\hline \multicolumn{2}{|l|}{$\begin{array}{l}\text { Decision-making strategy: Drought } \\
\text { resistant }\end{array}$} \\
\hline $\begin{array}{ll}\text { Decision-making } & \text { strategy: Short } \\
\text { duration cultivars } & \end{array}$ & Crops that matures 2 months or less eg. water melon \\
\hline $\begin{array}{l}\text { Decision-making strategy: Starting } \\
\text { early }\end{array}$ & eg. Planting immediately after Christmas \\
\hline $\begin{array}{l}\text { Decision-making strategy: Portfolio } \\
\text { of agrochemicals }\end{array}$ & $\begin{array}{l}\text { eg. Fungicides, pesticides, insecticides, categories of } \\
\text { feritlisers, weedicides, herbicides }\end{array}$ \\
\hline \multicolumn{2}{|l|}{$\begin{array}{l}\text { Decision-making strategy: Divers } \\
\text { planting dates }\end{array}$} \\
\hline $\begin{array}{ll}\text { Decision-making } & \text { strategy: } \\
\text { Transplanting in badges } & \end{array}$ & At least 2 weeks intervals between transplanting dates \\
\hline \multicolumn{2}{|l|}{$\begin{array}{l}\text { Decision-making strategy: varieties of } \\
\text { seeds }\end{array}$} \\
\hline $\begin{array}{l}\text { Decision-making strategy: Varieties } \\
\text { of seeds of the same crop }\end{array}$ & $\begin{array}{l}\text { Eg. Tomatoes has seminis, pecto mech, local cultivars } \\
\text { etc. }\end{array}$ \\
\hline \multicolumn{2}{|l|}{$\begin{array}{l}\text { Decision-making strategy: Switching } \\
\text { crops between seasons }\end{array}$} \\
\hline \multicolumn{2}{|l|}{$\begin{array}{l}\text { Decision-making } \quad \text { strategy: } \\
\text { Diversification }\end{array}$} \\
\hline $\begin{array}{l}\text { Decision-making } \\
\text { Intercropping }\end{array}$ & \\
\hline
\end{tabular}




\section{Supplementary Material-C}

Belonging to Chapter 4: Assessing the usability of weather information services for decision-making in farming: A case study in Southern Ghana

Appendix 4a: semi-structured interview guide for farmers

WEATHER INFORMATION SERVICES FOR DECISION-MAKING

- Have you been using weather information over the past years for farming and decisionmaking?

- If yes, which type of weather information do you use?

- What is the important source of weather information, and why do you use more of a particular type of information above others?

- How often do you use this source of information?

- What local weather information do you use for farming?

- Tell me about the indicators (information) about water availability, interpretations and its decision-making for farming

- Why is it important for you to receive information?

- Quality of the information: How good is the information? How does it help you?

○ Keywords: Reliable, timing, useful, important, easy to understand...

- Do you trust the information?

- How do you know that it is true?

- How do you receive this information?

○ Local conversation, telephone/SMS service...

- How did you get to know about this source of information?

- Which weather information do you get from mobile phones, television, or radios?

○ How has the use of these information sources changed in the past years?

\section{WEATHER INFORMATION PROVISION BY FARMERS}

- Who do you discuss farm-related activities with? What do you discuss?

○ If you noticed any changes regarding weather conditions (e.g. rainfall), who would you discuss it with?

- Which information do you share with other farmers or organizations?

- What are the reasons for not using a particular source of information?

- Which information related to the weather would you like to receive?

- How would you like to receive it?

○ Would you be willing to pay for it?

- Concluding questions

○ Is there anything else you would like to say or add? Is there anything you would like to ask?

Appendix 4b: Focus group discussion guide for farmers

\section{THE USE OF INFORMATION FOR FARMING UNDER UNCERTAIN CONDITIONS}

- What do you know about forecast information services?

- First record the number of people who are aware of the use of forecast information (local or scientific) to make decisions in farming.

- Also take note of the different contributions from those who are aware of the use of forecast and those who are not aware)

- What type of forecast information is used (local or scientific information)?

- Do you use more than one form of weather forecast? 
- Count the number of farmers who use a particular type of information or both and probe for reasons why they prefer a particular choice

- How did you know about scientific forecast information services?

- Mention the specific sources TV, extension officers, NGOs, researchers, radio, etc.

- Among all the information services that you have mentioned, which of them is usable and why?

- What information (indicators) do you use to detect onset, continuity, and end of the season?

- Tell me about the indicators (information) that are used for forecasting the weather, the interpretations and decision-making for farming

- What has been the trend and success with the use of local forecast information to predict the weather condition in this area?

- How would you describe the enthusiasm of other farmers regarding the use of scientific forecast information services for decision-making in farming?

- Probe for their readiness to a positive response

- Have you heard of e-agriculture, farmerline, esosko, and how they provide scientific forecast information services?

○ Probe for knowledge concerning how farmers use information from the abovementioned sources

\section{FACTORS AFFECTING THE USABILITY OF SCIENTIFIC FORECAST INFORMATION}

- What challenges do you have with the use of existing scientific forecast information

- Ask farmers to describe the level of satisfaction derived from the information provided by these organisations

- What kind of support have you received, if any, from certain entities

- Example extension officers, NGOs, and private organisations about the use of ICT tools to access scientific forecast information

- If yes, can you describe some of the packages you were introduced to?

- Example, the use of mobile phone, call centers, internet to receive messages

- Does accessibility to different types of ICT tools, such as the use of mobile phones, text, etc improve the usability of weather information? If not, what is required to make it relevant to farmers?

- Do you think characteristics such as literacy rate, language, timely delivery etc. determines the use of scientific forecast information for decision-making in farming?

- For those of you who are not using any form of formal forecast information services, do you have the intention(s) of using it to make decisions in farming?

- Probe for reasons why farmer will adopt or not adopt forecast information services

- What is your suggestion about ways by which formal forecast information can be made useful, usable, and exchangeable to farmers in this area?

Any other comments?

Thank you for participating in this discussion 


\section{Supplementary Material-D}

Belonging to Chapter 5: Coproducing Weather Forecast Information with and for Smallholder Farmers in Ghana: Evaluation and Design Principles

Table 5a: Questionnaire for farmers and agricultural extension agents: Co-production Evaluation Survey, Waterapps

\section{Demographic}

Name: Community: Gender: User type: farmer $\square$ Extension Officer

Water use type: Rainfed $\square$ Irrigation Both $\square$ Crops:

Age: 24 years or younger $\square$ 25-40 years $\square$ 40-64 years $\square$ 64 or older $\square$

Education: Primary $\square$ Secondary $\square$ University $\square$ Non-formal

How long have you been farming or working from this community (specify years):

2. Did you find the following co-production tools for the co-production of climate information services (CIS) relevant? (for both farmers and extension agents)

\begin{tabular}{|l|l|l|l|}
\hline The relevance of digital tools & $\begin{array}{l}\text { Highly } \\
\text { relevant }\end{array}$ & $\begin{array}{l}\text { Somewhat } \\
\text { relevant }\end{array}$ & $\begin{array}{l}\text { Not } \\
\text { relevant }\end{array}$ \\
\hline $\begin{array}{l}\text { Use of smartphone as a channel for CIS co-production (collect \& } \\
\text { receive information) }\end{array}$ & & & \\
\hline $\begin{array}{l}\text { Use of Weather App for collecting observation about local weather } \\
\text { indicators }\end{array}$ & & & \\
\hline $\begin{array}{l}\text { Use WhatsApp to receive forecast data and connect farmers, } \\
\text { agri/meteo extension officers and scientists }\end{array}$ & & & \\
\hline Use of Rain gauge to collect data & & & \\
\hline Use of Internet for the WhatsApp and smartphone & & & \\
\hline
\end{tabular}

3. How easy was it to use and understand the content of the local weather indicators install as a weather app for collecting data? (for both farmers and extension agents)

\begin{tabular}{|l|l|l|l|l|l|l|}
\hline Weather App content & \multicolumn{3}{|l|}{ Now } & \multicolumn{3}{l|}{ Before } \\
\cline { 2 - 6 } & $\begin{array}{l}\text { Very } \\
\text { easy }\end{array}$ & $\begin{array}{l}\text { Somewhat } \\
\text { easy }\end{array}$ & $\begin{array}{l}\text { Not } \\
\text { easy }\end{array}$ & $\begin{array}{l}\text { Very } \\
\text { easy }\end{array}$ & $\begin{array}{l}\text { Somewhat } \\
\text { easy }\end{array}$ & $\begin{array}{l}\text { Not } \\
\text { easy }\end{array}$ \\
\hline $\begin{array}{l}\text { Images (indicators, e.g. win, clouds on the } \\
\text { weather app) }\end{array}$ & & & & & & \\
\hline Symbols (e.g. Rain, No Rain) & & & & & & \\
\hline Text (within the weather app) & & & & & & \\
\hline
\end{tabular}




\begin{tabular}{|l|l|l|l|l|l|l|}
\hline $\begin{array}{l}\text { Manipulation of the app (e.g. open the app, } \\
\text { checkbox, and submit) }\end{array}$ & & & & & \\
\hline $\begin{array}{l}\text { Handle internet (put internet data on, load the } \\
\text { weather app page) }\end{array}$ & & & & & & \\
\hline
\end{tabular}

4. How easy was it to use and understand the WhatsApp tool and its messages bearing feedback on daily forecast data now and before the experiment? (for both farmers and extension agents)

\begin{tabular}{|l|l|l|l|l|l|l|}
\hline WhatsApp content & \multicolumn{2}{l|}{ Now } & \multicolumn{2}{l|}{ Before } \\
\cline { 2 - 7 } & $\begin{array}{l}\text { Very } \\
\text { easy }\end{array}$ & $\begin{array}{l}\text { Somewhat } \\
\text { easy }\end{array}$ & $\begin{array}{l}\text { Not } \\
\text { easy }\end{array}$ & $\begin{array}{l}\text { Very } \\
\text { easy }\end{array}$ & $\begin{array}{l}\text { Somewhat } \\
\text { easy }\end{array}$ & $\begin{array}{l}\text { Not } \\
\text { easy }\end{array}$ \\
\hline $\begin{array}{l}\text { Graphs (e.g. understand forecasts pie } \\
\text { charts) }\end{array}$ & & & & & & \\
\hline Text (Feedback text messages) & & & & & & \\
\hline $\begin{array}{l}\text { Manipulation of the app (e.g. find the app, } \\
\text { open read and write a report or ask } \\
\text { questions) }\end{array}$ & & & & & & \\
\hline Handle internet (Switch on data on) & & & & & & \\
\hline
\end{tabular}

5. How easy was the monitoring of the rainfall with the manual rain gauges now and before the experiment? (for both farmers and extension agents)

\begin{tabular}{|l|l|l|l|l|l|l|}
\hline \multirow{2}{*}{ Rain gauge handling } & \multicolumn{2}{|l|}{ Now } & \multicolumn{2}{l|}{ Before } \\
\cline { 2 - 7 } & $\begin{array}{l}\text { Very } \\
\text { easy }\end{array}$ & $\begin{array}{l}\text { Somewhat } \\
\text { easy }\end{array}$ & $\begin{array}{l}\text { Not } \\
\text { easy }\end{array}$ & $\begin{array}{l}\text { Very } \\
\text { easy }\end{array}$ & $\begin{array}{l}\text { Somewhat } \\
\text { easy }\end{array}$ & $\begin{array}{l}\text { Not } \\
\text { easy }\end{array}$ \\
\hline Setting up a rain gauge in your farm & & & & & & \\
\hline Record rainfall (measure amount in mm) & & & & & & \\
\hline Reporting of rainfall (date, time, amount) & & & & & & \\
\hline
\end{tabular}

6. Rate the importance of the co-produced information for your day to day decisions and activities? (for both farmers and extension agents)

\begin{tabular}{|l|l|l|l|}
\hline Usefulness of co-produced information & Highly relevant & Somewhat relevant & $\begin{array}{l}\text { Not } \\
\text { relevant }\end{array}$ \\
\hline Rainfall monitoring data (measurement) & & & \\
\hline Daily forecasts received from farmers observations & & & \\
\hline Daily forecasts received from scientific models & & & \\
\hline Dialogue (feedbacks via WhatsApp) & & & \\
\hline Local knowledge monitoring data (e.g. cloud, wind) & & & \\
\hline
\end{tabular}


7. What decisions do you make with the co-produced information? (for both farmers and extension agents)

\begin{tabular}{|l|l|l|l|l|l|l|l|}
\hline $\begin{array}{l}\text { Information co- } \\
\text { produced }\end{array}$ & $\begin{array}{l}\text { Prepare } \\
\text { land }\end{array}$ & $\begin{array}{l}\text { allocate } \\
\text { water for } \\
\text { irrigation }\end{array}$ & $\begin{array}{l}\text { Transplanting } \\
\text { seedlings }\end{array}$ & Fertilising & $\begin{array}{l}\text { Pesticide } \\
\text { application }\end{array}$ & $\begin{array}{l}\text { Labour/ } \\
\text { weeding }\end{array}$ & $\begin{array}{l}\text { Other } \\
\text { decision: }\end{array}$ \\
\hline $\begin{array}{l}\text { Rainfall } \\
\text { monitoring data }\end{array}$ & & & & & & \\
\hline $\begin{array}{l}\text { Farmers daily } \\
\text { local forecasts }\end{array}$ & & & & & & & \\
\hline $\begin{array}{l}\text { Daily forecasts } \\
\text { received from } \\
\text { scientific models }\end{array}$ & & & & & & & \\
\hline $\begin{array}{l}\text { Dialogue via } \\
\text { (feedback } \\
\text { WhatsApp) }\end{array}$ & & & & & & & \\
\hline $\begin{array}{l}\text { Local knowledge } \\
\text { monitoring data } \\
\text { (e.g. cloud, win, } \\
\text { sun) }\end{array}$ & & & & & & & \\
\hline
\end{tabular}

8. Has your daily farming decision improve in comparison to previous season (last year)? Yes, highly improved $\square$ Yes, somewhat improved $\square$ no improvement

9. Were you able to conciliate the co-produced experiment with your farming activities?

Yes $\square$ No $\square$ If No, explain why:

10. Has your level of knowledge in rain monitoring and weather forecast improved after the experiment? (for both farmers and extension agents)

\begin{tabular}{|l|l|l|l|}
\hline Knowledge improvement & Highly relevant & Somewhat relevant & $\begin{array}{l}\text { Not } \\
\text { relevant }\end{array}$ \\
\hline $\begin{array}{l}\text { Local/traditional (indicators and signs, e.g. cloud, } \\
\text { wind, observation) }\end{array}$ & & & \\
\hline Rainfall measurement and recording technique & & & \\
\hline $\begin{array}{l}\text { Forecast data from farmers indicators and } \\
\text { MeteoBlue }\end{array}$ & & & \\
\hline $\begin{array}{l}\text { Understanding of forecast uncertainty } \\
\text { (probability/percentage) }\end{array}$ & & & \\
\hline $\begin{array}{l}\text { Knowledge on rainfall variability/distribution across } \\
\text { communities }\end{array}$ & & & \\
\hline
\end{tabular}


11. How many people were you able to share your knowledge and data within your community?

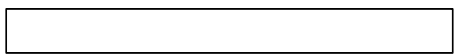

12. What changes are necessary to improve the co-production work in the future? (Tick as many options)

Integrate more farmers and extension officers in the co-production process

_Add long-term forecasts: seasonal rainfall, dry spell and onset information

Improve maintenance of the tools (phones, battery, chargers, rain gauge).

Provide more detailed forecasts (per community).

_. Allow the possibility to save farmers' observations offline (when the internet is unstable).

Share local knowledge observations to the WhatsApp

Improve internet connection

_ Update the web weather app a mobile app

Improve internet connection

__Update the web weather app a mobile app

_ Discuss further indicators/observations used for prediction on the WhatsApp page

_Other changes (please, specify)

13. Are you likely to continue with the co-production project in the future?

Very likely $1 \square 2 \square 3 \quad \square 4 \square 5 \square$ very unlikely

(If there is continuous support for the maintenance of the phone and the internet data)

Very likely $1 \square 2 \square 3 \square 4 \square 5 \square$ very unlikely

(If I have to use and maintain my smartphone and internet data)

14. Please provide any other general feedback to the WaterApps co-production experiment?

Thank you for your time 
Figure 5b. Interfaced of Weather App: Used to collect real-time local farmers indicators/forecasts and data at remote locations

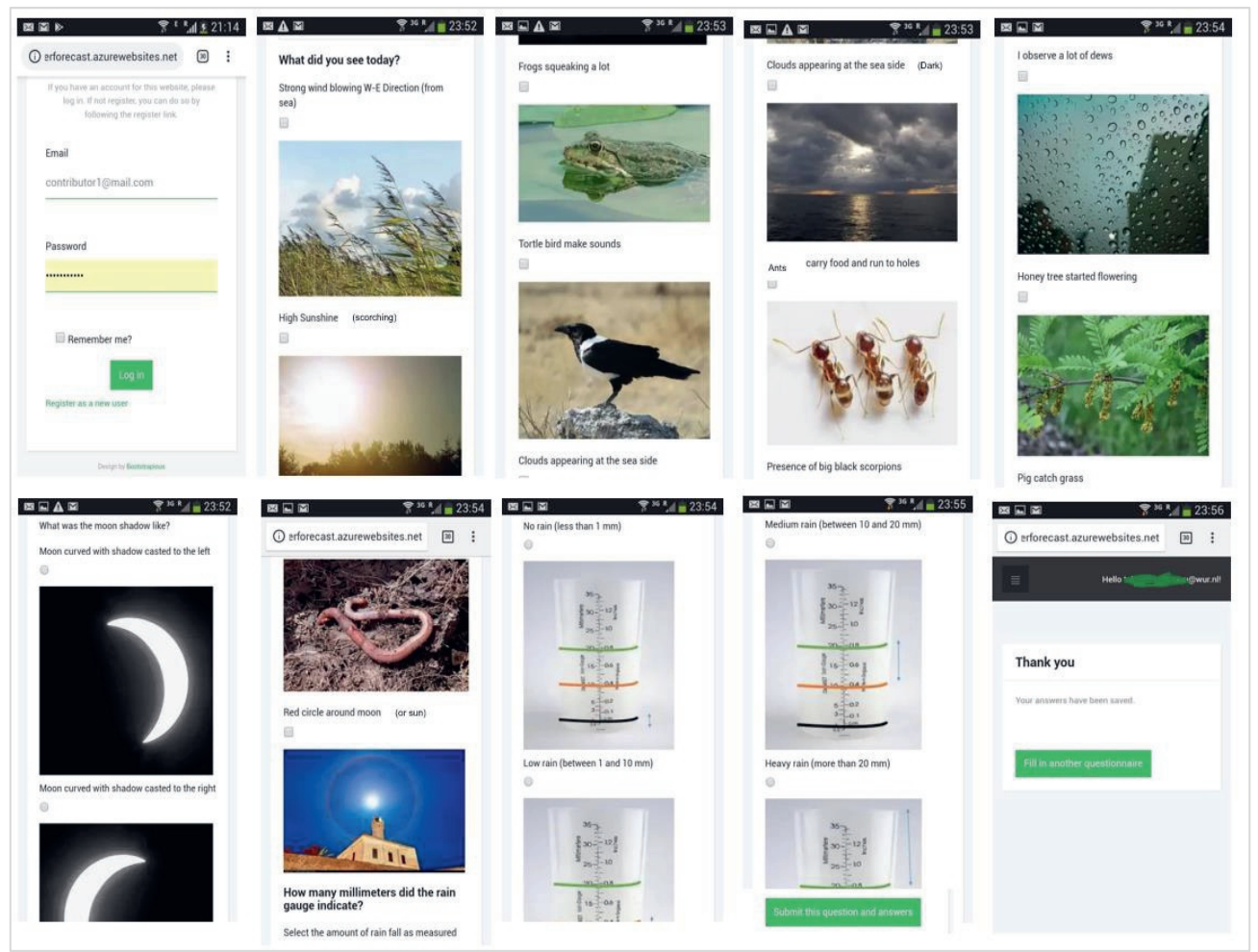


Figure 5c. Fig. S2: Interface of the WhatsApp : Used to interact to share local \& scientific forecasts

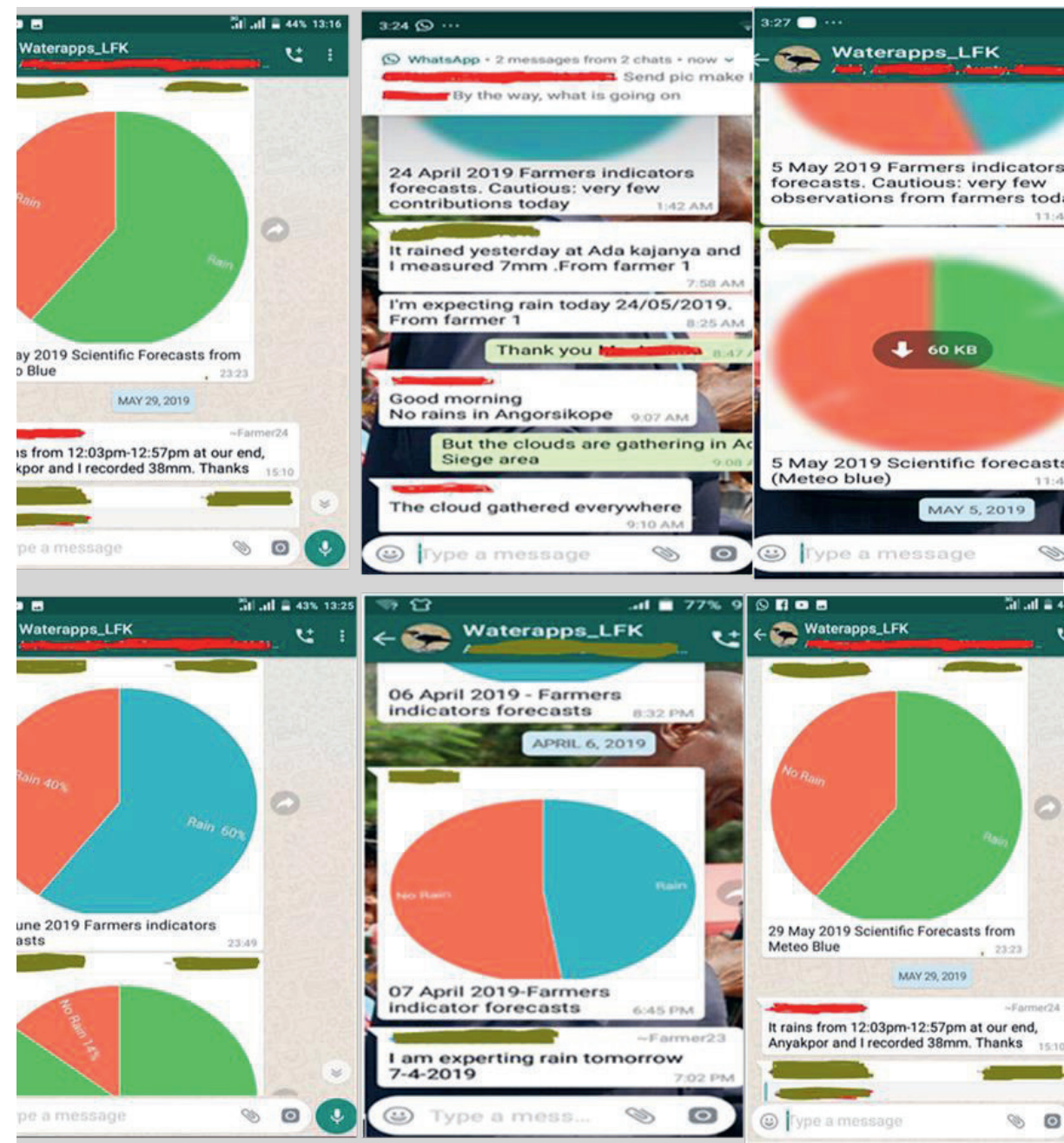


Figure 5d. Example of rain gauged used by a farmer to measure rainfall occurrence during the data collection period.
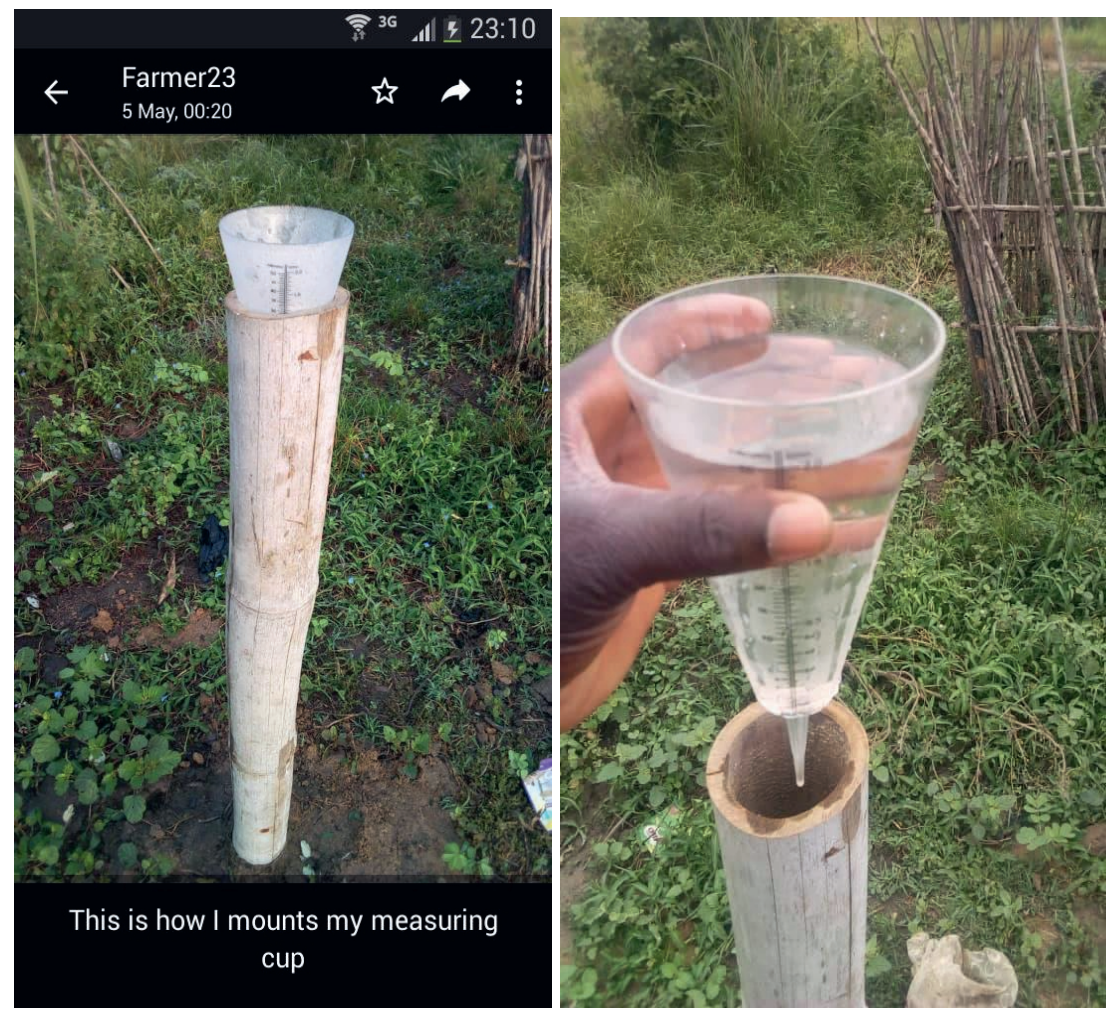

Daily rainfall is recorded at 9 AM. Rainfall occurrence is defined as rainfall record more than 1 $\mathrm{mm}$ and is based on the average rainfall collected from all stations/communities. 
Figure 5e. Sample of the smartphones used by farmers and agricultural extension agents

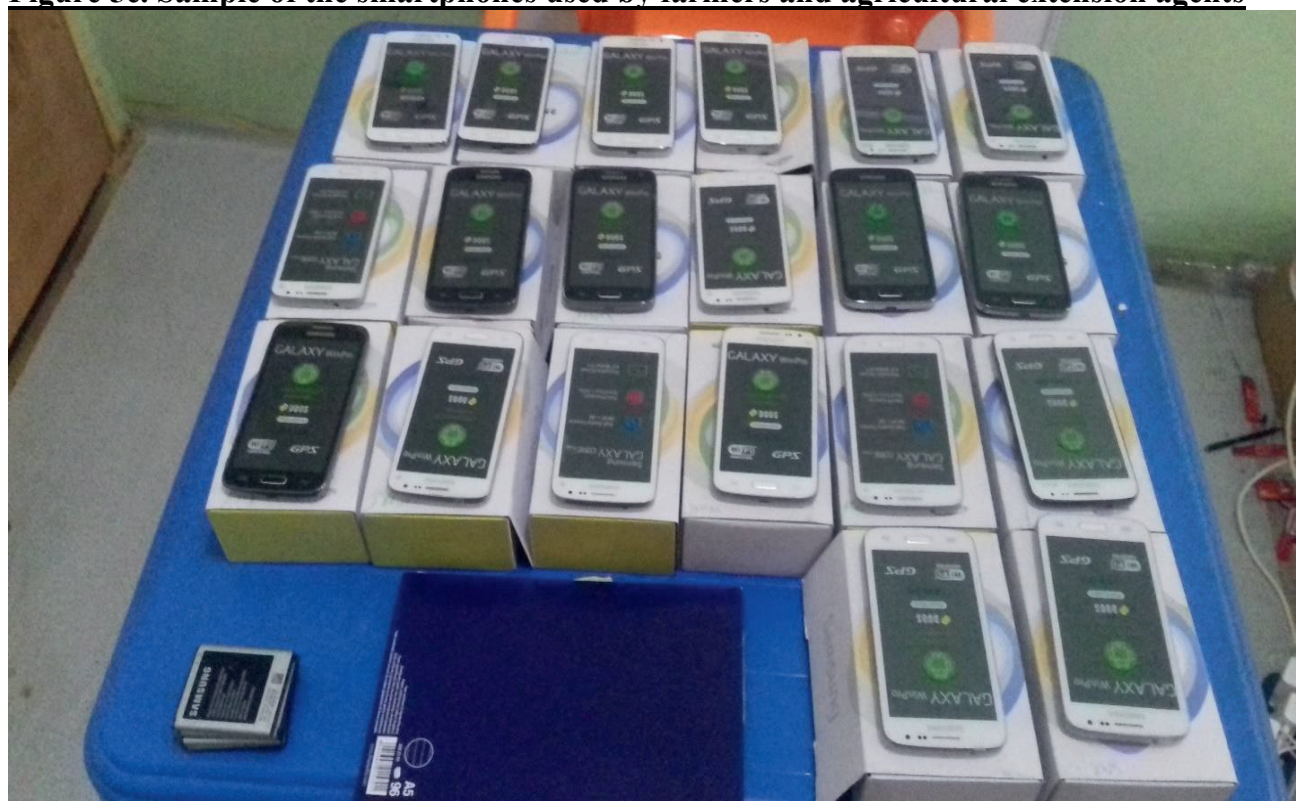

Appendix 5f. Emojis shared in the WhatsApp group
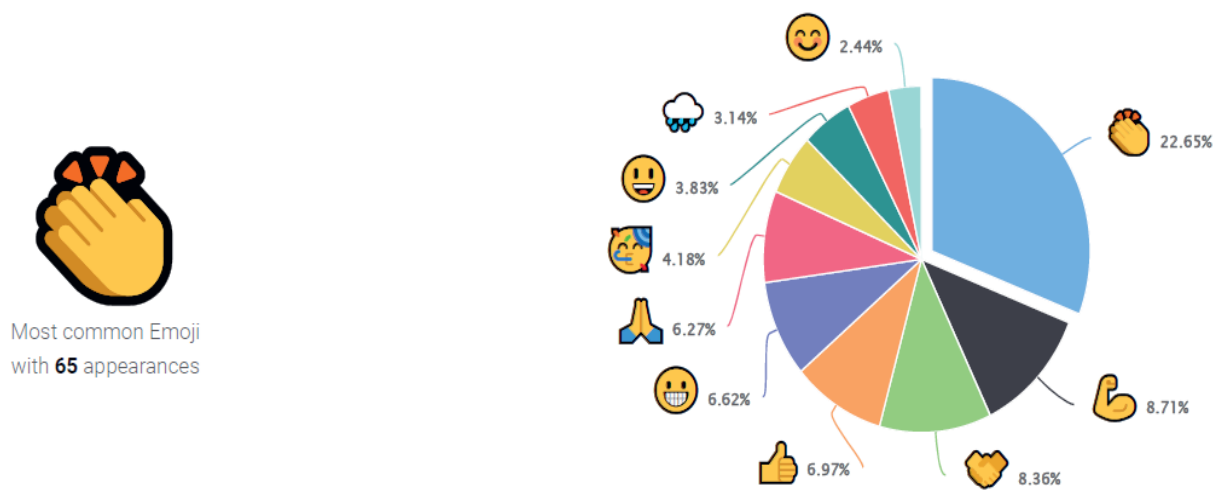
Table 5g: Bio-data on farmers who participated in the experimental research

\begin{tabular}{|l|l|l|l|l|}
\hline $\begin{array}{l}\text { Farmer } \\
\text { identity code }\end{array}$ & Age range & Gender & Level of Education & literacy level \\
\hline 1 & $25-40$ & Male & Senior-high-school & Literate \\
\hline 2 & $40-64$ & Male & Senior-high-school & Literate \\
\hline 3 & $25-40$ & Female & Non-formal education & Non-formal education \\
\hline 4 & $25-40$ & Male & Senior-high-school & Literate \\
\hline 5 & $40-64$ & Male & Senior-high-school & Literate \\
\hline 6 & $40-64$ & Male & Senior-high-school & Literate \\
\hline 7 & $25-40$ & Male & Senior-high-school & Literate \\
\hline 8 & $25-40$ & Male & Senior-high-school & Literate \\
\hline 9 & $25-40$ & Male & Senior-high-school & Literate \\
\hline 10 & $40-64$ & Male & Senior-high-school & Literate \\
\hline 11 & $25-40$ & Female & Senior-high-school & Literate \\
\hline 12 & $40-64$ & Male & Senior-high-school & Literate \\
\hline 13 & $40-64$ & Female & Non-formal education & Non-formal education \\
\hline 14 & $40-64$ & Male & Primary & Non-formal education \\
\hline 15 & $40-64$ & Female & Senior-high-school & Literate \\
\hline 16 & $40-64$ & Male & Non-formal education & Non-formal education \\
\hline 17 & $25-40$ & Male & Senior-high-school & Literate \\
\hline 18 & $40-64$ & Male & Senior-high-school & Literate \\
\hline 19 & $40-64$ & Male & Senior-high-school & Literate \\
\hline 20 & $40-64$ & Male & Middle school & Literate \\
\hline 21 & $40-64$ & Male & Senior-high-school & Literate \\
\hline 22 & $25-40$ & Male & Senior-high-school & Literate \\
\hline
\end{tabular}

Table 5h: Information on agri/meteo extension agents' participation in the research and evaluation

\begin{tabular}{|l|l|l|}
\hline $\begin{array}{l}\text { Number of agricultural extension } \\
\text { agents }\end{array}$ & Age & Sex \\
\hline 1 & $25-40$ & Male \\
\hline 2 & $25-40$ & Male \\
\hline 3 & $25-40$ & Male \\
\hline 4 & $40-64$ & Male \\
\hline 5 & $25-40$ & Male \\
\hline 6 & $40-64$ & Male \\
\hline
\end{tabular}


Table 5i: Summary of local forecast indicators for daily rainfall forecast in the WeatherApp

Table 5i: List of the local forecast indicators for the daily rainfall forecast at Ada East district used in the WeatherApp

\begin{tabular}{|c|c|}
\hline Indicators name & Indicator' signal used for daily rainfall prediction \\
\hline Wind & $\begin{array}{l}\text { When strong winds blow from the sea (usually from West to East } \\
\text { direction) } \\
\text { When the wind is blowing from the sea carrying dust (West-East } \\
\text { direction) with high intensity of the sun }\end{array}$ \\
\hline $\begin{array}{l}\text { Halo (around the } \\
\text { Sun) }\end{array}$ & If at sunset there is a red circle around the sun \\
\hline Sun & $\begin{array}{l}\text { If high intensity of sunshine is observed } \\
\text { If high intensity of sunshine and dust-wind blowing (from West to } \\
\text { East) is observed }\end{array}$ \\
\hline $\begin{array}{l}\text { Bird (Torle, Ploceus } \\
\text { cucullatus) }\end{array}$ & Make a lot of sounds \\
\hline Frog & When frogs start croaking a lot \\
\hline Pig & When pigs catch the grass and turning around it \\
\hline Moon (distribution) & $\begin{array}{l}\text { When the moon shape is curved such that the shadow is on the left side } \\
\text { When the moon shape is curved such that the shadow is on the right } \\
\text { side }\end{array}$ \\
\hline Worm (Abobortele) & Spread all over the grass after a previous rain \\
\hline Scorpion & When big black scorpions appear frequently on the farm \\
\hline Clouds & A thick cloud appears at the eastern side of the sea \\
\hline Ants & Carry their food or eggs to their holes \\
\hline Dew & $\begin{array}{l}\text { If from mid-night to the following morning there is a lot of dews } \\
\text { falling }\end{array}$ \\
\hline
\end{tabular}


Table 5j: Information on farmers on participated in the evaluation of the co-produced information

\begin{tabular}{|l|l|l|l|}
\hline Interview & Age range & Sex & School-level \\
\hline 1 & $25-40$ & Male & Senior High school \\
\hline 2 & $40-64$ & Male & Senior High school \\
\hline 3 & $25-40$ & Female & Nonformal education \\
\hline 4 & $25-40$ & Male & Senior High school \\
\hline 5 & $40-64$ & Male & Senior High school \\
\hline 6 & $40-64$ & Male & Senior High school \\
\hline 7 & $25-40$ & Male & Senior High school \\
\hline 8 & $25-40$ & Male & Senior High school \\
\hline 9 & $25-40$ & Male & Senior High school \\
\hline 10 & $40-64$ & Male & Senior High school \\
\hline 11 & $25-40$ & Female & Senior High school \\
\hline 12 & $40-64$ & Male & Senior High school \\
\hline 13 & $40-64$ & Male & Nonformal education \\
\hline 14 & $40-64$ & Male & Primary school \\
\hline 15 & $40-64$ & Female & Senior High school \\
\hline 16 & $40-64$ & Male & Nonformal education \\
\hline 17 & $25-40$ & Male & Senior High school \\
\hline
\end{tabular}

Table 5k: Count of messages, pictures and emojis exchanged via the WhatsApp group

\begin{tabular}{llll}
\hline Months & Messages & $\begin{array}{l}\text { Pictures/Graphs } \\
\text { (forecasts) }\end{array}$ & Emojis exchanges \\
\hline April & 164 & 33 & 92 \\
May & 324 & 70 & 103 \\
June & 154 & 61 & 62 \\
July & 93 & 35 & 30 \\
Total (5 $5^{\text {th }}$ April- $17^{\text {th }}$ July 2019) & 736 & 199 & 287 \\
\hline
\end{tabular}


Table 5l: Farming decisions that were made using the forecasts and data

Table $5 \mathrm{~h}$ provides analysis on decisions-making with the co-produced information. It gives the percentage of decisions that were more of interest by the 28 participants (22 Farmers and 6 extension agents).

\begin{tabular}{llllllll}
\hline & $\begin{array}{l}\text { Prepare } \\
\text { land }\end{array}$ & $\begin{array}{l}\text { Amount } \\
\text { of water to } \\
\text { allocate }\end{array}$ & $\begin{array}{l}\text { Seeding/ } \\
\text { transplan } \\
\mathrm{t}\end{array}$ & Fertilizing & $\begin{array}{l}\text { Pesticide } \\
\text { applicati } \\
\text { on }\end{array}$ & $\begin{array}{l}\text { Labor/we } \\
\text { eding }\end{array}$ & $\begin{array}{l}\text { Othe } \\
\text { rs }\end{array}$ \\
\hline $\begin{array}{l}\text { Rainfall } \\
\text { monitoring data }\end{array}$ & $\mathbf{6 4 \%}$ & $29 \%$ & $\mathbf{6 8 \%}$ & $\mathbf{6 4 \%}$ & $50 \%$ & $\mathbf{6 1 \%}$ & $50 \%$ \\
$\begin{array}{l}\text { Daily forecasts } \\
\text { from farmers }\end{array}$ & $50 \%$ & $25 \%$ & $\mathbf{5 7 \%}$ & $50 \%$ & $46 \%$ & $46 \%$ & $50 \%$ \\
$\begin{array}{l}\text { Daily forecasts } \\
\text { from scientific } \\
\text { models } \\
\text { (meteoblue) }\end{array}$ & $\mathbf{5 7 \%}$ & $29 \%$ & $\mathbf{6 1 \%}$ & $\mathbf{5 7 \%}$ & $46 \%$ & $46 \%$ & $50 \%$ \\
\hline
\end{tabular}

Table 5m: Significance of the results on the engagement, usability, usefulness, understanding and decisions improvement when considering a binomial distribution for the medium and high categories of responses. (for farmers)

\begin{tabular}{|c|c|c|c|c|c|c|c|c|c|}
\hline $\begin{array}{c}\text { Eval } \\
\text { uatio } \\
\mathrm{n} \\
\text { metri } \\
\mathrm{cs}\end{array}$ & $\begin{array}{l}\text { Digital } \\
\text { items or } \\
\text { tools }\end{array}$ & $\begin{array}{c}\text { Category } \\
\text { Level }\end{array}$ & $\begin{array}{l}\text { Functi } \\
\text { onality }\end{array}$ & $\begin{array}{l}\text { Numb } \\
\text { er of } \\
\text { succe } \\
\text { ss }\end{array}$ & $\begin{array}{c}\text { Total } \\
\text { numb } \\
\text { er of } \\
\text { farme } \\
\text { rs }\end{array}$ & $\begin{array}{c}\text { Prob } \\
\text { abilit } \\
y\end{array}$ & $\begin{array}{c}\text { Succ } \\
\text { ess } \\
\text { Prob } \\
\text { abilit } \\
\text { y }\end{array}$ & $\begin{array}{c}\mathrm{p}- \\
\text { value }\end{array}$ & $\begin{array}{c}\text { Sign } \\
0.1 \\
(+) \\
0.05 \\
(*) ; \\
0.01 \\
(* *) \\
0.001 \\
(* * *)\end{array}$ \\
\hline $\begin{array}{l}\text { Enga } \\
\text { geme }\end{array}$ & & $\begin{array}{l}\text { Medium and } \\
\text { High }\end{array}$ & & 15 & 22 & 0.5 & $\begin{array}{l}0.97 \\
3761\end{array}$ & $\begin{array}{c}0.0262 \\
39\end{array}$ & $*$ \\
\hline nt & & Low & & 7 & 22 & 0.5 & $\begin{array}{c}0.06 \\
69\end{array}$ & 0.9331 & \\
\hline \multirow[t]{5}{*}{$\begin{array}{l}\text { Usab } \\
\text { ility }\end{array}$} & \multirow{2}{*}{$\begin{array}{c}\text { WeatherA } \\
\text { pp (After } \\
\text { experime } \\
\text { nt) }\end{array}$} & $\begin{array}{c}\text { Somehow and } \\
\text { Very easy }\end{array}$ & \multirow[t]{2}{*}{$\begin{array}{l}\text { Manip } \\
\text { ulation }\end{array}$} & 16 & 22 & 0.5 & $\begin{array}{l}0.99 \\
155 \\
\end{array}$ & $\begin{array}{c}0.0084 \\
5\end{array}$ & $* *$ \\
\hline & & $\begin{array}{c}\text { Not easy and } \\
\text { NA }\end{array}$ & & 6 & 22 & 0.5 & $\begin{array}{l}0.02 \\
6239\end{array}$ & $\begin{array}{c}0.9737 \\
61\end{array}$ & \\
\hline & \multirow{2}{*}{$\begin{array}{l}\text { WhatsAp } \\
\mathrm{p} \text { (After } \\
\text { experime } \\
\mathrm{nt})\end{array}$} & $\begin{array}{c}\text { Somehow and } \\
\text { Very easy }\end{array}$ & \multirow[t]{2}{*}{ Graphs } & 16 & 22 & 0.5 & $\begin{array}{c}0.99 \\
155\end{array}$ & $\begin{array}{c}0.0084 \\
5\end{array}$ & $* *$ \\
\hline & & $\begin{array}{c}\text { Not easy and } \\
\text { NA }\end{array}$ & & 6 & 22 & 0.5 & $\begin{array}{l}0.02 \\
6239\end{array}$ & $\begin{array}{c}0.9737 \\
61\end{array}$ & \\
\hline & $\begin{array}{c}\text { Rain } \\
\text { gauges }\end{array}$ & $\begin{array}{c}\text { Somehow and } \\
\text { Very easy }\end{array}$ & $\begin{array}{l}\text { Reporti } \\
\text { ng }\end{array}$ & 15 & 22 & 0.5 & $\begin{array}{l}0.97 \\
3761 \\
\end{array}$ & $\begin{array}{c}0.0262 \\
39 \\
\end{array}$ & $*$ \\
\hline
\end{tabular}




\begin{tabular}{|c|c|c|c|c|c|c|c|c|c|}
\hline & $\begin{array}{c}\text { (After } \\
\text { experime } \\
n t)\end{array}$ & $\begin{array}{c}\text { Not easy and } \\
\text { NA }\end{array}$ & & 7 & 22 & 0.5 & $\begin{array}{c}0.06 \\
69\end{array}$ & 0.9331 & \\
\hline \multirow{16}{*}{$\begin{array}{c}\text { Usef } \\
\text { ulnes } \\
\text { s/Rel } \\
\text { evan } \\
\text { ce }\end{array}$} & \multirow[t]{10}{*}{ Tools } & $\begin{array}{c}\text { Somehow and } \\
\text { Very } \\
\text { Relevant }\end{array}$ & $\begin{array}{c}\text { Interne } \\
\mathrm{t}\end{array}$ & 14 & 22 & 0.5 & $\begin{array}{c}0.93 \\
31\end{array}$ & 0.0669 & + \\
\hline & & $\begin{array}{c}\text { Not Relevant } \\
\text { and NA }\end{array}$ & & 8 & 22 & 0.5 & $\begin{array}{r}0.14 \\
3139 \\
\end{array}$ & $\begin{array}{c}0.8568 \\
61 \\
\end{array}$ & \\
\hline & & $\begin{array}{c}\text { Somehow and } \\
\text { Very } \\
\text { Relevant } \\
\end{array}$ & $\begin{array}{l}\text { Rain } \\
\text { gauge }\end{array}$ & 18 & 22 & 0.5 & $\begin{array}{l}0.99 \\
9572\end{array}$ & $\begin{array}{c}0.0004 \\
28\end{array}$ & $* * *$ \\
\hline & & $\begin{array}{c}\text { Not Relevant } \\
\text { and NA }\end{array}$ & & 5 & 22 & 0.5 & $\begin{array}{l}0.00 \\
845\end{array}$ & $\begin{array}{c}0.9915 \\
5\end{array}$ & \\
\hline & & $\begin{array}{c}\text { Somehow and } \\
\text { Very } \\
\text { Relevant }\end{array}$ & $\begin{array}{l}\text { Smartp } \\
\text { hone }\end{array}$ & 17 & 22 & 0.5 & $\begin{array}{l}0.99 \\
7828\end{array}$ & $\begin{array}{c}0.0021 \\
72\end{array}$ & $* *$ \\
\hline & & $\begin{array}{c}\text { Not Relevant } \\
\text { and NA }\end{array}$ & & 6 & 22 & 0.5 & $\begin{array}{r}0.02 \\
6239 \\
\end{array}$ & $\begin{array}{c}0.9737 \\
61 \\
\end{array}$ & \\
\hline & & $\begin{array}{c}\text { Somehow and } \\
\text { Very } \\
\text { Relevant }\end{array}$ & $\begin{array}{l}\text { Weath } \\
\text { erApp }\end{array}$ & 18 & 22 & 0.5 & $\begin{array}{r}0.99 \\
9572\end{array}$ & $\begin{array}{c}0.0004 \\
28\end{array}$ & $* * *$ \\
\hline & & $\begin{array}{c}\text { Not Relevant } \\
\text { and NA }\end{array}$ & & 5 & 22 & 0.5 & $\begin{array}{l}0.00 \\
845\end{array}$ & $\begin{array}{c}0.9915 \\
5\end{array}$ & \\
\hline & & $\begin{array}{c}\text { Somehow and } \\
\text { Very } \\
\text { Relevant } \\
\end{array}$ & $\begin{array}{l}\text { Whats } \\
\text { App }\end{array}$ & 16 & 22 & 0.5 & $\begin{array}{c}0.99 \\
155\end{array}$ & $\begin{array}{c}0.0084 \\
5\end{array}$ & $* *$ \\
\hline & & $\begin{array}{c}\text { Not Relevant } \\
\text { and NA }\end{array}$ & & 7 & 22 & 0.5 & $\begin{array}{c}0.06 \\
69\end{array}$ & 0.9331 & \\
\hline & \multirow{6}{*}{$\begin{array}{l}\text { Informati } \\
\text { on and } \\
\text { data co- } \\
\text { produced }\end{array}$} & $\begin{array}{c}\text { Somehow and } \\
\text { Very } \\
\text { Relevant }\end{array}$ & $\begin{array}{c}\text { local } \\
\text { forecas } \\
t\end{array}$ & 18 & 22 & 0.5 & $\begin{array}{l}0.99 \\
9572\end{array}$ & $\begin{array}{c}0.0004 \\
28\end{array}$ & $* * *$ \\
\hline & & $\begin{array}{c}\text { Not Relevant } \\
\text { and NA }\end{array}$ & & 5 & 22 & 0.5 & $\begin{array}{l}0.00 \\
845\end{array}$ & $\begin{array}{c}0.9915 \\
5\end{array}$ & \\
\hline & & $\begin{array}{c}\text { Somehow and } \\
\text { Very } \\
\text { Relevant } \\
\end{array}$ & $\begin{array}{c}\text { rainfall } \\
\text { data }\end{array}$ & 18 & 22 & 0.5 & $\begin{array}{l}0.99 \\
9572\end{array}$ & $\begin{array}{c}0.0004 \\
28\end{array}$ & $* * *$ \\
\hline & & $\begin{array}{l}\text { Not Relevant } \\
\text { and NA }\end{array}$ & & 5 & 22 & 0.5 & $\begin{array}{l}0.00 \\
845\end{array}$ & $\begin{array}{c}0.9915 \\
5\end{array}$ & \\
\hline & & $\begin{array}{c}\text { Somehow and } \\
\text { Very easy }\end{array}$ & $\begin{array}{l}\text { Scienti } \\
\text { fic }\end{array}$ & 18 & 22 & 0.5 & $\begin{array}{l}0.99 \\
9572\end{array}$ & $\begin{array}{c}0.0004 \\
28\end{array}$ & $* * *$ \\
\hline & & $\begin{array}{c}\text { Not relevant } \\
\text { and NA }\end{array}$ & $\begin{array}{c}\text { forecas } \\
\mathrm{t}\end{array}$ & 5 & 22 & 0.5 & $\begin{array}{l}0.00 \\
845\end{array}$ & $\begin{array}{c}0.9915 \\
5\end{array}$ & \\
\hline $\begin{array}{l}\text { Unde } \\
\text { rstan } \\
\text { ding }\end{array}$ & $\begin{array}{c}\text { Forecast } \\
\text { uncertaint } \\
\mathrm{y}\end{array}$ & $\begin{array}{c}\text { Somehow and } \\
\text { highly } \\
\text { improved }\end{array}$ & & 18 & 22 & 0.5 & $\begin{array}{l}0.99 \\
9572\end{array}$ & $\begin{array}{c}0.0004 \\
28\end{array}$ & $* * *$ \\
\hline
\end{tabular}




\begin{tabular}{cccccccc}
\hline & $\begin{array}{c}\text { Not improve } \\
\text { and NA }\end{array}$ & 5 & 22 & 0.5 & 0.00 & 0.9915 & \\
& & & & & 845 & 5 & \\
\hline $\begin{array}{c}\text { Rainfall } \\
\text { distributio } \\
\mathrm{n}\end{array}$ & $\begin{array}{c}\text { Somehow and } \\
\text { highly } \\
\text { improved }\end{array}$ & 18 & 22 & 0.5 & 0.99 & 0.0004 & $* * *$ \\
& Not improve & & & & 9572 & 28 & \\
& and NA & 5 & 22 & 0.5 & 0.00 & 0.9915 & \\
\cline { 2 - 8 } & $\begin{array}{c}\text { Somehow and } \\
\text { highly } \\
\text { improved }\end{array}$ & 18 & 22 & 0.5 & 0.99 & 0.0004 & $* * *$ \\
& Decisions & & & & 9572 & 28 & \\
& Not improve & & & & & & \\
\hline & 5 & 22 & 0.5 & 0.00 & 0.9915 & \\
& & & & & 845 & 5 & \\
\hline
\end{tabular}

Table 5n: Significance of the results on the engagement, usability, usefulness, understanding and decisions improvement when considering a binomial distribution for the medium and high categories of responses. (for farmers)

\begin{tabular}{|c|c|c|c|c|c|c|c|c|c|}
\hline $\begin{array}{c}\text { Eval } \\
\text { uatio } \\
\mathrm{n} \\
\text { metri } \\
\text { cs }\end{array}$ & $\begin{array}{l}\text { Digital } \\
\text { items or } \\
\text { tools }\end{array}$ & $\begin{array}{c}\text { Category } \\
\text { Level }\end{array}$ & $\begin{array}{l}\text { Functi } \\
\text { onality }\end{array}$ & $\begin{array}{c}\text { Numb } \\
\text { er of } \\
\text { succe } \\
\text { ss }\end{array}$ & $\begin{array}{c}\text { Total } \\
\text { numb } \\
\text { er of } \\
\text { farme } \\
\text { rs }\end{array}$ & $\begin{array}{c}\text { Prob } \\
\text { abilit } \\
y\end{array}$ & $\begin{array}{c}\text { Succ } \\
\text { ess } \\
\text { Prob } \\
\text { abilit } \\
y\end{array}$ & $\begin{array}{c}\mathrm{p}- \\
\text { value }\end{array}$ & $\begin{array}{c}\text { Sign } \\
0.1 \\
(+) \\
0.05 \\
(*) ; \\
0.01 \\
(* *) \\
0.001 \\
(* * *)\end{array}$ \\
\hline \multirow{7}{*}{$\begin{array}{c}\text { Usef } \\
\text { ulnes } \\
\text { s/Rel } \\
\text { evan } \\
\text { ce }\end{array}$} & \multirow[t]{7}{*}{ Tools } & $\begin{array}{c}\text { Somehow and } \\
\text { Very } \\
\text { Relevant }\end{array}$ & $\begin{array}{c}\text { Interne } \\
t\end{array}$ & 3 & 6 & 0.5 & $\begin{array}{l}0.65 \\
625\end{array}$ & $\begin{array}{c}0.3437 \\
5\end{array}$ & \\
\hline & & $\begin{array}{c}\text { Not Relevant } \\
\text { and NA }\end{array}$ & & 3 & 6 & 0.5 & $\begin{array}{l}0.65 \\
625 \\
\end{array}$ & $\begin{array}{c}0.3437 \\
5\end{array}$ & \\
\hline & & $\begin{array}{c}\text { Somehow and } \\
\text { Very } \\
\text { Relevant }\end{array}$ & $\begin{array}{l}\text { Rain } \\
\text { gauge }\end{array}$ & 4 & 6 & 0.5 & $\begin{array}{l}0.89 \\
0625\end{array}$ & $\begin{array}{c}0.1093 \\
75\end{array}$ & + \\
\hline & & $\begin{array}{c}\text { Not Relevant } \\
\text { and NA }\end{array}$ & & 2 & 6 & 0.5 & $\begin{array}{l}0.34 \\
375\end{array}$ & $\begin{array}{c}0.6562 \\
5\end{array}$ & \\
\hline & & $\begin{array}{c}\text { Somehow and } \\
\text { Very } \\
\text { Relevant }\end{array}$ & $\begin{array}{c}\text { Smartp } \\
\text { hone }\end{array}$ & 6 & 6 & 0.5 & 1 & 0 & $* * *$ \\
\hline & & $\begin{array}{l}\text { Not Relevant } \\
\text { and NA }\end{array}$ & & 0 & 6 & 0.5 & $\begin{array}{l}0.01 \\
5625\end{array}$ & $\begin{array}{c}0.9843 \\
75\end{array}$ & \\
\hline & & $\begin{array}{c}\text { Somehow and } \\
\text { Very } \\
\text { Relevant }\end{array}$ & $\begin{array}{l}\text { Weath } \\
\text { erApp }\end{array}$ & 6 & 6 & 0.5 & 1 & 0 & $* * *$ \\
\hline
\end{tabular}




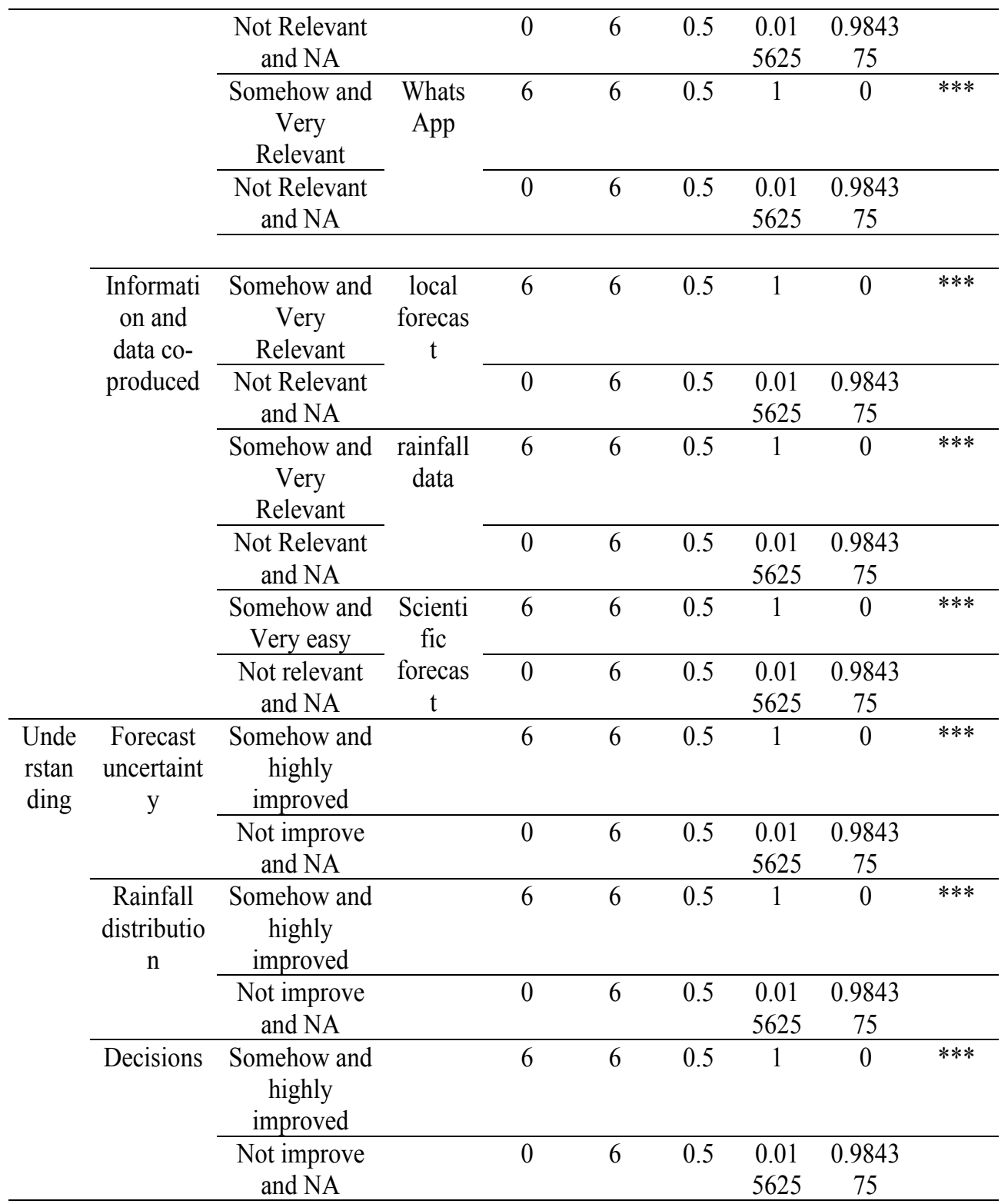

Table 50: Technical reports on issues by socio-demographic characteristics (age, gender and literacy)

Table 5o: Analysis of the technical issues reported by age, gender and literacy level from a total of 92 technical issues recorded during the testing phase.

Age $\quad$ Gender $\quad$ Literacy




\begin{tabular}{|c|c|c|c|c|c|c|}
\hline & $\begin{array}{c}\text { Young } \\
\text { farmers } \\
(<=49 \\
\text { years })\end{array}$ & $\begin{array}{l}\text { Elder } \\
\text { farmers } \\
(>=50)\end{array}$ & $\begin{array}{l}\text { M } \\
\text { al } \\
\mathrm{e}\end{array}$ & $\begin{array}{c}\mathrm{Fe} \\
\mathrm{ma} \\
\mathrm{le}\end{array}$ & $\begin{array}{l}\text { Primary } \\
\text { school and } \\
\text { below }\end{array}$ & $\begin{array}{c}\text { Secondary } \\
\text { School and } \\
\text { above }\end{array}$ \\
\hline Number of farmers & 12 & 10 & $\begin{array}{l}1 \\
8\end{array}$ & 4 & 5 & 17 \\
\hline $\begin{array}{l}\text { Technical issues reports } \\
\text { (smartphone use, apps, and } \\
\text { internet handling) }\end{array}$ & 35 & 57 & $\begin{array}{l}7 \\
6\end{array}$ & 16 & 27 & 65 \\
\hline $\begin{array}{c}\text { Technical difficulty ratio } \\
\text { (Total issues reported/Number } \\
\text { of farmers) }\end{array}$ & 2.92 & 5.7 & $\begin{array}{l}4 . \\
2 \\
2\end{array}$ & $\begin{array}{c}4.0 \\
0\end{array}$ & 5.40 & 3.82 \\
\hline
\end{tabular}

\section{Figure 5p: FarmerSupport APP under development}

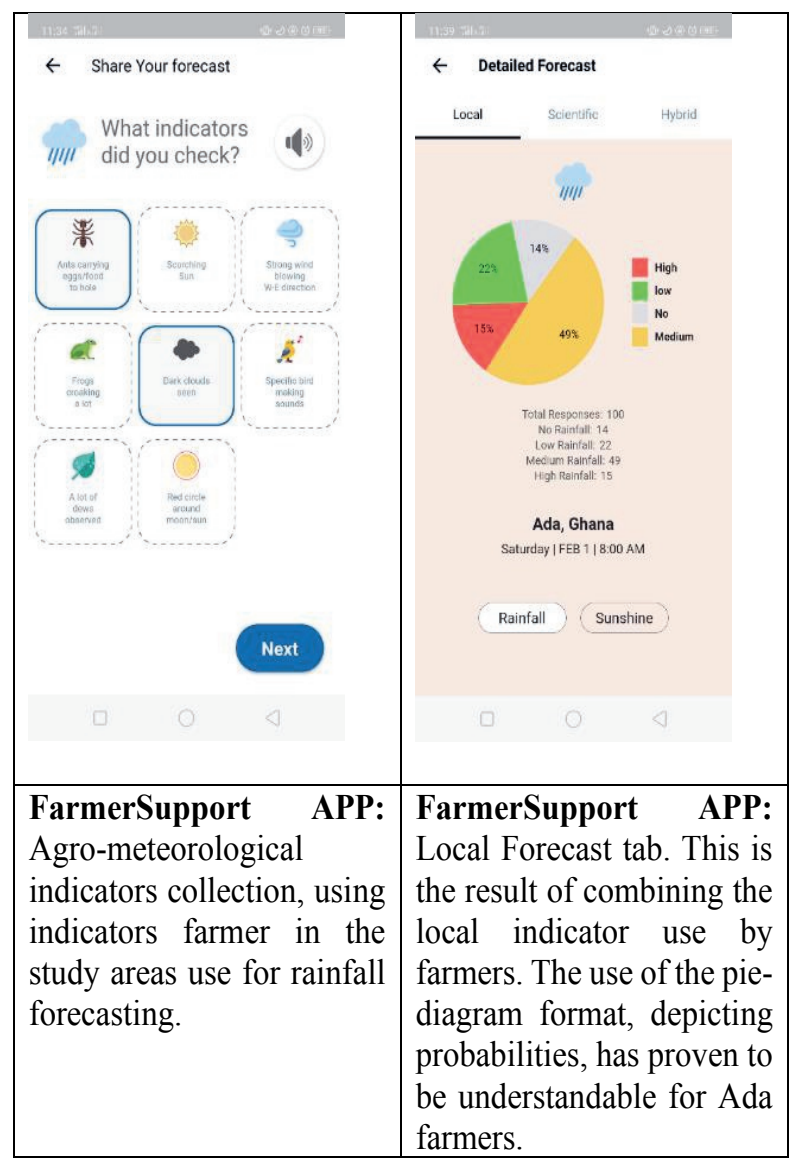




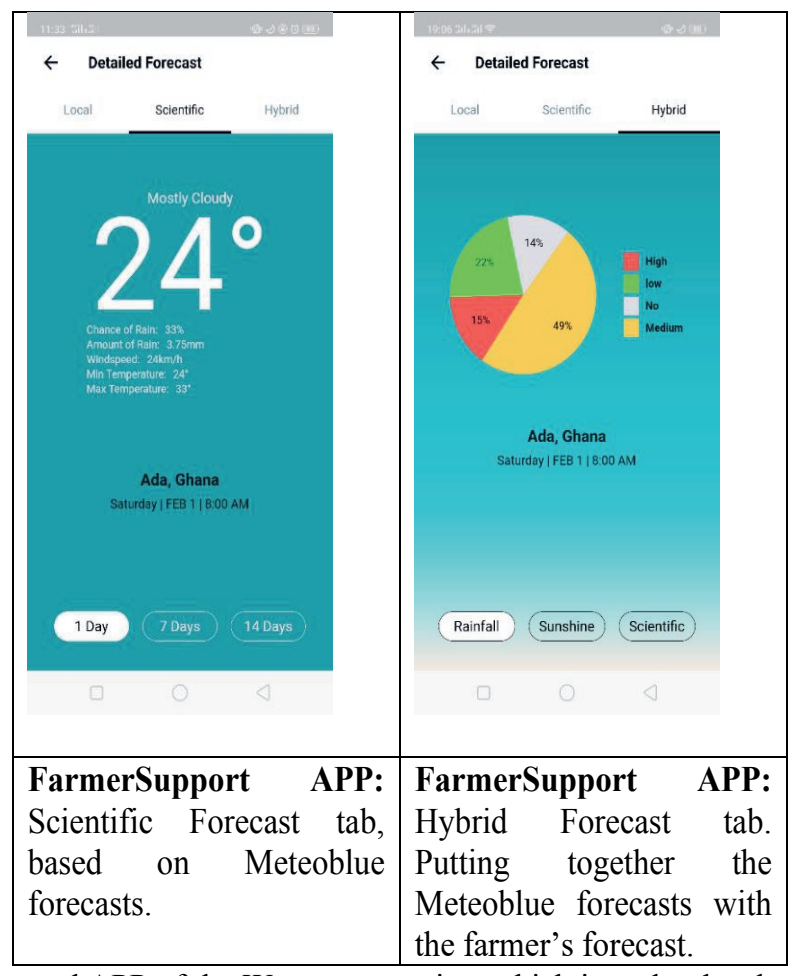

Details on the integrated APP of the Waterapps project which is under development can be found with the following link: https://xd.adobe.com/view/5fba136b-79e2-4793-5d9f-e8c8dfc3be71298b/?fullscreen 


\section{Supplementary Material-E}

Belonging to Chapter 6: Beyond 'experts knowledge': Locals and experts in a joint production of weatherApp and weather information for farming in the Volta Delta, Ghana Appendix 6a: semi-structured interview guide for farmers

Introduction to the interview

Note down: date and time of interview \& name of the interviewee

A brief explanation of the interview structure (questions and time)

Ask for consent to record the interview

\section{Motivation}

- Can you briefly describe your data collection pattern during the period of the research?

- Provide reasons why you abandoned or submitted data only on a specific period during the data collection phase of the research?

- What is your view/experience about the weatherapp project?

- How would you describe your task? Was it difficult or not?

- What motivated you to participate in this project?

- Which motivations were very relevant to your contribution to data collection

- Did any of the motivations change during data collection?

- Frequency of farmer participation during the period (experimental/actual season): Never, Less than once a month, Once a week, 2-3 times a week, daily and discontinued.

i. Sending information about a rainfall indicator

ii. Sending information about no rainfall indicator

iii. Sending information on rainfall record

iv. Sending information on the certainty of the prediction

v. Attending all workshops related to the weather apps

\section{Local forecasting knowledge}

- What type of indicator do you often send and why?

- Which indicator(s) did you spot but could send because we could not capture it in the App?

- Which of the indicators are mostly realised? Did it cause you to disregard other indicators on the app?

- What did you learn from collaborating with this project as a provider of local indicators?

- Did you feel your forecasting skills have improved? (Provide reasons)

\section{Challenges}

- What are the challenges associated with them: 1. project, 2. workshop, 3. the use of the smartphone, 4. WhatsApp, 5. rain gauge, and 6. researchers?

- How did any of these challenges affect your motivation and participation in data collection?

\section{Considerations for the continuation of the project in the future}

- Apart from WhatsApp and the App, what other mode could have worked for you?

- Would you want to pay for weather information? Provide reasons for your answer.

Thank you 
Summary of thesis 
Farming in developing countries is currently challenged by socio-environmental conditions, especially climate change, climate variability, and water scarcity amidst pressure to intensify production to meet increasing demand. This situation applies to farming in Ghana's Volta Delta, specifically the Ada East District, where food crop cultivation is dependent on rainfall, with limited irrigation facilities to support demand from urban markets. Recent trends in the occurrence of rainfall in the farming seasons in the delta region show the early onset of rainfall, early cessation of rainfall, prolong dry spell length during the farming season, short duration of the rainfall season, and too little or too much rainfall. The variability in rainfall conditions, including the limited availability of irrigation facilities for farming in the area, creates uncertainty in farmers' decisionmaking and practices concerning when to plough, when to sow seeds, crop selection and related variety, when to apply agrochemicals, and when to harvest. The uncertainty characterising farmers' decision-making has necessitated the application of weather information to ascertain when relevant decisions can be made. However, the available weather information is unusable for decisionmaking in farming because of factors arising from the farming context and because information providers are unable to meet certain design and delivery criteria. The reason for this failure is attributed to the fact that users are not included throughout the information production and delivery chain. In view of this shortfall, several studies have suggested the need to provide usable information for farming through a co-production approach that involves users at various stages, thereby leading to ownership of information and the integration of farmers' local knowledge and experience in the process of creating a weather information service (WIS).

Following this notion, this thesis examined how weather information can be made usable under uncertain conditions through the co-production of weather information with farmers in the Ada East District in Ghana. I formulated four research sub-questions to address the objective of the thesis. They are:

RQ1: Through what hybrid informational governance arrangements are weather information services provided, and with what effects?

RQ2: What flexible or robust decision-making strategies are applied to deal with uncertain weather conditions in farming?

RQ3: To what extent are existing weather information services usable for farming and what is required to enhance their usability?

RQ4: How can WIS be co-produced through the integration of scientific and local knowledge and what motivates farmers to participate in co-producing WIS?

The thesis adopts a transdisciplinary approach and a case study research design strategy. It employs qualitative research methods such as focus group discussions, interviews, workshops, and observations. The thesis comprises seven chapters; in Chapters 1 and 7, respectively, general background information and a synthesis of the major findings are provided. The four research subquestions are interrogated in Chapters 2-6. RQ1, RQ2, and RQ3 are addressed in Chapters 2, 3, and 4, respectively, and the answers to RQ4 are provided in Chapters 5 and 6.

Until recently, public information services have been provided solely by government organisations. With the advent of ICTs, public policy reforms, and increasing demand for information services, non-state organisations have now become involved in information provision. This has led to a variety of hybrid arrangements for information service delivery. Hence, in Chapter 2, I examined the informational governance arrangements resulting from the use of information and communication technology (ICT) to provide WIS for farming in the Ada East District, Ghana. I 
did this by first introducing a new conceptual framework for the study that links theories of informational governance, hybrid organisations, and hybrid governance. In the framework, I distinguished three forms of hybrid governance: 1) multiplicity, when multiple information services are provided in a complementary manner by government, business, and civil society organisations (CSOs); 2) intertwinement, when information services are jointly provided by organisations from two or three sectors; 3 ) coalescence, when there is a merger of roles, practices, and institutional logic from organisations from different sectors to form a new innovative entity or organisation. Findings from this chapter show that ICTs have enabled the provision of multiple WIS that vary in coverage, timing, and content. The use of ICTs seems to have led to intertwinement rather than separation among government, business, and CSOs in the delivery of WIS, combining technologies such as radio, mobile phones, SMS, call centres, and interactive voice response. ICTs have also played a role in promoting the coalescence of organisations from different sectors. ICT-enabled flows of weather information across scales, for example from international non-state organisations to farming communities in the study district, led to situations in which information bypassed national and district-level government organisations. Non-state organisations complemented or in some cases outplayed government organisations' role in information provision. However, government organisations such as the Ghana Meteorological Agency, the Ghana Television Station, and the Department of Agriculture and Development Unit remained lead providers of WIS for farming. The chapter drew the conclusion that, besides ICTs, factors such as inadequate state funding, international donor funding availability, and the application of specific business models contributed to the emergence of hybrid informational governance in the case study area.

Having identified the provision of WIS across scales by a variety of information providers to farmers in the Ada East District, in Chapter 3 I sought to examine farmers' decision-making and its adaptiveness under uncertain conditions. To attain this objective, I developed an adaptive decision-making framework where I defined the concept as a pattern of decisions characterised by the application of decision options that are flexible, robust, or both, in response to uncertain sociotechnical-environmental conditions. I specified that, for decision-making to be considered adaptive, the application of flexible or robust decision-making should be responsive to variable conditions. The chapter reveals that farmers in the Ada East District apply different decisionmaking patterns in response to the variable rainfall conditions. Flexible adaptive decision-making strategies applied by farmers include switching dates for sowing seeds through a wait-and-see or delay strategy, muddling through the farming season with the application of various options, and alternative irrigation strategies. Robust adaptive decision-making strategies include the portfolio strategy of transplanting seedlings in batches, selection of robust (hardy) crops, and intercropping or diversification. Depending on how farmers select strategies in response to uncertain rainfall conditions, I argue that some strategies were more adaptive than others. The conclusion drawn from the findings of this chapter is that ideas of adaptive decision-making should be integrated into the design and implementation of climate-related agricultural projects.

Following Chapter 3, I adapted Dilling and Lemos' (2011) concept on useful and usable information to examine the extent to which the existing WIS are usable for farming in the Ada East District. In Chapter 4, information design and delivery criteria were conceptualised to serve as analytical criteria to assess WIS usability. First, the chapter reveals 10 different WIS in the Ada East District in Ghana. Overall, farmer-to-farmer weather information was used by all farmers, whereas other types of information had varying levels of use. I found that the usability of each type of information was affected by disparate factors such as the origin of weather information in the 
farming communities, high level of interaction, timing/schedule delivery of weather information, accessible for a diverse audience, accessible level and mode of payment, among other factors. In spite of the finding that farmer-to-farmer weather information was the most used information in the farming communities in the study district, its usability was still constrained by reliability and accuracy regarding local forecast information. Hence, farmers complement their own forecasts with information from various sources when the certainty of their local weather indicators was not easily ascertained. During this phase of the thesis, I realised that farmers' local knowledge and scientific forecasts jointly had the potential to enable the delivery of usable information for farming. I concluded this chapter by proposing the integration of local knowledge and scientific forecasts to enhance the usability of weather information through a co-production approach.

The literature too suggests that usable weather and climate information can be produced if forecast information is produced jointly by farmers and scientists. To test the hypothesis and derive design requirements for the provision of weather and climate information services, in Chapter $5 \mathrm{I}$ evaluated the outcomes of an experimental co-design and co-production of weather forecasts in the Ada East District, Ghana. The co-design was conducted through participatory workshops, and it involved eliciting ideas on farmers' local knowledge such as bird movements, flowering plants, the shape of the moon, sunshine intensity, and wind pattern, among other indicators. Farmers' local knowledge also included the certainty attached to each of the indicators and the expected amount of rainfall. I collected this information and digitally entered it into a webpage smartphone app for farmers to collect data on their local observations. The experiment involved a user-driven design and testing of ICT-based digital (smartphones and apps) and rainfall monitoring tools by 22 farmers. Subsequently, farmers collected data with the weather app installed on their smartphones and recorded data on the actual rainfall amount with a rain gauge during the 2018/2019 study period. I disseminated feedback on farmers' local forecasts and scientific forecasts through a WhatsApp page for discussion. The results showed a positive evaluation of the intervention, expressed by the level of engagement, the increase in usability of the tools and understanding of forecast uncertainty, outreach capacity with other farmers, and improved daily farming decisions. The success of the intervention was attributed to the iterative design process, as well as the training, monitoring, and technical support provided. The results also showed that farmers' involvement in a co-design process enabled farmers to make decisions concerning the design of their local weather indicators into a mobile app. Farmers have their preferences and choices related to local weather indicators, the organisation of data collection such as frequency and timings for submitting data, and the mode of receiving feedback. Farmers' involvement and active participation in the co-design process showed how their context-specific knowledge and skills can enable the co-production of weather and climate information. I concluded this chapter by indicating that the application of modern technology in a co-production process with targeted training and monitoring can improve smallholder farmers' access to, and use of, weather and climate forecast information.

In Chapter 6, I examined the engagement and motivation of farmers participating in citizen science research that involved the co-production of weather and climate information integrating local knowledge and scientific forecasts. Farmers' participation in the collection of local weather indicators during the co-production process was observed over the 2018/2019 period. Following this, a one-to-one interview was conducted with all 22 farmers who participated in this citizen science research. The findings reveal different levels of engagement in terms of frequency and longevity. In terms of data collection frequency, the study recorded three categories: regular data 
collectors, occasional data collectors, and no data collection. Overall, most farmers became regular data collectors from May-July, 2019; the study recorded only two drop-outs.

The findings from the chapter also revealed that farmers had a variety of motivations for participating in the study, and there were changes in motivation over time. The desire to learn about weather information and contribute to providing information to the farming community were initial motivational factors mentioned by most farmers. However, some farmers' motivations changed to include the need to understand the science inherent in weather forecasting, social recognition and acknowledgment of farmers' contributions, availability of local indicators, interaction with experts, and other factors. I categorised the motivational factors on a continuum ranging from intrinsic regulation and identified and integrated motivations on the one hand, to introjected and extrinsic regulation on the other hand. Overall, farmers' intrinsic motivations superseded their extrinsic motivations. This finding implies that it is likely that farmers can sustain data collection in the long term without any external rewards. Barriers affecting farmers' motivation include literacy and numeracy issues, smartphone phobias, lack of time and fatigue, logistical issues with smartphones, telecommunication network issues, and electricity or frequent power outages. The findings in this chapter provide lessons on how the citizen science methodology can be designed for long-term engagement, given the type of motivations identified. They also provide lessons on the need to boost participants' motivations towards intrinsically regulated motivations as a means to sustain and upscale this form of research in a different context. The motivational factors and barriers reported in this study should be considered in citizen science projects, especially when such projects involve the use of new technologies such as smartphones and other related ICTs. Citizen science research provided weather information that corroborated the certainty in other forecast systems. This resulted in WIS use for decision-making in farming. I conclude that this citizen science programme can potentially contribute to the co-production of weather and climate information in a rural context. In situations where weather equipment is not readily available or is expensive to install in rural communities, meteorological agencies may consider adopting this approach to engage residents to provide localised data to support the production of accurate weather and climate forecasts. 
About the author 


\section{About the author}

Rebecca Sarku was born on the 3rd July 1985 in Tema, Ghana. She hails from Peki-Dzake in the Volta Region of Ghana. She is a product of Mawuli School, Ho, where she had her Senior High School education. Upon completion, she gained admission to the Kwame Nkrumah University of Science and Technology to read Bachelor of Arts in Social Science (Geography and Rural Development). After graduating, Rebecca worked as a tutor at the Wenchi Secondary School for her national service program and taught geography at the Akim State College

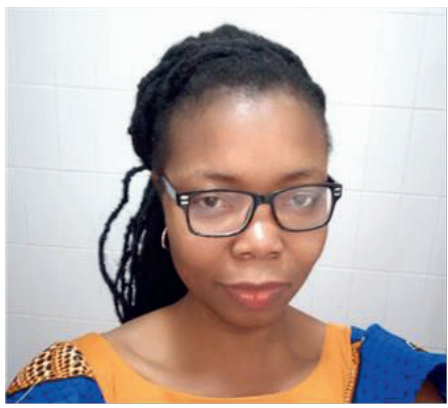
for a year.

In 2012, she started her Master of Philosophy degree program at the Department of Geography and Resource at the University of Ghana, Legon. She completed her Mphil studies in 2014 and was subsequently employed as a Teaching/Research Assistant in the same Department. Ever since, she has been involved in numerous research projects related to rural development, ICTs, agriculture and food security.

Rebecca was a Research Fellow at the Institute for Money, Technology, and Financial InclusionUniversity of California, sponsored by the Bill and Melinda Gate Foundation. Rebecca was a fellow of Sam Moyo African Institute for Agrarian Studies (SMAIAS) organised by Sam Moyo Agrarian Training Institute, the Food and Agriculture Organization of the United Nations (FAO) and the Agrarian South Network. She was also a fellow of African Women in Agricultural Research and Development (AWARD) and a recipient of the Orange Knowledge Program (OKP) scholarship.

In September 2016, Rebecca was admitted as a PhD Researcher at the Public Administration and Policy Group in the School of Social Science department of Wageningen University and Research under the Waterapps project funded by the Netherlands Organization for Scientific Research (NWO). Her study focuses on how to make weather and climate information usable for adaptive decision-making in an informational governance context. In her bid to contribute to knowledge in this sector, she was involved in developing weather and climate information, tailored for smallscale farming by combining scientific and local weather forecast knowledge with the aid of ICTs. Through this research, ICT tools and design principles have been generated to enable the coproduction of weather and climate information in other contexts. The design principles generated from her research is being tested in other regions in Ghana and Khulna-Bangladesh. She has been a recipient of several awards including travel grants to attend conferences and seminars to present her innovation. Notable among them is the Climate change Adaptation Futures Conference in Cape Town, South Africa and the Africa Climate Information Service innovation day at Addis Ababa, Ethiopia. Rebecca's research interest lies in climate change adaptation, climate information services, participatory research approaches, designing of governance arrangement and adaptive decision-making for food system and rural development. She aims to continue her research innovations towards enhancing the usability of climate information services and climate science among various actors in the rural and agricultural sectors. 


\section{List of publications}




\section{List of publications}

1. Sarku, R., van Slobbe, E., Siwale, A., Chudaska, R., Teermer, K. \& Dewulf, A. (2021). Tracing hybridity in the provision of ICT-enabled agricultural weather information services in Ghana. Journal of Agricultural and Food Information. doi.org/10.1080/10496505.2021.1874388

2. Sarku, R., Gbangou, T., Dewulf, A. \& Van Slobbe, E. (2020b). Beyond 'experts knowledge': Locals and experts in a joint production of weatherapp and weather information for farming in the Volta Delta, Ghana. Springer Nature, Handbook of Climate Change Management: Research, Leadership, Transformation. doi.org/10.1007/978-3-030-22759-3_114-1

3. Sarku, R., Dewulf, A., Slobbe, V.E, Termeer, K., \& Kranjac-Berisavljevic, G. (2020a). Adaptive decision-making under conditions of uncertainty: the case of farming in the Volta delta, Ghana, Journal of Integrative Environmental Sciences, 17(1), 1-33. doi:10.1080/1943815x.2020.1729207

4. Gbangou, T., Sarku, R., Slobbe, E.V., Ludwig, F., Kranjac-Berisavljevic, G. \& Paparrizos, S. (2020b). Coproducing Weather Forecast Information with and for Smallholder Farmers in Ghana: Evaluation and Design Principles. Atmosphere, 11, 902. doi:10.3390/atmos11090902

5. Sarku, R., van Slobbe, E., Termeer, K., Kranjac-Berisavljevic, G. \& Dewulf, A. (forthcoming). Assessing the usability of weather information services for decisionmaking in farming: A case study in Southern Ghana. Submitted to Journal of Climate Services.

6. Sarku R., Appiah D.O., Adiku P., Alare R.S., Dotsey S. (2021) Digital Platforms in Climate Information Service Delivery for Farming in Ghana. In: Leal Filho W., Ogugu N., Adelake L., Ayal D., da Silva I. (eds) African Handbook of Climate Change Adaptation. Springer, Cham. https://doi.org/10.1007/978-3-030-42091$8 \_44-1$

7. Boafo, James, Sarku R., \& Obodai., J. (2021). From the Kitchen to Fast Food Restaurants: The Changing Culture of Food in Urban Ghana. Food Studies: An Interdisciplinary Journal 10 (4): 15-34. doi:10.18848/2160-1933/CGP/v10i04/1534.

8. Filho, W.L., Stojanov, R., Wolf, F., Matandirotya, N.R., Manolas, E., Ploberger, C., AL-Ahdal, T.M.A., Al-Jawlahi, R.H., Sarku, R., Ayal, .Y., Tchiadje, N.F.T., Azam, F.M.S, \& Bhadwal, S. (Under review). Understanding Uncertainties in Climate Change Adaptation. Global Environmental Change. 
Completed training and supervision plan 


\section{Rebecca Sarku}

Wageningen School of Social Sciences (WASS)

Completed Training and Supervision Plan

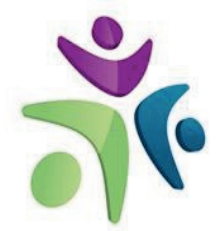

Wageningen School

of Social Sciences

\begin{tabular}{|c|c|c|c|}
\hline Name of the learning activity & Department/Institute & Year & ECTS \\
\hline \multicolumn{4}{|l|}{ A) Project related competences } \\
\hline $\begin{array}{l}\text { Facilitation multi-stakeholder partnership in food } \\
\text { systems }\end{array}$ & WCDI & 2019 & 6 \\
\hline $\begin{array}{l}\text { "Freesale, Wholesale and Retail of Hydro- } \\
\text { Meteorological Information Services: Case of } \\
\text { Farming in the Urbanising Volta River Delta, Ghana" }\end{array}$ & $\begin{array}{l}\text { Wageningen } \mathrm{PhD} \\
\text { symposium, WUR PhD } \\
\text { Council }\end{array}$ & 2018 & 1 \\
\hline Governance and Policy Change, PAP 30806 & WUR & 2017 & 6 \\
\hline $\begin{array}{l}\text { Designing Innovative Governance Arrangement, PAP } \\
30306\end{array}$ & WUR & 2017 & 3 \\
\hline $\begin{array}{l}\text { Practice-based Approaches and Environmental } \\
\text { Governance }\end{array}$ & WASS & 2018 & 0.5 \\
\hline $\mathrm{PhD}$ Writing Retreat & CSPS \&WCSG & 2018 & 1 \\
\hline Integrated Water Management, WSG 33806 & WUR & 2016 & 6 \\
\hline Writing research proposal & WUR & 2017 & 6 \\
\hline Effective strategies for academic writing & EVOCA & 2018 & 1.3 \\
\hline $\begin{array}{l}\text { Academic Publication and Presentation in the Social } \\
\text { Sciences }\end{array}$ & WASS & 2019 & 4 \\
\hline $\begin{array}{l}\text { Sociology and political science of environmental } \\
\text { transformations }\end{array}$ & WASS \& SENSE & 2020 & 1.5 \\
\hline Waterapp kick-off workshop & Waterapp project & 2016 & 1 \\
\hline $2^{\text {nd }}$ EVOCA Workshop & EVOCA & 2017 & 1 \\
\hline $3^{\text {rd }}$ EVOCA Workshop & EVOCA & 2018 & 1 \\
\hline Waterapp consortium workshop & Waterapp project & 2018 & 1 \\
\hline EVOCA/Waterapp in-country workshop & EVOCA & 2019 & 1 \\
\hline \multicolumn{4}{|l|}{ B) General research related competences } \\
\hline $\begin{array}{l}\text { "Freesale, Wholesale and Retail of Hydro- } \\
\text { Meteorological } \\
\text { Information Services: Case of Farming in the } \\
\text { Urbanising Volta River Delta, Ghana" }\end{array}$ & $\begin{array}{l}5^{\text {th }} \text { Adaptation Futures } \\
\text { Conference, Cape Town }\end{array}$ & 2018 & 1 \\
\hline African climate information service innovation day & AU/UNECA & 2017 & 1 \\
\hline Convener Wageningen PhD Symposium & WUR PhD Council & 2018 & 0.3 \\
\hline \multicolumn{4}{|l|}{ C) Career related competences/personal development } \\
\hline WASS introduction course & WASS & 2016 & 1 \\
\hline $\mathrm{PhD}$ carousel & WGS & $\begin{array}{l}2017 \\
2018\end{array}$ & 0.6 \\
\hline
\end{tabular}


Reviewing a Scientific Manuscript

Total 0.1

*One credit according to ECTS is on average equivalent to 28 hours of study load 
The research was financially supported by the Netherlands Organization for Scientific Research (NWO/WOTRO); grant No. W 07.69.204, under the Urbanizing Deltas of the World Program (UDW) and Waterapps project: Water information services for sustainable food production in periurban delta areas in Ghana and Bangladesh.

The Public Administration and Policy Group of Wageningen University and Research also covered the cost of printing this $\mathrm{PhD}$ thesis.

Thesis cover design: Rebecca Sarku

Photograph on the cover page: Rebecca Sarku

Printed by: proefschriftmaken (https://www.proefschriftmaken.nl/en/) 



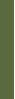

